\title{
jpen
}

AUTARQUIA ASSOCIADA À UNIVERSIDADE DE SÃO PAULO

DOSIMETRIA DE ALTAS DOSES DE RAIOS GAMA E ELÉTRONS COM DIODOS DE SI RESISTENTES A DANOS DE RADIAÇÃO

Kelly Cristina da Silva Pascoalino

Tese apresentada como parte dos requisitos para obtenção do Grau de Doutor em Ciências na Área de Tecnologia Nuclear - Aplicações

Orientadora:

Profa. Dra. Carmen Cecília Bueno 


\title{
INSTITUTO DE PESQUISAS ENERGÉTICAS E NUCLEARES
}

Autarquia associada à Universidade de São Paulo

\section{DOSIMETRIA DE ALTAS DOSES DE RAIOS GAMA E ELÉTRONS COM DIODOS DE SI RESISTENTES A DANOS DE RADIAÇÃO}

\author{
Kelly Cristina da Silva Pascoalino \\ Tese apresentada como parte dos \\ requisitos para obtenção do Grau de \\ Doutor em Ciências na Área de Tecnologia \\ Nuclear - Aplicações \\ Orientadora: \\ Profa. Dra. Carmen Cecília Bueno
}

Versão Corrigida

Versão Original disponível no IPEN

São Paulo

2014 
Á minha mãe, minha madrinha e meu marido, pelo amor e esforços ilimitados.

Para meu amado pai, em memória. 


\section{AGRADECIMENTOS}

À Deus, por me dar forças para lutar pelos meus sonhos e superar os momentos difíceis da minha vida.

À Profa. Dra. Carmen Cecília Bueno, pela paciência, confiança e compreensão, ao longo dos sete anos de convivência, além dos conselhos que contribuíram para a minha formação pessoal e profissional.

À Profa. Dra. Josemary Angélica Corrêa Gonçalves, por toda colaboração ao desenvolvimento deste projeto.

Ao Dr. Jaakko Härkönen, por fornecer, em colaboração, os diodos utilizados neste trabalho.

Aos engenheiros Carlos Gaia, Elizabeth Somessari, Samir Somessari e aos técnicos Hélio Antônio Paes e Carlos Sousa, grandes amigos, pela dedicação e esforços dispensados durante o desenvolvimento deste trabalho.

Ao chefe da divisão de empacotamento eletrônico Antônio L. Pacheco Rotondaro e aos técnicos Marinalva Muniz Rocha e Giuliano Maiolini do Centro de Tecnologia da Informação Renato Archer pela confecção das microsoldas e encapsulamento dos diodos utilizados.

Ao Departamento de Projeto e Fabricação do IPEN em nome de Paulo Alves Teixeira pela confecção das sondas dosimétricas, tampa da câmara de vácuo e demais suportes e peças utilizados neste trabalho.

Ao Instituto de Pesquisas Energéticas e Nucleares, pela contribuição à minha formação acadêmica, disponibilizando tecnologia suficiente para o desenvolvimento deste projeto. 
À Coordenação de Aperfeiçoamento de Pessoal de Nível Superior (CAPES), pela concessão da bolsa de doutorado.

Aos amigos do grupo de pesquisa, pela paciência e apoio em momentos difíceis.

Aos meu familiares em nome de Fernando Monteiro, Josefa Ap. Santana, Alexandra Siqueira Monteiro Silva e Thaís Ap. Santana por acreditarem no meu potencial e estarem ao meu lado em todos os momentos.

Aos meus amigos Lucia Mendes, Luiz Sérgio Romanato, Mario Bonadio e Edson Fagundes que ao final de cada dia, com palavras de incentivo e alegria me ajudaram a superar os obstáculos. 


\title{
DOSIMETRIA DE ALTAS DOSES DE RAIOS GAMA E ELÉTRONS COM DIODOS DE SI RESISTENTES A DANOS DE RADIAÇÃO
}

\author{
Kelly Cristina da Silva Pascoalino
}

\begin{abstract}
RESUMO
Neste trabalho foram avaliadas as principais características dosimétricas de diodos crescidos pelos métodos de Fusão Zonal (FZ) e Czochralski magnético $(\mathrm{MCz})$, resistentes a danos de radiação, quando aplicados em dosimetria de processos de irradiação industrial com elétrons $(1,5 \mathrm{MeV})$ e raios gama $\left({ }^{60} \mathrm{Co}\right)$. $\mathrm{O}$ sistema dosimétrico proposto baseia-se no registro de valores de correntes elétricas geradas nos diodos devido à passagem da radiação ionizante. A uniformidade de resposta de um lote de dispositivos foi analisada para os diodos FZ do tipo $\mathrm{n}$ irradiados com raios gama. Para uma dose de até 5 kGy obteve-se um coeficiente de variação de $1,25 \%$ dos valores de corrente elétrica registrados. A queda da sensibilidade dos diodos com o acúmulo de dose (Total lonizing Dose TID) foi observada, de acordo com o esperado, para ambos os diodos FZ e MCz, sendo mais acentuada para dispositivos do tipo $\mathrm{n}$ ou com resistividade menor, quando irradiados com raios gama. Nos procedimentos de irradiação com elétrons foram utilizados dois protótipos de sonda dosimétrica, sendo que um deles foi projetado para evitar a deterioração dos contatos elétricos e da metalização dos diodos, fenômeno observado durante o desenvolvimento do projeto. A queda da sensibilidade dos diodos FZ e MCz pré-irradiados foi de aproximadamente $10 \%$ e $40 \%$, respectivamente, durante os procedimentos de irradiação com elétrons para uma dose acumulada total de 1,25 MGy. A influência dos danos causados por esse tipo de radiação nas propriedades elétricas dos diodos $\mathrm{FZ}$ e $\mathrm{MCz}$ foi avaliada por meio das medições de corrente de fuga e da capacitância em função da tensão de polarização. A corrente de fuga, que aumenta com a dose de radiação acumulada, não contribui significativamente para a formação do sinal de corrente durante a irradiação, uma vez que os diodos são operados no modo fotovoltaico, ou seja, sem
\end{abstract}


tensão de polarização. Para o diodo $\mathrm{MCz}$ não foram observadas alterações significativas dos valores de tensão de depleção total, evidenciando sua maior tolerância aos danos induzidos pela radiação, como esperado. Como durante os procedimentos de irradiação com elétrons há uma variação acentuada dos valores de temperatura, a influência deste parâmetro para as medições de corrente elétrica foi avaliada por meio da extrapolação dos valores de corrente de fuga até $35^{\circ} \mathrm{C}$. A contribuição da corrente de fuga para a corrente induzida pela radiação, devido ao aumento da temperatura, não ultrapassa $0,1 \%$ para os diodos $\mathrm{FZ}$ e $\mathrm{MCz}$. A influência do tipo de radiação, elétrons ou raios gama, na pré-dose dos diodos foi avaliada para o dispositivo FZ do tipo n e observou-se que a pré-irradiação com elétrons é mais eficiente no tocante à queda da sensibilidade dos dispositivos. Os resultados apresentados neste trabalho indicam a potencialidade da aplicação dos diodos $\mathrm{FZ}$ e $\mathrm{MCz}$ como dosímetros em processos de irradiação de rotina com raios gama e elétrons. Vale ressaltar que a vantagem do sistema proposto reside na possibilidade de acompanhamento em tempo real dos processos envolvidos, sobretudo para elétrons, permitindo a monitoração dos parâmetros dos aceleradores, tais como velocidade de esteira e corrente elétrica de feixe. 


\title{
GAMMA AND ELECTRON HIGH DOSE DOSIMETRY WITH RAD-HARD SI DIODES
}

\author{
Kelly Cristina da Silva Pascoalino
}

\begin{abstract}
In this work the main dosimetric characteristics of rad-hard Float Zone (FZ) and magnetic Czochralski ( $\mathrm{MCz}$ ) diodes to electrons (1.5 MeV) and gamma $\left({ }^{60} \mathrm{Co}\right)$ radiation are evaluated. The dosimetric system proposed is based on electrical current measurements due to radiation interactions on the devices. The batch response uniformity was studied for the $n$-type FZ diodes irradiated with gamma rays. The coefficient of variation of the current measurement was about $1.25 \%$ at $5 \mathrm{kGy}$ of accumulated dose. A sensitivity decrease with the increase of the accumulated dose (Total lonizing Dose - TID) was observed for both FZ and MCz diodes. For gamma irradiation, these effect is more pronounced for n-type or smaller resistivity diodes. Two types of dosimetric probe were used on the electron irradiation procedures, one of them specially designed to avoid the deterioration of the electrical contacts and the diodes metallization. The sensitivity of the preirradiated $\mathrm{FZ}$ and $\mathrm{MCz}$ diodes fell about $10 \%$ and $40 \%$, respectively, during electron irradiation at 1.25 MGy of accumulated dose. The effect of electron radiation damage on the electrical properties of the diodes was studied by the means of leakage current and capacitance measurements as a function of bias voltage. The leakage current increases with the accumulated dose but does not contributes significantly to the current signal, since the diodes are operated in photovoltaic mode, without bias voltage. For the $\mathrm{MCz}$ diode no change in the full depletion voltage was observed, which indicates its higher tolerance to radiation-induced damage, as expected. During electron irradiation the temperature increases and in order to determine its influence for the current signals, the leakage current values were extrapolated up to $35{ }^{\circ} \mathrm{C}$. The contribution does not exceed $0.1 \%$ for $\mathrm{FZ}$ and
\end{abstract}


$M C z$ diodes. The effect of the radiation type, electrons or gamma rays, on the predose procedures was analyzed for the FZ $\mathrm{n}$-type device and was observed that the electron pre-irradiation is more efficient regarding the sensitivity decrease. The present work indicates the potential application of $\mathrm{FZ}$ and $\mathrm{MCz}$ diodes as dosimeters in gamma rays and in electron routine irradiation processes. It is worth noting that the proposed system advantage relies on the possibility of real-time monitoring of electron accelerator parameters. 


\section{SUMÁRIO}

Página

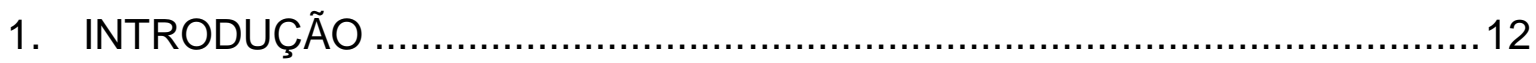

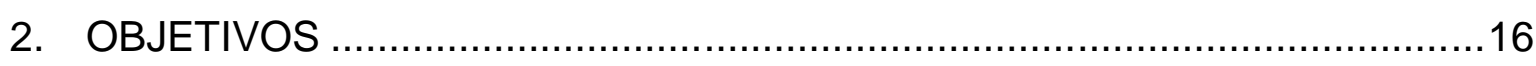

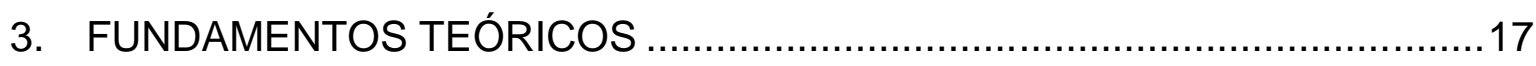

3.1 Interação da radiação com a matéria ..................................................... 17

3.1.1 Interação da radiação eletromagnética com a matéria ..........................17

3.1.2 Interação de partículas carregadas com a matéria .............................23

3.1.2.1 Interação dos elétrons com a matéria ............................................24

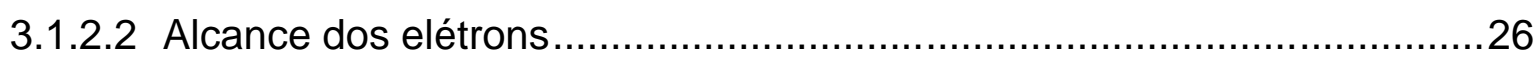

3.2 Diodos como dosímetros de radiação ...................................................29

3.2.1 Recombinação e geração de portadores .......................................... 30

3.2.1.1 Processos de recombinação ............................................................ 31

3.2.1.2 Processos de geração de portadores .............................................. 32

3.2.1.3 Estatística de Recombinação - Geração ............................................ 33

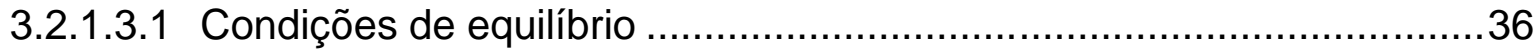

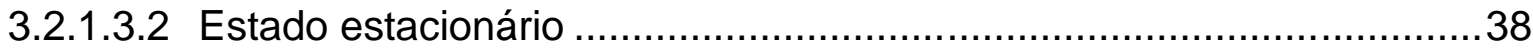

3.2.1.4 Análise dos processos R-G por meio de parâmetros físicos...................42

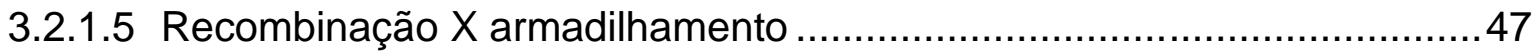

3.2.2 Transporte de portadores de carga ................................................ 48

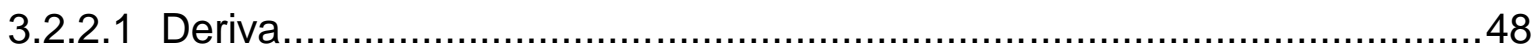

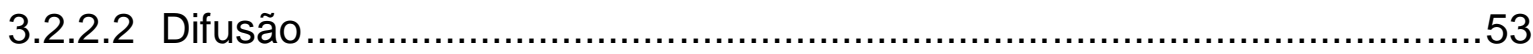

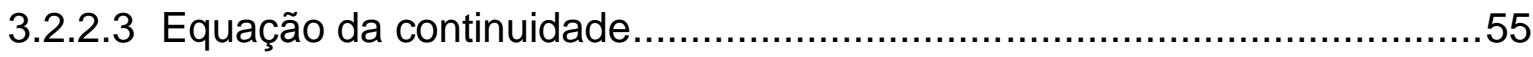

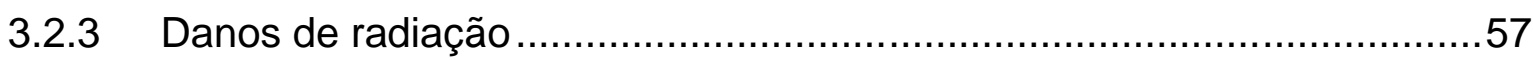

3.2.3.1 Impacto dos danos nas propriedades macroscópicas do detector ..........58

3.2.3.2 Detectores resistentes aos danos de radiação ...................................61

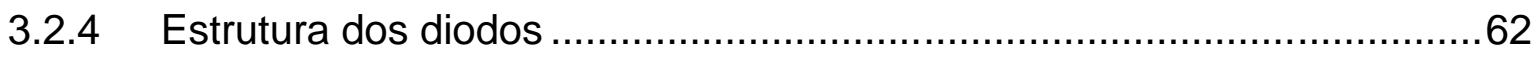

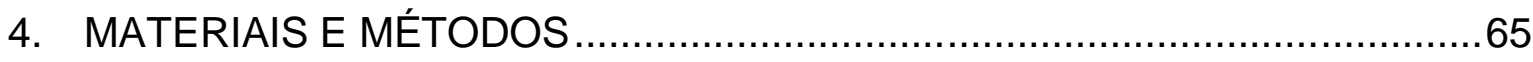

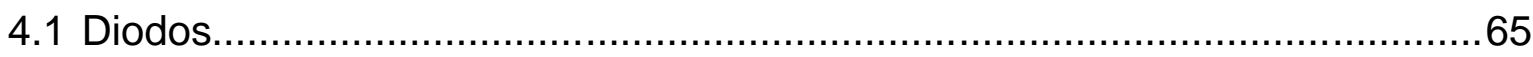

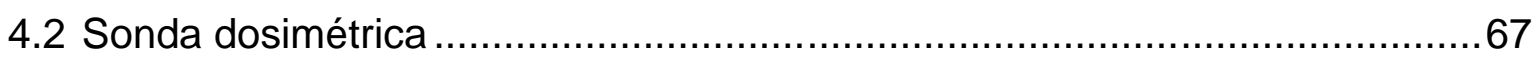

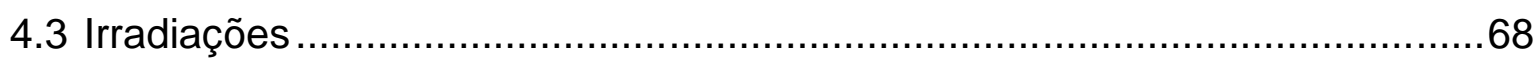

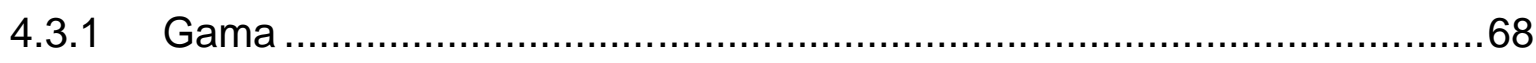

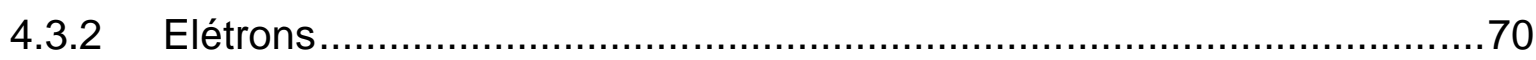


4.3.3 Caracterização elétrica .......................................................................

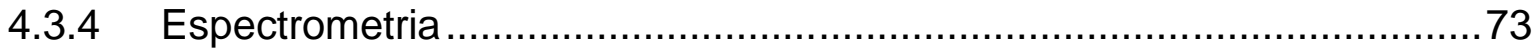

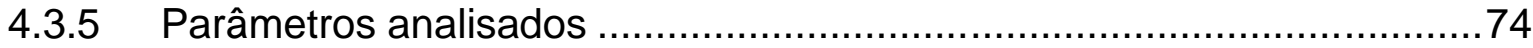

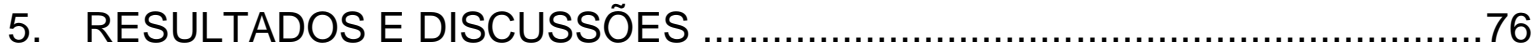

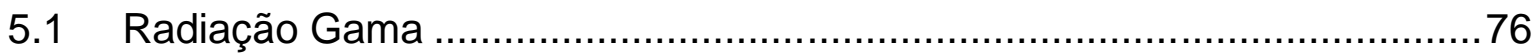

5.1.1 Resposta em função da taxa de dose................................................76

5.1.2 Sinais de corrente e uniformidade de lote............................................ 79

5.1.3 Queda da sensibilidade em corrente em função da dose ......................... 81

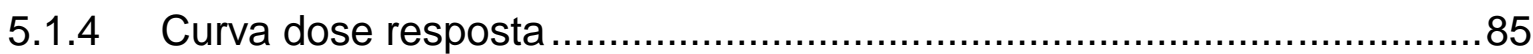

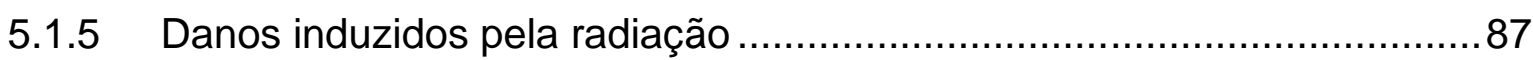

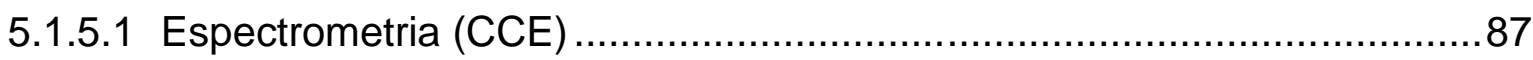

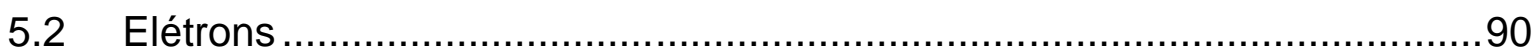

5.2.1 Resposta em função da taxa de dose ..................................................

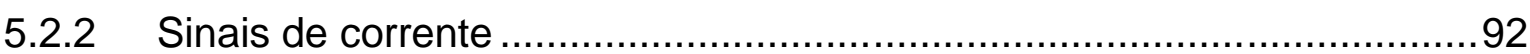

5.2.3 Queda da sensibilidade em corrente em função da dose ........................99

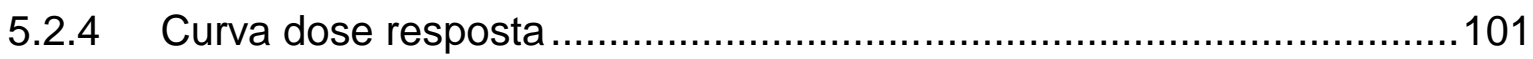

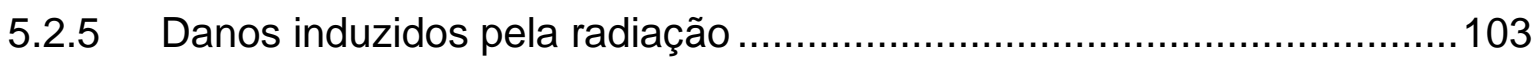

5.2.5.1 Curvas de corrente de fuga em função da tensão de polarização reversa (IV)

5.2.5.2 Curvas de capacitância em função da tensão de polarização reversa

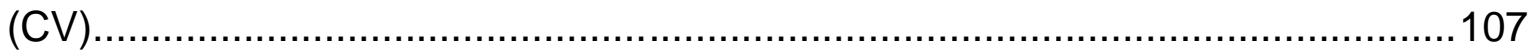

5.2.6 Influência da temperatura nas medidas de corrente …………...............110

5.2.7 Deterioração da sonda dosimétrica e periféricos ....................................118

5.3 Influência do procedimento de pré-irradiação na estabilidade de resposta

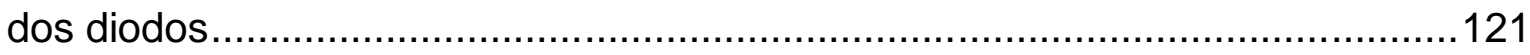

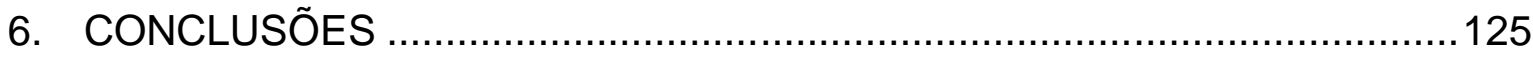

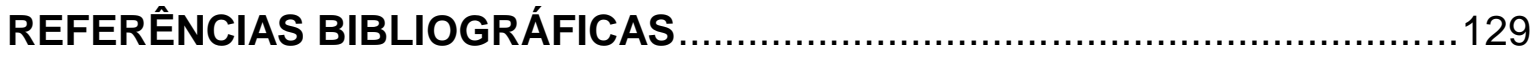




\section{LISTA DE FIGURAS}

FIGURA 1 - Importância relativa dos três principais tipos de interação da radiação gama com a matéria, relacionando o número atômico do absorvedor e a energia da radiação incidente [30]. 18

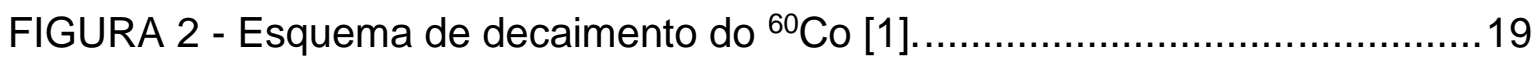

FIGURA 3 - Esquema da interação gama por espalhamento Compton [31].........19 FIGURA 4 - Distribuição angular do número de fótons espalhados após a interação Compton para diferentes valores de energia iniciais [30].

FIGURA 5 - Seções de choque do espalhamento Compton em função da energia do fóton incidente [31] 21

FIGURA 6 - Distribuição em energia dos elétrons Compton de recuo [31]. .22 FIGURA 7 - Perda de energia específica em função da energia dos elétrons incidentes no $\mathrm{Si}[24,33]$. .26

FIGURA 8 - Representação das possíveis trajetórias de elétrons com mesma energia incidindo em um dado meio [30].

FIGURA 9 - Diagrama indicando os caminhos possíveis de dois elétrons com energias iguais ao penetrarem em um absorvedor com espessura $x_{0}$ [32]

FIGURA 10 - Distribuição dos alcances e comprimento de trajetória para elétrons com energia de 0,02 MeV em um absorvedor gasoso (oxigênio) em CNTP [32]. 28 FIGURA 11 - Alcance mássico dos elétrons com diferentes valores de energia ao penetrarem no Si [24,33]. .29

FIGURA 12 - Diagrama esquemático do funcionamento de um diodo de junção como dosímetros de radiação [38]. 30

FIGURA 13 - Representação ilustrativa dos processos de recombinação direta (a), indireta (b) e Auger (c) [39]. 32 FIGURA 14 - Representação ilustrativa dos processos de geração direta (a) e indireta (b) [39]. .33

FIGURA 15 - Representação ilustrativa das possíveis transições que conduzem aos processos recombinação e geração via centros $R-G$ [39]. 34

FIGURA 16 - Representação ilustrativa da compensação entre os processos de recombinação e geração de portadores sob condições de equilíbrio (a) e estado estacionário (b) em um uma seção $\Delta x$ do material semicondutor [34]. 
FIGURA 17 - Diagrama ilustrativo da região semicondutora delimitada contendo centros R-G preenchidos e não preenchidos e elétrons [39].

FIGURA 18 - Representação ilustrativa da distribuição aleatória dos centros R-G no volume delimitado (a) e posicionamento imaginário dos mesmos em um único plano que os intercepta (b) [39].

FIGURA 19 - Diagrama ilustrativo da diferença entre os processos de recombinação e armadilhamento via centros R-G [39]. .48

FIGURA 20 - llustração do movimento de deriva: movimento dos portadores em um semicondutor polarizado (a), deriva de uma lacuna em escala microscópica (b) e em escala macroscópica (c) com a definição do parâmetro $\mathrm{v}_{\mathrm{d}}$ [39]. 49

FIGURA 21 - Mobilidade de elétrons no Si para valores diferentes de concentração de doadores [41].

FIGURA 22 - Mobilidade de elétrons e lacunas em função da concentração de impurezas para o Si e GaAs [41]. .52

FIGURA 23 - Vista ilustrativa de um semicondutor do tipo n polarizado. .53 FIGURA 24 - Vista ilustrativa de um semicondutor do tipo $n$ e variação da concentração de portadores em função da distância x [41]. .54 FIGURA 25 - Tensão de depleção em função da fluência equivalente de nêutrons para diodos crescidos por diferentes métodos e irradiados com prótons de diferentes energias [53]. 59

FIGURA 26 - Corrente de fuga em função da fluência equivalente de nêutrons para diodos crescidos por diferentes métodos e irradiados com prótons de diferentes energias [53].

FIGURA 27 - CCE em função da fluência equivalente de nêutrons para diodos epitaxiais crescidos por diferentes métodos e espessuras, irradiados com prótons de $24 \mathrm{GeV}$ [14].

FIGURA 28 - Diagrama esquemático sobre os três principais tipos de defeitos responsáveis pela alteração das propriedades elétricas dos dispositivos semicondutores [54].

FIGURA 29 - Ilustração das etapas de produção de diodos de $\mathrm{Si}$, como aqueles utilizados neste trabalho.

FIGURA 30 - llustração da face frontal dos diodos de Si ao término do processo de fabricação. 
FIGURA 31 - Fotografia dos diodos ( $25 \mathrm{~mm}^{2}$ cada) após o processo de fabricação sobre uma pastilha de Si [47].

FIGURA 32 - Fotografia da face frontal do diodo em escala normal (a) e ampliada (b) com destaque para o conjunto de 16 anéis de guarda.

FIGURA 33 - Diodo fixado sobre a base de cerâmica, com a face $p+$ microsoldada ao eletrodo de extração de sinais (a), e inserido na sonda dosimétrica de PMMA (b).

FIGURA 34 - Sonda dosimétrica preparada para os procedimentos de irradiação com raios gama (a) e elétrons (b, c), sendo o primeiro protótipo constituído por uma janela de Mylar $\AA^{\circledR}$ aluminizado (b) e o segundo por meio do encapsulamento dos diodos com uma resina termorrígida (c).

FIGURA 35 - Diagrama representativo da composição da câmara primária de irradiação do irradiador Gammacell 220 [61]. 69

FIGURA 36 - Cilindro de isopor, contendo em seu interior a sonda dosimétrica e o termopar do tipo K (a), posicionado no interior da câmara secundária do irradiador Gammacell 220.

FIGURA 37 - Diagrama esquemático do movimento da bandeja sobre a esteira em relação ao feixe de elétrons.

FIGURA 38 - Aparato experimental montado sobre a bandeja contendo as blindagens de acrílico para a proteção dos conectores e cabos. 71 FIGURA 39 - Diagrama de blocos do arranjo experimental para as medidas IV. .72 FIGURA 40 - Diagrama de blocos do arranjo experimental para as medidas CV.73 FIGURA 41 - Fotografia tirada da tampa da câmara de vácuo após a fixação da sonda dosimétrica (a) e desenho esquemático do posicionamento entre o diodo e o porta fonte (b) .73

FIGURA 42 - Diagrama de blocos do aparato experimental utilizado para o levantamento dos espectros alfa. .74 FIGURA 43 - Corrente elétrica gerada nos diodos FZ\#A e FZ\#B do tipo n, durante os processos de irradiação gama, em função da dose acumulada. As barras de incerteza dos valores de corrente são menores do que os pontos e representam menos do que $1 \%$ das medições.

FIGURA 44 - Corrente elétrica gerada nos diodos FZ\#A e FZ\#B do tipo n, durante os processos de irradiação gama, em função da dose acumulada, normalizadas para a taxa de dose de 7,465 kGy/h. As barras de incerteza dos valores de corrente 
são menores do que os pontos e representam menos do que $1 \%$ das medições.

FIGURA 45 - Curva dose resposta das amostras FZ\#A e FZ\#B do tipo n, irradiadas com raios gama. As barras de incerteza dos valores de carga acumulada são menores do que os pontos e representam menos do que $0,5 \%$ da grandeza. .....79 FIGURA 46 - Sinais de corrente obtidos com 9 diodos FZ do tipo n pertencentes ao mesmo lote e irradiados com valores distintos de dose. As barras de incerteza dos valores de corrente são menores do que os pontos e representam menos do que $1 \%$ das medições.

FIGURA 47 -Valores de corrente registrados com os 9 diodos $F Z$ do tipo $n$ pertencentes ao mesmo lote para a dose de até $5 \mathrm{kGy}$

FIGURA 48 - Corrente normalizada em função da dose acumulada para os diodos MCz\#A e MCz\#B do tipo n. As barras de incerteza dos valores de corrente normalizada são menores do que os pontos e representam menos do que $0,5 \%$ da grandeza.

FIGURA 49 - Corrente normalizada em função da dose acumulada para os diodos FZ\#B e FZ\#K do tipo $n$. As barras de incerteza dos valores de corrente normalizada são menores do que os pontos e representam menos do que $0,5 \%$ da grandeza.

FIGURA 50 - Corrente normalizada em função da dose acumulada para os diodos FZ\#L do tipo n e FZ\#M do tipo p. As barras de incerteza dos valores de corrente normalizada são menores do que os pontos e representam menos do que $0,5 \%$ da grandeza.

FIGURA 51 - Corrente normalizada em função da dose acumulada para os diodos MCz\#A do tipo n e MCz\#C do tipo p. As barras de incerteza dos valores de corrente normalizada são menores do que os pontos e representam menos do que $0,5 \%$ da grandeza.

FIGURA 52 - Curvas dose respostas dos diodos MCz\#A e MCz\#B do tipo n irradiados com raios gama. As barras de incerteza dos valores de carga acumulada são menores do que os pontos e representam menos do que $0,5 \%$ da grandeza.

FIGURA 53 - Curvas dose respostas dos diodos FZ\#B e FZ\#K do tipo $\mathrm{n}$ irradiados com raios gama. As barras de incerteza dos valores de carga acumulada são menores do que os pontos e representam menos do que $0,5 \%$ da grandeza. .....86 
FIGURA 54 - Espectros alfa do ${ }^{241} \mathrm{Am}$ obtidos com o diodo MCz\#D do tipo $\mathrm{n}$, irradiado com raios gama, para diferentes valores de dose acumulada.

FIGURA 55 - Resolução em função da dose acumulada obtida por meio dos espectros alfa registrados com o diodo $\mathrm{MCz} \# \mathrm{D}$ do tipo $\mathrm{n}$ irradiado com raios gama.

FIGURA 56 - Curvas IV do diodo MCz\#D do tipo n obtidas após cada intervalo de irradiação gama. As barras de incerteza dos valores de corrente de fuga são menores do que os pontos e representam menos do que $0,5 \%$ das medições. ...89 FIGURA 57 - Corrente de fuga do diodo MCz\#D do tipo $\mathrm{n}$ irradiado com raios gama, para a tensão de polarização reversa de $180 \mathrm{~V}$, em função da dose acumulada. As barras de incerteza dos valores de corrente de fuga são menores do que os pontos e representam menos do que $0,5 \%$ das medições. .90

FIGURA 58 - Corrente do diodo FZ\#E do tipo $\mathrm{n}$ em função da taxa de dose do acelerador de elétrons. As barras de incerteza dos valores de corrente são menores do que os pontos e representam menos do que $1 \%$ das medições.

FIGURA 59 - Corrente do diodo MCz\#E do tipo n em função da taxa de dose do acelerador de elétrons. As barras de incerteza dos valores de corrente são menores do que os pontos e representam menos do que $1 \%$ das medições .92 FIGURA 60 - Sinais de corrente em função do tempo obtidos com o diodo FZ\#G do tipo n para diferentes valores de dose. As barras de incerteza dos valores de corrente são menores do que os pontos e representam menos do que $1 \%$ das medições.

FIGURA 61 - Sinais de corrente em função do tempo obtidos com o diodo MCz\#F do tipo $\mathrm{n}$ para diferentes valores de dose. As barras de incerteza dos valores de corrente são menores do que os pontos e representam menos do que $1 \%$ das medições. 94

FIGURA 62 - Sinais de corrente registrados durante o estudo de repetibilidade

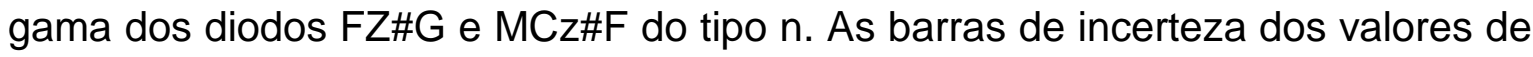
corrente são menores do que os pontos e representam menos do que $1 \%$ das medições.

FIGURA 63 - Número de interações dos elétrons com 1,5 MeV de energia em função da profundidade, para o protótipo antigo da sonda dosimétrica (sem resina). 
FIGURA 64 - Número de interações dos elétrons com 1,5 MeV de energia em função da profundidade, para o novo protótipo da sonda dosimétrica (resina).....96 FIGURA 65 - Sinais de corrente em função do tempo obtidos com o diodo FZ\#O do tipo $n$ para diferentes valores de dose. As barras de incerteza dos valores de corrente são menores do que os pontos e representam menos do que $1 \%$ das medições.

FIGURA 66 - Sinais de corrente em função do tempo obtidos com o diodo MCz\#G do tipo $\mathrm{n}$ para diferentes valores de dose. As barras de incerteza dos valores de corrente são menores do que os pontos e representam menos do que $1 \%$ das medições.

FIGURA 67 - Sinal de corrente em função do tempo obtido com o diodo FZ\#O do tipo n para uma dose de 3,56 kGy com delimitação do tempo de exposição sob o feixe de elétrons. As barras de incerteza dos valores de corrente são menores do que os pontos e representam menos do que $1 \%$ das medições. .98 FIGURA 68 - Sinal de corrente em função do tempo obtido com o diodo FZ\#O do tipo $\mathrm{n}$ durante um problema no rolete da esteira levando à parada do diodo sob o feixe de elétrons. As barras de incerteza dos valores de corrente são menores do que os pontos e representam menos do que $1 \%$ das medições. 99 FIGURA 69 - Corrente de pico média normalizada em função da dose acumulada

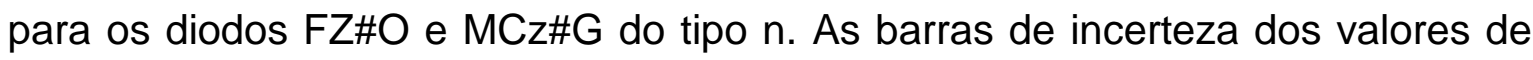
corrente normalizada são menores do que os pontos e representam menos do que $0,5 \%$ da grandeza. 100

FIGURA 70 - Corrente de pico média normalizada em função da dose acumulada para os diodos FZ\#J do tipo $n$ e $F Z \# N$ do tipo $p$. As barras de incerteza dos valores de corrente normalizada são menores do que os pontos e representam menos do que $0,5 \%$ da grandeza. 101 FIGURA 71 - Curvas dose respostas dos diodos FZ\#O e MCz\#G do tipo $\mathrm{n}$ irradiados com elétrons. As barras de incerteza dos valores de carga acumulada são menores do que os pontos e representam menos do que $0,5 \%$ da grandeza. 102 FIGURA 72 - Curvas dose respostas dos diodos FZ\#J do tipo n e FZ\#N do tipo $p$ irradiados com elétrons. As barras de incerteza dos valores de carga acumulada são menores do que os pontos e representam menos do que $0,5 \%$ da grandeza. 
FIGURA 73 - Curvas IV do diodo FZ\#O do tipo n para diferentes valores de dose acumulada. As barras de incerteza dos valores de corrente de fuga são menores do que os pontos e representam menos do que $0,5 \%$ das medições.

FIGURA 74 - Curvas IV do diodo MCz\#G do tipo $\mathrm{n}$ para diferentes valores de dose acumulada. As barras de incerteza dos valores de corrente de fuga são menores do que os pontos e representam menos do que $0,5 \%$ das medições. 105 FIGURA 75 - Curvas IV do diodo FZ\#J do tipo n para diferentes valores de dose acumulada. As barras de incerteza dos valores de corrente de fuga são menores do que os pontos e representam menos do que $0,5 \%$ das medições. 105 FIGURA 76 - Curvas IV do diodo FZ\#N do tipo p para diferentes valores de dose acumulada. As barras de incerteza dos valores de corrente de fuga são menores do que os pontos e representam menos do que $0,5 \%$ das medições. 106 FIGURA 77 - Curvas CV do diodo FZ\#O do tipo n para diferentes valores de dose acumulada. As incertezas dos valores de capacitância representam menos do que $8 \%$ das medições.

FIGURA 78 - Curvas CV do diodo MCz\#G do tipo n para diferentes valores de dose acumulada. As incertezas dos valores de capacitância representam menos do que 8\% das medições. 108

FIGURA 79 - Curvas CV do diodo FZ\#J do tipo n para diferentes valores de dose acumulada. As incertezas dos valores de capacitância representam menos do que $8 \%$ das medições. 108

FIGURA 80 - Curvas CV do diodo FZ\#N do tipo $p$ para diferentes valores de dose acumulada. As incertezas dos valores de capacitância representam menos do que $8 \%$ das medições. 109 FIGURA 81 - Corrente de fuga em função da temperatura, calculada para o diodo $\mathrm{FZ \# O}$ do tipo $\mathrm{n}$ à $0 \mathrm{~V}$, para diferentes valores de dose acumulada. As barras de incerteza dos valores de corrente de fuga são menores do que os pontos e representam menos do que $0,5 \%$ da gradeza.

FIGURA 82 - Corrente de fuga em função da temperatura, calculada para o diodo FZ\#O do tipo $\mathrm{n}$ à $20 \mathrm{~V}$, para diferentes valores de dose acumulada. As barras de incerteza dos valores de corrente de fuga são menores do que os pontos e representam menos do que $0,5 \%$ da grandeza.

FIGURA 83 - Corrente de fuga em função da temperatura, calculada para o diodo FZ\#O do tipo $\mathrm{n}$ à $40 \mathrm{~V}$, para diferentes valores de dose acumulada. As barras de 
incerteza dos valores de corrente de fuga são menores do que os pontos e representam menos do que $0,5 \%$ da grandeza.

FIGURA 84 - Corrente de fuga em função da temperatura, calculada para o diodo $\mathrm{FZ \# O}$ do tipo $\mathrm{n}$ à $60 \mathrm{~V}$, para diferentes valores de dose acumulada. As barras de incerteza dos valores de corrente de fuga são menores do que os pontos e representam menos do que $0,5 \%$ da grandeza.

FIGURA 85 - Corrente de fuga em função da temperatura, calculada para o diodo $M C z \# G$ do tipo $n$ à $0 \mathrm{~V}$, para diferentes valores de dose acumulada. As barras de incerteza dos valores de corrente de fuga são menores do que os pontos e representam menos do que $0,5 \%$ da grandeza.

FIGURA 86 - Corrente de fuga em função da temperatura, calculada para o diodo $M C z \# G$ do tipo $n$ à $200 \mathrm{~V}$, para diferentes valores de dose acumulada. As barras de incerteza dos valores de corrente de fuga são menores do que os pontos e representam menos do que $0,5 \%$ da grandeza. 113

FIGURA 87 - Corrente de fuga em função da temperatura, calculada para o diodo $M C z \# G$ do tipo $n$ à $400 \mathrm{~V}$, para diferentes valores de dose acumulada. As barras de incerteza dos valores de corrente de fuga são menores do que os pontos e representam menos do que $0,5 \%$ da grandeza. 114 FIGURA 88 - Corrente de fuga em função da temperatura, calculada para o diodo $M C z \# G$ do tipo $n$ à $450 \mathrm{~V}$, para diferentes valores de dose acumulada. As barras de incerteza dos valores de corrente de fuga são menores do que os pontos e representam menos do que $0,5 \%$ da grandeza. 114

FIGURA 89 - Corrente de fuga em função da temperatura, calculada para o diodo FZ\#J do tipo $n$ à $250 \mathrm{kGy}$, para diferentes valores tensão de polarização. As barras de incerteza dos valores de corrente de fuga são menores do que os pontos e representam menos do que $0,5 \%$ da grandeza. 115 FIGURA 90 - Corrente de fuga em função da temperatura, calculada para o diodo FZ\#N do tipo $p$ à 250 kGy, para diferentes valores tensão de polarização. As barras de incerteza dos valores de corrente de fuga são menores do que os pontos e representam menos do que $0,5 \%$ da grandeza. 116 FIGURA 91 - Contribuição percentual da corrente de fuga na corrente de fundo, gerada durante a irradiação, para os diodos $\mathrm{FZ \# O} \mathrm{e} \mathrm{MCz} \# \mathrm{G}$, do tipo $\mathrm{n}$, à $0 \mathrm{~V}$ e dose acumulada de 1,25 MGy. As barras de incerteza dos valores de Ifugal $/$ fundo são menores do que os pontos e representam menos do que $0,5 \%$ da grandeza. ...117 
FIGURA 92 - Contribuição percentual da corrente de fuga na corrente de fundo, gerada durante a irradiação, para os diodos $\mathrm{FZ \# J} \mathrm{do} \mathrm{tipo} \mathrm{n}$ e $\mathrm{FZ \# N}$ do tipo $\mathrm{p}$ à $0 \mathrm{~V}$ e dose acumulada de $250 \mathrm{kGy}$. As barras de incerteza dos valores de Ifugal $_{\text {fundo }}$ são menores do que os pontos e representam menos do que $0,5 \%$ da grandeza. ...117 FIGURA 93 - Degradação das sondas dosimétricas após irradiação com elétrons de $1,5 \mathrm{MeV}$. 119

FIGURA 94 - Degradação inicial das sondas dosimétricas após irradiação com elétrons de $1,5 \mathrm{MeV}$. 119

FIGURA 95 - Degradação inicial da caixa acrílica utilizada para a proteção dos conectores elétricos durante os processos de irradiação com elétrons.

FIGURA 96 - Segundo estágio de degradação da caixa acrílica utilizada para a proteção dos conectores elétricos durante os processos de irradiação com elétrons.

FIGURA 97 - Terceiro estágio de degradação da caixa acrílica utilizada para a proteção dos conectores elétricos durante os processos de irradiação com elétrons.

FIGURA 98 - Sinais de corrente registrados com os diodos FZ\#C (pré-irradiado com elétrons) e FZ\#P (pré-irradiado com raios gama) do tipo $n$ durante o procedimento de irradiação gama. As barras de incerteza dos valores de corrente são menores do que os pontos e representam menos do que $1 \%$ das medições. 122

FIGURA 99 - Sinais de corrente registrados com os diodos FZ\#C (pré-irradiado com elétrons) e FZ\#P (pré-irradiado com raios gama) do tipo $n$ durante o procedimento de reprodutibilidade gama. As barras de incerteza dos valores de corrente são menores do que os pontos e representam menos do que $1 \%$ das medições. 123

FIGURA 100 - Sinais de corrente registrados com os diodos FZ\#C (pré-irradiado com elétrons) e FZ\#P do tipo $n$ (pré-irradiado com raios gama) durante todo o procedimento de irradiação gama. As barras de incerteza dos valores de corrente normalizada são menores do que os pontos e representam menos do que $0,5 \%$ da grandeza. 


\section{INTRODUÇÃO}

A radiação diretamente e indiretamente ionizante vem sendo utilizada há décadas para provocar alterações nas propriedades dos materiais com diferentes finalidades. Entretanto, foi a partir da década de 50 que os procedimentos de processamento por radiação, utilizando por exemplo, aceleradores de elétrons e irradiadores gama, passaram a ser realizados em escala industrial. Atualmente existem mais de 1500 aceleradores de elétrons em uso para diferentes aplicações e com diferentes características em todo o mundo. As três principais aplicações da radiação ionizante são a esterilização de instrumentos médicos; a irradiação de alimentos para a redução de patógenos, desinfestação de pragas ou extensão da vida útil; e a modificação de polímeros com a melhora de suas propriedades termoplásticas, polimerização, degradação, cross-linking entre outras. A irradiação de carnes embaladas e alimentos preparados para dieta hospitalar, além da indução de coloração em gemas de pedras preciosas, são exemplos de processos com doses mais elevadas (maiores do que $50 \mathrm{kGy}$ ). Aplicações secundárias incluem ainda a modificação das propriedades de dispositivos semicondutores e tratamento de efluentes [1-3].

O Brasil possui 9 aceleradores de elétrons, com energias de feixe que variam entre $200 \mathrm{keV}$ e $10 \mathrm{MeV}$, e cerca de 5 irradiadores gama de grande porte, ambos utilizados para diferentes aplicações. No Centro de Tecnologia das Radiações do Instituto de Pesquisas Energéticas Nucleares, IPEN-CNEN/SP, estão instalados um acelerador de elétrons e um irradiador gama de grande porte, utilizados em diferentes atividades de pesquisa e desenvolvimento [2].

Os dosímetros, que devem ser utilizados com precisão principalmente em aplicações relacionadas diretamente com a saúde humana, também são utilizados para a calibração dos parâmetros dos irradiadores e aceleradores de elétrons $[1,4]$. Para os irradiadores gama, os dosímetros utilizados comumente são os de polimetilmetacrilato (PMMA), que apresentam uma indução de coloração que depende da dose de radiação absorvida. Este tipo de dosímetro pode ser utilizado para um intervalo de dose de 0,1 kGy a 50 kGy. Para os processos de irradiação em aceleradores de elétrons, por outro lado, são comumente utilizados dosímetros 
de filme, como por exemplo, o triacetato de celulose (CTA) que está disponível comercialmente desde 1980. Este dosímetro, constituído pelo elemento triacetato de celulose adicionado de um plastificante, pode ser utilizado em intervalos de dose de 10 kGy a 300 kGy para irradiação com feixe de elétrons. Com a interação da radiação, reações químicas envolvendo o CTA e o plastificante induzem uma coloração no filme. Em ambos os casos (PMMA e CTA), a dose de radiação absorvida é determinada através das medidas de absorvância em um comprimento de onda apropriado [1].

A utilização desses dosímetros requer cuidados quanto à preparação (CTA), calibração, armazenamento, manipulação e interpretação correta dos resultados. Além disso, são dosímetros passivos, ou seja, sua leitura e, portanto, a determinação da dose entregue ao produto é realizada após o procedimento de irradiação [1,4]. Essas desvantagens são minimizadas mediante a utilização de um sistema dosimétrico que permita a monitoração em tempo real dos procedimentos de irradiação [4]. Em processamento por feixe de elétrons, este tipo de sistema dosimétrico permite que o operador certifique os parâmetros do acelerador em tempo real bem como as consequentes instabilidades nos valores de dose [4].

$\mathrm{Na}$ literatura são encontrados apenas dois sistemas dosimétricos de monitoração em tempo real dos procedimentos de irradiação em aceleradores de elétrons [4-6]. Um deles, denominado Monitorad®, consiste em um instrumento eletrônico baseado em detectores de raios $X$, que registram a radiação de Bremsstrahlung gerada por elétrons de alta energia quando atravessam a janela do acelerador. Após a análise e tratamento dos sinais obtém-se a taxa de dose e a energia do feixe de elétrons bem como a dose entregue ao produto [4,5]. Outro sistema proposto baseia-se na utilização de dois sensores acoplados na entrada e saída do produto com relação ao feixe, de maneira que a diferença entre os sinais dos sensores é relacionada com a dose [6].

Em aplicações médicas, a dosimetria em tempo real para feixes de elétrons e fótons tem sido rotineiramente realizada por sistemas constituídos por diodos de Sílicio (Si) [7-9]. As características destes semicondutores, tais como elevada relação sinal ruído e excelente resolução espacial e temporal tornam os diodos de $\mathrm{Si}$ candidatos promissores à aplicação em processamento por radiação. Entretanto, ao longo desses procedimentos, os detectores ficam sujeitos a doses elevadas de radiação que podem induzir danos em suas estruturas. As alterações 
da concentração efetiva de dopantes (tensão de depleção), corrente de fuga e o aumento da probabilidade de armadilhamento dos portadores de carga (redução da eficiência de coleta de cargas - CCE) são fatores consequentes dos diferentes tipos de danos e que, portanto, afetam as propriedades macroscópicas dos detectores [10-17].

Diversos estudos têm sido realizados com a finalidade de desenvolver detectores semicondutores mais resistentes aos danos induzidos pela radiação. Um dos mais importantes resultados, obtidos por estes estudos, mostrou que a presença de oxigênio, em concentrações elevadas $\left(10^{17} \mathrm{~cm}^{-3}\right)$, na estrutura dos detectores de $\mathrm{Si}$, aumenta a tolerância aos danos de radiação responsáveis pelas alterações da tensão de depleção total destes dispositivos [18-20]. Os dispositivos crescidos pelo método de Fusão Zonal (FZ), que são amplamente utilizados na área da Física de Altas Energias (FAE), apresentam concentração de oxigênio da ordem de $10^{16} \mathrm{~cm}^{-3}$. Por outro lado, os dispositivos crescidos pelo método de Czochralski (Cz) também apresentam elevada concentração de oxigênio em sua estrutura $\left(10^{17} \mathrm{~cm}^{-3}\right)$, intrínseca ao processo de crescimento. Uma variação do método de crescimento $\mathrm{Cz}$ padrão consiste na aplicação de um campo magnético externo e produz dispositivos com uma distribuição mais homogênea de impurezas assim como resistividade elevada (Magnetic Czochralski - MCz). A comparação do desempenho dos diodos $\mathrm{FZ}$ e $\mathrm{MCz}$, no tocante a resistência aos danos induzidos por radiações de diferentes natureza e energias tem sido relatada em diversos artigos [11,12,19-23].

A possibilidade de utilização de diodos semicondutores resistentes aos danos de radiação em aplicações dosimétricas na área de processamento por radiação gama e elétrons tem sido investigada em nosso grupo de pesquisas [19,24-26]. Os resultados anteriormente obtidos demonstraram que a sensibilidade (em corrente e em carga) desses dispositivos diminui com a dose acumulada decorrente da redução do comprimento de difusão dos portadores minoritários e a alteração do volume sensível dos diodos. Para mitigar este efeito e aumentar a estabilidade de resposta dosimétrica, os diodos são pré-irradiados para promover a saturação dos estados de recombinação criados na estrutura do detector pela passagem da radiação [27-29].

Neste contexto insere-se este projeto de doutorado onde são comparadas as respostas de sistemas dosimétricos de rotina baseados em diodos 
FZ e MCz para a dosimetria de processamento de materiais por elétrons. $\mathrm{O}$ princípio de operação do sistema dosimétrico proposto reside nas medidas de taxas de dose por meio das correntes elétricas geradas nos diodos, não polarizados, durante todo o tempo de exposição à radiação. Como os diodos ficam sujeitos a elevadas doses de radiação, também estão sendo estudados os danos de radiação produzidos por elétrons com energia de 1,5 MeV, priorizando-se a queda da sensibilidade em função da dose e alterações das propriedades elétricas dos dispositivos. 


\section{OBJETIVOS}

- Desenvolvimento e calibração de dosímetros baseados em diodos de Si resistentes a danos de radiação para medidas de elevadas doses de radiação gama e elétrons em processos de irradiação.

- Estudo dos danos provocados por radiação gama e elétrons nos diodos de Si e materiais estruturais da sonda dosimétrica. 


\section{FUNDAMENTOS TEÓRICOS}

Neste capítulo são apresentados os conceitos teóricos fundamentais para o entendimento deste trabalho.

\subsection{Interação da radiação com a matéria}

Os diferentes tipos de radiação interagem com a matéria por meio de processos distintos e característicos que dependem, entre outros, da energia incidente. Os principais processos de interação da radiação eletromagnética e elétrons com a matéria são apresentados a seguir.

\subsubsection{Interação da radiação eletromagnética com a matéria}

A radiação eletromagnética interage com a matéria através de processos específicos e diferentes daqueles de partículas carregadas, que serão, por sua vez, discutidos a seguir. Entre os diferentes processos de interação que competem entre si, o processo dominante é definido pela seção de choque parcial que leva em consideração, entre outros parâmetros, a energia da radiação e o número atômico do meio absorvedor. Aqui, restringiremos à descrição dos três principais processos de interação, para fótons de energias baixas (menor que $10 \mathrm{MeV}$ ). São eles:

- Espalhamento Compton: interação com elétrons cuja energia de ligação aos átomos do meio absorvedor é muito menor do que a energia dos fótons e que, portanto, serão tratados como elétrons "livres".

- Efeito fotoelétrico: interação onde toda a energia do fóton é transferida a elétrons de valência dos átomos do meio, de maneira que estes são ejetados, tornando-se livres.

- Produção de pares: processo através do qual a energia do fóton, mais elevada, é suficiente para criar um par elétron-pósitron na vizinhança da região de interação.

A importância relativa dos três processos descritos, como função do número atômico do meio absorvedor, $Z$, e energia dos fótons incidentes, é representada na FIG. 1. A linha contínua à direita, no gráfico, representa as energias para as quais o efeito fotoelétrico e espalhamento Compton são igualmente prováveis, em função do número atômico do meio de interação. Da 
mesma maneira, a linha contínua à esquerda, representa os valores de energia para os quais o espalhamento Compton e produção de pares são igualmente prováveis. Assim, três regiões de predominância de meios de interação podem ser definidas a partir da FIG. 1.

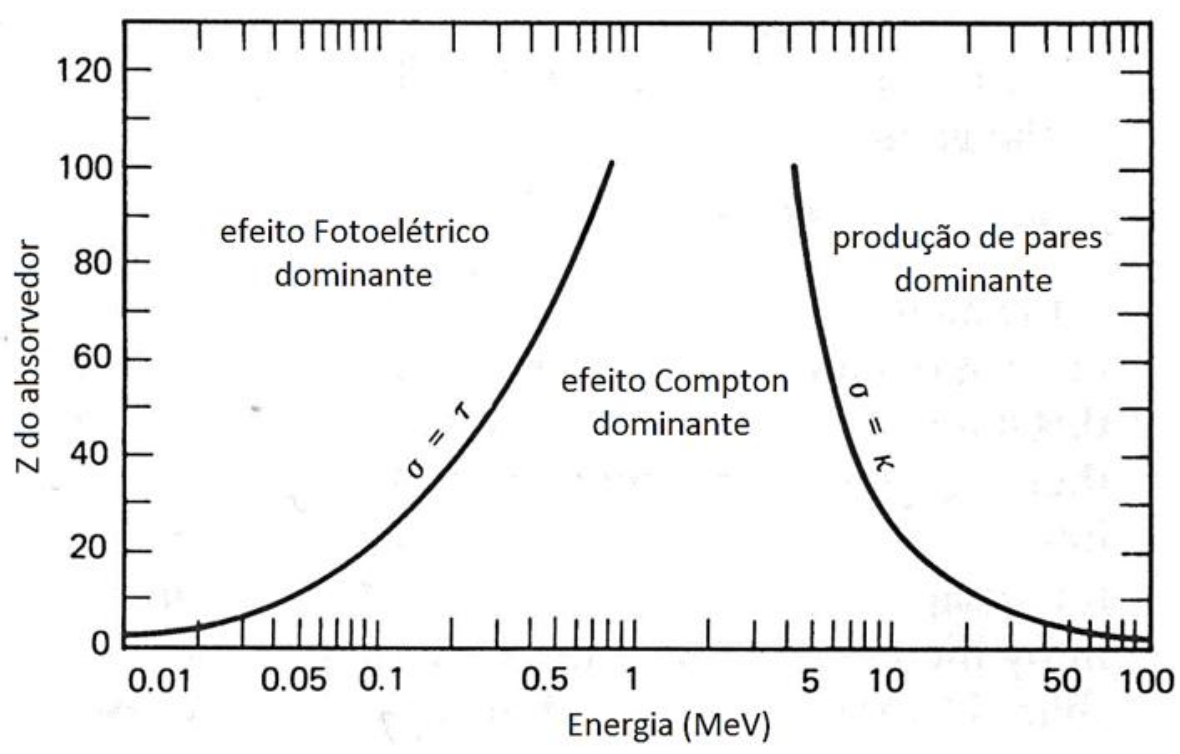

FIGURA 1 - Importância relativa dos três principais tipos de interação da radiação gama com a matéria, relacionando o número atômico do absorvedor e a energia da radiação incidente [30].

Neste trabalho, uma fonte de radiação eletromagnética de ${ }^{60} \mathrm{Co}$ foi utilizada para fins de caracterização de um sistema dosimétrico baseado em diodos de Si $(Z=14)$, como será detalhado adiante. A radiação eletromagnética proveniente do decaimento beta do ${ }^{60} \mathrm{Co}$ é composta predominantemente por fótons com dois valores de energia bem definidos, 1,173 MeV e 1,332 MeV [30], como pode ser observado no esquema de decaimento apresentado na FIG. 2. Com base nessas informações e, utilizando a relação apresentada na FIG. 1, pode-se concluir que o espalhamento Compton é dominante na interação da radiação gama proveniente do ${ }^{60} \mathrm{Co}$ com o Si. Por este motivo, esse processo será mais detalhado a seguir. 


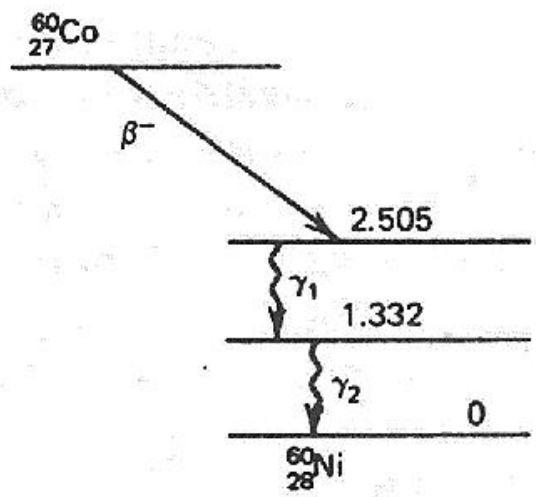

$\gamma_{1}: 1.173 \mathrm{MeV} \gamma(100 \%)$

$\gamma_{2}: 1.332 \mathrm{MeV} \gamma(100 \%)$

FIGURA 2 - Esquema de decaimento do ${ }^{60} \mathrm{Co}[1]$.

\section{Espalhamento Compton:}

Neste tipo de interação o fóton colide com um elétron do meio absorvedor, considerado inicialmente em repouso, e ambos são desviados de sua direção ou posição inicial. $\mathrm{Na}$ interação, o fóton transfere parte de sua energia ao elétron, que é então denominado elétron de recuo. A FIG. 3 apresenta um esquema do processo de interação, onde $\varphi$ e $\theta$ representam os ângulos de espalhamento do elétron de recuo e do fóton, com energia inicial hv, com relação a direção de incidência, respectivamente. T e hv' representam a energia cinética do elétrons de recuo e a energia do fóton espalhado, respectivamente.

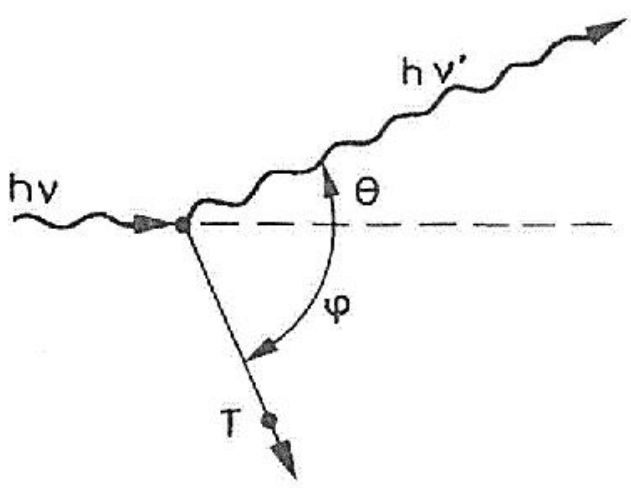

FIGURA 3 - Esquema da interação gama por espalhamento Compton [31].

Aplicando a conservação de momento e energia, tem-se que:

$$
\mathrm{h} v^{\prime}=\frac{\mathrm{h} v}{1+\gamma(1-\cos \theta)}
$$




$$
\mathrm{T}=\mathrm{h} v-\mathrm{h} v^{\prime}
$$

sendo $\gamma=\mathrm{h} v / \mathrm{m}_{\mathrm{e}} \mathrm{c}^{2}$.

As Eq. 1 e 2 impõem que quanto menor o ângulo de espalhamento do fóton, menor será a energia transferida para o elétron de recuo. Se o fóton, após a interação, é retroespalhado, ou seja, $\theta=180^{\circ}$, o elétron de recuo adquire um valor de energia máximo, dado por:

$$
\mathrm{E}_{\text {máx }}=\frac{\mathrm{h} v}{1+\frac{1}{2 \gamma}}
$$

A distribuição angular dos raios gama espalhados é dada pela seção de choque diferencial $\mathrm{d} \sigma / \mathrm{d}$, derivada primeiramente por Klein e Nishina [32]:

$$
\frac{\mathrm{d} \sigma}{\mathrm{d}}=\frac{\mathrm{r}_{0}{ }^{2}}{2} \cdot \frac{1}{[1+\gamma(1-\cos \theta)]^{2}} \cdot\left(1+\cos ^{2} \theta+\frac{\gamma^{2}(1-\cos \theta)^{2}}{1+\gamma(1-\cos \theta)}\right)
$$

sendo $r_{0}$ o raio clássico do elétron. A distribuição é apresentada na FIG. 4 para valores distintos de energia dos fótons incidentes. É possível notar que para raios gama com energias maiores o espalhamento direto, $\theta<90^{\circ}$, é favorecido.

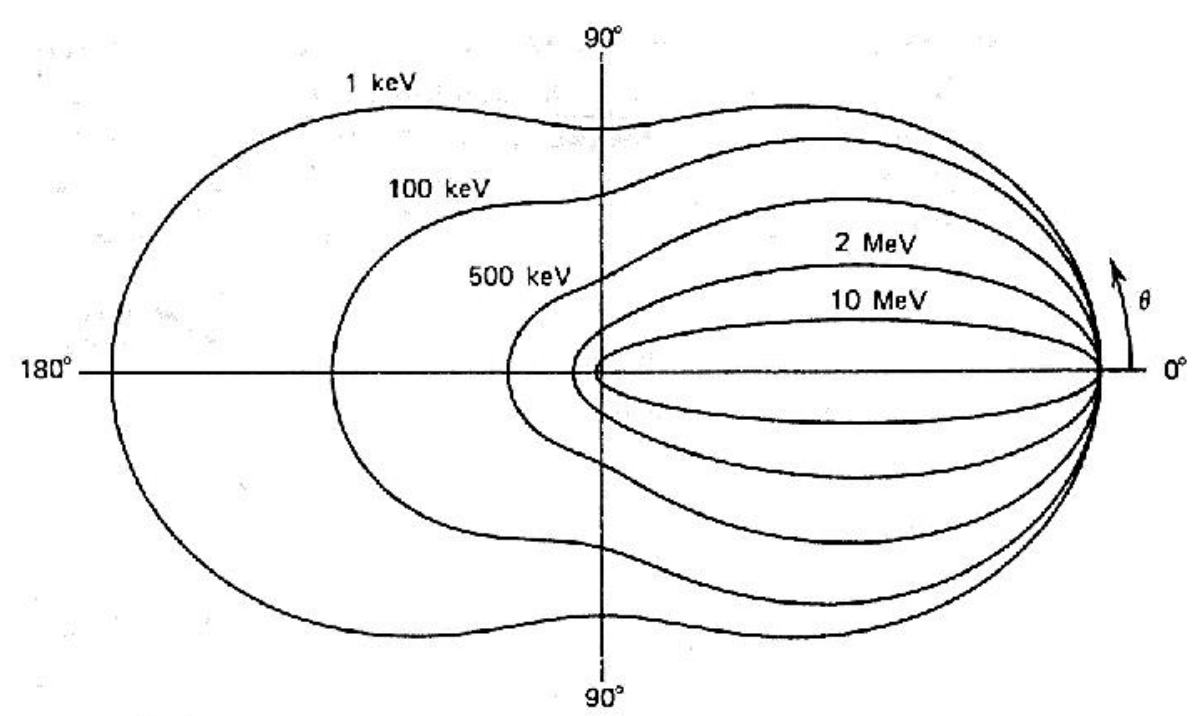

FIGURA 4 - Distribuição angular do número de fótons espalhados após a interação Compton para diferentes valores de energia iniciais [30].

Integrando-se a fórmula apresentada na Eq. 4, obtém-se a probabilidade total, por elétron, para a ocorrência de interação Compton, $\sigma_{c}$. Essa probabilidade é apresentada como função da energia do raio gama incidente na FIG. 5. 
Como mencionado anteriormente, no espalhamento Compton, a energia do fóton incidente é transmitida parcialmente para o elétron de recuo. O restante da energia é então carregada pelo fóton espalhado. Assim, é importante definir duas outras grandezas denominadas como seção de choque de espalhamento e de absorção da radiação por efeito Compton, $\sigma^{s}$ e $\sigma^{a}$, respectivamente. Ambas as grandezas podem ser extraídas a partir da fórmula de Klein-Nishina e são apresentadas na FIG. 5 como função da energia do fóton incidente.

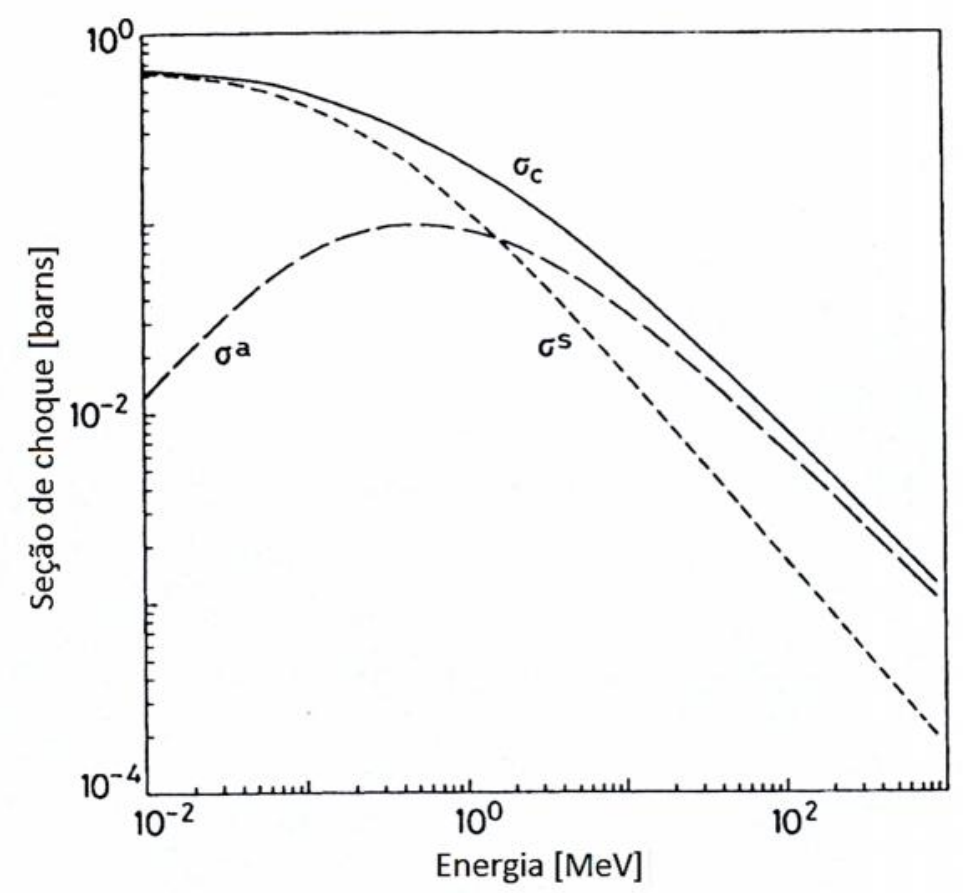

FIGURA 5 - Seções de choque do espalhamento Compton em função da energia do fóton incidente [31].

A seção de choque de espalhamento, $\sigma^{\text {s }}$, é definida como a fração média da energia total contida em um fóton espalhado e é representada matematicamente pela Eq. 5.

$$
\sigma^{\mathrm{s}}=\frac{\mathrm{h} v^{\prime}}{\mathrm{h} v} \cdot \sigma_{\mathrm{c}}
$$

Por outro lado, a seção de choque de absorção, $\sigma^{\mathrm{a}}$, é definida pela diferença entre as seções de choque total e de espalhamento por efeito Compton (Eq. 6) e representa a probabilidade da energia $T$ ser transferida a um elétron durante a interação do fóton por efeito Compton.

$$
\sigma^{\mathrm{a}}=\sigma_{\mathrm{c}}-\sigma^{\mathrm{s}}
$$


Ainda a partir da fórmula de Klein-Nishina é possível obter a distribuição de energia dos elétrons de recuo. Esse parâmetro é bastante útil para a detecção da radiação gama e é dado por:

$$
\frac{\mathrm{d} \sigma}{\mathrm{dT}}=\frac{\pi \mathrm{r}_{0}{ }^{2}}{\mathrm{~m}_{\mathrm{e}} \mathrm{c}^{2} \gamma^{2}} \cdot\left[2+\frac{\mathrm{s}^{2}}{\gamma^{2}(1-\mathrm{s})^{2}}+\frac{\mathrm{s}}{1-\mathrm{s}} \cdot\left(\mathrm{s}-\frac{2}{\gamma}\right)\right]
$$

sendo $\mathrm{m}_{\mathrm{e}}$ a massa de repouso do elétron.

A distribuição $\mathrm{d} \sigma / \mathrm{dT}$ é apresentada na FIG. 6 para diferentes valores de energia dos fótons incidentes. A energia de recuo máxima do elétron espalhado, apresentado matematicamente na Eq. 3, corresponde ao pico de intensidade apresentado na FIG. 6 e é conhecido como borda Compton ou Compton edge.

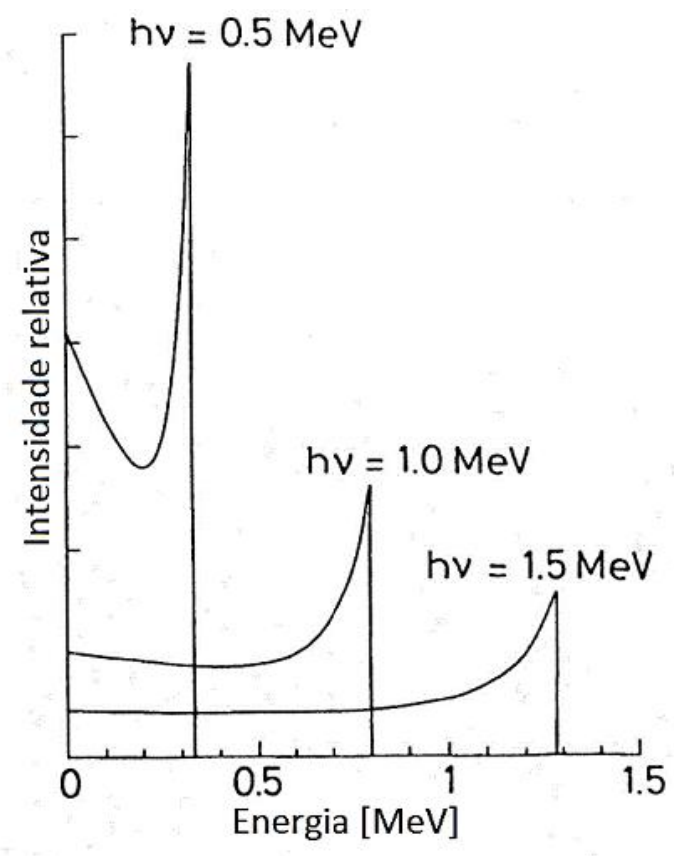

FIGURA 6 - Distribuição em energia dos elétrons Compton de recuo [31].

Outros dois processos de interação por espalhamento de fótons com a matéria são relacionados diretamente com o processo Compton: Thomson e Rayleigh. Enquanto a base do espalhamento Compton envolve as características corpusculares da radiação eletromagnética, no espalhamento Thomson são suas características ondulatórias que predominam. O espalhamento Thomson corresponde então ao espalhamento dos fótons por elétrons livres, do meio de interação, no limite clássico. De fato, para energias baixas com relação a energia de repouso dos elétrons, a fórmula de Klein-Nishina reduz a: 


$$
\sigma_{\mathrm{th}}=\frac{8 \pi}{3} \cdot \mathrm{r}_{0}{ }^{2}
$$

sendo $\sigma_{\text {th }}$ a seção de choque do espalhamento Thomson.

O espalhamento Rayleigh, por sua vez, consiste da interação de um fóton com o átomo como um todo. Neste caso todos os elétrons do átomo participam da interação. Sobretudo, é importante ressaltar que em ambos, Thomson e Rayleigh, processos não há transferência de energia para o meio (elétrons ou átomos) e por este motivo somente uma alteração na direção do fóton é observada (espalhamento coerente).

\subsubsection{Interação de partículas carregadas com a matéria}

As partículas carregadas, ao atravessarem um meio absorvedor, interagem com elétrons e núcleos atômicos transferindo parte de sua energia inicial. Os principais processos de interação são:

(a) Colisão elástica com elétrons atômicos;

(b) Colisão inelástica com elétrons atômicos;

(c) Colisão elástica com o núcleo;

(d) Colisão inelástica com o núcleo.

O processo (a) é somente relevante para partículas de baixa energia, inferior a $100 \mathrm{eV}$. Já o processo (b), responsável pelos fenômenos de ionização e excitação, é o mais comum e a principal forma de perda de energia de partículas carregadas. Em contrapartida, o processo (c) deixa de ser importante quando o processo de interação ocorre com partículas pesadas, tornando-se mais importante para partículas leves, como os elétrons, por exemplo. A colisão inelástica com o núcleo (d), entretanto, é menos provável que o processo (c) e pode ser desprezada para a interação de partículas pesadas e levada em consideração para partículas leves com energias elevadas. A emissão de radiação de bremsstrahlung (freamento) é um exemplo do resultado do processo de interação inelástico com o núcleo.

Assim como para a interação da radiação gama, a partir de agora, o tópico será restringido de acordo com a aplicação deste trabalho. Portanto, a seguir serão descritos somente os processos e características da interação dos elétrons, partículas leves, com a matéria. 


\subsubsection{Interação dos elétrons com a matéria}

Os processos de interação apresentados anteriormente que são relevantes para a análise da interação dos elétrons com a matéria, conduzindo à perda de energia do feixe incidente, podem ser divididos em duas principais partes: perda de energia por colisão e por emissão de radiação (bremsstrahlung). Para elétrons com energias da ordem de $\mathrm{MeV}$ ou menores, o processo de perda de energia por emissão de radiação tem menor contribuição do que os processos de colisão. Sobretudo, a probabilidade de bremsstrahlung aumenta rapidamente com o aumento da energia de maneira que, para energias da ordem de dezenas de $\mathrm{MeV}$, a perda de energia por emissão de radiação é comparável ou mais predominante do que a perda de energia por colisão.

Assim, a perda de energia total por unidade de trajetória é dada por:

$$
\left(\frac{\mathrm{dE}}{\mathrm{dx}}\right)_{\mathrm{total}}=\left(\frac{\mathrm{dE}}{\mathrm{dx}}\right)_{\mathrm{rad}}+\left(\frac{\mathrm{dE}}{\mathrm{dx}}\right)_{\mathrm{col}}
$$

sendo, $(\mathrm{dE} / \mathrm{dx})_{\text {rad }}$ e $(\mathrm{dE} / \mathrm{dx})_{\text {col }}$ as perdas de energia dos elétrons, por unidade de trajetória, por emissão de radiação e colisão, respectivamente.

\section{Perda de energia por colisão:}

A perda de energia por colisão, formulada por Bethe [30], é representada matematicamente na Eq. 10. Essa expressão é derivada da fórmula de Bethe-Block tradicional, para partículas carregadas pesadas, por meio de duas correções principais. Na primeira correção são admitidos grandes desvios dos elétrons incidentes, devido principalmente a diferença entre sua massa e a das partículas pesadas. Além disso, como os elétrons incidentes colidem com elétrons atômicos, partículas idênticas, na segunda correção considera-se impossível distinguir a partícula incidente da partícula alvo. Com as devidas correções tem-se que [30]:

$$
\left(\frac{\mathrm{dE}}{\mathrm{dx}}\right)_{\mathrm{col}}=\frac{2 \pi \mathrm{e}^{4} \mathrm{NZ}}{\mathrm{m}_{\mathrm{e}}}\left(\begin{array}{l}
\ln \frac{\mathrm{m}_{\mathrm{e}} \mathrm{v}^{2} \mathrm{E}}{2 \mathrm{I}^{2}\left(1-\beta^{2}\right)}-(\ln 2)\left(2 \sqrt{1-\beta^{2}}-1+\beta^{2}\right)+\left(1-\beta^{2}\right)+ \\
+\frac{1}{8}\left(1-\sqrt{1-\beta^{2}}\right)^{2}
\end{array}\right)
$$

sendo:

$\mathrm{N}$ e Z - Densidade e número atômico do meio absorvedor.

$\checkmark$ e $E$ - Velocidade e energia da partícula incidente.

$\beta$ - Razão v/c da partícula incidente. 
I - Potencial de excitação médio. Essa grandeza está relacionada basicamente com a frequência orbital média dos estados de ligação dos elétrons atômicos e com a constante de Planck. Os valores atribuídos para este parâmetro variam mas podem ser extraídos a partir de medidas experimentais do poder de freamento [31].

Perda de energia por emissão de radiação:

Classicamente, toda partícula carregada emite radiação quando submetida a uma aceleração [30]. Como a emissão de bremsstrahlung depende da intensidade do campo elétrico que atua sobre o elétron, a quantidade de elétrons atômicos ao redor do núcleo influencia na probabilidade de emissão, pois, os mesmos agem como uma espécie de blindagem para este campo. Além disso, a probabilidade de emissão de bremsstrahlung varia com o inverso do quadrado da massa da partícula incidente, tornando, como mencionado anteriormente, esse fenômeno mais importante para partículas leves, como os elétrons.

A perda de energia de elétrons por unidade de trajetória por emissão de radiação é dada por [30]:

$$
\left(\frac{\mathrm{dE}}{\mathrm{dx}}\right)_{\mathrm{rad}}=\frac{\mathrm{NEZ}(\mathrm{Z}+1) \mathrm{e}^{4}}{137 \mathrm{~m}_{\mathrm{e}}{ }^{2} \mathrm{c}^{4}} \cdot\left(4 \cdot \ln \frac{2 \mathrm{E}}{\mathrm{m}_{\mathrm{e}} \mathrm{c}^{2}}-\frac{4}{3}\right)
$$

A Eq. 11 expressa, como já mencionado, a forte dependência da probabilidade de emissão de bremsstrahlung com a energia da partícula incidente e com o inverso do quadrado de sua massa. Além disso, é possível observar uma dependência linear com $Z^{2}$, indicando que a perda de energia por emissão de radiação é mais predominante para meios absorvedores com números atômicos elevados.

A taxa de perda de energia, dada pela relação entre as perdas de energia por colisão e emissão de radiação é de aproximadamente:

$$
\frac{(\mathrm{dE} / \mathrm{dx})_{\mathrm{rad}}}{(\mathrm{dE} / \mathrm{dx})_{\text {col }}} \cong \frac{\mathrm{EZ}}{700}
$$

onde a energia $\mathrm{E}$ é dada em unidades de MeV.

Neste trabalho, como será detalhado adiante, foi utilizado um acelerador que produz elétrons com energias de $1,5 \mathrm{MeV}$. Como o meio de interesse considerado é o $\mathrm{Si}$, obtém-se que a perda de energia por emissão de radiação contribui em aproximadamente 3\% (Eq. 13) para a perda total de energia. Essa 
afirmação pode ser ainda verificada por meio da curva da perda de energia específica, FIG. 7, (perda de energia normalizada pela densidade do material) obtida por meio do programa ESTAR (stopping power and range tables for electrons) disponibilizado pelo National Institute of Standard and Technology (NIST) [33].

$$
\frac{\left(\mathrm{dE} / \mathrm{dx}_{\mathrm{rad}}\right.}{\left(\mathrm{dE} / \mathrm{dx}_{\text {col }}\right.} \cong 0,03
$$

\section{Silício}

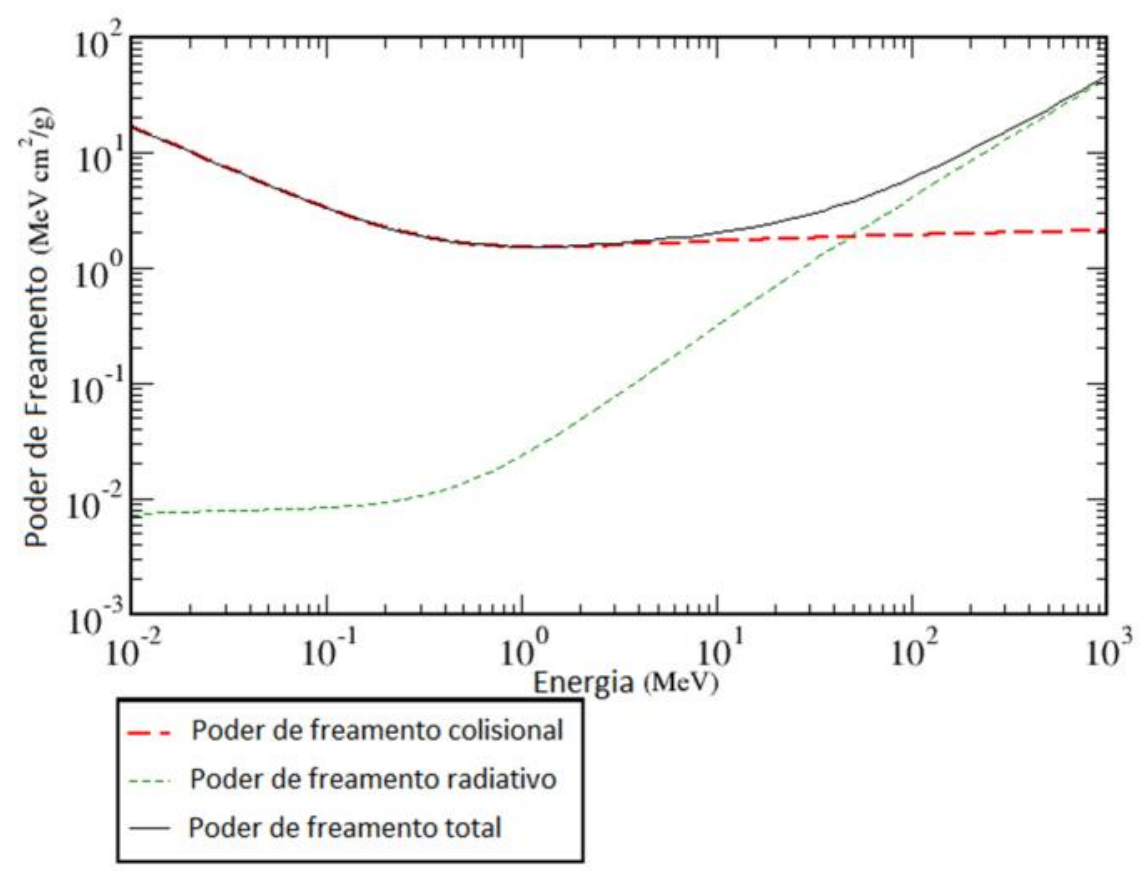

FIGURA 7 - Perda de energia específica em função da energia dos elétrons incidentes no Si $[24,33]$.

\subsubsection{Alcance dos elétrons}

Integrando-se as expressões da perda de energia, obtém-se um parâmetro denominado comprimento de trajetória médio $(\overline{\mathrm{S}})$. Este parâmetro indica o comprimento de trajetória da partícula no interior do meio absorvedor. Os elétrons, no entanto, ao penetrarem no meio absorvedor sofrem espalhamentos múltiplos com os núcleos atômicos e descrevem trajetórias tortuosas no meio. Por este motivo, experimentalmente é mais relevante utilizar o alcance como grandeza para tratar da distância de penetração dos elétrons em um dado material. A FIG. 8 
representa uma série de trajetórias de elétrons provenientes de uma fonte monoenergética.

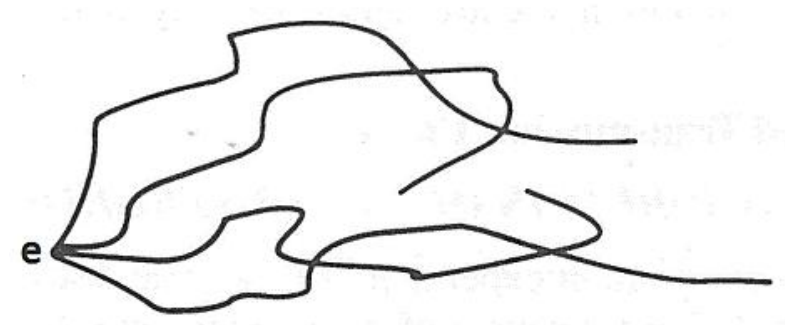

FIGURA 8 - Representação das possíveis trajetórias de elétrons com mesma energia incidindo em um dado meio [30].

O alcance de uma partícula carregada em um meio absorvedor é definido como a distância de penetração da partícula, no material, na direção de sua incidência. Seus valores, para feixes monoenergéticos, por exemplo, seguem uma distribuição estatística de maneira que existe um valor médio $(\bar{R})$ equivalente a espessura do material capaz de reduzir o número de elétrons incidentes pela metade. As diferenças entre os valores do comprimento de trajetória e alcance podem variar entre $20 \%$ e $400 \%$ dependendo da energia e do material [31]. $\mathrm{Na}$ FIG. 9 é apresentado um diagrama representativo de um material absorvedor com espessura $x_{0}$, sendo penetrado por dois elétrons com energias iguais e alcances, $R_{1}$ e $R_{2}$, diferentes.

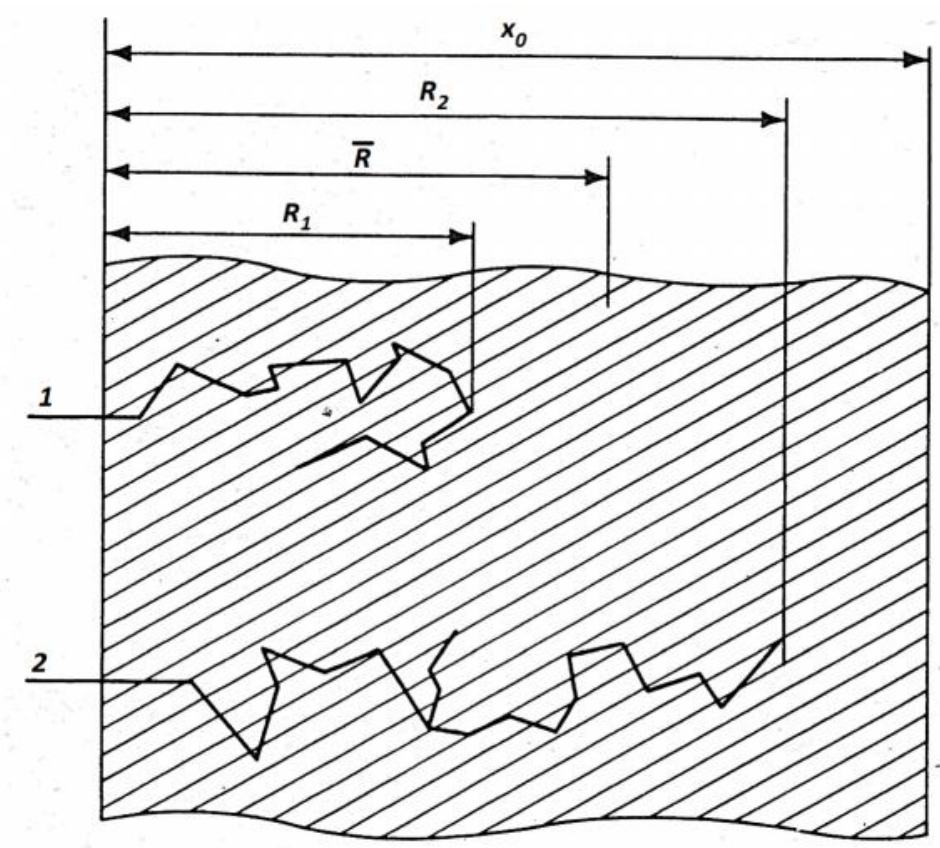

FIGURA 9 - Diagrama indicando os caminhos possíveis de dois elétrons com energias iguais ao penetrarem em um absorvedor com espessura $\mathrm{x}_{0}$ [32]. 
Para um feixe de elétrons monoenergético, o alcance médio equivale a aproximadamente metade do valor do comprimento de trajetória, como pode ser observado na FIG. 10 para elétrons com energia de 0,02 MeV atravessando um meio gasoso composto por oxigênio em condições normais de temperatura e pressão (CNTP). Outra definição comumente utilizada é o alcance e comprimento de trajetória extrapolados, $R_{\text {ex }}$ e $S_{\text {ex }}$. Ambos são obtidos a partir da extrapolação da parte linear, no final da curva de transmissão, para zero [30]. Pode-se observar que somente cerca de $3 \%$ dos elétrons atravessam o absorvedor a uma espessura equivalente ao comprimento de trajetória médio [32].

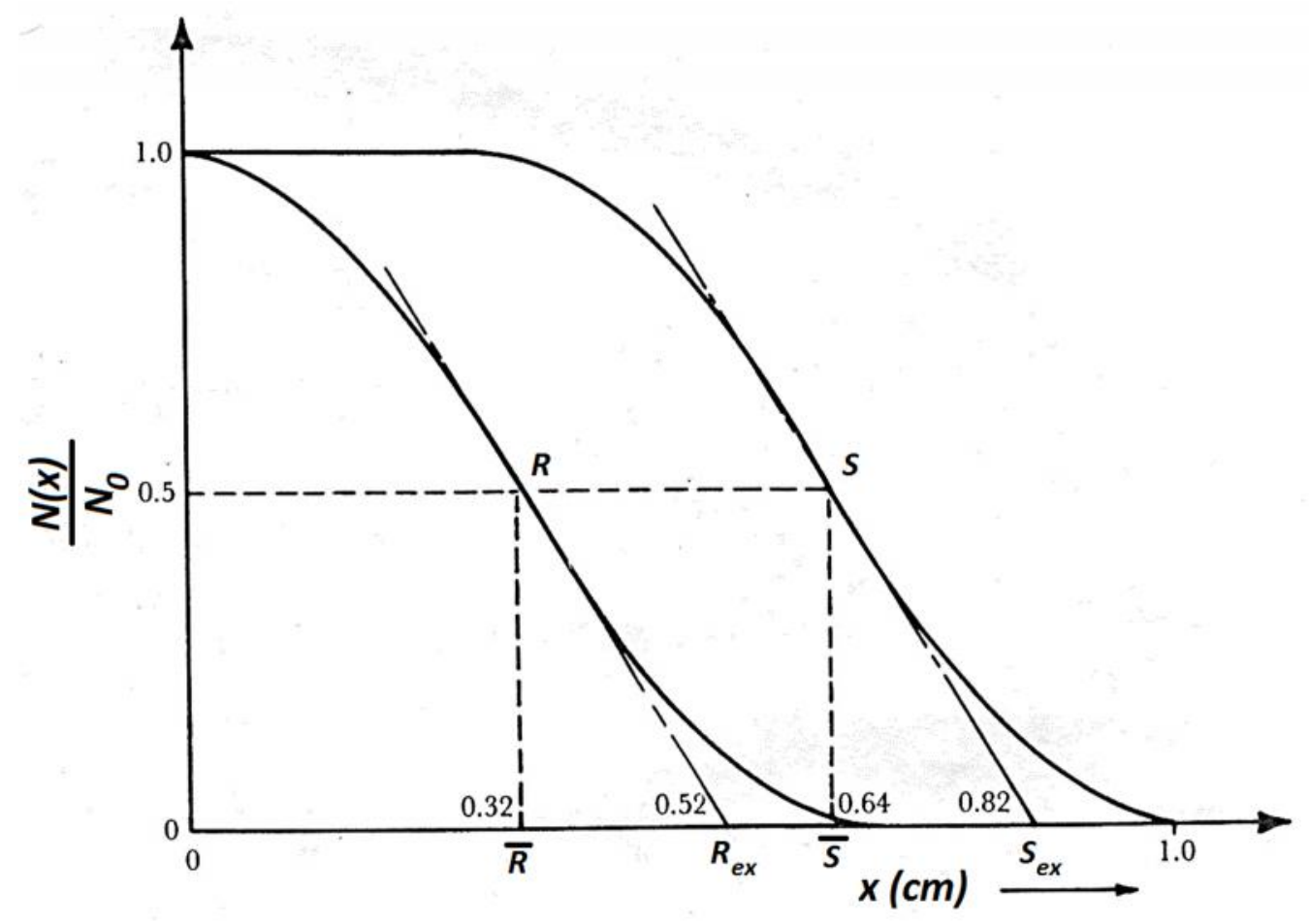

FIGURA 10 - Distribuição dos alcances e comprimento de trajetória para elétrons com energia de 0,02 MeV em um absorvedor gasoso (oxigênio) em CNTP [32].

Na FIG. 11 é apresentada a curva do alcance mássico, alcance linear normalizado pela densidade do material, em função da energia dos elétrons incidentes no $\mathrm{Si}$, obtida com o programa ESTAR. 


\section{Silício}

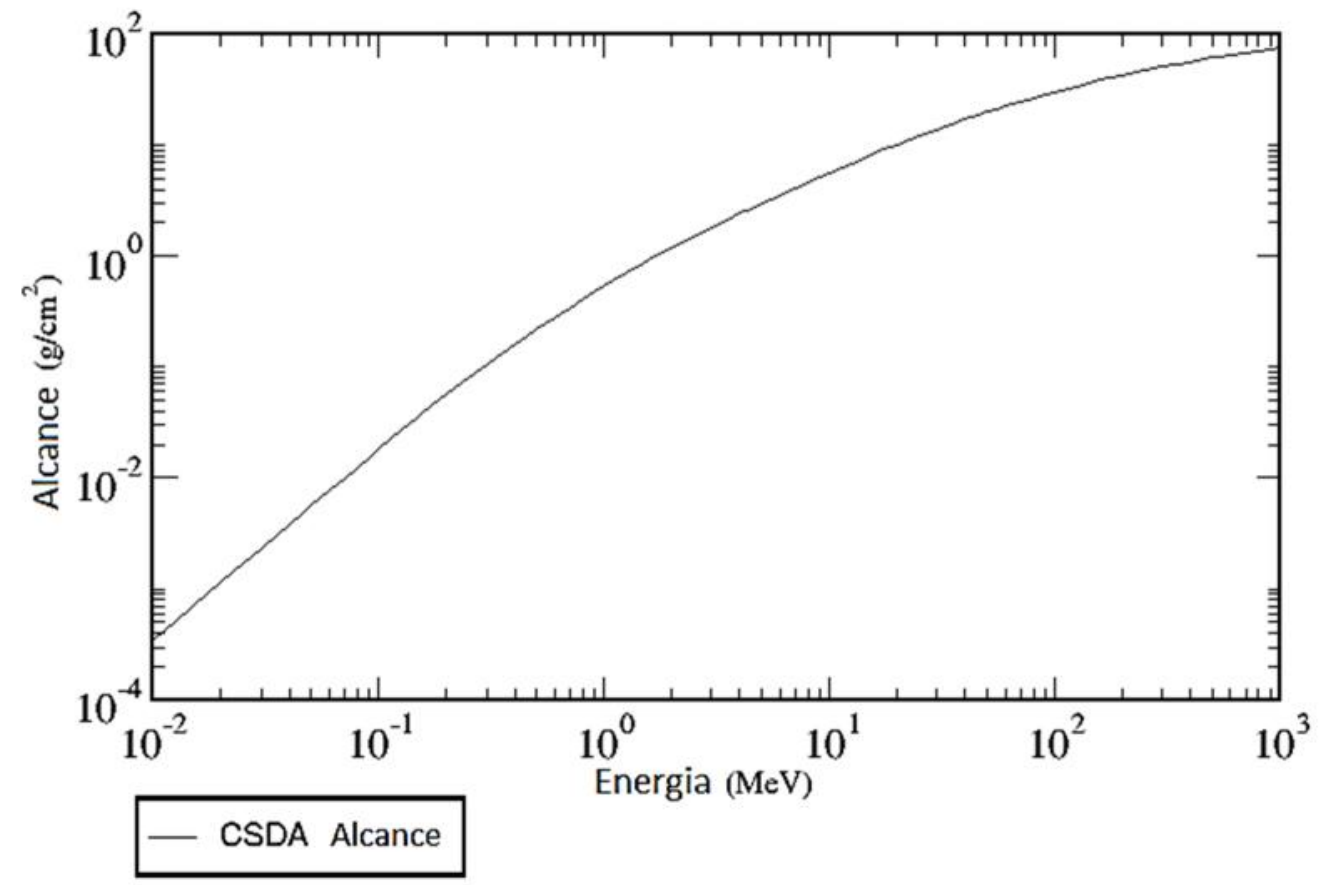

FIGURA 11 - Alcance mássico dos elétrons com diferentes valores de energia ao penetrarem no Si $[24,33]$.

\subsection{Diodos como dosímetros de radiação}

Os diodos de junção apresentam algumas vantagens que fazem deles candidatos promissores na área da dosimetria das radiações. São elas [25,28,3437]:

- Sensibilidade maior (aproximadamente 18000 vezes) do que câmaras de ionização padrão com o mesmo volume;

- Dimensões pequenas com elevada resolução espacial;

- Boa estabilidade mecânica;

- Possibilidade de operação no modo passivo ou ativo, como monitor online.

Para dosimetria, os diodos são utilizados sem polarização externa e, normalmente conectados diretamente à entrada de um amperímetro [28]. A radiação que penetra no dispositivo gera pares elétron-lacunas (e-l) por meio dos processos característicos, como aqueles descritos nas seções anteriores deste trabalho. Os pares e-I produzidos dentro de um comprimento de difusão ( $L_{n}$ e $L_{p}$ ) são separados pelo campo elétrico inerente da junção, $\Psi_{0}$, e coletados nos terminais do diodo (anodo e catodo) [28,38]. Neste caso, a corrente elétrica gerada no dispositivo pela interação da radiação é devida predominantemente aos 
portadores minoritários, elétrons na região tipo p e lacunas na região tipo n. Na FIG. 12 é apresentado um diagrama esquemático da formação e separação dos pares e-l em um diodo de junção.

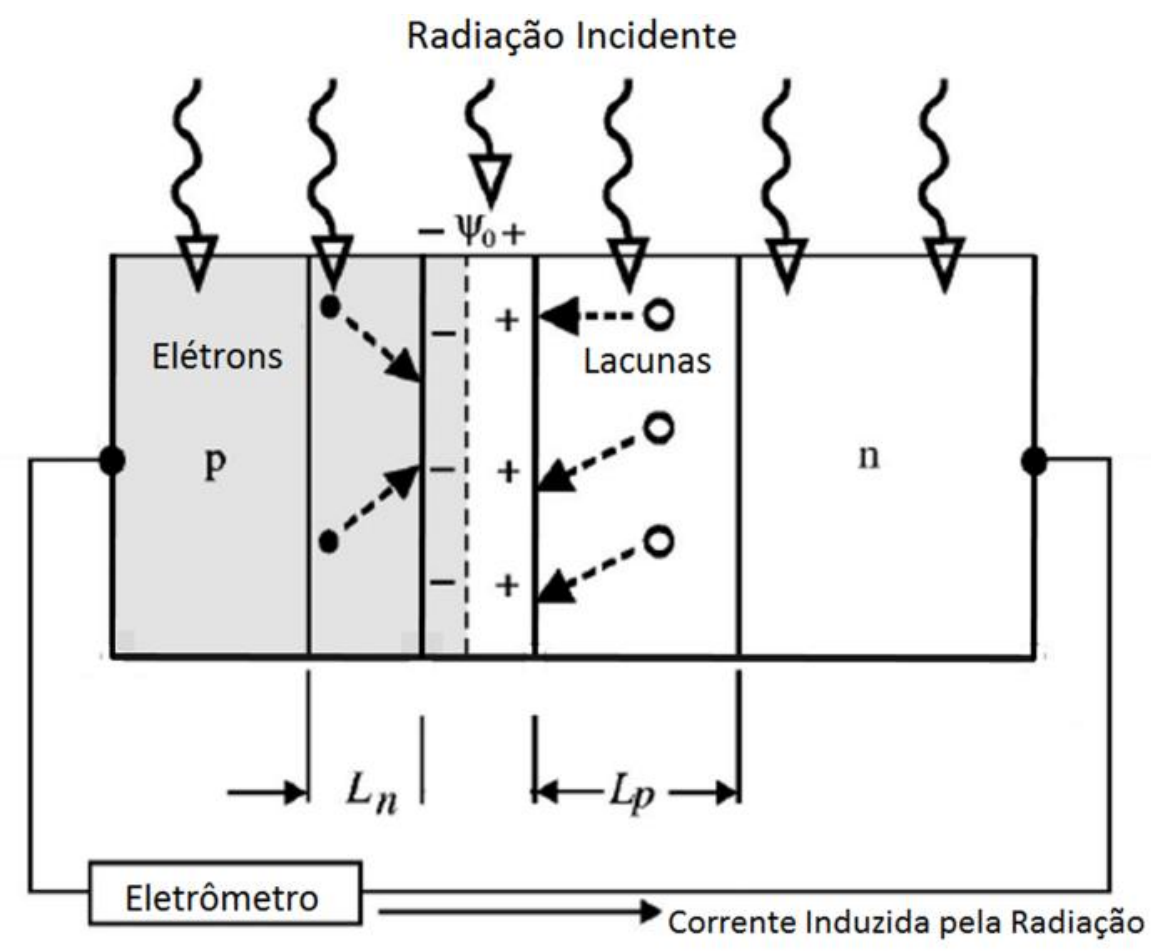

FIGURA 12 - Diagrama esquemático do funcionamento de um diodo de junção como dosímetros de radiação [38].

Serão apresentadas a seguir algumas características teóricas sobre os diodos de $\mathrm{Si}$, como aqueles utilizados neste trabalho. Inicialmente serão abordados os conceitos de geração e recombinação de portadores de carga bem como a descrição matemática destes processos. Em seguida serão apresentados alguns conceitos sobre o transporte de portadores de carga pelo material semicondutor, efeitos da radiação e finalizando com uma breve descrição do processo de fabricação e estrutura dos diodos utilizados neste trabalho.

\subsubsection{Recombinação e geração de portadores}

Fenômenos como irradiação, excitação óptica, aplicação de campo elétrico ou introdução de defeitos nos materiais semicondutores podem conduzir à geração ou recombinação dos portadores de carga (elétrons e lacunas) [39-41]. Por definição, a recombinação de um portador ocorre quando o mesmo é aniquilado ou destruído, sendo, o fenômeno oposto, ou seja, a criação de um portador, denominado como geração. As definições apresentadas são generalizadas uma vez que um número elevado de diferentes processos pode levar a recombinação e 
geração dos portadores de carga [39]. A seguir serão apresentados alguns dos principais processos em questão.

\subsubsection{Processos de recombinação}

Os processos de recombinação podem ser do tipo direto, processo característico para o Arseneto de Gálio (GaAs), ou indireto, característico para o Si, por exemplo [40-41]. As descrições de cada mecanismo e suas principais características são:

- Recombinação direta (banda-a-banda):

Este é o processo conceitualmente mais simples entre os demais processos de recombinação. Como pode ser observado na FIG. 13a, este processo envolve apenas a aniquilação direta de um elétron da banda de condução $\left(E_{c}\right)$ com uma lacuna da banda de valência (Ev). Neste processo é comum que o excesso de energia envolvido na transição entre os estados de energia seja liberado sob a forma de um fóton de luz $[39,41]$.

Quando a energia e o momento liberados no processo de recombinação direta são transferidos para um terceiro portador, o processo passa a ser denominado recombinação Auger. Quando o portador que adquire a energia do processo é um elétron da banda de condução, por exemplo, ele poderá se movimentar livremente pela estrutura e será termalizado através de sucessivas colisões com a rede cristalina. Este processo é ilustrado na FIG. 13c, onde, os degraus representam a perda sucessiva de energia do elétron livre. O processo de recombinação Auger é relevante em casos onde a concentração de portadores é elevada, ou seja, estruturas com elevada concentração de dopantes ou alto nível de injeção de portadores [39,41].

- Recombinação indireta:

Este processo de recombinação ocorre através da transição para níveis intermediários introduzidos na banda proibida (ET) como resultado, por exemplo, da presença de impurezas na estrutura do semicondutor. Estes níveis intermediários serão denominados, a partir de agora, centros R-G (recombinação-geração). Assim, a recombinação ocorrerá quando um elétron e uma lacuna forem capturados simultaneamente para um centro $R-G$ aniquilando-se. $O$ processo também pode ser descrito como uma transição fracionada de um único portador; um elétron, por exemplo, da banda de condução que faz a transição para o centro R-G e em seguida para a banda de valência recombinando-se com uma lacuna. Este 
processo está representado na FIG. 13b. É importante salientar que, embora, todos os níveis introduzidos na banda proibida possam agir como centros R-G, a probabilidade de ocorrer a recombinação a partir da transição para um destes centros depende fortemente da profundidade do nível do centro introduzido. Ou seja, se o nível do centro R-G é considerado raso, cuja definição será descrita em outro momento, a probabilidade de ocorrer a recombinação de um portador é baixa à temperatura ambiente e, portanto, um portador capturado por este centro é normalmente reemitido antes de se recombinar com o portador oposto. Neste caso diz-se apenas que o portador foi armadilhado durante um dado intervalo de tempo [39].

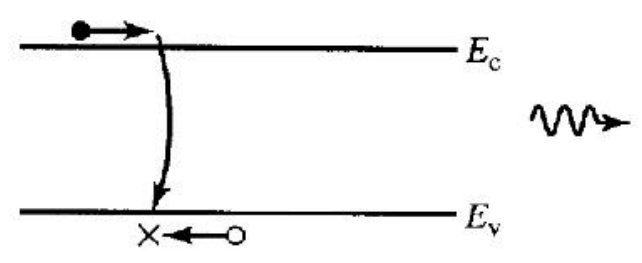

(a)

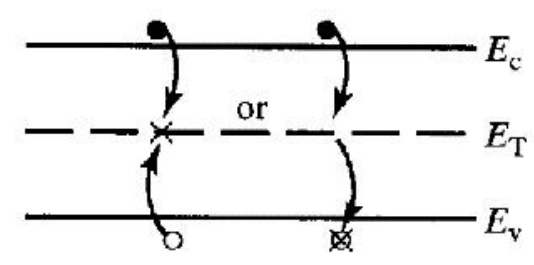

(b)

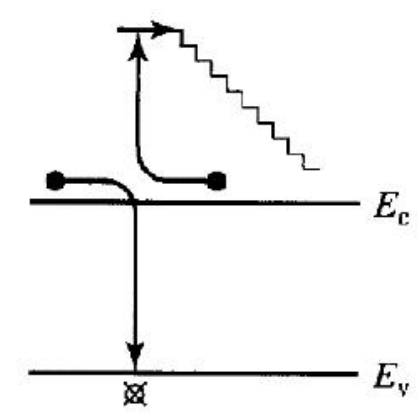

(c)

FIGURA 13 - Representação ilustrativa dos processos de recombinação direta (a), indireta (b) e Auger (c) [39].

\subsubsection{Processos de geração de portadores}

Os processos de geração de portadores são processos contrários aos de recombinação. Para a criação de um par de portadores, par elétron-lacuna, é necessário que o sistema adquira uma quantidade de energia. Esta energia pode ser absorvida termicamente ou através da irradiação do material semicondutor com partículas ou luz. Assim como os processos de recombinação, os processos de geração podem ser diretos ou indiretos, via centros R-G, e são ilustrados nas FIG. $14 \mathrm{a}$ e $14 \mathrm{~b}$, respectivamente. 


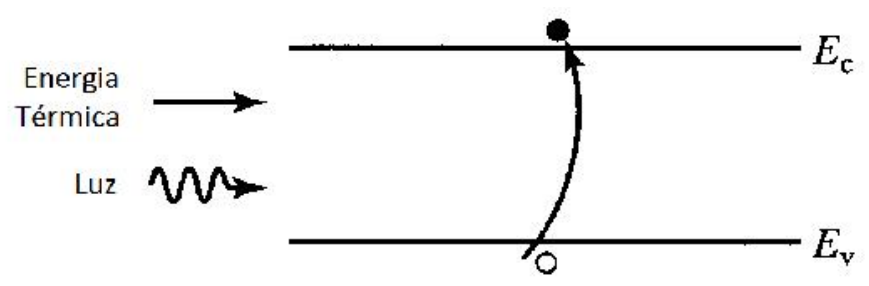

(a)

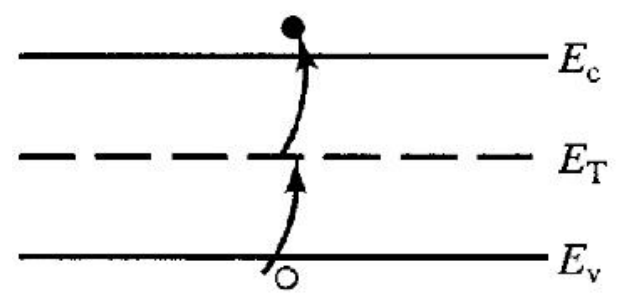

(b)

FIGURA 14 - Representação ilustrativa dos processos de geração direta (a) e indireta (b) [39].

\subsubsection{Estatística de Recombinação - Geração}

Nesta etapa os processos de recombinação e geração, via centros R-G, serão descritos matematicamente. Esta descrição consiste em avaliar a variação da concentração de portadores com o tempo, ou seja, obter as relações $\left(\frac{\partial n}{\partial t}\right)$, para elétrons, $\mathrm{e}\left(\frac{\partial \mathrm{p}}{\partial \mathrm{t}}\right)$, para lacunas. As descrições serão realizadas com base em um semicondutor que contenha um único tipo de centro R-G. Embora os semicondutores possam conter um número elevado de diferentes tipos de centros $\mathrm{R}-\mathrm{G}$, é comum que somente um deles seja dominante para o processo efetivo de recombinação de portadores. Durante a análise a seguinte terminologia será utilizada:

$\left.\frac{\partial \mathrm{n}}{\partial \mathrm{t}}\right|_{\mathrm{RG}}:$ taxa da alteração da concentração de elétrons com o tempo devido aos processos de recombinação e geração via centros $R-G$.

$\left.\frac{\partial \mathrm{p}}{\partial \mathrm{t}}\right|_{\mathrm{RG}}$ : taxa da alteração da concentração de lacunas com o tempo devido aos processos de recombinação e geração via centros $R-G$.

$\mathrm{n}_{\mathrm{T}}$ : concentração de centros R-G ocupados por elétrons.

$\mathrm{p}_{\mathrm{T}}$ : concentração de centros R-G não ocupados (vazios). 
$N_{T}$ : concentração de centros R-G $\left(N_{T}=n_{T}+p_{T}\right)$.

É importante enfatizar que $\partial \mathrm{n} / \partial \mathrm{t}$ e $\partial \mathrm{p} / \partial \mathrm{t}$ são taxas líquidas, o que significa que serão negativas quando os processos de recombinação forem predominantes aos processos de geração. Da mesma maneira, esta taxa será positiva quando os processos de geração forem predominantes aos processos de recombinação [39].

O primeiro passo para a descrição em questão é avaliar o número de transições de portadores possíveis, via centros R-G. As transições possíveis, quatro ao todo e ilustradas na FIG. 15, são:

(a) captura de um elétron por um centro R-G;

(b) emissão de um elétron a partir de um centro R-G;

(c) captura de uma lacuna por um centro R-G;

(d) emissão de uma lacuna a partir de um centro R-G.

As transições (c) e (d) são equivalentes a transição de um elétron do centro R-G para a banda de valência e a transição de um elétron da banda de valência para o centro R-G, respectivamente. Estas alternativas são ilustradas também na FIG. 15.

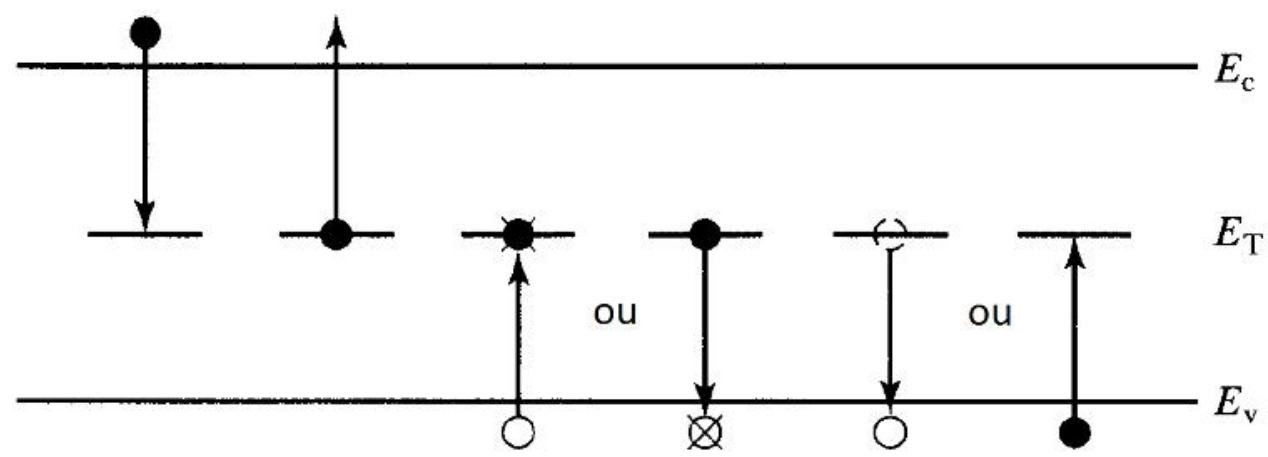

(a)

(b)

(c)

(d)

FIGURA 15 - Representação ilustrativa das possíveis transições que conduzem aos processos recombinação e geração via centros R-G [39].

Como somente as transições (a) e (b) afetam a concentração de elétrons da mesma maneira como somente as transições (c) e (d) afetam a concentração de lacunas, pode-se escrever:

$$
\left.\frac{\partial \mathrm{n}}{\partial \mathrm{t}}\right|_{\mathrm{RG}}=\left.\frac{\partial \mathrm{n}}{\partial \mathrm{t}}\right|_{(\mathrm{a})}+\left.\frac{\partial \mathrm{n}}{\partial \mathrm{t}}\right|_{(\mathrm{b})}
$$




$$
\left.\frac{\partial \mathrm{p}}{\partial \mathrm{t}}\right|_{\mathrm{RG}}=\left.\frac{\partial \mathrm{p}}{\partial \mathrm{t}}\right|_{(\mathrm{c})}+\left.\frac{\partial \mathrm{p}}{\partial \mathrm{t}}\right|_{(\mathrm{d})}
$$

A ocorrência do processo fundamental (a) depende basicamente da existência de elétrons para a captura além da disponibilidade de centros R-G não ocupados. Se um destes termos é nulo, então $\partial \mathrm{n} /\left.\partial \mathrm{t}\right|_{(\mathrm{a})} \rightarrow 0$. Além disso, se um dos termos em questão aumentar duas vezes o valor inicial, espera-se que a variação da concentração de elétrons devida a transição (a) também aumente duas vezes, ou seja, espera-se que $\partial \mathrm{n} / \partial \mathrm{t}_{\text {(a) }}$ seja proporcional a concentração de elétrons no semicondutor e a concentração de centros R-G não ocupados [39]. Em outras palavras:

$$
\partial \mathrm{n} /\left.\partial \mathrm{t}\right|_{(\mathrm{a})}=-\mathrm{c}_{\mathrm{n}} \cdot \mathrm{p}_{\mathrm{T}} \cdot \mathrm{n}
$$

sendo $\mathrm{c}_{n}$ uma constante denominada coeficiente de captura de elétrons $\left(\mathrm{cm}^{3} / \mathrm{s}\right)$.

O coeficiente $c_{n}$ é positivo por definição e, por este motivo, o sinal negativo é adicionado na Eq. 16, uma vez que a transição (a) é responsável pela redução do número de elétrons na banda de condução.

Com relação à alteração da concentração de elétrons devido às transições do tipo (b), pressupõe-se que haja uma proporcionalidade entre esta taxa, a concentração de centros R-G ocupados e a concentração de estados disponíveis, vazios, na banda de condução. Quando um semicondutor é considerado não degenerado ${ }^{1}$, a maioria dos estados na banda de condução permanecem não ocupados a todo o momento. Assim, a concentração de estados disponíveis na banda de condução, que é constante, pode ser incorporada na constante de proporcionalidade entre a taxa da variação de elétrons e a concentração de centros R-G preenchidos [39]. Desta maneira:

$$
\partial n /\left.\partial t\right|_{(b)}=e_{n} \cdot n_{T}
$$

sendo en uma constante denominada coeficiente de emissão de elétrons $\left(\mathrm{s}^{-1}\right)$.

\footnotetext{
1 Um semicondutor é considerado degenerado quando a quantidade de impurezas presentes na estrutura é da ordem ou superior a $10^{20} \mathrm{~cm}^{-3}$, assim, a interação entre os átomos de impureza não é desprezível e os níveis introduzidos deixam de ser discretos originando novas bandas de energia. Como consequência os estados localizados na banda de condução ou acima dela estão preenchidos com elétrons mesmo para a temperatura de $0 \mathrm{~K}$ [43].
} 
Diferente do caso anterior, a variação da concentração de elétrons devido a transições do tipo (b) é considerada positiva, pois, este tipo de transição contribui para o aumento do número de elétrons na banda de condução.

Para as transições (c) e (d) são aplicados argumentos análogos àqueles utilizados para a definição das transições (a) e (b). Assim:

$$
\begin{gathered}
\partial p /\left.\partial t\right|_{(c)}=-c_{p} \cdot n_{T} \cdot p \\
\partial p /\left.\partial t\right|_{(d)}=e_{p} \cdot p_{T}
\end{gathered}
$$

sendo $c_{p}$ e $e_{p}$ os coeficientes de captura e emissão de lacunas, respectivamente.

Assumindo que os processos de recombinação sejam predominantes aos processos de geração, as variações das concentrações de elétrons e lacunas com o tempo, via centros R-G, passam a ser denominadas taxas líquidas de recombinação de elétrons e lacunas, respectivamente [39]. Assim, substituindo as Eq. 16, 17, 18 e 19 nas Eq.14 e 15, tem-se que:

$$
\begin{aligned}
& r_{n}=\left.\frac{\partial n}{\partial t}\right|_{R G}=c_{n} \cdot p_{T} \cdot n-e_{n} \cdot n_{T} \\
& r_{p}=\left.\frac{\partial p}{\partial t}\right|_{R G}=c_{p} \cdot n_{T} \cdot p-e_{p} \cdot p_{T}
\end{aligned}
$$

As Eq. 20 e 21 são bastante generalizas e podem ser aplicadas nas mais diversas situações onde os processos de recombinação e geração de portadores ocorrem em semicondutores, via centros R-G, segundo as transições (a), (b), (c) e (d), descritas anteriormente.

\subsection{Condições de equilíbrio}

As Eq. 20 e 21 podem ser simplificadas quando o semicondutor sob análise obedece às condições de equilíbrio. Quando isso acontece, as definições anteriores podem ser reformuladas com base no "princípio do balanço detalhado" que pode ser enunciado como [39]:

Princípio do balanço detalhado - Sob condição de equilíbrio cada processo fundamental e seu inverso devem se balancear independente de qualquer outro processo que possa ocorrer no interior do material. 
Quando aplicado aos processos de recombinação, via centros R-G, o princípio do balanço detalhado sugere que as transições (a) e (b), bem como (c) e (d) se auto balanceiem. Assim:

$$
\left.\begin{array}{l}
r_{n}=0 \\
r_{p}=0
\end{array}\right\} \text { sob condições de equilíbrio }
$$

A análise das taxas de recombinação líquidas de elétrons e lacunas, sob condições de equilíbrio, permite a determinação dos coeficientes de emissão e captura dos portadores de carga:

$$
\begin{aligned}
& e_{n}=\frac{c_{n} \cdot p_{T} \cdot n}{n_{T}}=c_{n} \cdot n_{1} \\
& e_{p}=\frac{c_{p} \cdot n_{T} \cdot p}{p_{T}}=c_{p} \cdot p_{1}
\end{aligned}
$$

As constantes $\mathrm{n}_{1}$ e $\mathrm{p}_{1}$ introduzidas nas Eq. 22 e 23 são calculadas a partir de outros parâmetros pré-estabelecidos, como pode ser observado. Reescrevendo então as taxas de recombinações líquidas de elétrons e lacunas, para a condição de equilíbrio, tem-se que:

$$
\begin{aligned}
& r_{n}=\left.\frac{\partial n}{\partial t}\right|_{R G}=c_{n}\left(p_{T} \cdot n-n_{T} \cdot n_{1}\right) \\
& r_{p}=\left.\frac{\partial p}{\partial t}\right|_{R G}=c_{p}\left(n_{T} \cdot p-p_{T} \cdot p_{1}\right)
\end{aligned}
$$

Como os coeficientes de emissão e captura de portadores foram considerados como inalterados sob condições de equilíbrio e de não equilíbrio, a validade das Eq. 24 e 25 pode ser questionada [39].

Com algumas substituições matemáticas:

$$
\begin{aligned}
& n_{1}=\frac{p_{T} \cdot n}{n_{T}}=\left(\frac{N_{T}-n_{T}}{n_{T}}\right) \cdot n=\left(\frac{N_{T}}{n_{T}}-1\right) \cdot n \\
& p_{1}=\frac{n_{T} \cdot p}{p_{T}}=\left(\frac{N_{T}-p_{T}}{p_{T}}\right) \cdot p=\left(\frac{N_{T}}{p_{T}}-1\right) \cdot p
\end{aligned}
$$

Da teoria básica de semicondutores, sabe-se que a concentração de elétrons e lacunas nas bandas de condução e valência, sob condições de equilíbrio são [39-41]: 


$$
\begin{aligned}
& n=n_{i} \cdot e^{\left(E_{F}-E_{i}\right) / k \cdot T} \\
& p=p_{i} \cdot e^{\left(E_{i}-E_{F}\right) / k \cdot T}
\end{aligned}
$$

sendo $E_{F}, E_{i}, k$ e $T$ a energia de Fermi, energia de Fermi para o semicondutor intrínseco, constante de Boltzman e temperatura absoluta, respectivamente.

Assim:

$$
\begin{aligned}
& n_{1}=\left(\frac{N_{T}}{n_{T}}-1\right) \cdot n_{i} \cdot e^{\left(E_{F}-E_{i}\right) / k \cdot T} \\
& p_{1}=\left(\frac{N_{T}}{p_{T}}-1\right) \cdot p_{i} \cdot e^{\left(E_{i}-E_{F}\right) / k \cdot T}
\end{aligned}
$$

Outras simplificações podem ser feitas manipulando-se matematicamente as razões $\mathrm{N}_{\mathrm{T}} / \mathrm{n}_{\mathrm{T}}$ e $\mathrm{N}_{\mathrm{T}} / \mathrm{p}_{\mathrm{T}}$ por meio da teoria básica sobre semicondutores extrínsecos. Sobretudo, estas aproximações não serão apresentadas, pois, não contribuem significativamente para 0 desenvolvimento deste trabalho.

\subsection{Estado estacionário}

$\mathrm{Na}$ maioria dos problemas analisados, assume-se que os dispositivos semicondutores operam em regime estacionário ou quase estacionário ${ }^{2}$. Por este motivo, nesta seção, as taxas de recombinação líquida de elétrons e lacunas serão reescritas para estas condições.

O primeiro passo é identificar o que ocorre no interior de um semicondutor em regime estacionário e distinguir esta condição da abordada anteriormente. Em ambas as situações, a variação da concentração de portadores e de centros R-G preenchidos com o tempo é nula [39]. Como mencionado, essa afirmação é válida para a condição de equilíbrio, já que cada transição se auto balanceia com seu inverso. No regime estacionário, sobretudo, a variação da concentração de portadores com o tempo é nula por meio de uma compensação

${ }^{2} \mathrm{~A}$ hipótese de estado quase estacionário refere-se a situação onde as alterações das variáveis do sistema, tais como, n, p e campo elétrico, são baixas comparadas com as alterações dos processos fundamentais. Sob condições de estado quase estacionário, o estado instantâneo do sistema pode ser considerado como uma etapa do estado estacionário e, por este motivo, as relações são válidas [39]. 
entre todos os processos e transições que ocorrem no interior do semicondutor. Esta diferença é ilustrada na FIG. 16. Assim é possível notar que a taxa de recombinação líquida dos portadores não é nula para um semicondutor em regime estacionário.

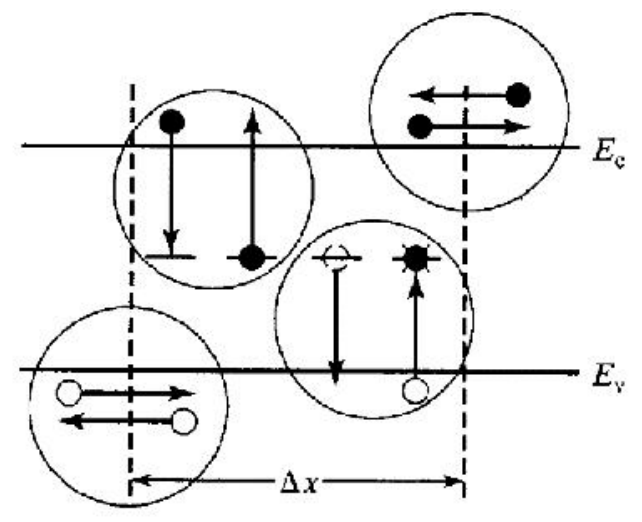

(a)

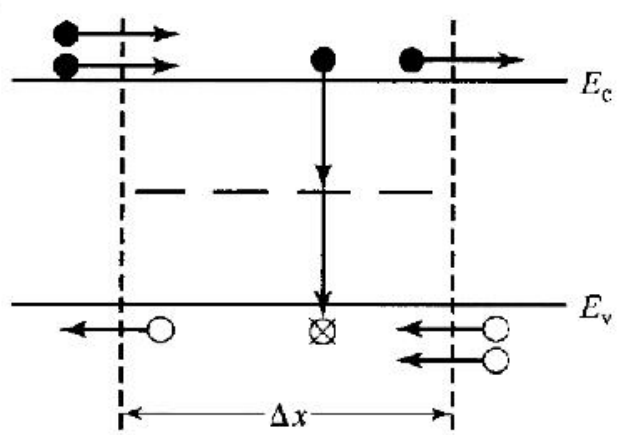

(b)

FIGURA 16 - Representação ilustrativa da compensação entre os processos de recombinação e geração de portadores sob condições de equilíbrio (a) e estado estacionário (b) em um uma seção $\Delta x$ do material semicondutor [34].

Considerando então, que a concentração de centros R-G ocupados é nula e que esta concentração só pode ser alterada por meio das transições (a), (b), (c) e (d), tem-se que [39]:

$$
\begin{gathered}
\frac{\mathrm{dn}_{\mathrm{T}}}{\mathrm{dt}}=-\left.\frac{\partial \mathrm{n}}{\partial \mathrm{t}}\right|_{\mathrm{RG}}+\left.\frac{\partial \mathrm{p}}{\partial \mathrm{t}}\right|_{\mathrm{RG}}=r_{\mathrm{n}}-r_{\mathrm{p}}=0 \\
\left.r_{\mathrm{n}}=r_{\mathrm{p}}\right\} \text { sob regime estacionná rio }
\end{gathered}
$$

Igualando as Eq. 24 e 25:

$$
\begin{gathered}
r_{n}=r_{p}=c_{n}\left(p_{T} \cdot n-n_{T} \cdot n_{1}\right)=c_{p}\left(n_{T} \cdot p-p_{T} \cdot p_{1}\right) \\
c_{n} \cdot\left(N_{T}-n_{T}\right) \cdot n-c_{n} \cdot n_{T} \cdot n_{1}=c_{p} \cdot n_{T} \cdot p-c_{p} \cdot\left(N_{T}-n_{T}\right) \cdot p_{1} \\
n_{T}=\frac{c_{n} \cdot N_{T} \cdot n+c_{p} \cdot N_{T} \cdot p_{1}}{c_{n} \cdot\left(n+n_{1}\right)+c_{p} \cdot\left(p+p_{1}\right)}
\end{gathered}
$$

O resultado apresentado na Eq. 35 pode ser utilizado nas Eq. 24 e 25 associado com a substituição matemática $n_{1} \cdot p_{1}=n_{i}{ }^{2}$, baseada na manipulação das Eq. 30 e 31 e na teoria básica sobre semicondutores para obter-se assim a taxa de recombinação líquida no semicondutor em regime estacionário $(R)$ : 


$$
R=r_{n}=r_{p}=\frac{n \cdot p-n_{i}^{2}}{\frac{1}{c_{p} \cdot N_{T}} \cdot\left(n+n_{1}\right)+\frac{1}{c_{n} \cdot N_{T}} \cdot\left(p+p_{1}\right)}
$$

Com base nos termos da Eq. 36 pode-se definir o tempo de vida dos portadores minoritários, elétrons $\left(\tau_{n}\right)$ e lacunas $\left(\tau_{p}\right)$ [39-41]:

$$
\begin{aligned}
& \tau_{n}=\frac{1}{C_{n} \cdot N_{T}} \\
& \tau_{p}=\frac{1}{C_{p} \cdot N_{T}}
\end{aligned}
$$

Assim, a Eq. 36 pode ser reescrita como:

$$
R=\frac{n \cdot p-n_{i}^{2}}{\tau_{p} \cdot\left(n+n_{1}\right)+\tau_{n} \cdot\left(p+p_{1}\right)}
$$

O resultado obtido na Eq. 39 é comumente referenciado em toda a literatura disponível sobre dispositivos semicondutores [39-41]. É importante salientar que os tempos de vida dos portadores minoritários são definidos como o tempo médio que cada portador sobrevive no interior do material até que ocorra a recombinação [39-41,44]. Este parâmetro pode ser determinado experimentalmente através de diferentes técnicas, sendo que a mais utilizada consiste na monitoração da redução de portadores, com o tempo, injetados inicialmente a partir da iluminação do dispositivo em um curto intervalo de tempo [45].

\section{Estado estacionário (condições especiais):}

As relações das taxas de recombinação líquidas de elétrons e lacunas sob regime estacionário ainda podem ser simplificadas frente a algumas condições especiais. A seguir estas simplificações serão abordadas a partir da validade da Eq. 39 para condições de injeção de portadores em nível baixo.

A injeção em nível baixo refere-se à magnitude relativa das alterações das concentrações de portadores resultante de uma perturbação. Assim, a injeção é considerada de nível baixo quando a alteração da concentração de portadores é muito menor quando comparada à concentração dos portadores majoritários sob condições de equilíbrio [39]. Se $n$ e $p$ representam as concentrações de portadores sob condições arbitrárias, $\mathrm{n}_{0}$ e $\mathrm{p}_{0}$ as concentrações de portadores sob equilíbrio, 
e $\mathrm{n}=\mathrm{n}-\mathrm{n}_{0}$ e $\mathrm{p}=\mathrm{p}-\mathrm{p}_{0}$ as alterações nas concentrações de portadores, então, a condição de injeção de nível baixo implica que, para um material do tipo $\mathrm{n}$ :

$$
\Delta \mathrm{n}, \Delta \mathrm{p}<\mathrm{n}_{0}\left(\mathrm{n} \approx \mathrm{n}_{0}\right)
$$

E para um material do tipo $p$ :

$$
\Delta \mathrm{n}, \Delta \mathrm{p}<\mathrm{p}_{0}\left(\mathrm{p} \approx \mathrm{p}_{0}\right)
$$

Para prosseguir com as simplificações desejadas na Eq. 39, duas aproximações serão admitidas. Na primeira delas admite-se que o centro R-G dominante introduz um nível de energia no meio da banda proibida, de forma que $\mathrm{n}_{1} \cong \mathrm{p}_{1} \cong \mathrm{n}_{\mathrm{i}}$. Na segunda aproximação considera-se que a concentração de centros $R-G$ é suficientemente baixa de maneira que $n \cong p$ [39]. Substituindo $n$ e p na Eq. 39:

$$
R=\frac{\left(n_{0}+\Delta n\right) \cdot\left(p_{0}+\Delta p\right)-n_{i}^{2}}{\tau_{p} \cdot\left(n_{0}+\Delta n+n_{1}\right)+\tau_{n} \cdot\left(p_{0}+\Delta p+p_{1}\right)}
$$

Com as aproximações assumidas anteriormente:

$$
R=\frac{n_{0} \cdot p_{0}+\Delta p \cdot p_{0}+n_{0} \cdot \Delta p-n_{i}{ }^{2}}{\tau_{p} \cdot\left(n_{0}+\Delta p+n_{i}\right)+\tau_{n} \cdot\left(p_{0}+\Delta p+n_{i}\right)}
$$

Embora a Eq. 43 seja válida para semicondutores do tipo $n$ e $p$, a descrição matemática que segue será detalhada para um semicondutor do tipo $\mathrm{n}$. As seguintes relações podem ser estabelecidas:

$$
\begin{gathered}
n_{0} \cdot p_{0}=n_{i}^{2} \\
n_{0} \cdot \Delta p>>p_{0} \cdot \Delta p \quad\left(n_{0}>>p_{0}\right) \\
n_{0} \cdot \Delta p>>p^{2} \quad\left(n_{0}>\Delta p\right) \\
\tau_{p} \cdot\left(n_{0}+\Delta p+n_{i}\right) \approx \tau_{p} \cdot n_{0} \quad\left(n_{0}>>p ; n_{0}>>n_{i}\right) \\
\tau_{p} \cdot n_{0}>>\tau_{n} \cdot\left(p_{0}+\Delta p+n_{i}\right) \quad\left(n_{0}>>p_{0}+\Delta p+n_{i} ; \tau_{n} \approx \tau_{p}\right)
\end{gathered}
$$

Substituindo as simplificações expressas nas Eq. 44-48 na Eq. 43, obtém-se que a taxa de recombinação líquida dos portadores em um semicondutor do tipo $\mathrm{n}$ sob regime estacionário e condição de injeção de nível baixo é dada por [39-41,44-45]: 


$$
R=\frac{\Delta p}{\tau_{p}}
$$

Analogamente, a taxa de recombinação líquida dos portadores em um semicondutor do tipo p sob regime estacionário e condição de injeção de nível baixo é dada por:

$$
\mathrm{R}=\frac{\Delta \mathrm{n}}{\tau_{\mathrm{n}}}
$$

Se as considerações corretas forem feitas para a condição de nível alto de injeção de portadores de carga, então, as taxas de recombinação líquida para materiais semicondutores do tipo $n$ e $p$, respectivamente, serão dadas por:

$$
\begin{aligned}
& R=\frac{\Delta p}{\left(\tau_{n}+\tau_{p}\right)} \\
& R=\frac{\Delta n}{\left(\tau_{n}+\tau_{p}\right)}
\end{aligned}
$$

\subsubsection{Análise dos processos R-G por meio de parâmetros físicos}

Nesta seção a estatística dos processos de recombinação e geração de portadores, descrita anteriormente, será reformulada introduzindo-se alguns parâmetros físicos de interesse. Para isso, admite-se uma região delimitada do semicondutor contendo centros R-G não preenchidos, vazios, elétrons livres e centros R-G ocupados, preenchidos; todos representados na FIG. 17. Devido as inúmeras colisões entre os elétrons livres e os átomos da estrutura, a trajetória deste portador é descrita por traços não contínuos e aleatórios. Um elétron será capturado, segundo este diagrama, quando penetrar a esfera que representa um centro $R-G$ vazio [39]. 


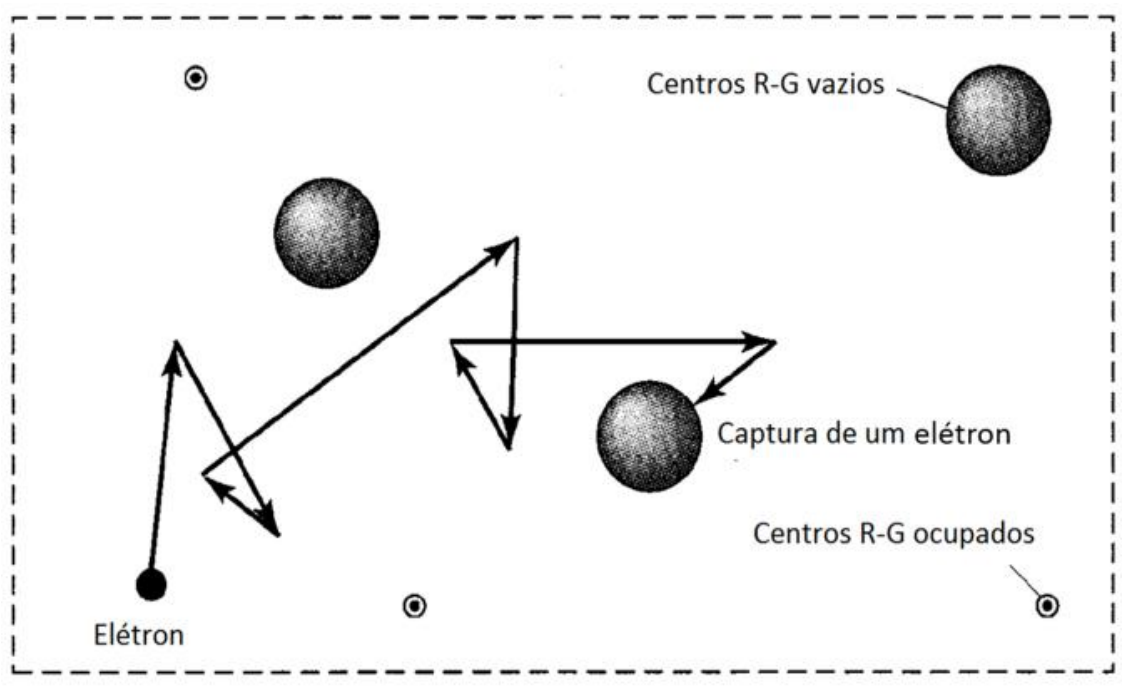

FIGURA 17 - Diagrama ilustrativo da região semicondutora delimitada contendo centros R-G preenchidos e não preenchidos e elétrons [39].

Presume-se que quanto maior a distância percorrida por um elétron por unidade de tempo, no interior do semicondutor, maior será a probabilidade de ser capturado por um centro R-G. Assim, a probabilidade de captura será fortemente dependente da velocidade do elétron. Para a condição de equilíbrio estabelecida, a velocidade de um elétron livre no interior de um semicondutor é basicamente resultado da energia térmica média transferida a ele. Com o valor desta energia, derivada dos conhecimentos básicos sobre semicondutores, $3 \cdot \mathrm{k} \cdot \mathrm{T} / 2$, tem-se que:

$$
\frac{1}{2} \cdot \mathrm{m} \cdot \mathrm{v}_{\mathrm{th}}{ }^{2}=\frac{3}{2} \cdot \mathrm{k} \cdot \mathrm{T}
$$

sendo $\mathrm{V}_{\text {th }}$ a velocidade térmica ou de equilíbrio do elétron.

Sob condições de não equilíbrio existem, é claro, outras componentes que devem ser adicionadas a velocidade do elétron, senão a térmica. Entretanto, estas demais componentes serão consideradas desprezíveis frente à velocidade térmica.

Em um intervalo de tempo t, um elétron percorrerá uma distância média igual a $v_{\text {th }} \cdot t$ no interior do semicondutor, atravessando assim um volume total de $A \cdot v_{\text {th }} \cdot t$, sendo que $A$ representa a área da seção transversal do material, normal ao caminho dos elétrons. Neste volume delimitado, a concentração de centros R-G 
vazios é representada pelo parâmetro $\mathrm{p}_{\mathrm{T}}$. Assim, o número de centros $\mathrm{R}$ - $\mathrm{G}$ vazios no espaço em questão será igual a $\mathrm{p}_{\mathrm{T}} \cdot \mathrm{A} \cdot \mathrm{v}_{\mathrm{th}} \cdot \mathrm{t}$.

Os centros R-G são aleatoriamente distribuídos no interior do volume de material delimitado. Sendo assim, para a descrição matemática da probabilidade de captura de um elétron por um centro R-G, todos os centros contidos neste volume serão trazidos imaginariamente para um único plano interceptado por eles. Esta configuração imaginária é ilustrada nas FIG. 18a e 18b. A área planar de um único centro R-G representado na FIG. $18 \mathrm{~b}$ é igual a $\sigma_{n}=\pi \cdot r^{2}$, sendo $r$ o raio da esfera que representa o centro R-G em questão. Considerando agora todo o volume atravessado pelo elétron, a área total dos centros R-G vista por este portador será igual a: $\mathrm{p}_{\mathrm{T}} \cdot \mathrm{A} \cdot \sigma_{\mathrm{n}} \cdot \mathrm{v}_{\mathrm{th}} \cdot \mathrm{t}$. Sobretudo, a fração de área que dá origem a captura será: $p_{T} \cdot A \cdot \sigma_{n} \cdot v_{t h} \cdot t / A$. A probabilidade de um elétron ser então capturado no volume delimitado é dada por $p_{T} \cdot \sigma_{n} \cdot v_{\text {th }} \cdot t$ e a taxa de captura, ou seja, a probabilidade de um elétron ser capturado por unidade de tempo é igual a $\mathrm{p}_{\mathrm{T}} \cdot \sigma_{\mathrm{n}} \cdot \mathrm{v}_{\mathrm{th}}$. A dedução detalhada até o momento leva em consideração um único elétron, assim, considerando uma concentração de $n$ elétrons disponíveis para a captura, a probabilidade do processo pode ser reescrita como [39]:

$$
\partial \mathrm{n} /\left.\partial \mathrm{t}\right|_{(\mathrm{a})}=-\sigma_{\mathrm{n}} \cdot \mathrm{v}_{\mathrm{th}} \cdot \mathrm{p}_{\mathrm{T}} \cdot \mathrm{n}
$$

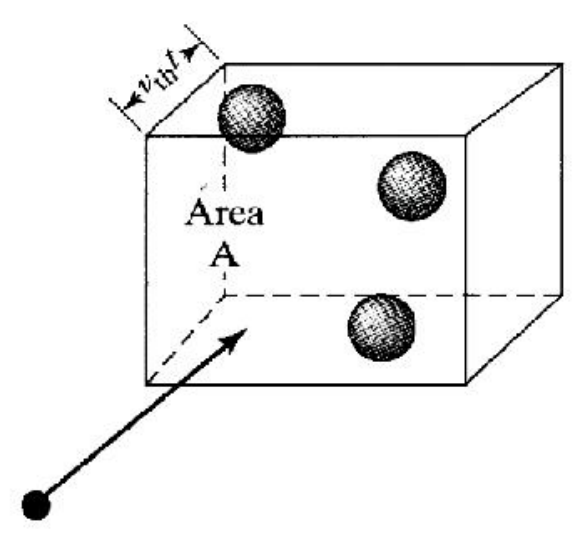

(a)

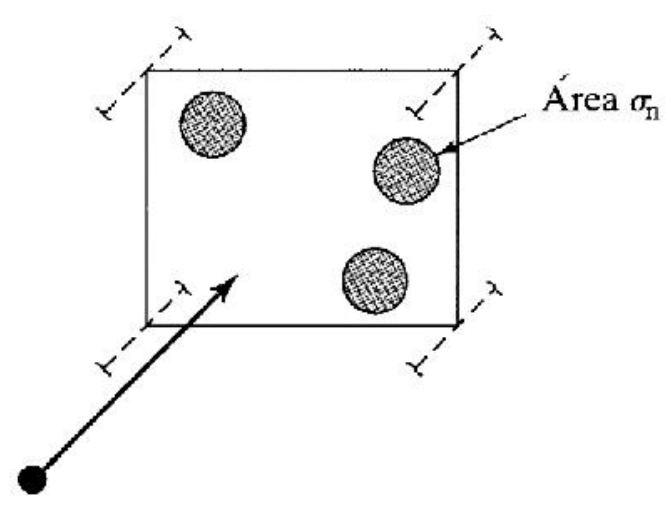

(b)

FIGURA 18 - Representação ilustrativa da distribuição aleatória dos centros R-G no volume delimitado (a) e posicionamento imaginário dos mesmos em um único plano que os intercepta (b) [39]. 
A Eq. 54 é equivalente a Eq. 16, sendo assim, possível a determinação do coeficiente de captura de elétrons por meio de parâmetros físicos.

$$
c_{n}=-\sigma_{n} \cdot v_{\text {th }}
$$

Analogamente, o coeficiente de captura de lacunas é definido como:

$$
c_{p}=-\sigma_{p} \cdot v_{t h}
$$

sendo $\sigma_{n}$ e $\sigma_{p}$ parâmetros conhecidos e denominados como secções de choque de captura de elétrons e lacunas, respectivamente.

Se a função distribuição de Fermi, F, for utilizada para representar a probabilidade de um centro R-G estar ocupado por um elétron, pode-se então representar a concentração de centros não ocupados no interior do semicondutor por $N_{\mathrm{T}} \cdot(1-F)$. Lembrando que a função distribuição de Fermi é definida para a condição de equilíbrio como [41]:

$$
F=\frac{1}{1+e^{\left(E_{T}-E_{F}\right) / k \cdot T}}
$$

A Eq. 54 pode ser reescrita como:

$$
\partial \mathrm{n} /\left.\partial \mathrm{t}\right|_{(\mathrm{a})}=\mathrm{R}_{\mathrm{a}}=\sigma_{\mathrm{n}} \cdot \mathrm{v}_{\mathrm{th}} \cdot \mathrm{n} \cdot \mathrm{N}_{\mathrm{T}} \cdot(1-\mathrm{F})
$$

O parâmetro $R_{a}$ foi inserido com o intuito de facilitar a visualização das expressões matemáticas que serão apresentadas a partir de agora. Este parâmetro representa particularmente a variação da concentração de elétrons com o tempo, devido às transições do tipo (a). Entretanto, demais parâmetros serão inseridos e representados pela letra " $R$ " representando as variações das concentrações de portadores com o tempo, devido às transições indicadas no índice subscrito à letra.

Analogamente:

$$
R_{c}=\sigma_{p} \cdot v_{t h} \cdot p \cdot N_{T} \cdot F
$$

Para descrever as taxas $R_{b}$ e $R_{d}$, os coeficientes de emissão de elétrons e lacunas devem também ser obtidos em termos de parâmetros físicos. Para isso, analogamente ao artifício utilizado anteriormente, utiliza-se o princípio do equilíbrio, onde $\mathrm{R}_{\mathrm{a}}=\mathrm{R}_{\mathrm{b}}$ e $\mathrm{R}_{\mathrm{c}}=\mathrm{R}_{\mathrm{d}}$. Assim: 


$$
\begin{gathered}
R_{a}=\sigma_{n} \cdot v_{t h} \cdot n \cdot N_{T} \cdot(1-F)=R_{b}=e_{n} \cdot N_{T} \cdot F \\
e_{n}=\frac{\sigma_{n} \cdot v_{t h} \cdot n \cdot N_{T} \cdot(1-F)}{N_{T} \cdot F}
\end{gathered}
$$

Substituindo as Eq. 28 e 57 na Eq. 61, tem-se que:

$$
e_{n}=\sigma_{n} \cdot v_{t h} \cdot n_{i} \cdot e^{\left(E_{T}-E_{i}\right) / k \cdot T}
$$

Analogamente:

$$
\begin{gathered}
R_{c}=\sigma_{p} \cdot v_{t h} \cdot p \cdot N_{T} \cdot F=R_{d}=e_{p} \cdot N_{T} \cdot(1-F) \\
e_{p}=\frac{\sigma_{p} \cdot v_{t h} \cdot p \cdot N_{T} \cdot F}{N_{T} \cdot(1-F)}
\end{gathered}
$$

Substituindo as Eq. 29 e 57 na Eq. 64, tem-se que:

$$
e_{p}=\sigma_{p} \cdot v_{t h} \cdot n_{i} \cdot e^{\left(E_{i}-E_{T}\right) / k \cdot T}
$$

Portanto:

$$
\begin{aligned}
& R_{b}=\sigma_{n} \cdot v_{t h} \cdot N_{T} \cdot F \cdot n_{i} \cdot e^{\left(E_{T}-E_{i}\right) / k \cdot T} \\
& R_{d}=\sigma_{p} \cdot v_{t h} \cdot N_{T} \cdot(1-F) \cdot n_{i} \cdot e^{\left(E_{T}-E_{i}\right) / k \cdot T}
\end{aligned}
$$

As Eq. 58, 59, 66 e 67 expressam as taxas de variação dos portadores de carga com o tempo devido as transições do tipo (a), (b), (c) e (d), respectivamente, via centros R-G. Estas equações são válidas para qualquer condição de operação do semicondutor, embora os coeficientes de emissão de elétrons e lacunas tenham sido obtidos a partir das relações de equilíbrio [39].

Agora serão analisadas as relações obtidas para um semicondutor do tipo n sob a condição de regime estacionário, partindo, equivalente ao desenvolvido anteriormente, do princípio de balanço detalhado. Segundo este princípio, tem-se que [41]:

$$
\frac{\partial \mathrm{n}}{\partial \mathrm{t}}=\mathrm{G}_{\mathrm{L}}-\left(\mathrm{R}_{\mathrm{a}}-\mathrm{R}_{\mathrm{b}}\right)=0
$$

sendo $G_{L}$ a taxa geração de portadores devido, por exemplo, a iluminação da estrutura. 
Analogamente para as lacunas:

$$
\frac{\partial \mathrm{p}}{\partial \mathrm{t}}=\mathrm{G}_{\mathrm{L}}-\left(\mathrm{R}_{\mathrm{c}}-\mathrm{R}_{\mathrm{d}}\right)=0
$$

Mesclando as Eq. 68 e 69, obtém-se que:

$$
\mathrm{G}_{\mathrm{L}}=\mathrm{R}_{\mathrm{a}}-\mathrm{R}_{\mathrm{b}}=\mathrm{R}_{\mathrm{c}}-\mathrm{R}_{\mathrm{d}}=0=\mathrm{U}
$$

sendo o parâmetro $U$ introduzido, a taxa de recombinação líquida para um semicondutor sob o regime estacionário.

Com extensas manipulações matemáticas chega-se que [41]:

$$
U=\frac{\sigma_{n} \cdot \sigma_{p} \cdot v_{t h} \cdot N_{T} \cdot\left(p \cdot n-n_{i}{ }^{2}\right)}{\sigma_{p} \cdot\left[p+n_{i} \cdot e^{\left(E_{i}-E_{T}\right) / k \cdot T}\right]+\sigma_{n} \cdot\left[n+n_{i} \cdot e^{\left(E_{T}-E_{i}\right) / k \cdot T}\right]}
$$

A Eq. 71, expressa a taxa de recombinação líquida dos portadores de carga em um semicondutor em regime estacionário como função de parâmetros físicos amplamente utilizados na área da física dos dispositivos semicondutores.

\subsubsection{Recombinação $X$ armadilhamento}

Todos os processos que conduzem à recombinação de portadores de carga, via centros R-G, descritos anteriormente, correspondem ao armadilhamento de um portador pelo centro em questão e posterior emissão para a banda de valência ou condução, concluindo o processo de recombinação. Entretanto, os centros rasos, como já mencionado, não são considerados centros R-G eficazes, pois, reemitem o portador armadilhado em um intervalo de tempo curto e o processo de recombinação não é concluído [40]. Esta diferença é ilustrada na FIG. 19.

Surge então a necessidade de introduzir um novo parâmetro físico a fim de diferenciar o processo de recombinação do processo de armadilhamento. Este parâmetro é o tempo de armadilhamento efetivo $\left(\tau_{\text {eff }}\right)$ que corresponde ao tempo médio que um portador permanece em movimento no interior do material antes de ser armadilhado e então reemitido. 


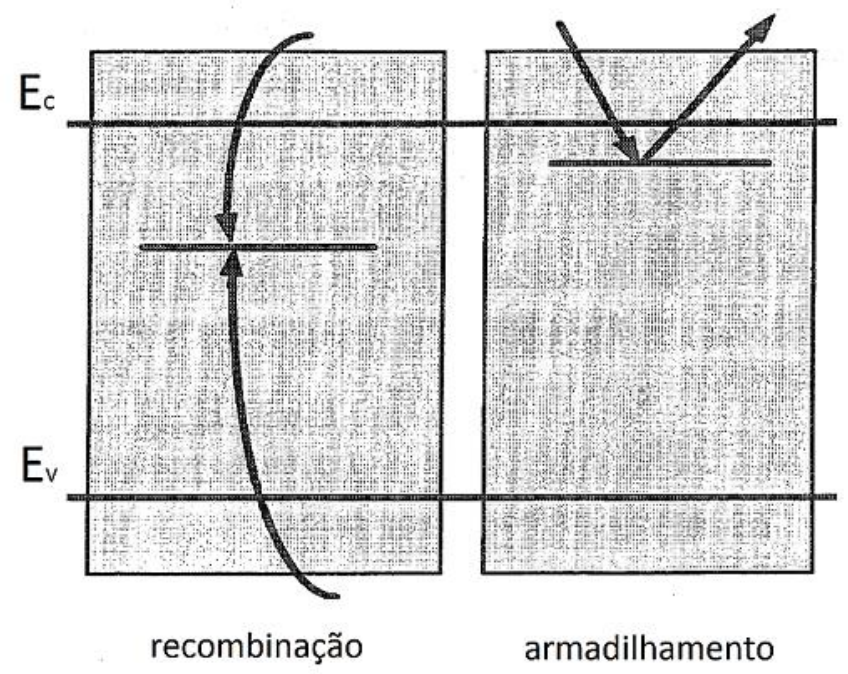

FIGURA 19 - Diagrama ilustrativo da diferença entre os processos de recombinação e armadilhamento via centros $R-G$ [39].

Partindo do conteúdo apresentado anteriormente sobre a estatística de recombinação via captura do portador por centros $\mathrm{R}-\mathrm{G}$, pode-se analogamente definir a probabilidade de armadilhamento de elétrons e lacunas como $[11,40]$ :

$$
\begin{array}{ll}
\frac{1}{\tau_{\text {eff }}}=\sigma_{\mathrm{n}} \cdot \mathrm{v}_{\mathrm{th}} \cdot \mathrm{N}_{\mathrm{T}} \cdot(1-\mathrm{F}) & \text { para elétrons } \\
\frac{1}{\tau_{\text {eff }}}=\sigma_{\mathrm{p}} \cdot \mathrm{v}_{\text {th }} \cdot \mathrm{N}_{\mathrm{T}} \cdot \mathrm{F} & \text { para lacunas }
\end{array}
$$

Alguns estudos mostraram que, para dispositivos semicondutores fortemente irradiados, a probabilidade de armadilhamento dos portadores é diretamente proporcional a fluência da radiação, ou seja, o tempo médio entre a criação de um portador no interior do material e sua captura por um centro R-G diminui com o aumento da fluência de radiação [39].

\subsubsection{Transporte de portadores de carga}

Neste tópico serão apresentadas as descrições dos principais processos de transporte de portadores de carga em um material semicondutor, sobretudo, sob efeito de campo elétrico ou gradiente de cargas.

\subsubsection{Deriva}

O fenômeno de deriva está relacionado com o movimento dos portadores de carga devido a aplicação de um campo elétrico (E) no material semicondutor. Quando isso ocorre, uma força elétrica age sobre os portadores, de 
maneira que as lacunas são aceleradas na mesma direção do campo elétrico enquanto os elétrons são acelerados na direção oposta (FIG. 20a). A desaceleração do portador ocorre devido as sucessivas colisões com a estrutura cristalina resultando em um deslocamento líquido na direção do campo elétrico como apresentado na FIG. 20b. A distância média percorrida pelos portadores entre cada colisão é denominada caminho livre médio e a velocidade média desenvolvida, considerada um parâmetro macroscópico, é denominada velocidade de deriva, $\mathrm{v}_{\mathrm{d}}$ [39].

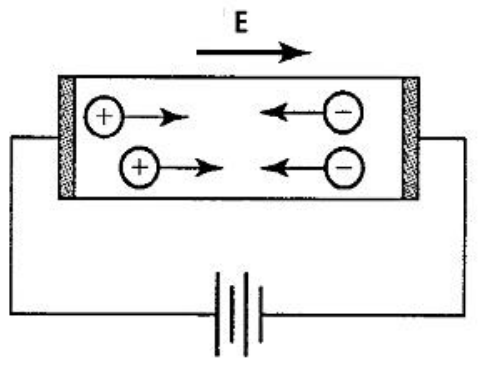

(a)

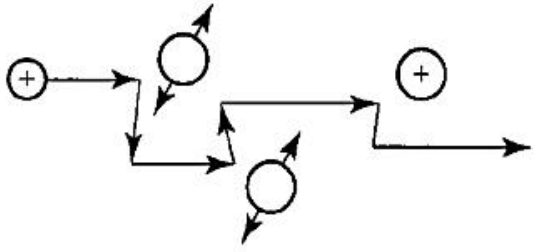

(b)

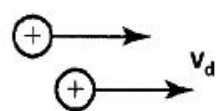

(c)

FIGURA 20 - llustração do movimento de deriva: movimento dos portadores em um semicondutor polarizado (a), deriva de uma lacuna em escala microscópica

(b) e em escala macroscópica (c) com a definição do parâmetro $\mathrm{v}_{\mathrm{d}}$ [39].

A velocidade de deriva do elétron, por exemplo, que será nomeada a partir de como $\mathrm{v}_{\mathrm{n}}$, pode ser obtida a partir das relações básicas de momento:

$$
-\mathrm{q} \cdot \mathrm{E} \cdot \mathrm{t}_{\mathrm{c}}=\mathrm{m}_{\mathrm{n}} \cdot \mathrm{v}_{\mathrm{n}}
$$

sendo $t_{c}$ o tempo livre médio entre cada colisão sucessiva.

Isolando a velocidade de deriva na Eq. 74 tem-se que:

$$
v_{n}=-\left(\frac{q \cdot t_{c}}{m_{n}}\right) \cdot E
$$

De acordo com a Eq. 75 pode-se notar que a velocidade de deriva é proporcional ao campo elétrico aplicado por um fator de proporcionalidade denominado mobilidade, $\mathrm{n}$. Este parâmetro descreve o quão influenciado por um campo elétrico é o movimento do portador de carga. A velocidade de deriva das lacunas, $v_{p}$, é obtida de forma análoga e, por consequência pode ser reescrita como: 


$$
\begin{gathered}
\mathrm{v}_{\mathrm{n}}=-{ }_{\mathrm{n}} \cdot \mathrm{E} \\
\mathrm{v}_{\mathrm{p}}={ }_{\mathrm{p}} \cdot \mathrm{E}
\end{gathered}
$$

para elétrons e lacunas, respectivamente.

A mobilidade, que está relacionada diretamente com o tempo livre médio, é afetada pelo número de colisões entre o portador e a rede cristalina. Diferentes mecanismos de espalhamento caracterizam os processos de colisão, sobretudo, os dois mais importantes são: espalhamento com átomos da estrutura e de impurezas [41].

Os espalhamentos com átomos da estrutura são consequência da agitação térmica à qualquer temperatura acima de zero absoluto. Portanto, enquanto a agitação térmica aumenta, a mobilidade diminui com o aumento da temperatura. Por outro lado, os espalhamentos com átomos de impurezas ocorre por interação colombiana entre o portador de carga e um dopante ionizado (doador ou aceitador). A probabilidade deste tipo de espalhamento aumenta com a concentração de dopantes e diminui com o aumento da temperatura, pois, para temperaturas elevadas os portadores de carga adquirem velocidades maiores e sentem com menor intensidade a presença dos dopantes [41].

A mobilidade dos portadores de carga pode então ser dividida em duas componentes, sendo uma delas consequência do espalhamento com átomos da estrutura, L, e a outra do espalhamento com átomos de impureza, ${ }_{\mathrm{I}}$.

$$
\underline{1}=\frac{1}{\mathrm{~L}}+\frac{1}{\mathrm{I}}
$$

Analogamente, define-se a probabilidade de ocorrência de uma colisão, $\tau_{\mathrm{C}}$, como:

$$
\frac{1}{\tau_{\mathrm{C}}}=\frac{1}{\tau_{\mathrm{C}, \mathrm{L}}}+\frac{1}{\tau_{\mathrm{C}, \mathrm{I}}}
$$

sendo $\tau_{C, L}$ e $\tau_{C, I}$ as probabilidades de ocorrência de colisão entre o portador e átomos das estruturas e de impurezas, respectivamente.

Na FIG. 21 são apresentados os resultados de medidas da mobilidade de elétrons como função da temperatura, no $\mathrm{Si}$, para cinco valores de 
concentrações de doadores diferentes. Na mesma figura é apresentada também a dependência teórica da mobilidade devido a ambos os espalhamentos, com átomos da estrutura e com átomos de impureza. Como esperado, para amostras com concentrações mais baixas de dopantes, o espalhamento com a estrutura é dominante, enquanto que para amostras contendo concentrações maiores de dopantes o espalhamento com átomos de impureza é significativo para temperaturas baixas.

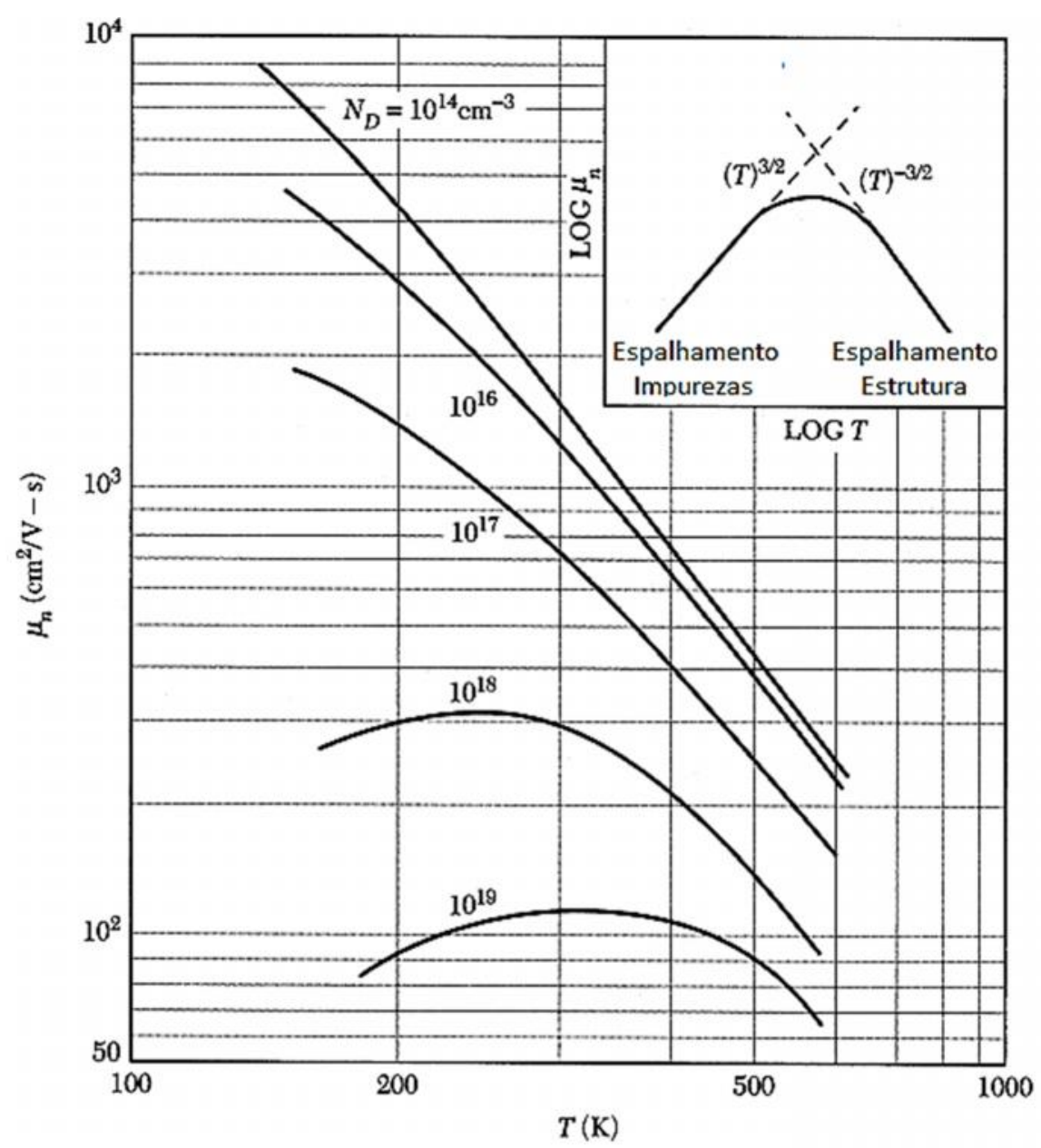

FIGURA 21 - Mobilidade de elétrons no Si para valores diferentes de concentração de doadores [41].

As mobilidades de elétrons e lacunas são apresentadas na FIG. 22 como função da concentração de impurezas para o Si e GaAs à temperatura ambiente. Para a maioria dos semicondutores, como é possível notar a partir da FIG. 22, a mobilidade dos elétrons é maior do que a mobilidade das lacunas. Isso porque segundo os princípios de física quântica, a massa efetiva dos elétrons é menor do 
que a massa efetiva das lacunas [39-41]. O parâmetro no eixo direito da FIG. 22, denominado constante de difusão será abordado a seguir.
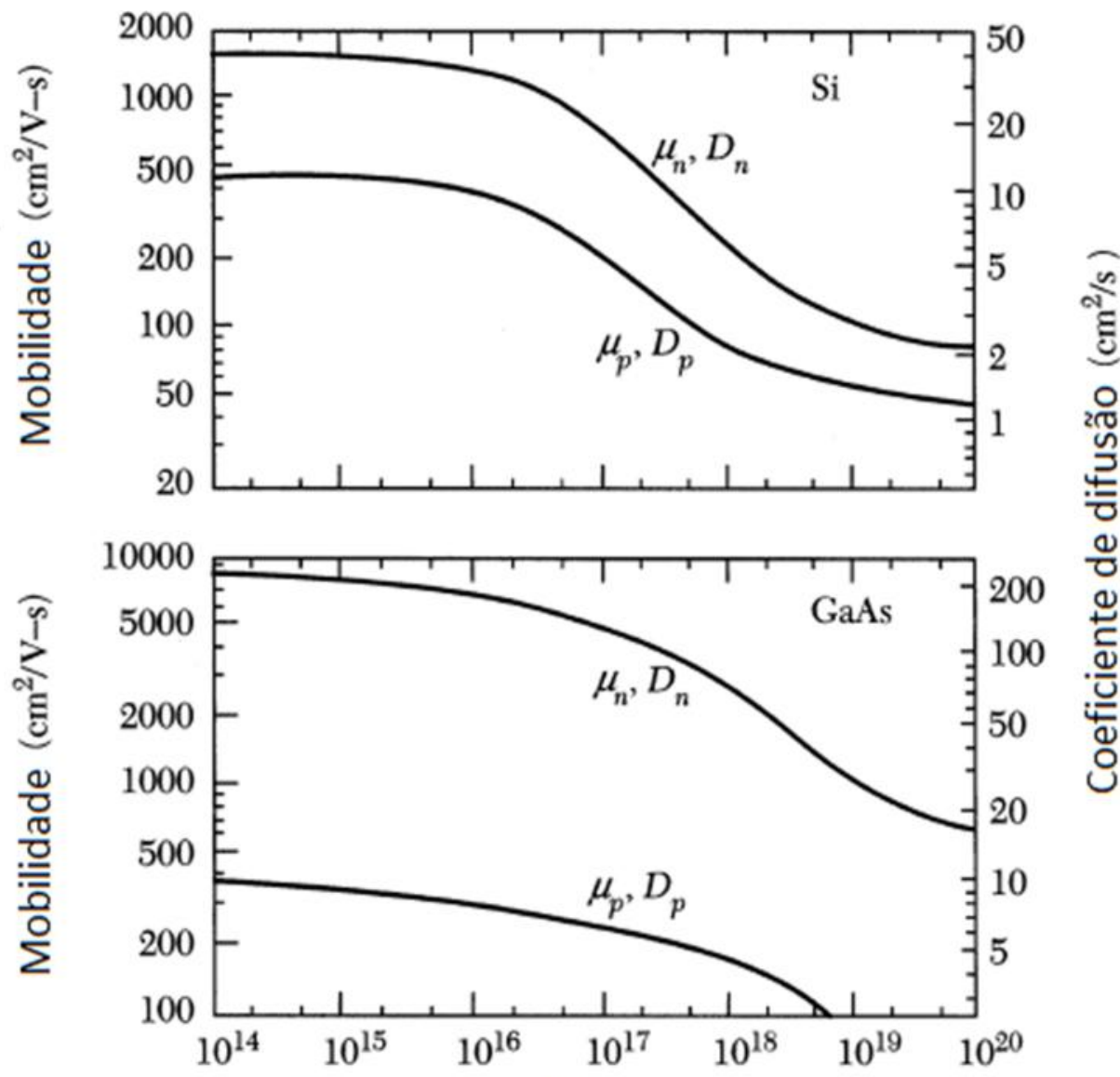

Concentração de impurezas $\left(\mathrm{cm}^{-3}\right)$

FIGURA 22 - Mobilidade de elétrons e lacunas em função da concentração de impurezas para o Si e GaAs [41].

A deriva dos portadores de carga no interior do material semicondutor gera uma corrente de deriva que, como esperado, é favorecida pelo campo elétrico aplicado. O número de elétrons que atravessam uma seção normal de área $\mathrm{A}$ em um tempo t, em um semicondutor do tipo $n$, por exemplo, é igual a $n \cdot v_{n} \cdot t \cdot A$, FIG. 23. Assim, a carga total que atravessa o plano, por unidade de tempo, ou a corrente de deriva é dada por:

$$
\mathrm{i}_{\mathrm{d}, \mathrm{n}}=\mathrm{q} \cdot \mathrm{n} \cdot \mathrm{v}_{\mathrm{n}} \cdot \mathrm{A}
$$

A densidade de corrente de deriva, definida como a corrente por unidade de área, será igual a:

$$
\mathrm{J}_{\mathrm{d}, \mathrm{n}}=\mathrm{q} \cdot{ }_{\mathrm{n}} \cdot \mathrm{n} \cdot \mathrm{E}
$$

Analogamente para as lacunas: 


$$
\mathrm{J}_{\mathrm{d}, \mathrm{p}}=\mathrm{q} \cdot{ }_{\mathrm{p}} \cdot \mathrm{p} \cdot \mathrm{E}
$$

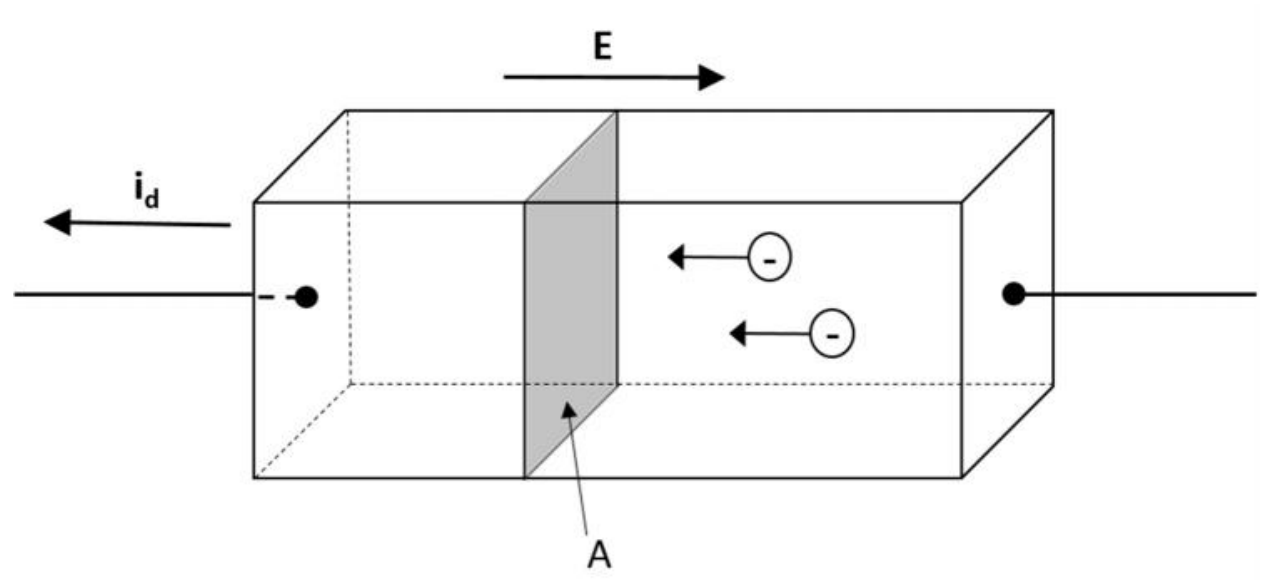

FIGURA 23 - Vista ilustrativa de um semicondutor do tipo n polarizado.

\subsubsection{Difusão}

Quando há uma variação espacial da concentração de carga em um material semicondutor, os portadores tendem a migrar de uma região com concentração elevada para outra de baixa concentração [39-41]. Esse movimento de compensação caracteriza o processo de difusão dos portadores de carga.

O movimento dos elétrons, em um material do tipo $\mathrm{n}$, por exemplo, na ausência de campo elétrico é aleatório e a velocidade adquirida por eles é devida unicamente a velocidade térmica, $\mathrm{v}_{\mathrm{th}}$. Assumindo-se que o movimento seja unidimensional, metade dos elétrons que, dentro de um caminho livre médio, I, atravessam a seção transversal de área $A$, movimentam-se na direção $+x$. Analogamente a outra metade movimenta-se na direção -x. O esquema é ilustrado na FIG. 24.

O número de elétrons que atravessam a seção nas direções $+x$ e -x são dados por:

$$
\begin{aligned}
& \overrightarrow{\mathrm{n}}=\frac{\mathrm{A}}{2} \int_{-1}^{0} \mathrm{n}(\mathrm{x}) \mathrm{dx} \\
& \overline{\mathrm{n}}=\frac{\mathrm{A}}{2} \int_{0}^{1} \mathrm{n}(\mathrm{x}) \mathrm{dx}
\end{aligned}
$$


Como I é uma grandeza cujos valores são pequenos, a expansão da função $\mathrm{p}(\mathrm{x})$ em série de Taylor em torno de $\mathrm{x}=0$ pode ser aproximada para [39]:

$$
\mathrm{n}(\mathrm{x}) \cong \mathrm{n}(0)+\frac{\mathrm{dn}}{\mathrm{dx}} \cdot \mathrm{x}
$$

$\operatorname{com} I \leq \mathrm{x} \leq I$.
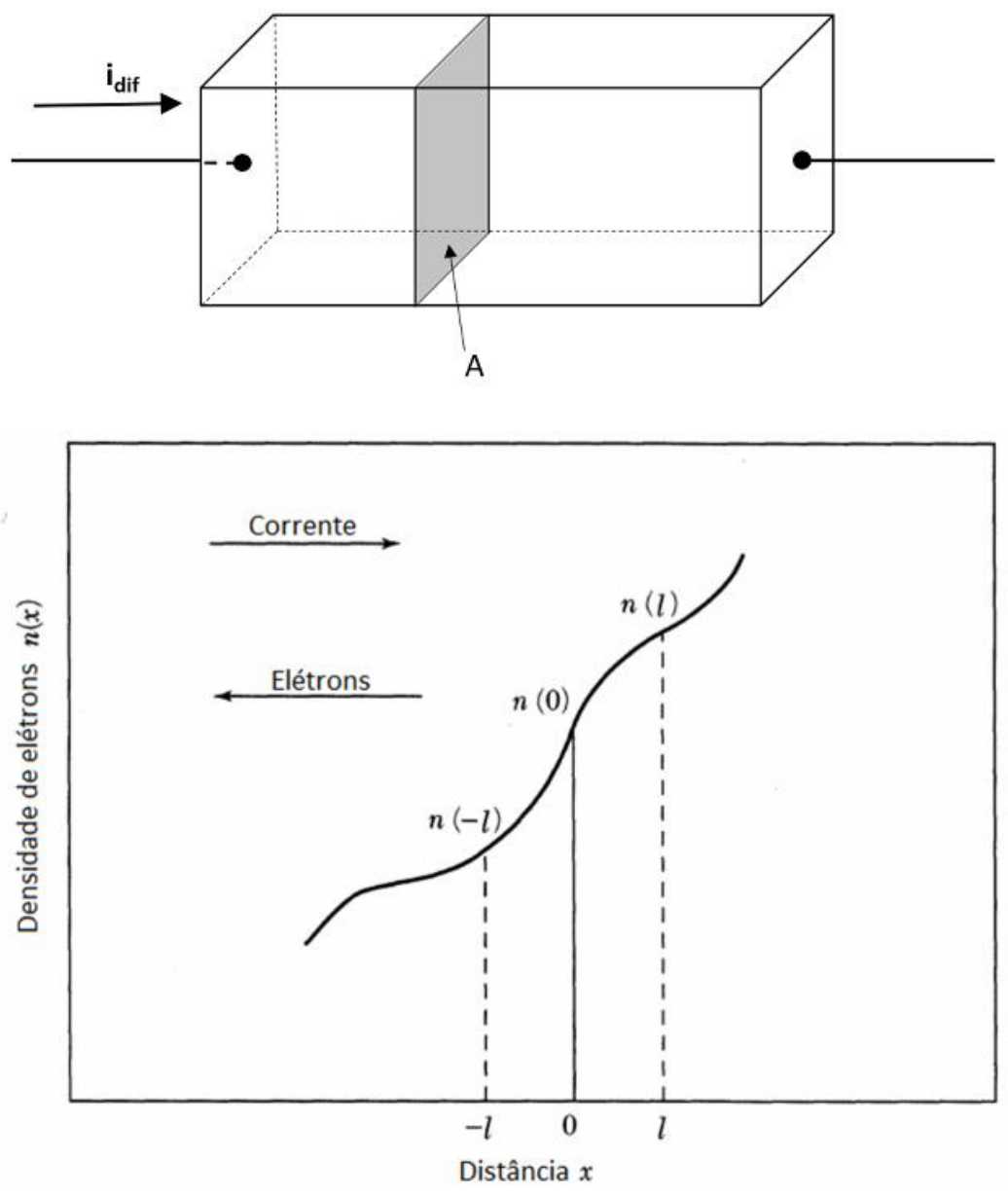

FIGURA 24 - Vista ilustrativa de um semicondutor do tipo $\mathrm{n}$ e variação da concentração de portadores em função da distância x [41].

Substituindo o resultado apresentado na Eq. 85, nas Eq. 83 e 84, temse que:

$$
\begin{aligned}
& \overrightarrow{\mathrm{n}}=\frac{1}{2} \mathrm{Al} \cdot \mathrm{n}(0)-\frac{1}{2} \mathrm{~A} \frac{\mathrm{dn}}{\mathrm{dx}} \cdot \frac{1^{2}}{2} \\
& \overline{\mathrm{n}}=\frac{1}{2} \mathrm{Al} \cdot \mathrm{n}(0)+\frac{1}{2} \mathrm{~A} \frac{\mathrm{dn}}{\mathrm{dx}} \cdot \frac{1^{2}}{2}
\end{aligned}
$$

para as direções $+x$ e -x, respectivamente. 
O número líquido de elétrons que atravessam a seção no tempo $1 / \mathrm{v}_{\text {th }}$ é dado por:

$$
\vec{n}-\overleftarrow{n}=-A \frac{d n}{d x} \cdot \frac{1^{2}}{2}
$$

Como consequência, a corrente e a densidade de corrente de difusão são dadas por:

$$
\begin{aligned}
& \mathrm{i}_{\mathrm{dif,n}}=\frac{1}{2} \mathrm{qAv}_{\mathrm{th}} 1 \frac{\mathrm{dn}}{\mathrm{dx}} \\
& \mathrm{J}_{\text {dif,n }}=\mathrm{q}\left(\frac{\mathrm{v}_{\mathrm{th}} 1}{2}\right) \frac{\mathrm{dn}}{\mathrm{dx}}
\end{aligned}
$$

Na Eq. 90, o termo $\mathrm{v}_{\text {th }} 1 / 2$ é denominado coeficiente de difusão ou difusividade, $D_{n}$, para elétrons. De maneira análoga define-se a densidade de corrente de difusão para lacunas:

$$
J_{\text {dif,p }}=-q D_{p} \frac{d p}{d x}
$$

As relações obtidas para o movimento unidimensional dos portadores de carga podem ser generalizadas de maneira que:

$$
\begin{aligned}
& \mathrm{J}_{\text {dif, } \mathrm{n}}=\mathrm{qD}_{\mathrm{n}} \nabla \mathrm{n} \\
& \mathrm{J}_{\text {dif, } \mathrm{p}}=-\mathrm{qD}_{\mathrm{p}} \nabla \mathrm{p}
\end{aligned}
$$

Na FIG. 22 os valores dos coeficientes de difusão são apresentados em função da concentração de impurezas, para os elétrons e lacunas no Si e GaAs, respectivamente. Os coeficientes de difusão são associados às mobilidades dos portadores por meio das relações de Einstein, para elétrons e lacunas [39-41]:

$$
\begin{aligned}
& D_{n}=\left(\frac{k T}{q}\right)_{n} \\
& D_{p}=\left(\frac{k T}{q}\right)_{p}^{p}
\end{aligned}
$$

\subsubsection{Equação da continuidade}

Nas seções anteriores, os fenômenos de transporte, deriva e difusão, além dos processos de geração e recombinação via centros R-G, foram 
apresentados individualmente. Quando todos estes processos são levados em consideração, ocorrendo simultaneamente em um material semicondutor, passam a ser descritos pela equação da continuidade para elétrons e lacunas [39].

$$
\begin{aligned}
& \frac{\partial \mathrm{n}}{\partial \mathrm{t}}=\frac{1}{\mathrm{q}} \vec{\nabla} \cdot \overrightarrow{\mathrm{J}}_{\mathrm{dif}, \mathrm{n}}-\mathrm{r}_{\mathrm{n}}+\mathrm{g}_{\mathrm{n}} \\
& \frac{\partial \mathrm{p}}{\partial \mathrm{t}}=-\frac{1}{\mathrm{q}} \vec{\nabla} \cdot \overrightarrow{\mathrm{J}}_{\mathrm{dif}, \mathrm{p}}-\mathrm{r}_{\mathrm{p}}+\mathrm{g}_{\mathrm{p}}
\end{aligned}
$$

sendo $g_{n}$ e $g_{p}$ a variação da concentração de elétrons e lacunas no tempo devido a processos adicionais como geração por radiação, por exemplo.

As expressões apresentadas nas Eq. 96 e 97 são amplamente utilizadas como base para a descrição de fenômenos de transporte na maioria dos dispositivos semicondutores, como os diodos, por exemplo [39]. Uma das aplicações da equação da continuidade consiste na obtenção da equação de difusão dos portadores minoritários que pode, por sua vez, ser empregada para o cálculo da sensibilidade de diodos quando utilizados em dosimetria das radiações [12]. Neste caso, são admitidas algumas simplificações teóricas: (a) o sistema sob análise é unidimensional (x); (b) a análise é estritamente restrita aos portadores minoritários; (c) o campo elétrico pode ser considerado nulo na região semicondutora sob análise; (d) a concentração de portadores minoritários, sob condição de equilíbrio, não é função da posição; (e) a análise é feita sob condições de nível de injeção baixo e (f) não há outros processos, exceto geração luminosa, GL, que competem entre si no interior do material [39]. Com as simplificações mencionadas, as equações para os portadores minoritários, elétrons e lacunas, são dadas por:

$$
\begin{aligned}
& \frac{\partial \mathrm{n}_{\mathrm{p}}}{\partial \mathrm{t}}=\mathrm{D}_{\mathrm{n}} \frac{\partial^{2} \mathrm{n}_{\mathrm{p}}}{\partial \mathrm{x}^{2}}-\frac{\mathrm{n}_{\mathrm{p}}}{\tau_{\mathrm{n}}}+\mathrm{G}_{\mathrm{L}} \\
& \frac{\partial \mathrm{p}_{\mathrm{n}}}{\partial \mathrm{t}}=\mathrm{D}_{\mathrm{p}} \frac{\partial^{2} \mathrm{p}_{\mathrm{n}}}{\partial \mathrm{x}^{2}}-\frac{\mathrm{p}_{\mathrm{n}}}{\tau_{\mathrm{p}}}+\mathrm{G}_{\mathrm{L}}
\end{aligned}
$$

Os índices $\mathrm{p}$ e $\mathrm{n}$ foram acrescentados às concentrações de elétrons $\mathrm{e}$ lacunas, respectivamente, somente para intensificar a validade das Eq. 98 e 99 para portadores minoritários. 


\subsubsection{Danos de radiação}

A utilização de diodos convencionais na dosimetria das radiações envolvendo doses elevadas é limitada. Nessas condições a radiação induz ao aparecimento de danos microscópicos na estrutura semicondutora que afetam diretamente as propriedades macroscópicas dos dispositivos.

Os danos gerados no volume do dispositivo são originados a partir do deslocamento de átomos da estrutura que são, por sua vez, responsáveis pela formação de defeitos primários [40,42,46-48]. O mecanismo dominante da formação de defeitos primários em um semicondutor é a colisão elástica de uma partícula com um átomo do cristal [48]. Com a colisão, o átomo absorve uma quantidade de energia denominada energia de recuo $E_{R}$. Sobretudo, para que seja deslocado da sua posição regular na estrutura, é necessário que o átomo possua uma energia de recuo superior a energia de deslocamento, $E_{D}$, que é definida a partir da distribuição da probabilidade do deslocamento em função de ER. O valor de $E_{D}$, que depende do material, corresponde a energia para a qual a probabilidade de deslocamento do átomo é de 50\%. Para o Si, por exemplo, Ed é igual a $25 \mathrm{eV}$ [40]. O átomo deslocado e a posição vaga deixada por ele na estrutura são denominados interstício, I, e vacância, V. Ambos, I e V, são móveis à temperatura ambiente e, por isso, quando formados nessa temperatura se recombinam e nenhum dano permanece no dispositivo. As vacâncias e interstícios remanescentes migram pela estrutura do semicondutor e realizam diversas reações entre si e com átomos de impurezas formando os denominados defeitos pontuais.

Se $E_{R}<E_{D} 0$ átomo não será deslocado e, somente vibrações serão transferidas à rede cristalina, entretanto, se $E_{R}>E_{D} 0$ átomo deslocado possuirá energia suficiente para deslocar outros átomos da estrutura e originar assim um efeito de dano em cascata denominado cluster [40, 42]. Para a formação deste tipo de defeito é necessário um limiar de energia de aproximadamente $35 \mathrm{keV}$ para nêutrons e $8 \mathrm{MeV}$ para elétrons [46].

De acordo com as informações anteriores, é possível notar que os danos no volume dos dispositivos não dependem somente da energia, mas do tipo da partícula. Ambos os defeitos, pontuais e cluster, podem afetar seriamente a performance do dispositivo, dependendo da sua concentração, nível de energia e seções de choque de captura para elétrons e lacunas [46]. Neste trabalho, foram utilizados dois tipos de radiação, gama, proveniente do ${ }^{60} \mathrm{Co}$, e elétrons, 
provenientes de uma acelerador (1,5 MeV). Devido à natureza e energia das radiações utilizadas, é possível afirmar que em ambos os casos somente defeitos pontuais serão gerados na estrutura dos dispositivos semicondutores e, por isso, a influência deste tipo de defeito nas propriedades macroscópicas do detector será descrito em maiores detalhes a seguir.

\subsubsection{Impacto dos danos nas propriedades macroscópicas do detector}

Os danos induzidos pela radiação introduzem centros R-G na banda proibida dos semicondutores e afetam diretamente suas propriedades elétricas conduzindo a alteração da concentração efetiva de dopantes e, portanto, tensão de depleção total, aumento da corrente de fuga com a dose de radiação e redução da eficiência de coleta de cargas (CCE) [10-17, 42, 45-47].

A relação entre os parâmetros microscópicos e a alteração das propriedades descritas, será apresentada em maiores detalhes a seguir:

Concentração efetiva de dopantes:

Os defeitos introduzidos no semicondutor pela influência da radiação podem alterar o estado de carga dos dopantes iniciais do dispositivo. Isso porque, quando ocupados com elétrons, e, dependendo da sua posição em relação ao nível de Fermi, os defeitos podem se tornar neutro, positivamente e negativamente carregados. Essa alternância do estado de carga dos defeitos conduz a alteração da concentração efetiva de dopantes e, portanto, da tensão de depleção total [42,46-47, 49-50]. Na FIG. 25 são apresentados os valores de tensão de depleção total em função da fluência equivalente de nêutrons $(1 \mathrm{MeV})^{3}$ para diodos crescidos por diferentes métodos e irradiados com prótons de 10, 20 e $30 \mathrm{MeV}$ de energia.

É possível observar, na FIG. 25, que a tensão de depleção dos dispositivos, que são inicialmente do tipo $n$, decresce com o aumento da fluência até um valor mínimo a partir do qual os valores de tensão aumentam. Este ponto de inflexão corresponde ao fenômeno de inversão de tipo do dispositivo que está relacionado com a inversão do tipo inicial, devido a remoção e introdução de níveis aceitadores ou doadores como consequência dos danos descritos anteriormente

\footnotetext{
${ }^{3}$ Para fins de normalização propõe-se que os efeitos dos danos induzidos por diferentes partículas sejam apresentados em função da fluência de nêutrons com energia igual a $1 \mathrm{MeV}$. Estes efeitos induzidos em dispositivos semicondutores são proporcionais a seção de choque de dano por deslocamento (D), que, por sua vez, depende da natureza e energia da partícula incidente. Assim, por meio da normalização dos valores de $D$ para partículas arbitrárias, com relação a nêutrons de $1 \mathrm{MeV}$ de energia, obtém-se também a normalização da fluência [51-52].
} 
[10-17, 42, 45-47]. Para irradiação gama, por exemplo, dispositivos com concentração baixa de oxigênio apresentam o fenômeno de inversão de tipo em aproximadamente 2 MGy de dose [19].

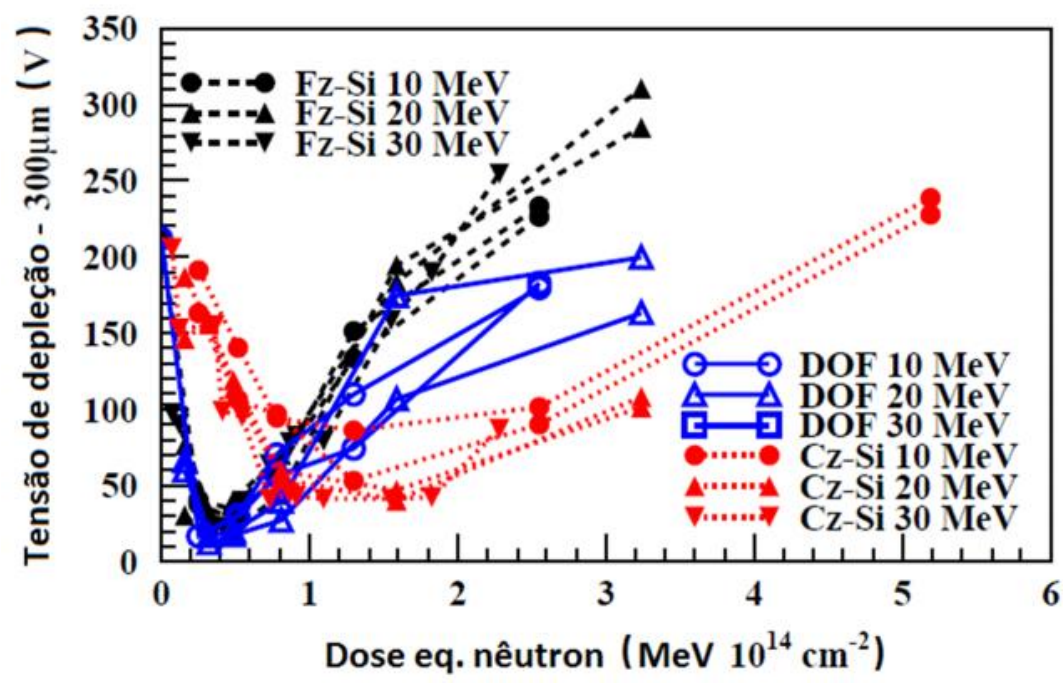

FIGURA 25 - Tensão de depleção em função da fluência equivalente de nêutrons para diodos crescidos por diferentes métodos e irradiados com prótons de diferentes energias [53].

\section{Corrente de fuga:}

Os níveis de energia profundos, criados no meio da banda proibida, agem como centros de geração de elétrons e lacunas e são responsáveis pelo aumento da corrente de fuga do dispositivo semicondutor [42,46-47, 49-50]. Tem sido observado uma relação linear entre o aumento da corrente de fuga dos dispositivos e a dose de radiação. Na FIG. 26 são apresentados os valores da corrente de fuga de diodos crescidos por métodos diferentes e irradiados com prótons.

O processo de geração de portadores via níveis profundos e, portanto, a corrente de fuga dos diodos semicondutores é sensível a temperatura e, portanto, alguns estudos propõe o resfriamento dos dispositivos a fim de inibir este processo [46].

\section{Eficiência de coleta de cargas (CCE):}

Os níveis de energia criados na banda proibida podem agir como centros de armadilhamento e capturar os portadores de carga gerados a partir da interação da radiação, por exemplo. Se o tempo de desarmadilhamento for inferior ao tempo de resposta do sistema eletrônico associado ao dispositivo, então o portador é liberado e contribui para a formação do sinal de resposta do diodo. Se o contrário 
é verdade, há uma redução do número de portadores coletados e assim uma redução da CCE [42,46-47, 49-50]. É importante ressaltar que somente os níveis profundos contribuem efetivamente para este processo, uma vez que os níveis rasos são ionizados à temperatura ambiente desarmadilhando rapidamente o portador capturado. Na FIG. 27 é apresentada a relação entre a CCE e a fluência equivalente de nêutrons para diodos epitaxiais crescidos por diferentes métodos e espessuras irradiados com prótons de energia igual a $24 \mathrm{GeV}$ [14].

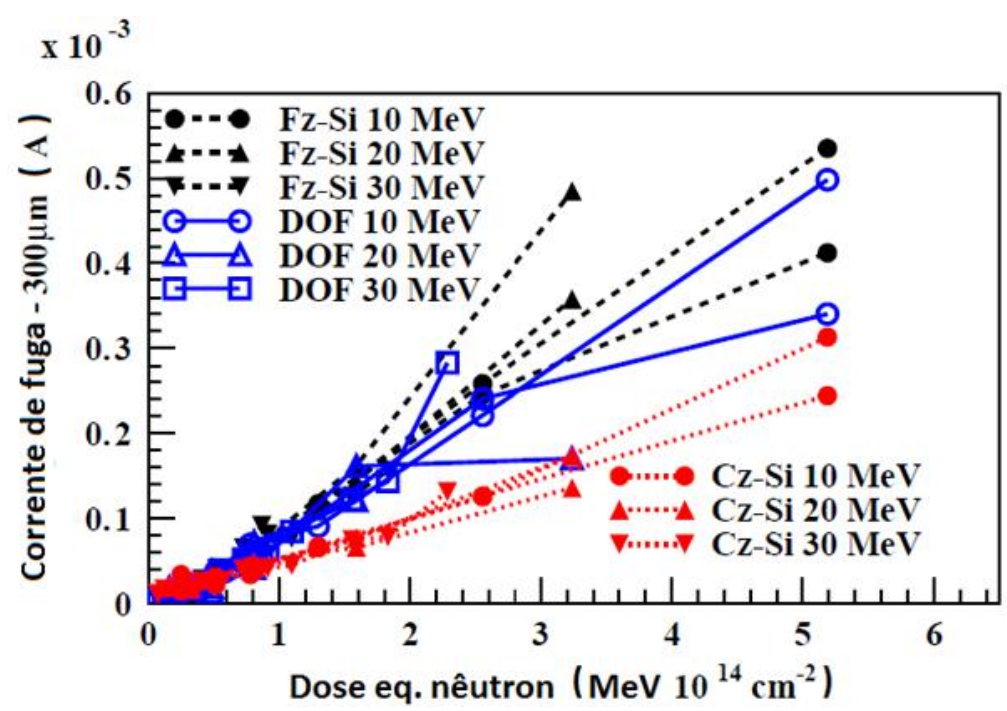

FIGURA 26 - Corrente de fuga em função da fluência equivalente de nêutrons para diodos crescidos por diferentes métodos e irradiados com prótons de diferentes energias [53].

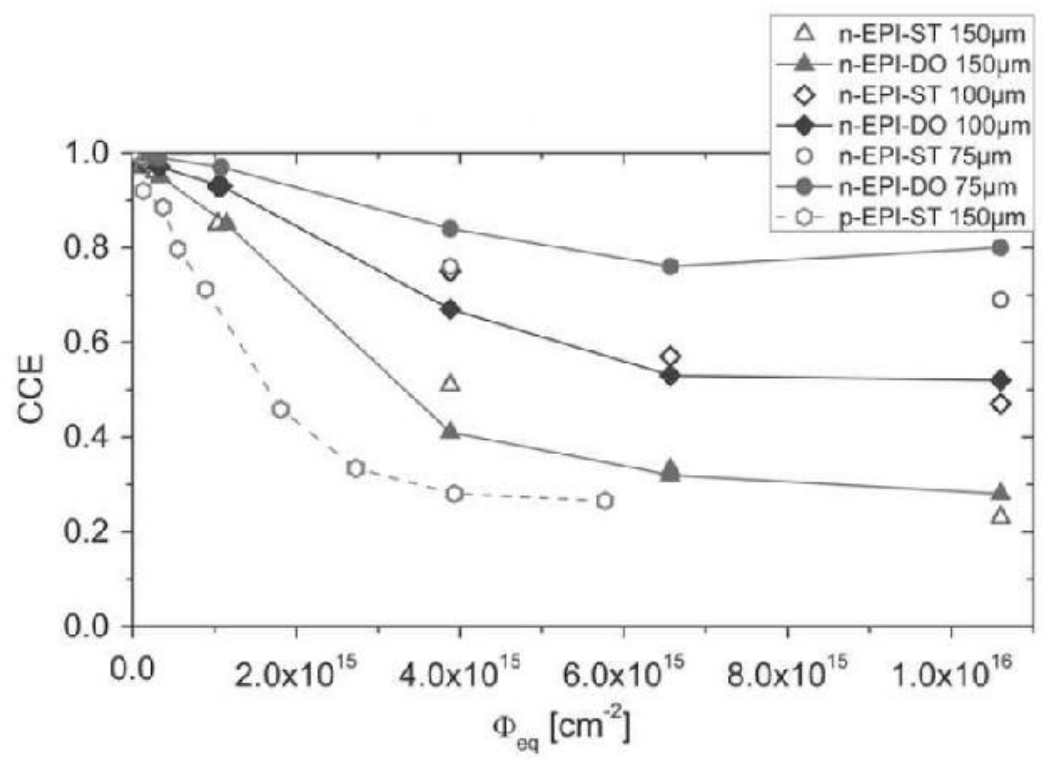

FIGURA 27 - CCE em função da fluência equivalente de nêutrons para diodos epitaxiais crescidos por diferentes métodos e espessuras, irradiados com prótons de $24 \mathrm{GeV}$ [14]. 
Um resumo do tipo do defeito e seu impacto nas propriedades elétricas dos dispositivos semicondutores é apresentado na FIG. 28.

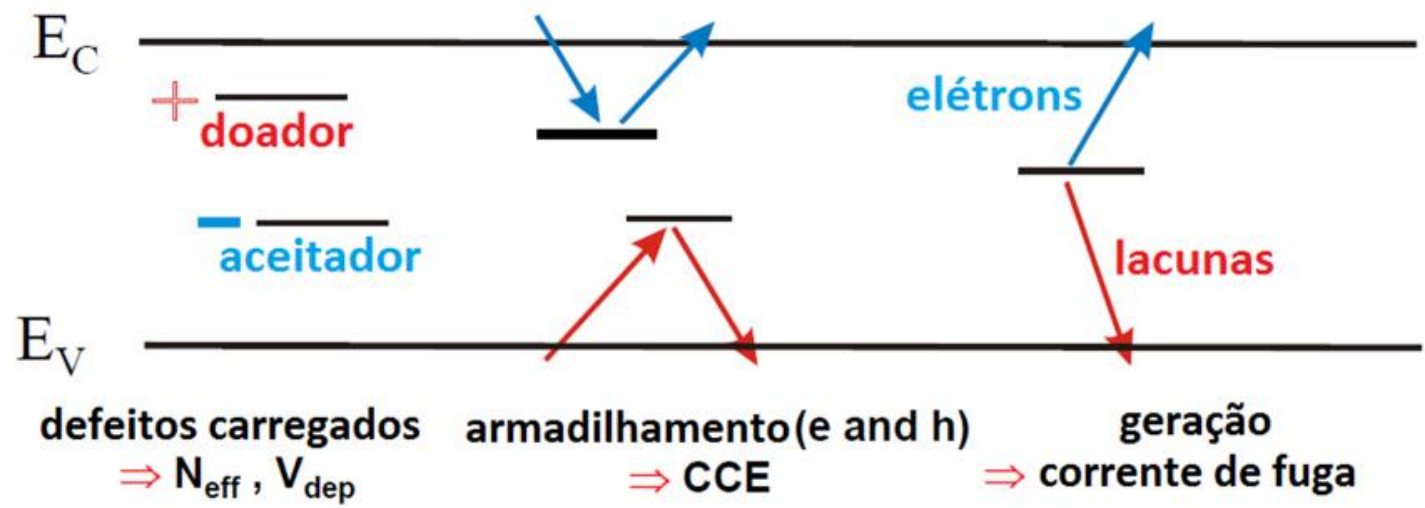

FIGURA 28 - Diagrama esquemático sobre os três principais tipos de defeitos responsáveis pela alteração das propriedades elétricas dos dispositivos semicondutores [54].

\subsubsection{Detectores resistentes aos danos de radiação}

Devido à elevada resistividade e concentração baixa de impurezas, os detectores de Si são amplamente produzidos a partir de pastilhas do tipo $\mathrm{n}$ crescidas pelo método FZ [55-56]. Sobretudo, estudos realizados por meio da colaboração RD48 do CERN (European Organization for Nuclear Research), na década de 90, evidenciaram que a presença do oxigênio, em concentrações elevadas $\left(10^{17} \mathrm{~cm}^{-3}\right)$, nas estruturas dos detectores semicondutores, sobretudo os de Si, aumenta a tolerância dos dispositivos aos danos de radiação [18-20, 55-56]. O efeito do oxigênio é mais proeminente para dispositivos irradiados com raios gama [49]. Por este motivo, ainda no tocante as pesquisas desenvolvidas por meio da colaboração RD48, desenvolveu-se o método de Fusão Zonal com difusão de oxigênio (DOFZ). Neste método uma grande quantidade de oxigênio é difundida na pastilha semicondutora, crescida pelo método FZ, por um longo período de tempo. Diodos do tipo DOFZ apresentam concentração de oxigênio cerca de uma ordem de grandeza maior do que aqueles crescidos pelo método FZ [55-56].

Por outro lado, dispositivos crescidos pelo método $\mathrm{Cz}$, que possuem concentração elevada de oxigênio inerente ao processo de crescimento, podem ser utilizados como detectores de radiação, pois, apresentam também resistividade suficientemente elevada. Se, durante o processo de crescimento, um campo magnético for aplicado ao tarugo fundido ( $\mathrm{MCz}$ ) uma quantidade menor de impurezas como alumínio e boro se difunde por meio da erosão do cadinho. Assim, 
obtém-se pastilhas com maior homogeneidade e com os benefícios mencionados: concentração de oxigênio e resistividade elevada [55-56]. As diferenças relatadas podem ser observadas nas FIG. 25 e 26, onde é possível observar a maior tolerância dos dispositivos com elevada concentração de oxigênio, sobretudo $\mathrm{Cz}$, com relação as alterações induzidas pelos danos de radiação.

O efeito do oxigênio é atribuído, segundo modelos, a supressão de um nível aceitador profundo. A reação que resulta no aglomerado de dois interstícios de oxigênio, tende a compensar o efeito de carga espacial negativa gerada por estes aceitadores e, assim, suprimir sua influência nas propriedades elétricas dos dispositivos [49,57-58].

Neste trabalho foram utilizados diodos resistentes aos danos de radiação, que contém em suas estruturas concentração elevada de oxigênio. Além disso, para comparação, em diferentes momentos também foram utilizados diodos FZ. Por este motivo, as principais características estruturais destes tipos de diodos serão apresentadas a seguir.

\subsubsection{Estrutura dos diodos}

Os diodos de junção utilizados neste trabalho foram produzidos a partir de pastilhas de Si crescidas pelos métodos FZ e MCz. Em ambos os casos o processo de fabricação é semelhante e será descrito sucintamente a seguir para um dispositivo do tipo $\mathrm{n}$.

As pastilhas, de elevada resistividade, são inicialmente submetidas a um processo de implantação iônica para a formação da face posterior do dispositivo $\mathrm{n}^{+}$. A implantação é feita com íons de fósforo $(P)$ de $70 \mathrm{keV}$ de energia e com uma dose total de $6 \times 10^{14}$ íons $/ \mathrm{cm}^{2}$. Em seguida uma camada de óxido com aproximadamente $300 \mathrm{~nm}$ é crescida sobre a pastilha com a finalidade principal de proteger a área, não ativa ao processo, de futuras contaminações. Para a implantação da região $\mathrm{p}^{+}$, é empregada a técnica de fotolitografia com a finalidade de obter janelas, previamente demarcadas, na camada de óxido onde a nova região será implantada. A implantação é feita com íons de boro (B) de $30 \mathrm{keV}$ de energia e com uma dose total de $10^{15}$ íons $/ \mathrm{cm}^{2}$. O restante do dióxido de silício $\left(\mathrm{SiO}_{2}\right)$ é então removido e uma nova camada de óxido é crescida sobre a estrutura. Durante esta etapa as regiões implantadas, B e $\mathrm{P}$, difundem-se para aproximadamente 3,5 $\mu \mathrm{m}$ e $7 \mu \mathrm{m}$ a partir da superfície, respectivamente. A técnica de fotolitografia é aplicada mais uma vez de maneira que novas janelas são abertas através do $\mathrm{SiO}_{2}$ 
e sobre as camadas $\mathrm{p}^{+}$, como é possível observar no último quadro da FIG. 29, que ilustra todo o processo descrito. Através das janelas, por meio da técnica de sputtering, uma camada de aproximadamente $500 \mathrm{~nm}$ de alumínio (Al) é inserida sobre a face frontal do dispositivo. Por meio da mesma técnica uma camada de aproximadamente $200 \mathrm{~nm}$ de espessura é inserida sobre a face posterior do dispositivo. $\mathrm{O} \mathrm{SiO}_{2}$ remanescente é então totalmente removido [46-47,55-56]. Os diodos do tipo p são produzidos da mesma maneira, sobretudo, com a inversão das posições dos implantes, ou seja, B na face posterior e P na face frontal. Uma outra possibilidade é iniciar o processo com uma pastilha do tipo $p$, sendo que neste caso o procedimento detalhado permanece inalterado.

(1)
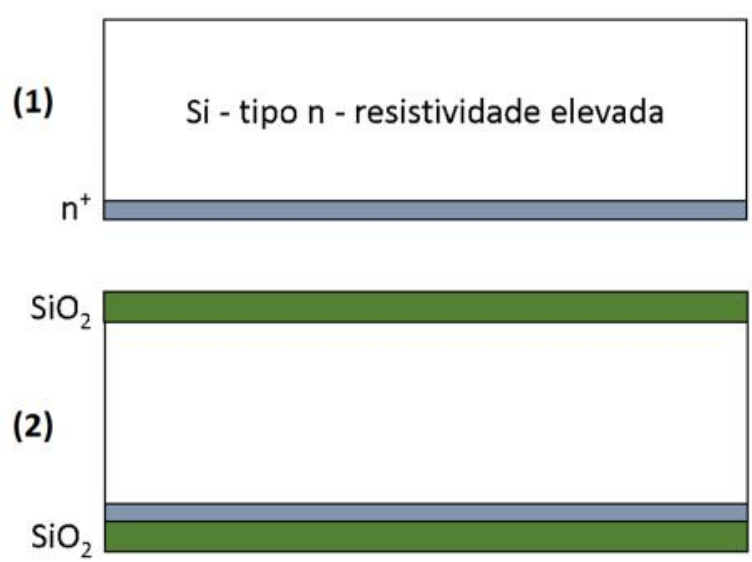

(3)

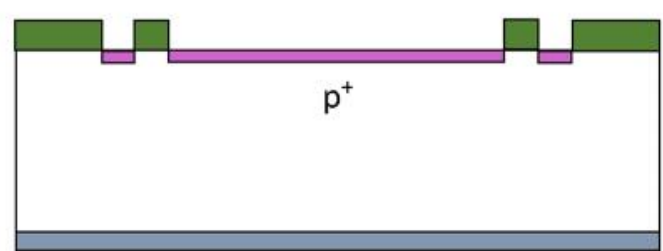

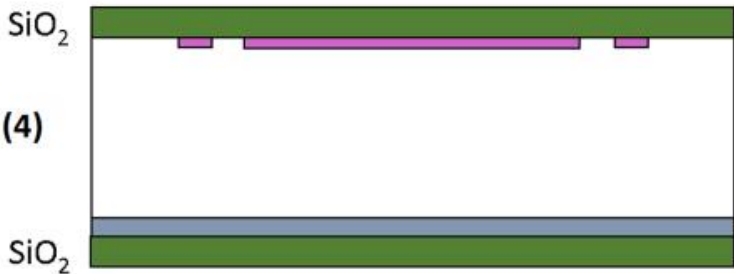

(5)
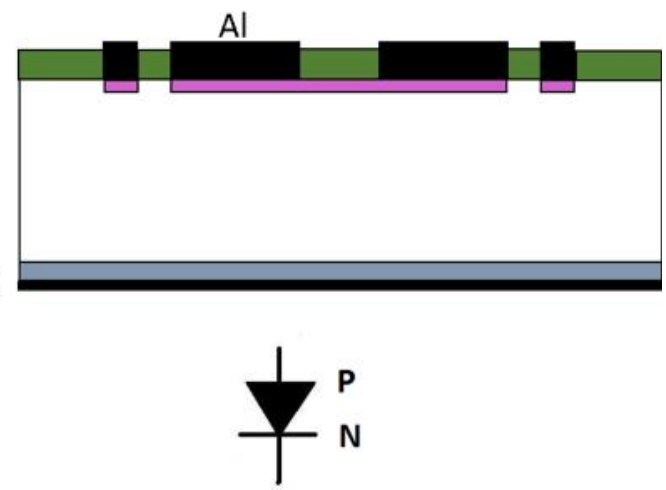

FIGURA 29 - Ilustração das etapas de produção de diodos de Si, como aqueles utilizados neste trabalho.

Na FIG. 30 é apresentada uma imagem ilustrativa da face frontal dos diodos após sua produção. Em seguida, na FIG. 31 é apresentada uma fotografia de diversos dispositivos produzidos em uma única pastilha de $\mathrm{Si}$. 


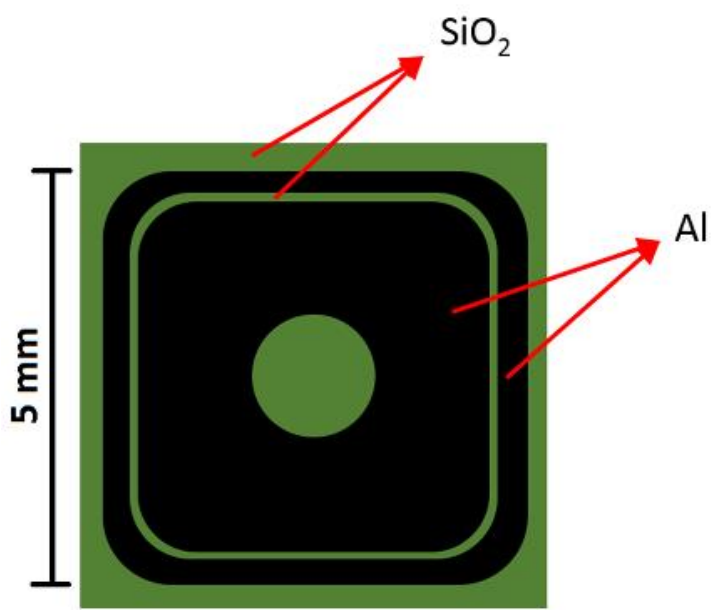

FIGURA 30 - Ilustração da face frontal dos diodos de Si ao término do processo de fabricação.

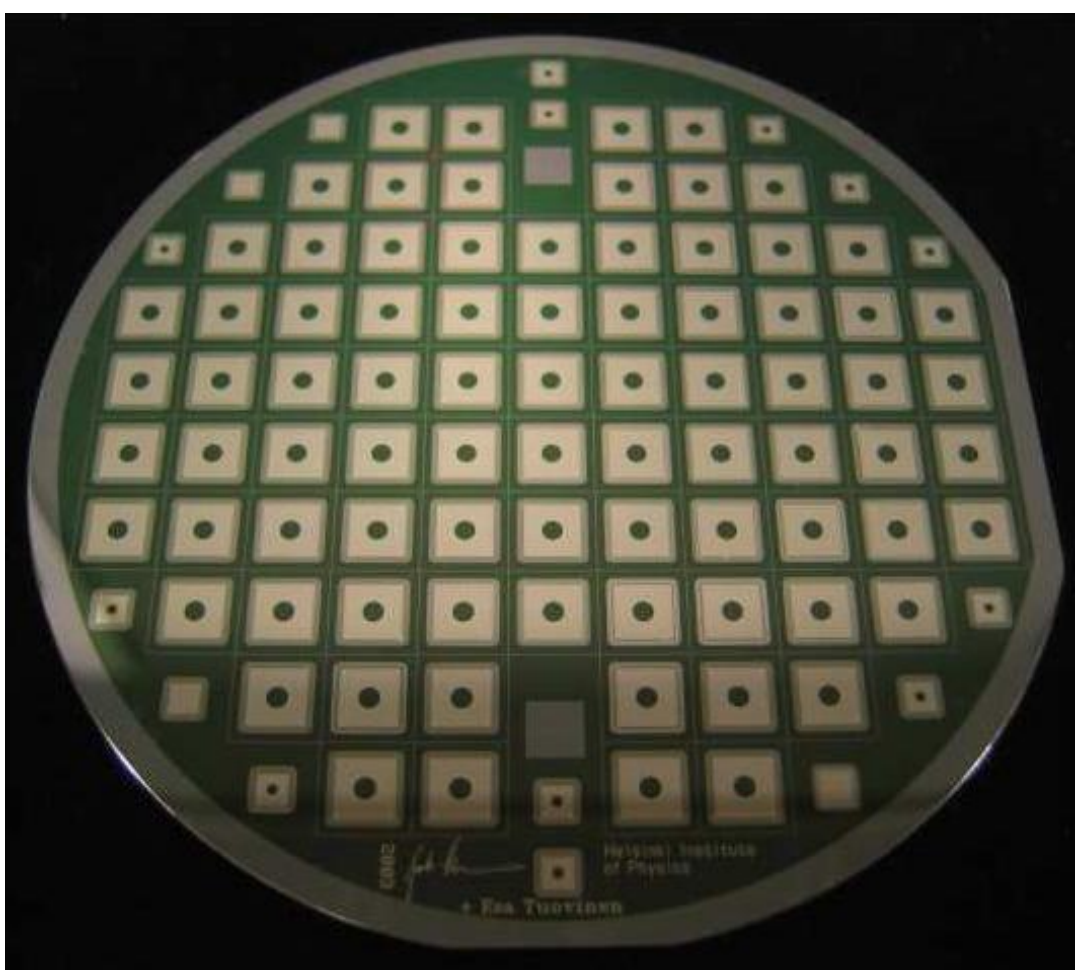

FIGURA 31 - Fotografia dos diodos (25 mm² cada) após o processo de fabricação sobre uma pastilha de Si [47]. 


\section{MATERIAIS E MÉTODOS}

\subsection{Diodos}

Os diodos utilizados neste trabalho foram produzidos por cristais de $\mathrm{Si}$ crescidos pelos métodos de $\mathrm{FZ}$ e $\mathrm{MCz}$ e processados no Centro de Microeletrônica da Universidade Tecnológica de Helsinque (Finlândia). Ambos os tipos de diodos possuem uma estrutura de 16 anéis de guarda, destinados a inibir a ruptura durante a variação do potencial elétrico, quando necessário, e reduzir a contribuição da corrente superficial no ruído eletrônico, como pode ser observado nas FIG. 32a e 32b por meio das fotos obtidas no Laboratório de Microeletrônica da Escola Politécnica da USP (LME/Poli-USP). No centro do diodo, FIG. 32a, observa-se um círculo mais escuro onde não há metalização da face do dispositivo uma vez que esta região é destinada à incidência de laser para estudos de danos de radiação.

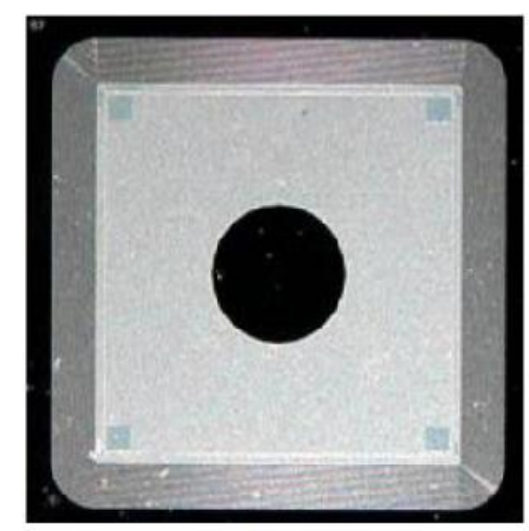

(a)

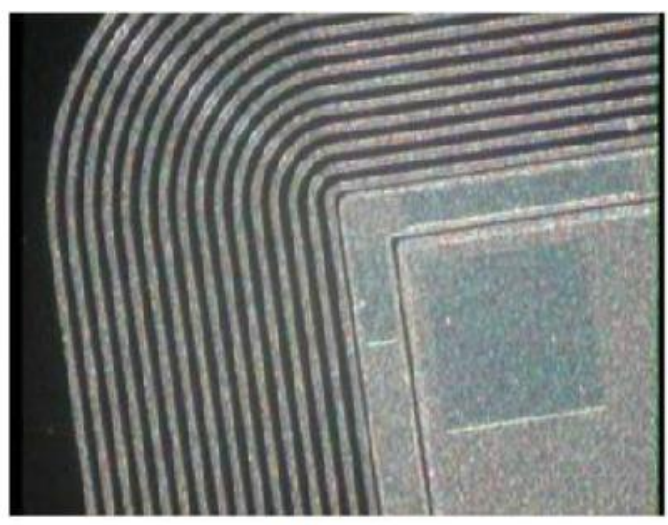

(b)

FIGURA 32 - Fotografia da face frontal do diodo em escala normal (a) e ampliada (b) com destaque para o conjunto de 16 anéis de guarda.

As características elétricas e estruturais destes diodos, fornecidas pelo fabricante, tais como, tensão de depleção total $\left(\mathrm{V}_{\mathrm{FD}}\right)$, corrente de fuga à tensão de depleção total (IF@V $\mathrm{FD}$ ), área útil (A), espessura da pastilha (d), resistividade $(\rho)$ e tipo de dopagem, são apresentadas na TAB. 1 para irradiações com raios gama $(\gamma)$ e elétrons (e). 
TABELA 1 - Características elétricas e estruturais e tipo de irradiação dos diodos utilizados.

\begin{tabular}{|c|c|c|c|c|c|c|c|c|}
\hline Diodo & $\#$ & $\begin{array}{l}V_{F D} \\
(V)\end{array}$ & $\begin{array}{c}\mathrm{I} F @ V_{\mathrm{FD}} \\
(\mathrm{nA})\end{array}$ & $\begin{array}{c}\text { A } \\
\left(\mathrm{mm}^{2}\right)\end{array}$ & $\begin{array}{c}d \\
(\mu \mathrm{m})\end{array}$ & $\begin{array}{c}\rho \\
(\mathrm{k} \Omega . \mathrm{cm})\end{array}$ & Tipo & Irradiação \\
\hline \multirow{15}{*}{ FZ } & $A$ & 29 & 20 & 25 & 300 & 10 & $\mathrm{n}$ & $\gamma$ \\
\hline & B & 25 & 7 & 25 & 300 & 10 & $\mathrm{n}$ & $\gamma$ \\
\hline & C & 30 & 9 & 25 & 300 & 10 & $\mathrm{n}$ & $\gamma / e$ \\
\hline & D & 27 & 9 & 25 & 300 & 10 & $\mathrm{n}$ & $\gamma$ \\
\hline & E & 28 & 8 & 25 & 300 & 10 & $\mathrm{n}$ & $\gamma / e$ \\
\hline & $\mathrm{F}$ & 27 & 6,5 & 25 & 300 & 10 & $\mathrm{n}$ & $\gamma$ \\
\hline & $\mathrm{G}$ & 25 & 6 & 25 & 300 & 10 & $n$ & $\gamma / e$ \\
\hline & $\mathrm{H}$ & 25 & 8 & 25 & 300 & 10 & $n$ & $\gamma$ \\
\hline & 1 & 27 & 9 & 25 & 300 & 10 & $\mathrm{n}$ & $\gamma$ \\
\hline & $J$ & 27 & 15 & 25 & 300 & 10 & $n$ & $\gamma / e$ \\
\hline & K & 25 & 7 & 25 & 300 & 1,4 & $n$ & $\gamma$ \\
\hline & L & 10 & 15 & 25 & 300 & 10 & $n$ & $\gamma / e$ \\
\hline & $M$ & 50 & 12 & 25 & 300 & 10 & $p$ & $\gamma$ \\
\hline & $\mathrm{N}$ & 35 & 1,5 & 25 & 300 & 10 & $p$ & e \\
\hline & O & 30 & 8 & 25 & 300 & 10 & $\mathrm{n}$ & e \\
\hline \multirow{7}{*}{$\mathrm{MCz}$} & A & 350 & 0,4 & 25 & 300 & $0,9-1$ & $n$ & $\gamma$ \\
\hline & B & 330 & 7 & 25 & 300 & $0,9-1$ & $\mathrm{n}$ & $\gamma$ \\
\hline & C & 117 & 1,2 & 25 & 300 & $0,9-1$ & $p$ & $\gamma$ \\
\hline & D & 330 & 8 & 25 & 300 & $0,9-1$ & $\mathrm{n}$ & $\gamma$ \\
\hline & $E$ & 300 & 8 & 25 & 300 & $0,9-1$ & $\mathrm{n}$ & e \\
\hline & $\mathrm{F}$ & 350 & 6 & 25 & 300 & $0,9-1$ & $\mathrm{n}$ & e \\
\hline & G & 350 & 5 & 25 & 300 & $0,9-1$ & $\mathrm{n}$ & e \\
\hline
\end{tabular}




\subsection{Sonda dosimétrica}

Os diodos, fornecidos originalmente sem os terminais elétricos, foram fixados individualmente sobre uma base de alumina (aproximadamente $0,7 \mathrm{~mm}$ de espessura) com uma fina camada de ouro eletrodepositada, permitindo a ligação dos eletrodos de polarização e de extração dos sinais. Para a fixação dos diodos na base de alumina utilizou-se a cola prata condutiva CE 8500 (Hyso|®). A extração do sinal durante os processos de irradiação foi feita por meio de um eletrodo microsoldado na face p+ dos dispositivos, FIG. 33a. Os processos de microsoldagem dos eletrodos e fixação dos dispositivos sobre a base de alumina foram realizados no Centro de Tecnologia da Informação - Renato Archer em Campinas.

Após a montagem na base de cerâmica, os diodos foram fixados individualmente no interior de uma sonda confeccionada em PMMA preto, FIG. 33b. A extração dos sinais de corrente, gerados durante os processos de irradiação, foi realizada utilizando um conector do tipo $L E M O \AA$ de engate rápido.
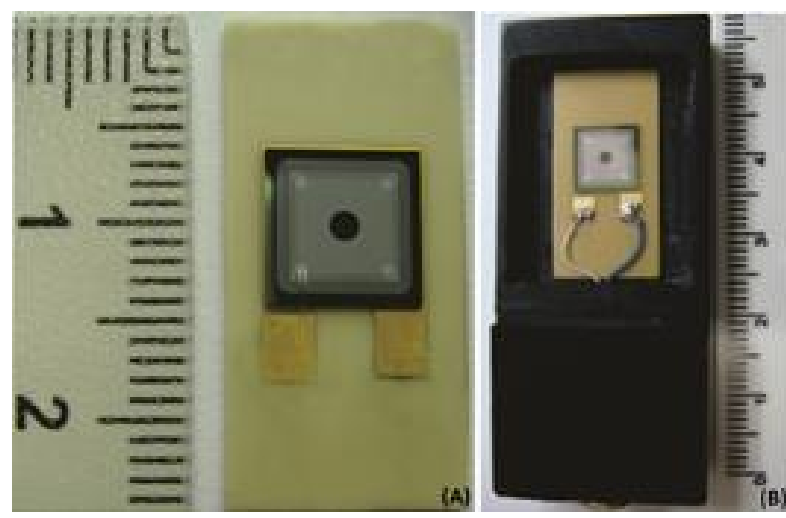

FIGURA 33 - Diodo fixado sobre a base de cerâmica, com a face p+ microsoldada ao eletrodo de extração de sinais (a), e inserido na sonda dosimétrica de PMMA

(b).

Para os procedimentos de irradiação com raios gama a sonda dosimétrica foi recoberta com uma tampa de PMMA preta, como pode ser observado na FIG. 34a. O aparato protege o diodo de impactos mecânicos e da luz. Para a irradiação com elétrons, no entanto, a tampa da sonda dosimétrica possui uma janela de $M y l a r{ }^{\circledR}$ aluminizado de $3,6 \mathrm{~g} / \mathrm{cm}^{2}$ de espessura, suficientemente fina para minimizar a perda de energia da radiação incidente, FIG. 34b. Abaixo do Mylar $\circledast$ foi colocada uma camada de plástico filme (PVC) a fim de evitar a deposição do alumínio proveniente da janela da sonda sobre os contatos dos dispositivos [24]. 
A fim de evitar a deterioração dos contatos elétricos, como será detalhado no item 5.2.2, e reduzir a influência da temperatura e umidade na sensibilidade dos dispositivos [24, 59], durante os procedimentos de irradiação com elétrons um novo protótipo de sonda dosimétrica foi utilizado. Neste novo modelo os diodos foram revestidos com uma resina termorrígida preta (Loctite® 3549) no interior da sonda dosimétrica FIG. 34c.

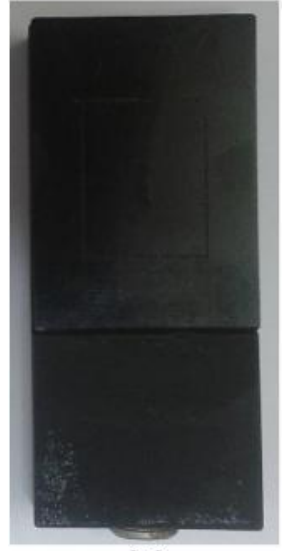

(A)

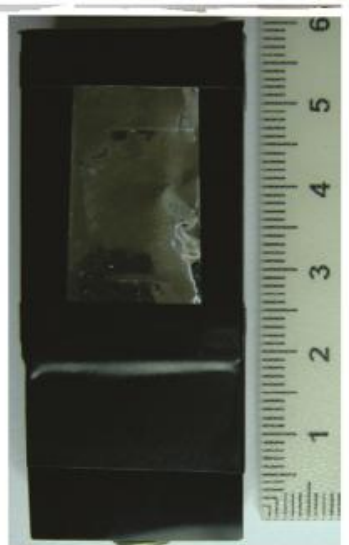

(B)

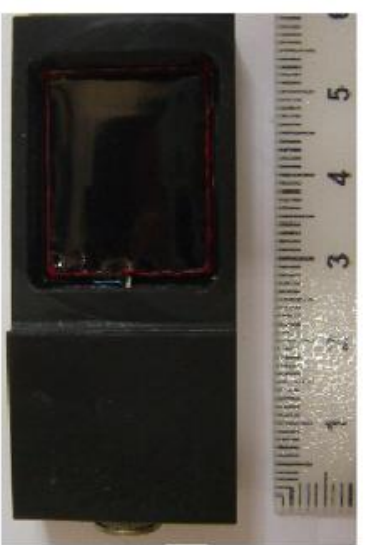

(C)

FIGURA 34 - Sonda dosimétrica preparada para os procedimentos de irradiação com raios gama (a) e elétrons (b, c), sendo o primeiro protótipo constituído por uma janela de Mylar ${ }^{\circledR}$ aluminizado (b) e o segundo por meio do encapsulamento dos diodos com uma resina termorrígida (c).

\subsection{Irradiações}

\subsubsection{Gama}

Para os procedimentos de irradiação gama, utilizou-se o irradiador Gammacell 220, da Nordion, que possui uma câmara de irradiação com capacidade útil de 3,6 L e apresenta formato cilíndrico com 26 lápis constituídos individualmente por 7 pastilhas de ${ }^{60} \mathrm{Co}$, FIG. 35. A taxa de dose no centro da câmara, de 1,535 kGy/h, foi recentemente determinada por dosimetria Alanina em março de 2012 pelo Laboratorio de Dosimetria de Altas Dosis (LDAD - Argentina) por meio do projeto IAEA (ARCAL) LDAD-CNEA RLA 8046, com uma incerteza de 2,75 \%. Portanto, para cada medida foi necessário realizar a correção da taxa de dose pelo fator de decaimento da fonte, uma vez que o irradiador foi certificado em data diferente daquela em que foram feitas as medidas. Esta correção é realizada mensalmente pelos responsáveis pela instalação irradiadora.

A sonda dosimétrica foi colocada na posição central do interior de um cilindro de isopor, FIG. 36a, com dimensões ligeiramente menores do que as da 
câmara de irradiação. O posicionamento da sonda garante homogeneidade de dose uma vez que a mesma foi centralizada no campo de radiação do irradiador. Ao lado da sonda dosimétrica foi inserido um termopar do tipo $\mathrm{K}$ que, conectado ao multímetro 89 IV da Fluke $\AA$, permitiu a monitoração dos valores de temperatura durante os processos. O cilindro de isopor é posicionado na câmara secundária do irradiador, FIG. 36b, que, por meio de um motor elétrico, é levada até a câmara primária, onde os diodos ficam expostos à radiação.

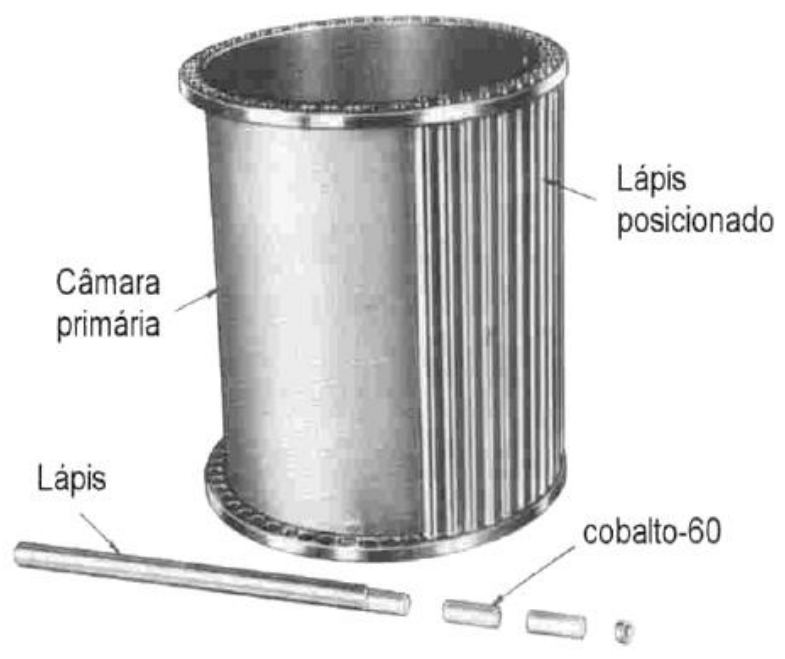

FIGURA 35 - Diagrama representativo da composição da câmara primária de irradiação do irradiador Gammacell 220 [61].

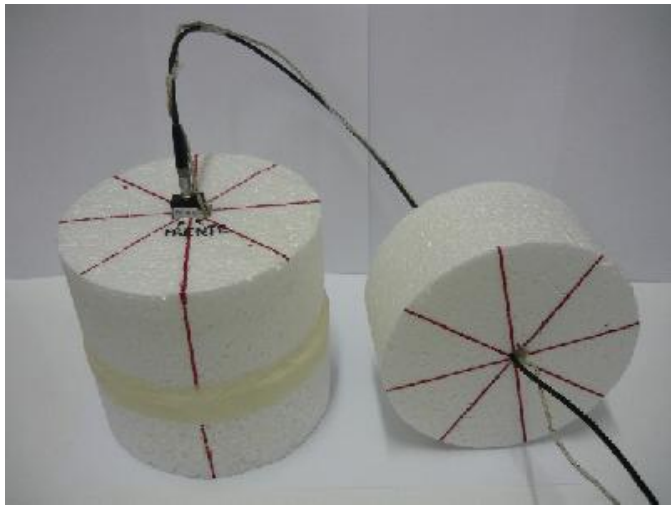

(A)

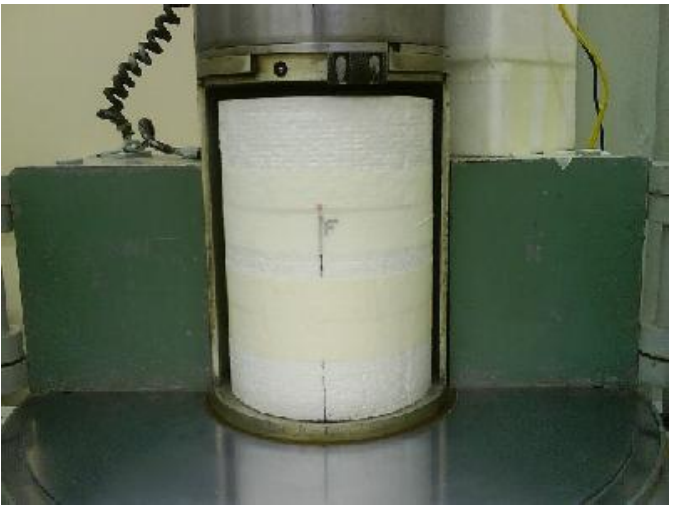

(B)

FIGURA 36 - Cilindro de isopor, contendo em seu interior a sonda dosimétrica e o termopar do tipo K (a), posicionado no interior da câmara secundária do irradiador Gammacell 220.

O eletrodo coletor (face $\mathrm{p}+$ ) foi conectado diretamente, por meio de cabo coaxial, na entrada de eletrômetros de elevada impedância de entrada (Keithley® 617 e Keithley ${ }^{\circledR}$ 6517B) para o registro das correntes geradas pela incidência da 
radiação no volume sensível de cada diodo. Os sinais de corrente foram extraídos diretamente dos eletrômetros via cabo GPIB para um computador dotado com interface programada em LabViewß.

\subsubsection{Elétrons}

O acelerador de elétrons utilizado para os processos de irradiação foi o DC 1500/25/4 - JOB 188 de 1,5 MeV de energia, instalado no Centro de Tecnologia das Radiações CTR-IPEN/SP. Os parâmetros do acelerador, como corrente de feixe e velocidade da esteira, $1 \mathrm{~mA}$ e $3,36 \mathrm{~m} / \mathrm{min}$, respectivamente, foram escolhidos para reproduzir as condições experimentais usuais em procedimentos de irradiação realizados neste acelerador. A taxa de dose utilizada, obtida a partir dos ajustes dos parâmetros do acelerador, é de 4,0 kGy/s.

Para as irradiações a sonda dosimétrica foi posicionada em uma bandeja e esta colocada sobre uma esteira cujo movimento em relação ao feixe de elétrons é representado na FIG. 37. Cada ciclo de irradiação é constituído por duas passagens (ida e volta) do diodo sob a janela do acelerador. $\mathrm{O}$ aparato utilizado para a irradiação é apresentado na FIG. 38 juntamente com a proteção dos cabos e conectores.

O registro das correntes elétricas geradas nos diodos foi feito segundo o mesmo procedimento detalhado no item 4.3.1, utilizando os eletrômetros Keithley® 617 e Keithley ${ }^{\circledR}$ 6517B e interface programada em LabView®. Para efeitos comparativos os diodos FZ\#L e MCz\#G foram irradiados simultaneamente evitando as influências de possíveis alterações nos parâmetros do acelerador nas suas respostas dosimétricas. Durante toda a irradiação, a temperatura foi monitorada por um termopar do tipo K conectado ao multímetro 89 IV da Fluke®. Não foram observados valores de temperatura superiores a $35^{\circ} \mathrm{C}$. 


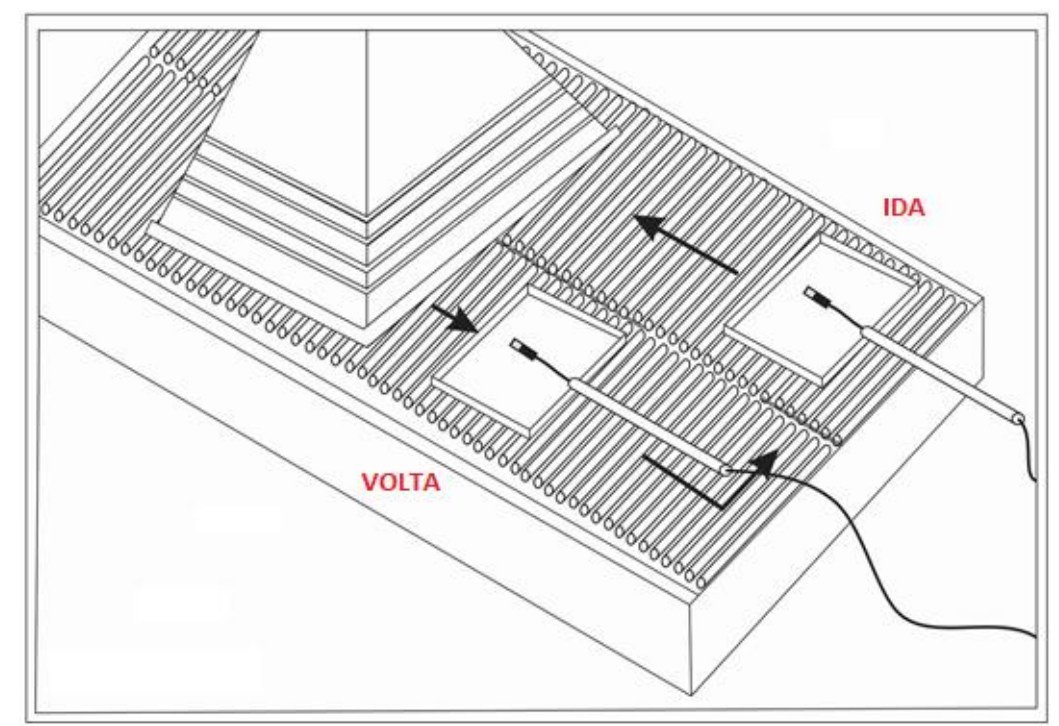

FIGURA 37 - Diagrama esquemático do movimento da bandeja sobre a esteira em relação ao feixe de elétrons.

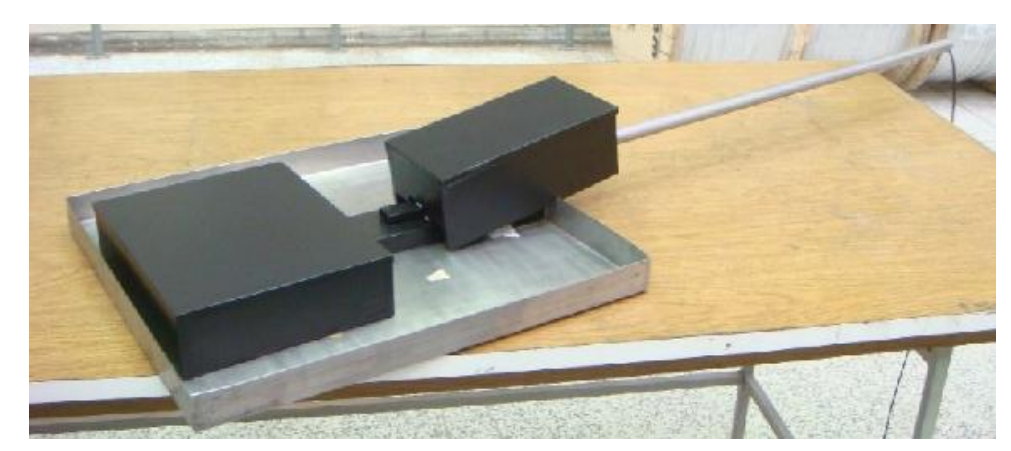

FIGURA 38 - Aparato experimental montado sobre a bandeja contendo as blindagens de acrílico para a proteção dos conectores e cabos.

\subsubsection{Caracterização elétrica}

As medidas de corrente de fuga em função da tensão de polarização reversa (curvas IV) das amostras $\mathrm{FZ}$ e MCz foram feitas utilizando-se o eletrômetro Keithley ${ }^{\circledR}$ 6517B, segundo o diagrama apresentado na FIG. 39. Durante as medidas, os diodos foram blindados eletricamente por uma caixa metálica posicionada o mais próximo possível do eletrômetro para evitar a introdução de capacitâncias parasitas no sistema. $O$ isolamento térmico foi garantido acondicionando o conjunto em um suporte de isopor e a temperatura no seu interior monitorada por um termopar tipo K conectado ao multímetro $89 \mathrm{IV}$ da Fluke ${ }^{\circledR}$. A temperatura do laboratório foi mantida em $23{ }^{\circ} \mathrm{C}$ por meio de um sistema convencional de ar-condicionado. As medidas foram extraídas do eletrômetro via cabo GPIB, como mencionado no item 4.3.1. Os valores de corrente de fuga 
medidos (IT) foram corrigidos para a temperatura de referência $\left(20^{\circ} \mathrm{C} ; \mathrm{I}_{20}\right)$ segundo as EQ. 100 e 101 [21,60].

$$
\begin{gathered}
\frac{\mathrm{I}_{20}}{\mathrm{I}_{\mathrm{T}}}=\left(\frac{293,2}{273,2+\mathrm{T}}\right)^{2} \cdot \mathrm{e}^{\mathrm{y}} \\
\mathrm{y}=\left[\frac{-\mathrm{E}_{\mathrm{g}}}{2 \cdot \mathrm{k}_{\mathrm{B}}} \cdot\left(\frac{1}{293,2}-\frac{1}{273,2+\mathrm{T}}\right)\right]
\end{gathered}
$$

sendo $E_{g}, k_{B}$ e $T$ a energia de gap, a constante de Boltzman e a temperatura durante as medidas, respectivamente.

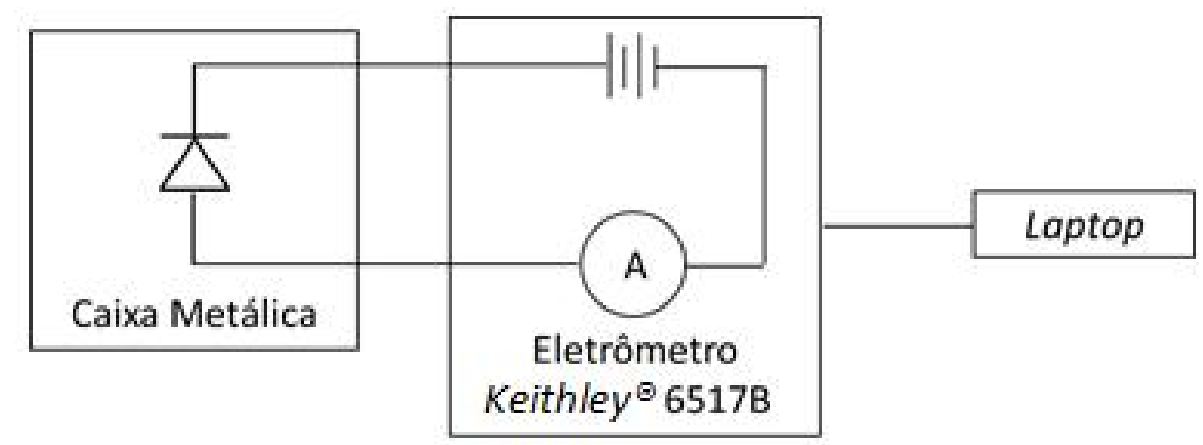

FIGURA 39 - Diagrama de blocos do arranjo experimental para as medidas IV.

Um circuito projetado e construído com base no sistema de amplificação de sinais OPA656U [28] foi utilizado para a obtenção das medidas de capacitância (C) em função da tensão de polarização reversa. O método utilizado baseia-se na conhecida dependência do ganho em tensão de um amplificador com a reatância capacitiva do dispositivo em teste, representada na Eq.102 [62]:

$$
\mathrm{C}=\frac{\mathrm{V}_{\mathrm{AC}}}{\mathrm{R} \cdot 2 \cdot \pi \cdot \mathrm{f}_{\mathrm{in}} \cdot \mathrm{V}_{\text {in }}}
$$

sendo $V_{A C}, R$, fin $e V_{i n}$, a amplitude do sinal na saída do circuito, a resistência interna do circuito, a frequência e amplitude do sinal injetado na entrada do circuito, respectivamente.

Com o diodo polarizado reversamente (Fonte ORTEC $\AA$ 659), as medidas de capacitância foram realizadas injetando-se na entrada do amplificador sinais elétricos senoidais de $200 \mathrm{mV}$ de amplitude e $10 \mathrm{kHz}$ de frequência, provenientes de um gerador de funções Minipa® MFG-4220. Para cada valor de tensão, as amplitudes dos sinais de entrada e de saída do amplificador foram medidas em um osciloscópio Tektronix® TDS3034. O diagrama do aparato 
utilizado no processo de caracterização CV das amostras é apresentado na FIG. 40.

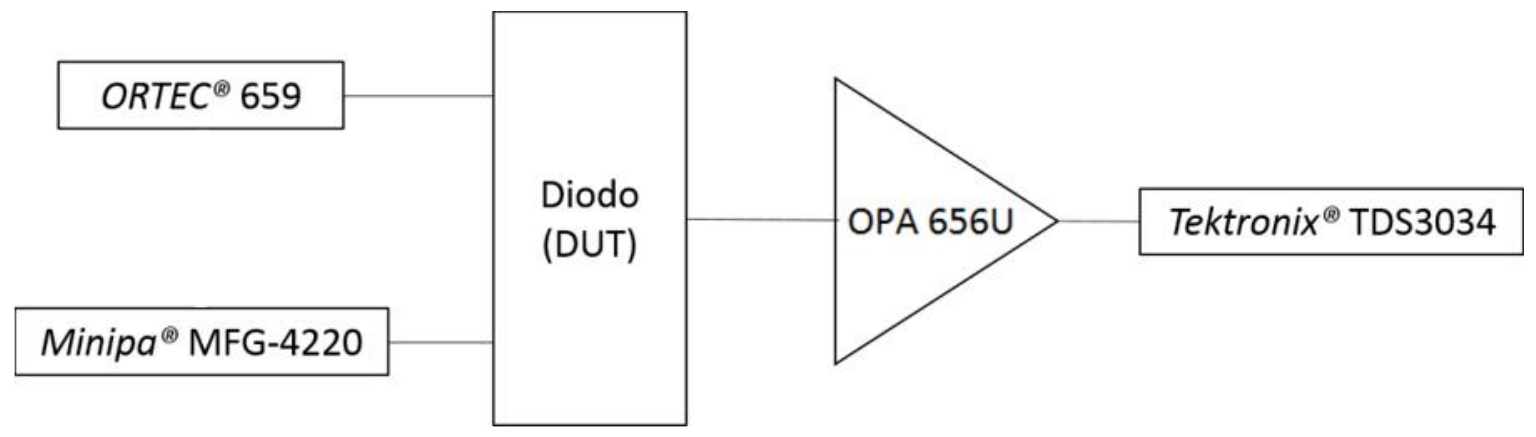

FIGURA 40 - Diagrama de blocos do arranjo experimental para as medidas CV.

\subsubsection{Espectrometria}

O diodo $\mathrm{MCz}$ D foi utilizado como espectrômetro alfa a fim de avaliar a perda de resolução e possível CCE com a dose de radiação gama. Para isso utilizou-se uma câmara de vácuo de aço inox contendo em seu interior um suporte onde foi colocada uma fonte radioativa de ${ }^{241} \mathrm{Am}$. Na tampa da câmara foi colocado um suporte de acrílico para acondicionar a sonda dosimétrica de maneira que o centro do diodo estivesse alinhado com o centro da fonte radioativa. $O$ aparato descrito é apresentado nas FIG. 41a e 41b.

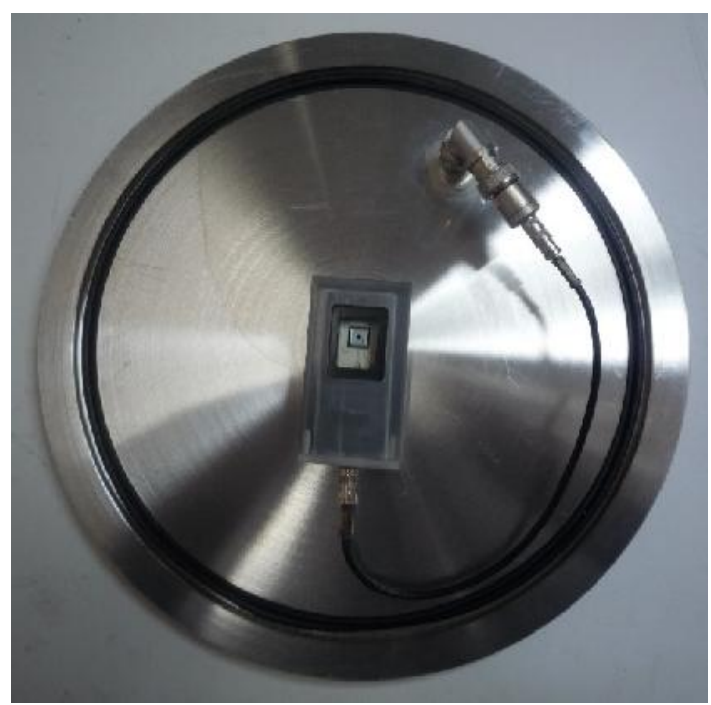

(A)

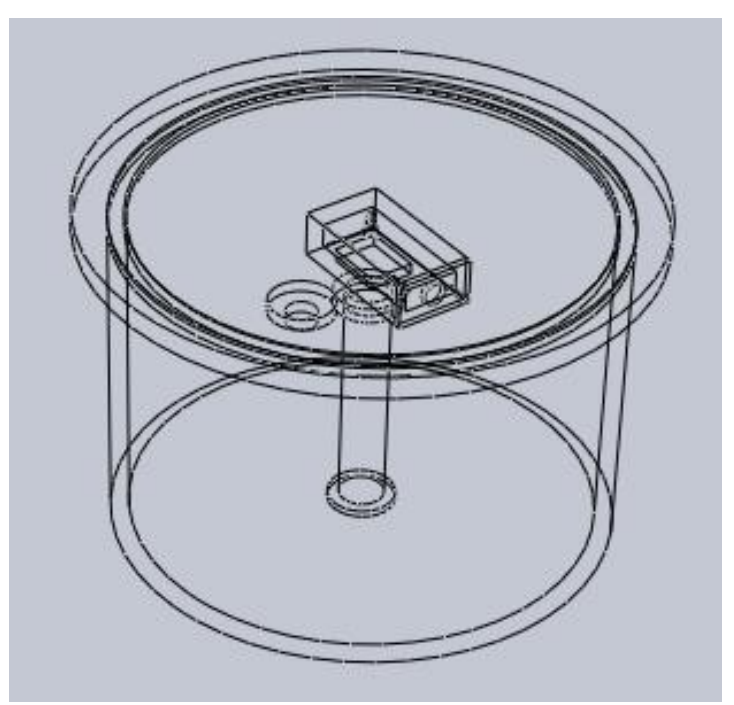

(B)

FIGURA 41 - Fotografia tirada da tampa da câmara de vácuo após a fixação da sonda dosimétrica (a) e desenho esquemático do posicionamento entre o diodo e o porta fonte (b).

Um pré-amplificador (ORTEC® $142 \mathrm{IH}$ ) foi conectado diretamente na parte externa da tampa da câmara de vácuo permitindo assim a polarização e 
extração dos sinais provenientes do diodo. $\mathrm{A}$ face $\mathrm{p}^{+}$do diodo foi polarizada negativamente com a fonte de tensão ORTEC® 659 garantindo a polarização reversa do dispositivo. Os impulsos elétricos provenientes do pré-amplificador, gerados no diodo pela incidência das partículas alfa, foram formatados e amplificados pelo amplificador linear ORTEC $\AA 572$ e em seguida enviados ao analisador multicanal ORTEC $\AA$ Spectrum Ace - 8k. O valor da constante de tempo $(1 \mu \mathrm{s})$ do amplificador foi escolhido a partir de testes preliminares visando obter a melhor resolução possível. A partir destes testes também foi escolhido o valor de tensão de polarização do diodo (180 V) visando os mesmos objetivos.

Os sinais elétricos obtidos na saída do amplificador foram monitorados através do osciloscópio Tektronix® TDS3034 como se pode observar na FIG. 42 que apresenta o diagrama de todo o aparato utilizado.

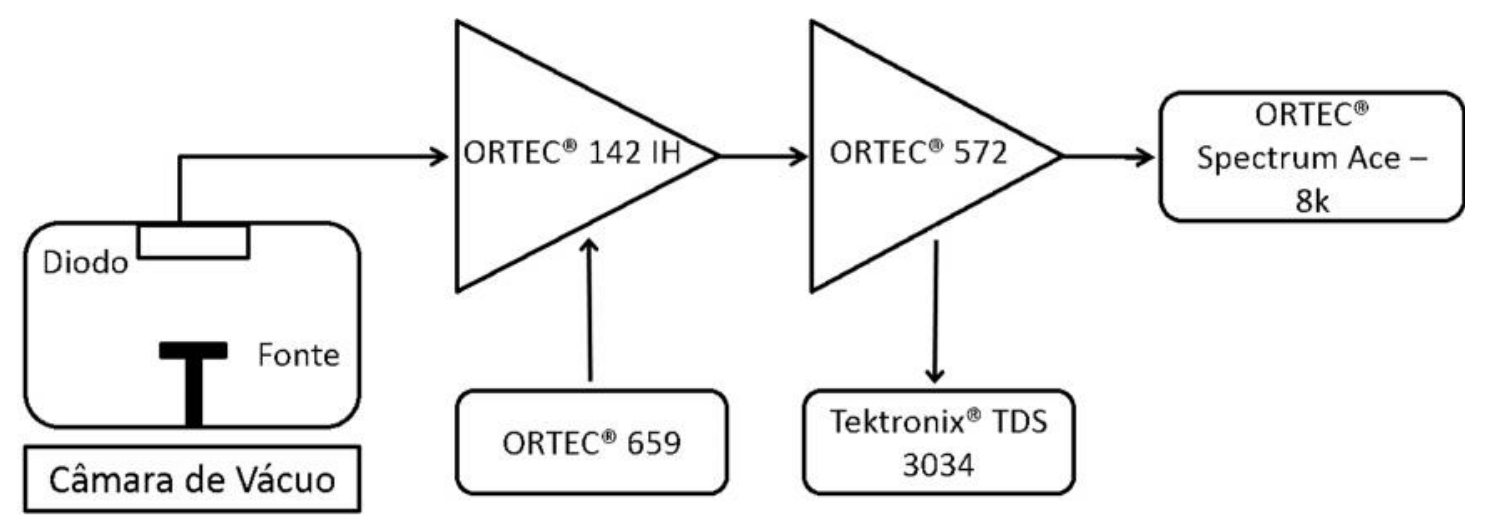

FIGURA 42 - Diagrama de blocos do aparato experimental utilizado para o levantamento dos espectros alfa.

\subsubsection{Parâmetros analisados}

A corrente elétrica, gerada nos diodos a partir da interação da radiação, está relacionada diretamente com a taxa de dose do processo e é, portanto, a grandeza dosimétrica utilizada neste trabalho $[36,38,63]$. Sendo assim, entende-se a partir de agora por resposta em corrente do diodo a corrente elétrica gerada em sua estrutura. Durante os processos de irradiação gama, onde a taxa de dose é constante, espera-se que a variação dos valores de corrente seja devida unicamente aos efeitos dos danos e consequente queda de sensibilidade dos diodos. Por outro lado, nos processos de irradiação com elétrons, onde, devido ao movimento da esteira com relação ao feixe, a taxa de dose é variável com o tempo, espera-se obter uma variação dos valores de corrente. Assim, para a análise dos resultados obtidos com elétrons, que serão apresentados no item 5, são 
considerados os valores máximos de corrente (corrente de pico), obtidos quando o diodo passa exatamente pela saída do feixe de elétrons.

Outro parâmetro avaliado neste trabalho é a carga gerada nos diodos durante a irradiação. Este parâmetro secundário é obtido por meio da integração dos sinais de corrente ao longo do tempo de irradiação e é utilizado na construção da curva de resposta dos dispositivos, uma vez que está diretamente relacionado com a dose acumulada. É importante ressaltar que, como os efeitos da dose de radiação nos diodos são cumulativos, nas curvas dose resposta são apresentados os valores de carga e dose acumulados.

Os parâmetros discutidos, corrente e carga, serão apresentados com os devidos valores de incertezas associados. Em cada caso foram considerados os valores de incerteza do tipo B devido especificamente aos eletrômetros. Outras possíveis componentes foram desprezadas por não contribuírem significativamente. Para as demais medidas os valores de incertezas do tipo A e B foram associadas segundo as recomendações do Guia para Expressão de Incerteza de Medição (GUM) [64]. 


\section{RESULTADOS E DISCUSSÕES}

Neste capítulo são apresentados os principais resultados obtidos durante o desenvolvimento deste trabalho seguido da discussão acerca dos mesmos.

\subsection{Radiação Gama}

Aqui são apresentados os resultados obtidos para diodos irradiados com raios gama.

\subsubsection{Resposta em função da taxa de dose}

Duas amostras, FZ\#A e FZ\#B, pertencentes ao mesmo lote de diodos, foram irradiadas em dois irradiadores Gammacell, sendo um pertencente ao Departamento de Energia Nuclear da Universidade Federal de Pernambuco (DEN - UFPE) e outro instalado no CTR-IPEN/SP, como descrito no item 4.3.1. As taxas de dose em ambos os irradiadores foi de 7,465 kGy/h e 2,18 kGy/h, respectivamente, sendo os diodos irradiados em etapas de acordo com a disponibilidade da agenda das máquinas. Os valores de corrente obtidos durante os processos de irradiação são apresentados na FIG. 43, em função da dose acumulada. Para o intervalo de dose de 460 kGy a 600 kGy, aproximadamente, os valores de corrente do diodo FZ\#B não foram registrados devido a um problema no fornecimento de energia elétrica. É importante ressaltar que a diferença entre os valores de dose acumulados, em cada uma das amostras, está diretamente relacionado com o tempo disponível para a utilização dos irradiadores. 


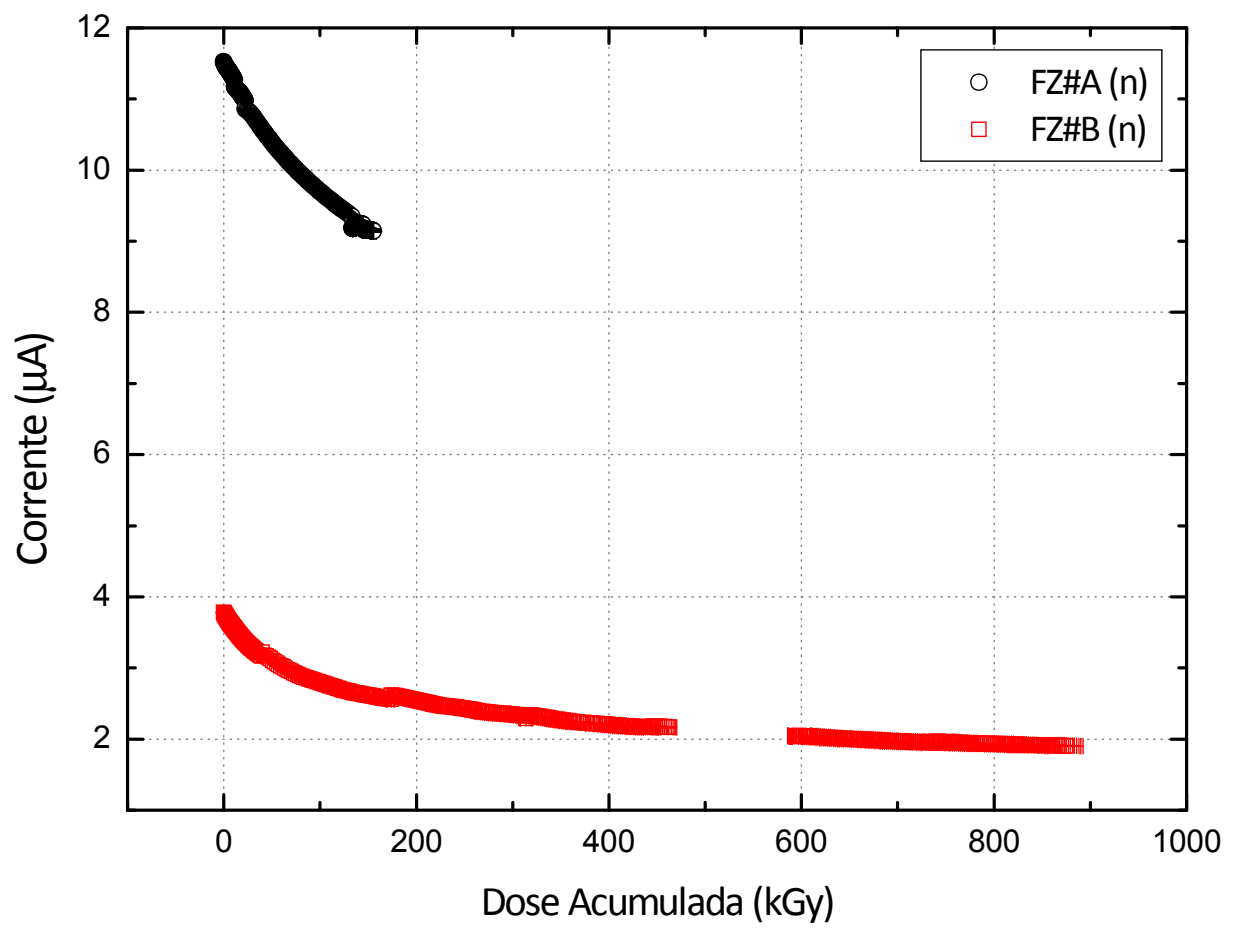

FIGURA 43 - Corrente elétrica gerada nos diodos FZ\#A e FZ\#B do tipo n, durante os processos de irradiação gama, em função da dose acumulada. As barras de incerteza dos valores de corrente são menores do que os pontos e representam menos do que $1 \%$ das medições.

A diferença entre os valores de corrente iniciais, registrados com cada um dos diodos, é esperada uma vez que este parâmetro dosimétrico está diretamente relacionado com a taxa de injeção de portadores e, portanto, com a taxa de dose. A diminuição dos valores de corrente com a dose acumulada devese essencialmente aos fenômenos de armadilhamento e recombinação de portadores, descritos no item 3.2.1.5 deste trabalho. Esta diminuição é mais acentuada no início da irradiação e menos significativa para valores de dose mais elevados. Uma possível explicação está relacionada com a saturação da criação de defeitos de níveis profundos, de maneira que para doses mais elevadas somente os defeitos de níveis rasos, que podem ser facilmente ionizados à temperatura ambiente, encontram-se ativos e contribuem para o armadilhamento de portadores. É importante ressaltar que, como já mencionado, um portador de carga armadilhado pode contribuir para a formação do sinal de corrente do detector se 0 tempo de desarmadilhamento for menor do que o tempo de coleta de cargas do sistema. 


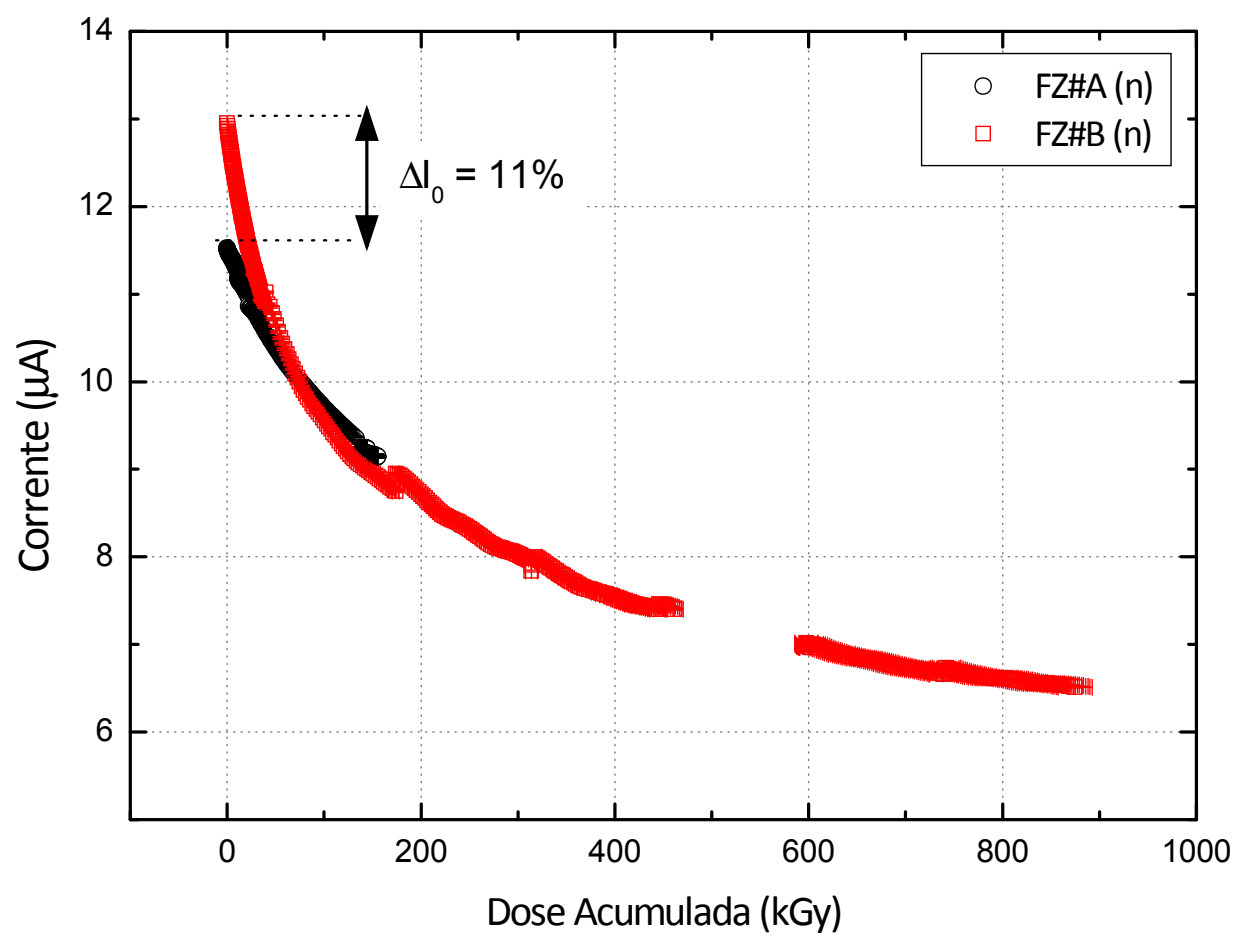

FIGURA 44 - Corrente elétrica gerada nos diodos FZ\#A e FZ\#B do tipo n, durante os processos de irradiação gama, em função da dose acumulada, normalizadas para a taxa de dose de 7,465 kGy/h. As barras de incerteza dos valores de corrente são menores do que os pontos e representam menos do que $1 \%$ das medições.

Para avaliar a resposta com a taxa de dose, os valores de corrente da amostra FZ\#B foram normalizados para a taxa de dose de 7,465 kGy/h. Essa normalização ou, correção, é obtida pela multiplicação da razão entre os valores das taxas de dose pelo valor de corrente que será corrigido. Os novos valores são apresentados na FIG. 44 em conjunto com os valores de corrente obtidos com o diodo FZ\#A. Uma diferença de aproximadamente $11 \%$ foi obtida entre os primeiros valores de corrente, I0, obtidos com as amostras A e B, como pode ser observado na FIG. 44. Parte dessa diferença pode estar relacionada com a não uniformidade da resposta dosimétrica do lote de diodos, que será, então, avaliado a seguir. Sobretudo, para uma análise concreta, pontos adicionais com diferentes valores de taxas de dose devem ser avaliados. Este tipo de estudo tem sido realizado também para diodos comerciais de Si $[61,65]$.

Na FIG. 45 são apresentadas as curvas dose resposta, ou seja, carga acumulada em função da dose acumulada, dos diodos FZ\#A e FZ\#B. As curvas são praticamente coincidentes evidenciando que, no tocante à carga, a resposta dos diodos independe da taxa de dose. 


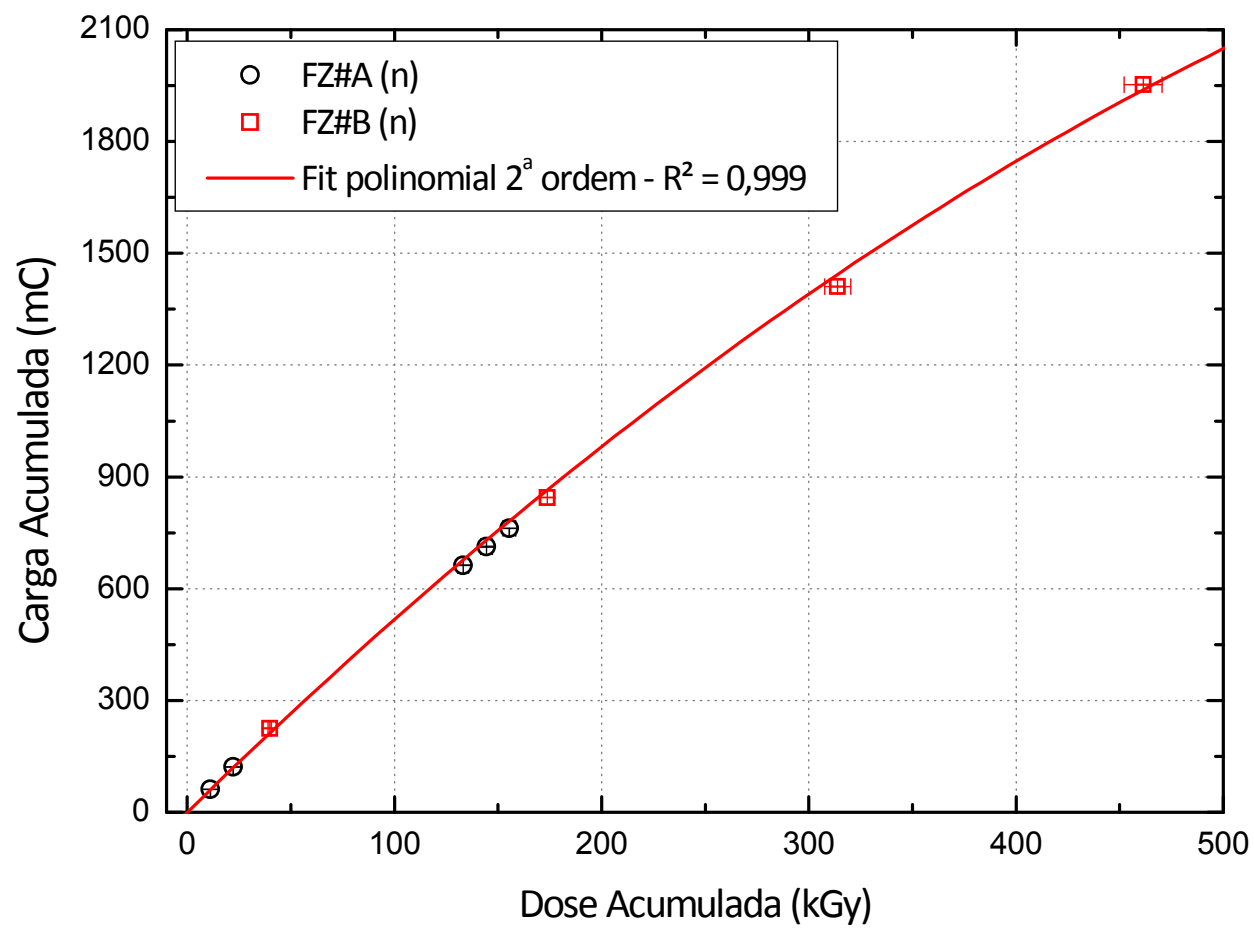

FIGURA 45 - Curva dose resposta das amostras FZ\#A e FZ\#B do tipo n, irradiadas com raios gama. As barras de incerteza dos valores de carga acumulada são menores do que os pontos e representam menos do que $0,5 \%$ da grandeza.

\subsubsection{Sinais de corrente e uniformidade de lote}

Os diodos B, C, D, E, F, G, H, I e J, ambos do tipo FZ e pertencentes ao mesmo lote, foram irradiados no CTR-IPEN/SP com valores de dose distintos, como pode ser observado na TAB. 2, e taxas de dose de 2,16 kGy/h e 2,18 kGy/h [66]. Os sinais de corrente registrados e corrigidos para a maior taxa de dose são apresentados na FIG. 46 para cada um dos diodos utilizados.

O coeficiente de variação máximo dos valores de corrente, registrados para uma dose de até $5 \mathrm{kGy}$, foi de aproximadamente 1,25\% indicando uma excelente uniformidade de resposta do lote de diodos para os limites de dose avaliados. Os valores de corrente registrados são apresentados de forma ampliada para a dose de até 5 kGy na FIG. 47 evidenciando a variação das medições indicada pelo coeficiente de 1,25\%. 
TABELA 2 - Valores de dose com os quais os 9 diodos FZ do tipo $\mathrm{n}$ pertencentes ao mesmo lote foram irradiados.

\begin{tabular}{cc} 
Diodo & Dose (kGy) \\
\hline C & 5 \\
D & 10 \\
E & 15 \\
F & 20 \\
G & 25 \\
H & 30 \\
I & 35 \\
B & 40 \\
J & 50 \\
\hline
\end{tabular}

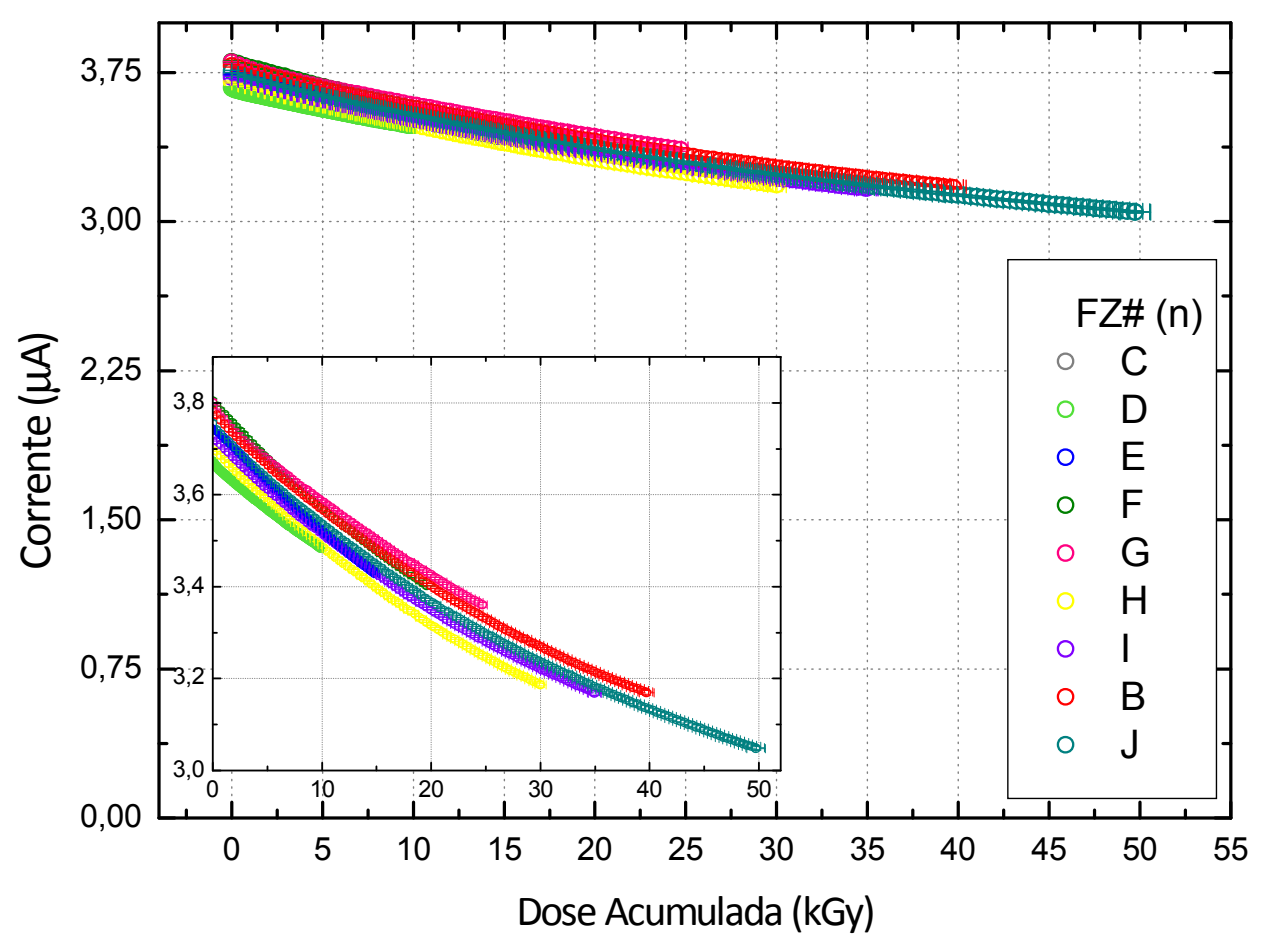

FIGURA 46 - Sinais de corrente obtidos com 9 diodos FZ do tipo n pertencentes ao mesmo lote e irradiados com valores distintos de dose. As barras de incerteza dos valores de corrente são menores do que os pontos e representam menos do que $1 \%$ das medições. 


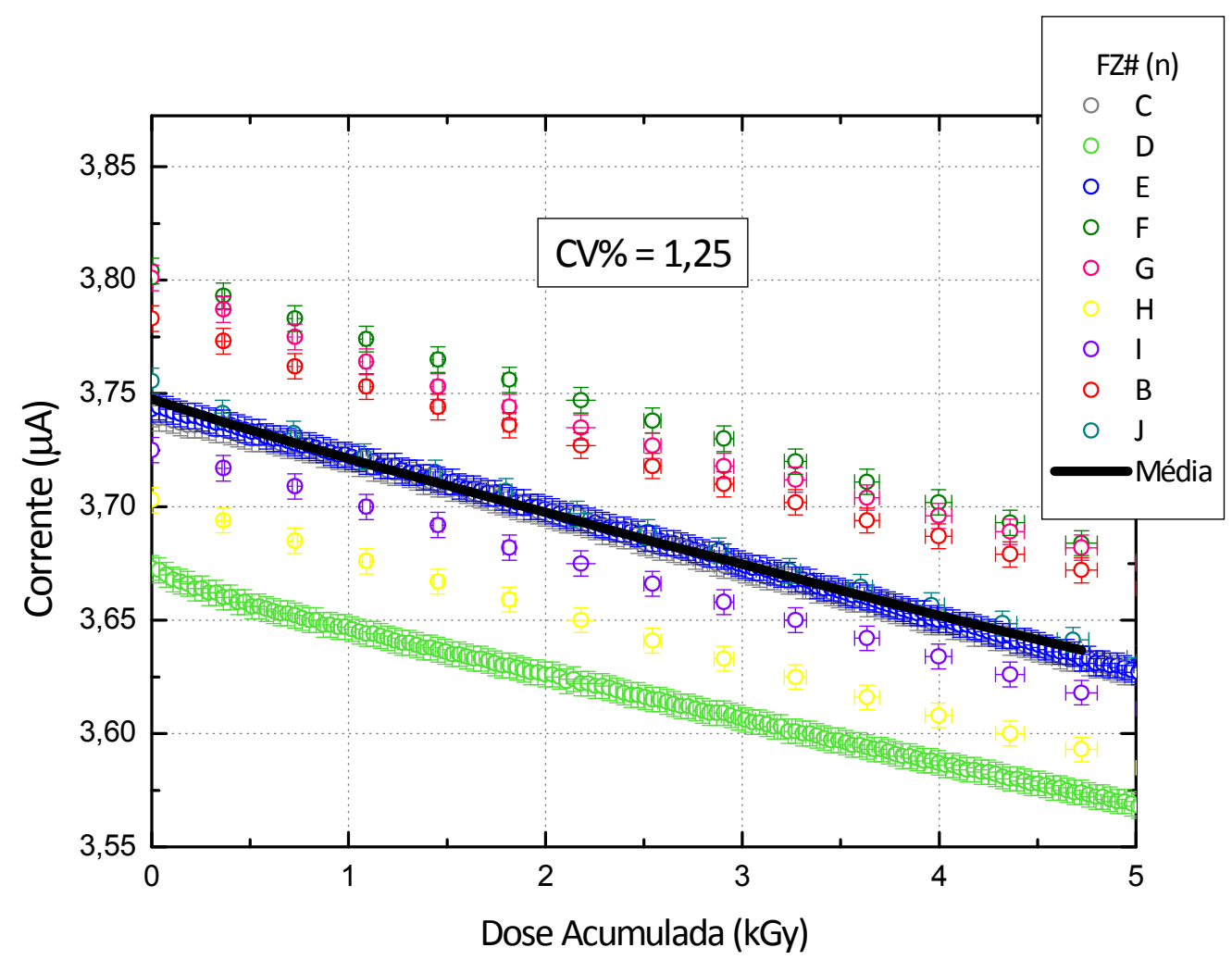

FIGURA 47 -Valores de corrente registrados com os 9 diodos FZ do tipo $\mathrm{n}$ pertencentes ao mesmo lote para a dose de até 5 kGy.

\subsubsection{Queda da sensibilidade em corrente em função da dose}

A queda dos valores de corrente e, portanto, sensibilidade dos diodos com o acúmulo de dose, representa um dos maiores impedimentos para a utilização destes dispositivos em dosimetria de processos com doses elevadas. Este problema pode ser contornado com a pré-irradiação, reduzindo a queda da sensibilidade e levando os dispositivos a regiões de estabilidade de resposta. Para determinar o valor exato da pré-dose é necessário, entre outros, conhecer o comportamento dos diodos no tocante à queda da sensibilidade. Este comportamento foi avaliado para diodos $\mathrm{FZ}$ e $\mathrm{MCz}$ do tipo $\mathrm{n}$ e $\mathrm{p}$ em reposta à radiação gama.

Os diodos $\mathrm{FZ \# B}$ e MCZ\#A foram irradiados com uma dose total de $873 \mathrm{kGy}$ com uma taxa de dose de 2,18 kGy/h enquanto que os diodos FZ\#K e $\mathrm{MCz \# B}$ receberam uma dose de $275 \mathrm{kGy}$ à taxa de dose de 2,52 kGy/h. Os valores de corrente normalizados, apresentados na FIG. 48, para os diodos $\mathrm{MCz}$, em função da dose acumulada, foram obtidos pela divisão dos valores de corrente registrados em um tempo arbitrário e aquele obtido no início do processo de irradiação. 


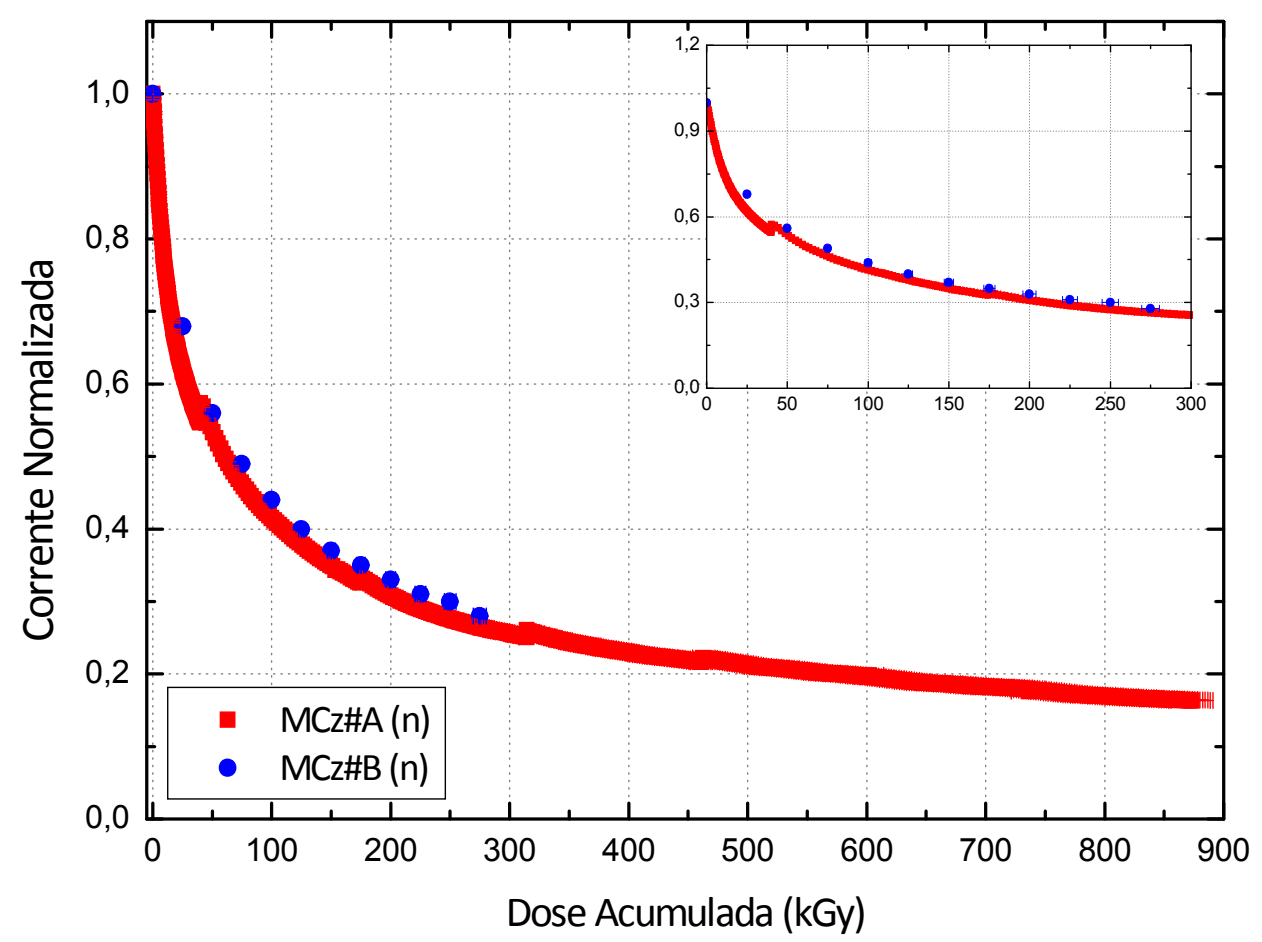

FIGURA 48 - Corrente normalizada em função da dose acumulada para os diodos MCz\#A e MCz\#B do tipo n. As barras de incerteza dos valores de corrente normalizada são menores do que os pontos e representam menos do que $0,5 \%$ da grandeza.

A queda da sensibilidade em corrente dos diodos MCz\#A e MCz\#B é reprodutível, de maneira que para uma dose acumulada de 250 kGy ambos os diodos perdem cerca de $70 \%$ da amplitude inicial de seus valores de corrente (FIG. 48). Como esperado e mencionado anteriormente, a queda da sensibilidade é menos significativa para valores de dose mais elevados. De fato, o coeficiente de variação dos valores de corrente, obtidos com o diodo MCz\#A, é menor do que $1 \%$ para valores de dose superiores a $700 \mathrm{kGy}$ reforçando a escolha deste valor como pré-dose para dispositivos semelhantes aos referenciados neste trabalho [25].

O mesmo estudo foi desenvolvido para os diodos FZ\#B e FZ\#K, com valores de resistividade nominal diferentes, $1,4 \mathrm{k} \Omega . \mathrm{cm}$ e $10 \mathrm{k} \Omega . \mathrm{cm}$, respectivamente. Os valores de corrente normalizada em função da dose acumulada são apresentados na FIG. 49 para os diodos FZ\#B e FZ\#K. De acordo com os resultados obtidos o diodo FZ\#B, com maior resistividade, apresenta uma queda menor na sensibilidade em corrente quando comparado ao diodo FZ\#K. Para uma dose total de $250 \mathrm{kGy}$ a sensibilidade do diodo FZ\#B reduz cerca de $36 \%$ do seu valor inicial enquanto para o diodo FZ\#K essa queda chega a $70 \%$. Essa 
diferença de comportamento está diretamente relacionada com a concentração efetiva de dopantes (resistividade) e os efeitos dos danos induzidos pela radiação [67]. Um diodo com resistividade baixa apresenta uma quantidade menor de dopantes e impurezas, como o oxigênio, por exemplo, cujo efeito benéfico para a resistência dos diodos aos danos induzidos pela radiação foi discutido anteriormente.

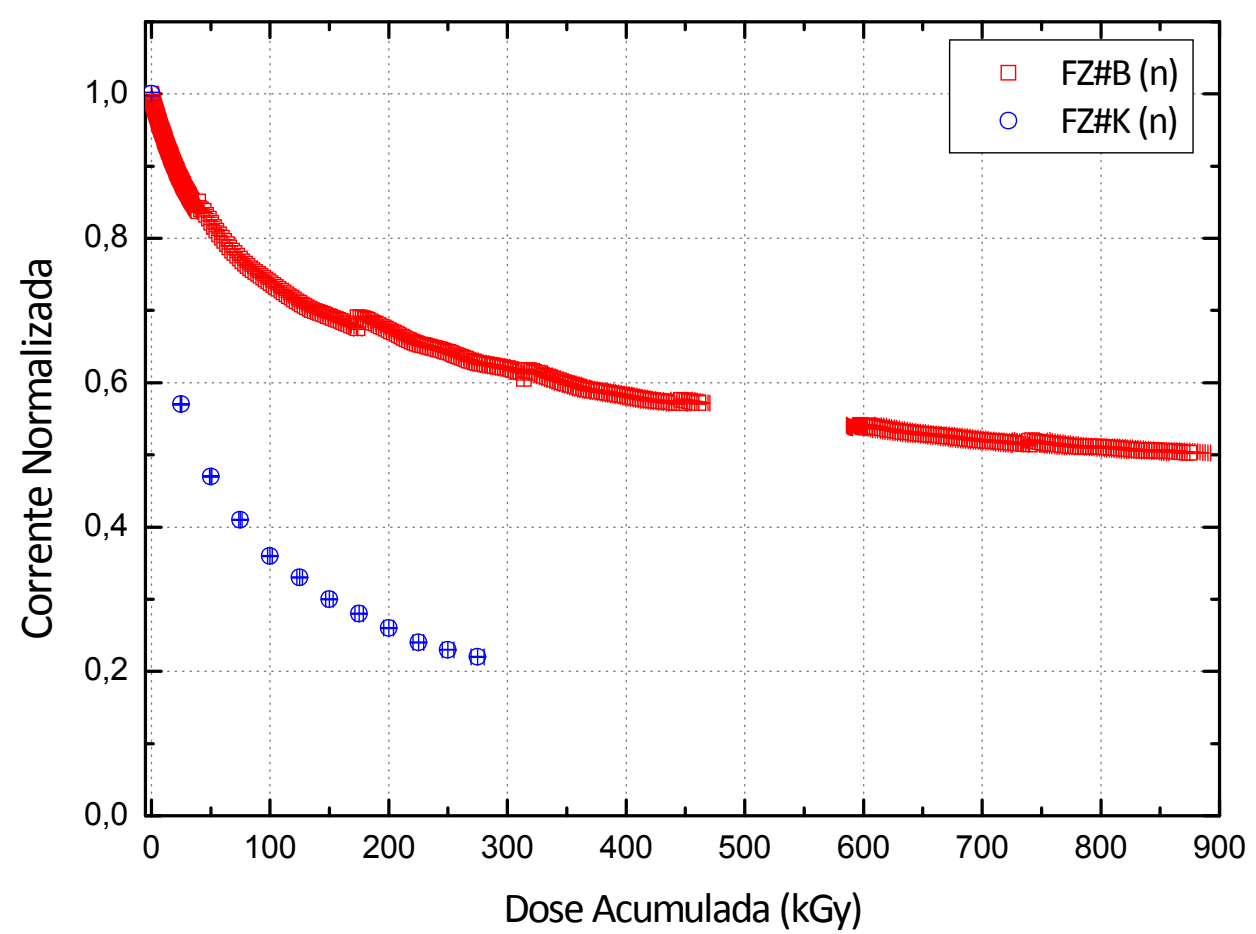

FIGURA 49 - Corrente normalizada em função da dose acumulada para os diodos FZ\#B e FZ\#K do tipo $n$. As barras de incerteza dos valores de corrente normalizada são menores do que os pontos e representam menos do que $0,5 \%$ da grandeza.

O tipo inicial de dopagem, $\mathrm{n}$ ou $\mathrm{p}$, também é mencionado amplamente na literatura como sendo um fator que contribui para a queda da sensibilidade dos diodos com o acúmulo de dose [36, 67-68]. Para avaliar essa influência os diodos FZ\#L (n) e FZ\#M (p), ambos pertencentes ao mesmo lote, foram irradiados com $45 \mathrm{kGy}$ de dose a uma taxa de 1,93 kGy/h. Os valores de corrente normalizada em função da dose acumulada são apresentados na FIG. 50 para as amostras L e M. Como esperado, o diodo FZ do tipo $\mathrm{p}$ apresenta uma queda inferior, 2,5\%, de sensibilidade quando comparado ao diodo do tipo n, $13 \%$.

A dependência da queda da sensibilidade com o tipo inicial de dopagem também foi avaliada para os diodos MCz\#A (n) e MCz\#C (p), pertencentes ao mesmo lote. $\mathrm{O}$ diodo $\mathrm{MCz} \# \mathrm{C}$ foi irradiado segundo o procedimento descrito no item 
4.3.1 com uma dose total de $179 \mathrm{kGy}$ a uma taxa de dose de 2,04 kGy/h. O diodo MCz\#A foi irradiado com uma dose total de $873 \mathrm{kGy}$, conforme o procedimento descrito anteriormente, porém, para comparação com o diodo $\mathrm{MCz} \# \mathrm{C}$, os valores de corrente normalizada são apresentados para doses de até 175 kGy na FIG. 51.

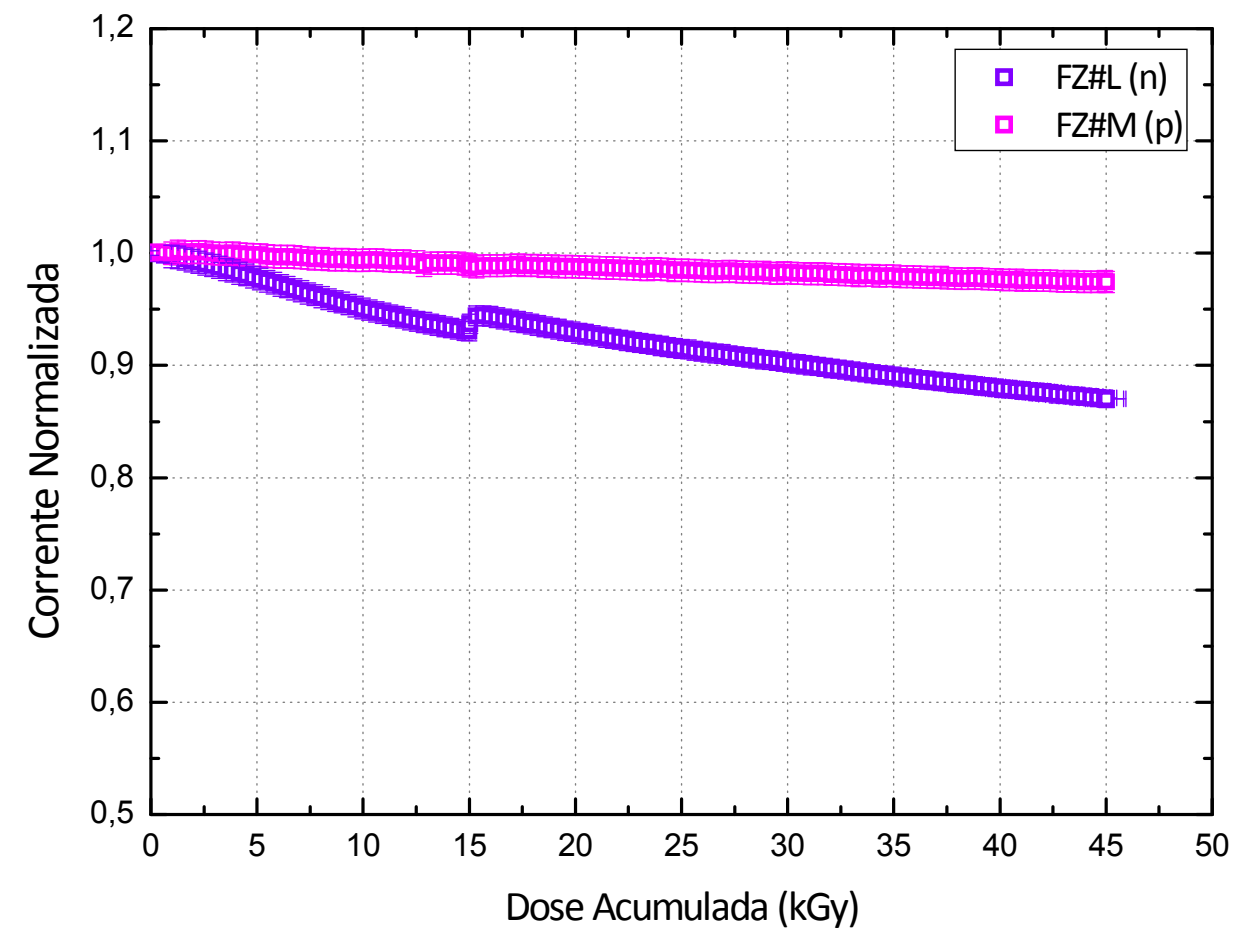

FIGURA 50 - Corrente normalizada em função da dose acumulada para os diodos FZ\#L do tipo $n$ e FZ\#M do tipo $p$. As barras de incerteza dos valores de corrente normalizada são menores do que os pontos e representam menos do que $0,5 \%$ da grandeza.

O comportamento dos diodos $\mathrm{MCz} n$ e p é similar ao dos diodos $\mathrm{FZ} \mathrm{n}$ e $\mathrm{p}$, de maneira que, como mencionado, a queda da sensibilidade com o acúmulo de dose é menos significativa para diodos do tipo $\mathrm{p}$. Essa diferença está relacionada com o tipo de portador minoritário em cada um dos casos, lacunas no diodo tipo $\mathrm{n}$ e elétrons no diodo tipo p. As lacunas possuem uma seção de choque de captura por centros R-G superior à dos elétrons. Essas diferenças podem ser maiores ou menores dependendo do tipo de radiação que incide nos diodos [36, 67-68].

Observou-se ainda que a dependência da queda da sensibilidade com o tipo de dopagem é mais significativa para diodos $\mathrm{MCz}$ do que para diodos FZ. Para a dose de $45 \mathrm{kGy}$ a diferença entre os valores de corrente normalizada das amostras do tipo n e p é de aproximadamente $37 \%$ e $10 \%$ para diodos MCz e FZ respectivamente. 


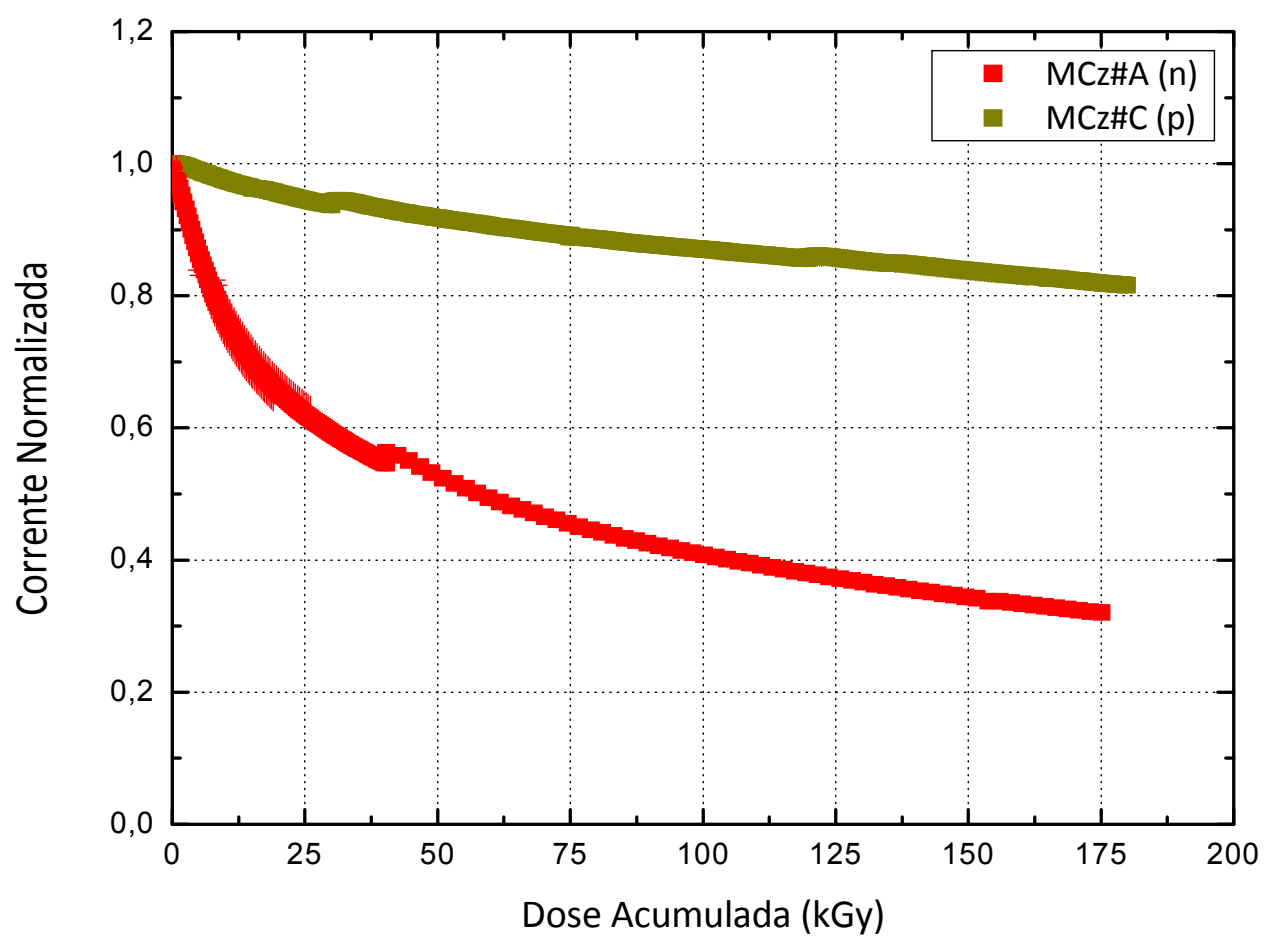

FIGURA 51 - Corrente normalizada em função da dose acumulada para os diodos MCz\#A do tipo $n$ e MCz\#C do tipo p. As barras de incerteza dos valores de corrente normalizada são menores do que os pontos e representam menos do que $0,5 \%$ da grandeza.

\subsubsection{Curva dose resposta}

A curva dose resposta dos diodos MCz\#A e MCz\#B, FZ\#B e FZ\#K do tipo n são apresentadas nas FIG. 52 e 53, respectivamente. Os valores de carga foram obtidos por meio da integração dos sinais de corrente em função do tempo.

Sabe-se que a resposta em carga dos diodos não é linear com a dose acumulada, entretanto, o modelo teórico que descreve seu comportamento ainda é desconhecido [24-26]. Resultados anteriormente obtidos em nosso grupo indicam que a resposta dos diodos pode ser ajustada a polinômios de segunda ordem para dispositivos que tenham sido submetidos ao tratamento de pré-irradiação. Para dispositivos que não foram pré-irradiados, como aqueles cujas respostas foram apresentadas nas FIG. 52 e 53, a curva dose resposta é melhor ajustada a polinômios de ordem maior ou igual a dois, dependendo dos valores de dose acumulada alcançados [24-26].

As curvas dose respostas dos diodos MCz, apresentadas na FIG. 52, são coincidentes e representam, novamente, a boa reprodutibilidade de resposta de diodos do mesmo tipo irradiados com raios gama. Por outro lado, a diferença entre as curvas dose respostas dos diodos FZ, FIG. 53, que é mais significativa 
para valores de dose mais elevados, como esperado é decorrente da diferença entre os valores de resistividade de cada uma das amostras.

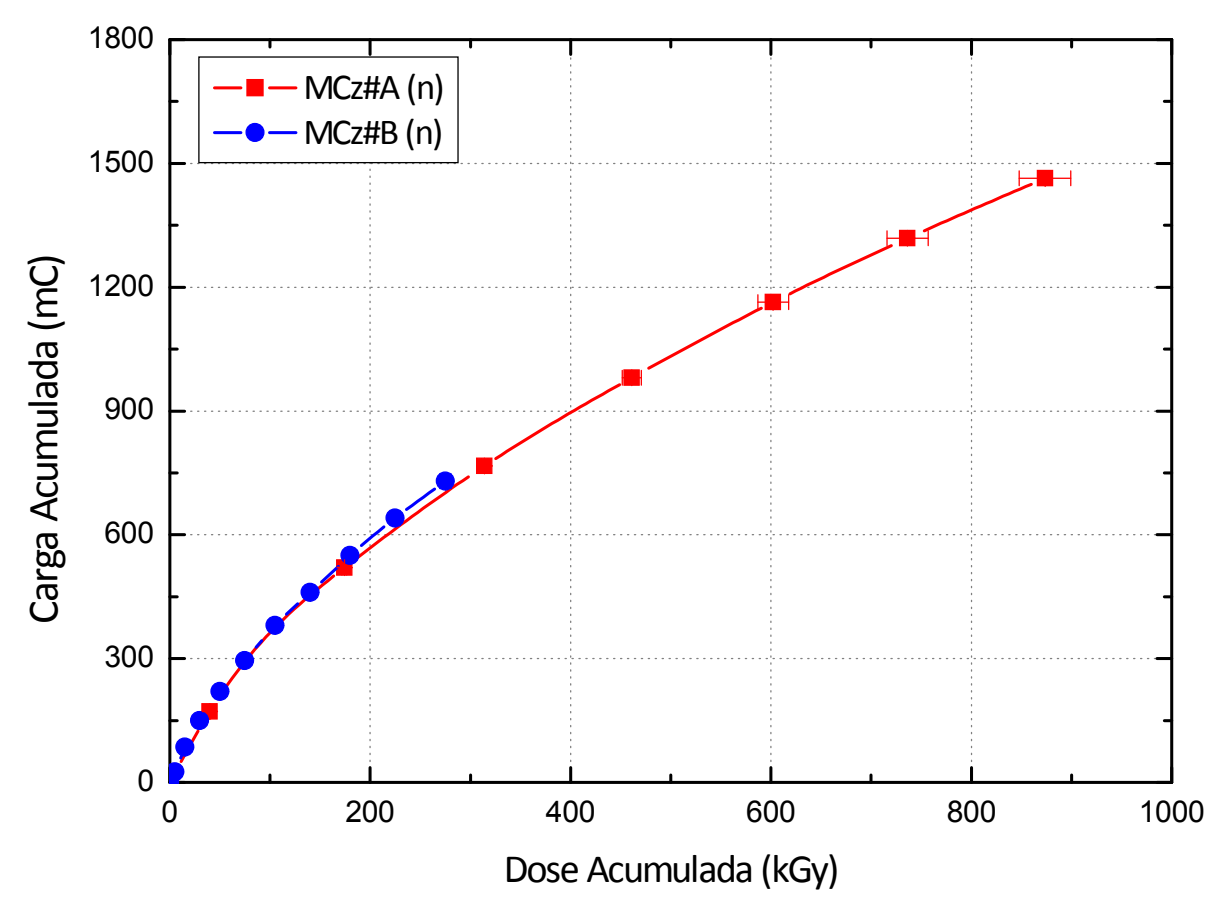

FIGURA 52 - Curvas dose respostas dos diodos MCz\#A e MCz\#B do tipo $n$ irradiados com raios gama. As barras de incerteza dos valores de carga acumulada são menores do que os pontos e representam menos do que $0,5 \%$ da grandeza.

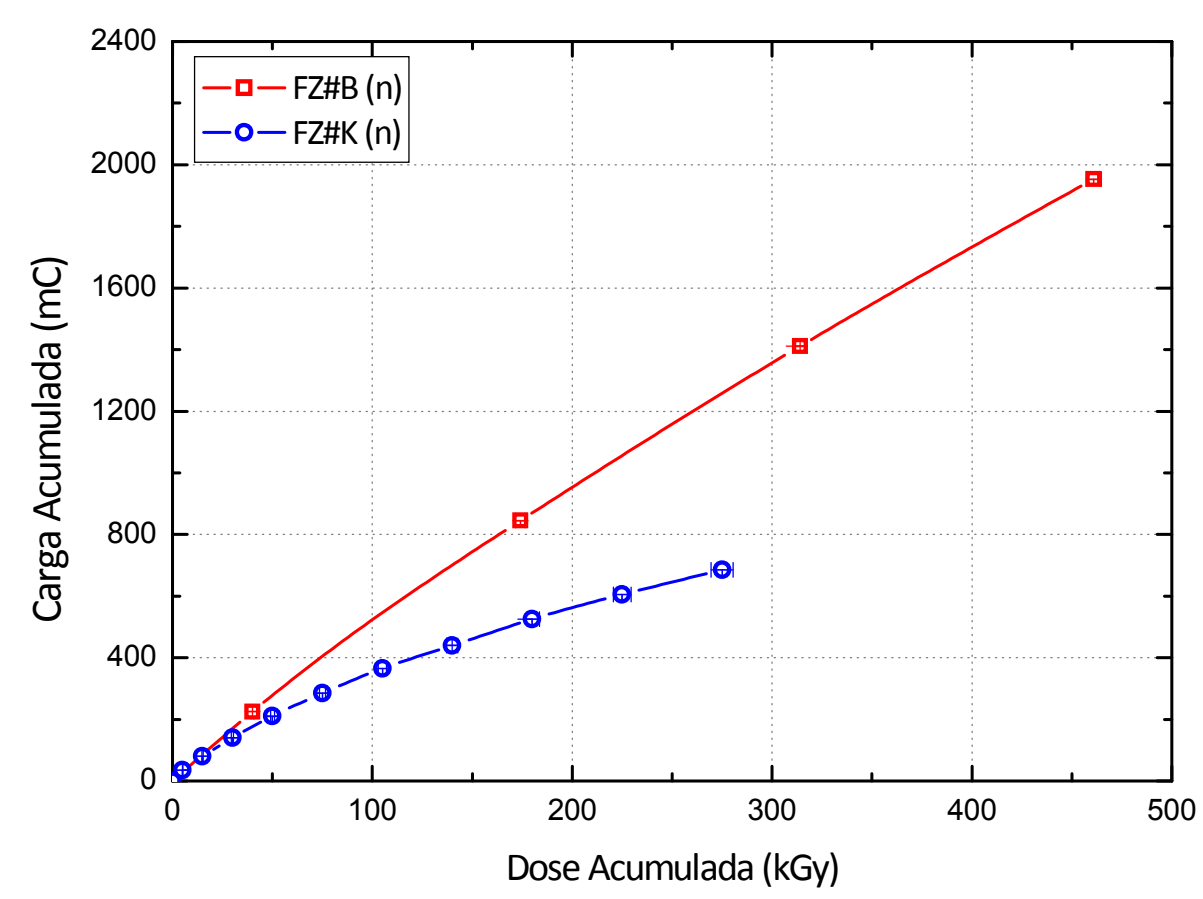

FIGURA 53 - Curvas dose respostas dos diodos FZ\#B e FZ\#K do tipo $n$ irradiados com raios gama. As barras de incerteza dos valores de carga acumulada são menores do que os pontos e representam menos do que $0,5 \%$ da grandeza. 


\subsubsection{Danos induzidos pela radiação}

O estudo da influência dos danos induzidos pela radiação gama nas propriedades elétricas de diodos $\mathrm{FZ}$ e $\mathrm{MCz}$ do tipo $\mathrm{n}$, foi amplamente avaliada em trabalhos anteriores [25-26]. De acordo com os resultados obtidos nestes trabalhos nenhuma alteração significativa nos valores de corrente de fuga e tensão de depleção total (capacitância) foi observada para valores de dose de até 900 kGy, aproximadamente. Entretanto, como discutido previamente no item 3.2.3.1 deste trabalho, além da corrente de fuga e tensão de depleção a CCE também é amplamente afetada pelos danos de radiação. Embora a análise deste parâmetro seja de interesse maior para diodos irradiados com elétrons, no primeiro momento, a técnica, que será descrita a seguir, foi utilizada a caráter de validação para um diodo irradiado com raios gama.

\subsubsection{Espectrometria (CCE)}

A CCE está relacionada com a quantidade de cargas coletada por um diodo e pode ser extraída diretamente da diferença entre espectros obtidos com estes dispositivos para valores diferentes de dose acumulada. Por este motivo este parâmetro afeta também a resolução dos espectros que é, neste trabalho, o parâmetro de estudo. Para isso, seguindo o procedimento descrito no item 4.3.4, o diodo MCZ\#D foi irradiado com raios gama em três etapas de aproximadamente $123 \mathrm{kGy}$ de dose cada a uma taxa de 1,374 kGy/h. Este diodo já havia sido irradiado com 50 kGy de dose para um estudo anterior com raios gama. Os espectros, adquiridos durante uma hora, são apresentados na FIG. 54 para os diferentes valores de dose acumulada.

A diferença entre os canais dos picos principais, observados para cada valor de dose acumulada, não está dentro do intervalo de incerteza associado. Certamente uma dispersão em energia está relacionada com o problema, que, por sua vez, pode ser atribuída a diferenças na posição relativa do diodo no interior da câmara de vácuo. Todo o aparato foi projetado com o mínimo de folga possível entre a sonda dosimétrica e o suporte para a mesma, na tampa da câmara, entretanto, qualquer espaçamento adicional pode levar a alteração do ângulo fontedetector quando se faz vácuo. O resultado seria uma diferença na energia efetiva da partícula alfa, incidente no volume sensível do diodo.

A resolução, calculada a partir da Eq. 103, é apresentada na FIG. 55 como função da dose acumulada [30]. 


$$
\mathrm{R}(\%)=\frac{\mathrm{FWHM}}{\mathrm{H}_{0}} \cdot 100
$$

sendo FWHM (full width at half maximum) a largura do pico à meia altura e $\mathrm{H}_{0} \mathrm{O}$ canal do pico principal.

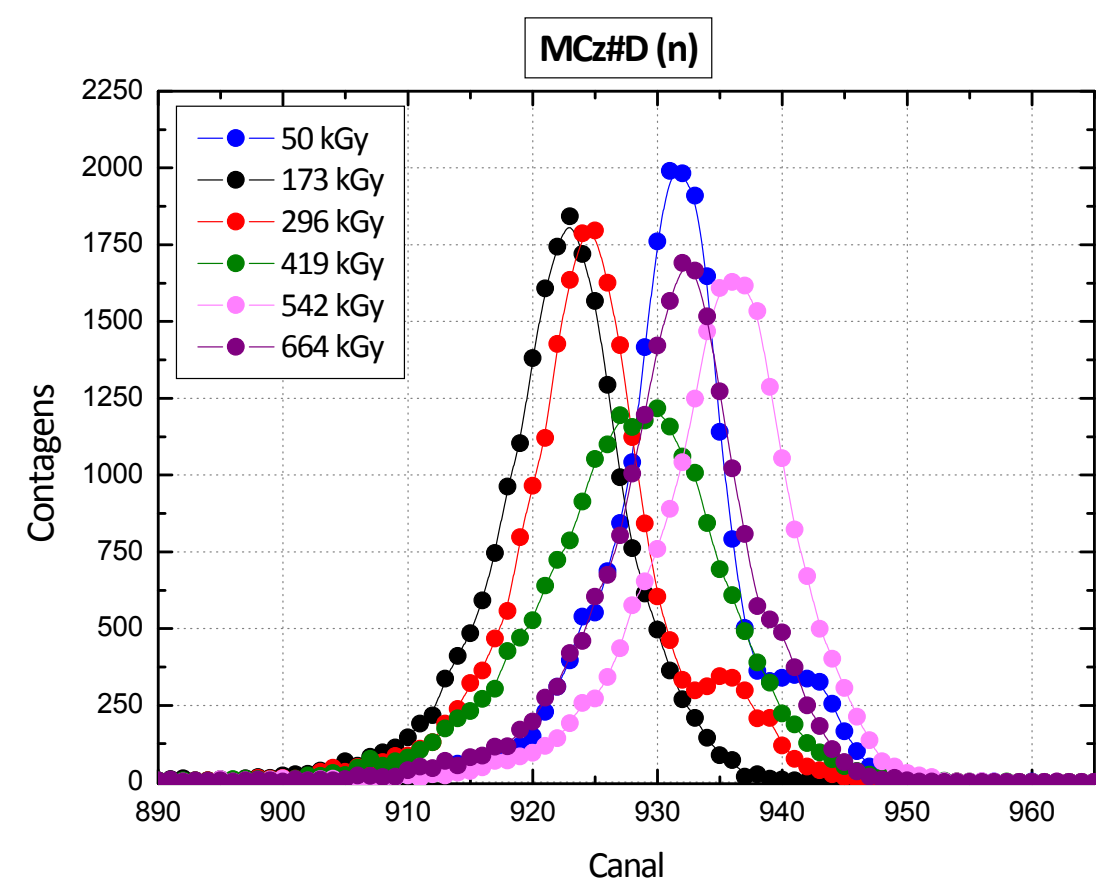

FIGURA 54 - Espectros alfa do ${ }^{241}$ Am obtidos com o diodo MCz\#D do tipo n, irradiado com raios gama, para diferentes valores de dose acumulada.

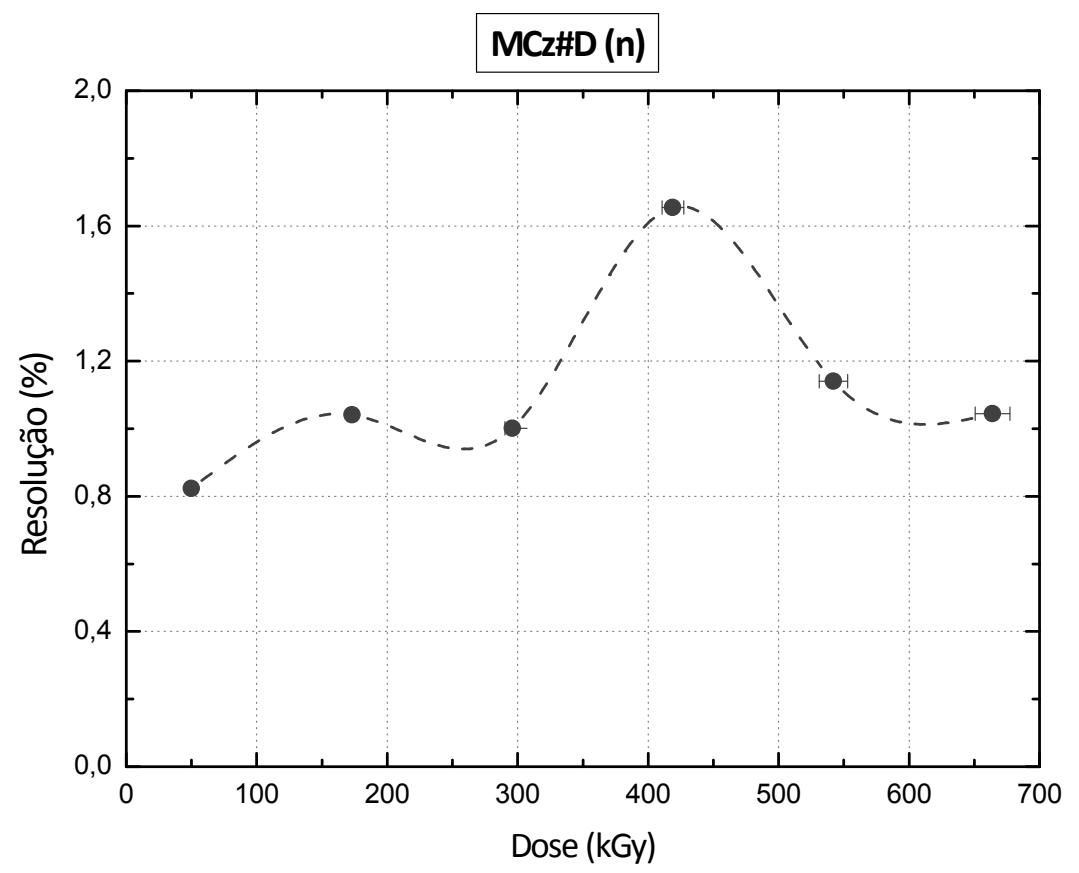

FIGURA 55 - Resolução em função da dose acumulada obtida por meio dos espectros alfa registrados com o diodo $M C z \# D$ do tipo $n$ irradiado com raios gama. 
A resolução do diodo $\mathrm{MCz} \# \mathrm{D}$ permanece praticamente inalterada exceto para o valor de 419 kGy de dose acumulada. Não foram observadas alterações que possam estar relacionadas à influência dos danos induzidos pela radiação, contudo, outros parâmetros devem ser levados em consideração.

Diversos fatores são apontados por influenciarem a resolução do diodo como detector de radiação, entre eles o ruído eletrônico. As fontes de ruído eletrônico em espectrometria das radiações são divididas em duas principais categorias: ruídos em série e paralelo. A corrente de fuga dos diodos é, por sua vez, um fator contribuinte do ruído em paralelo e em situações extremas pode afetar amplamente a resolução do detector [69]. Com o intuito de avaliar qualquer influência deste parâmetro, além do levantamento dos espetros alfa, a corrente de fuga do diodo MCz\#D foi monitorada após cada etapa de irradiação em função da tensão de polarização reversa (curvas IV), FIG. 56.

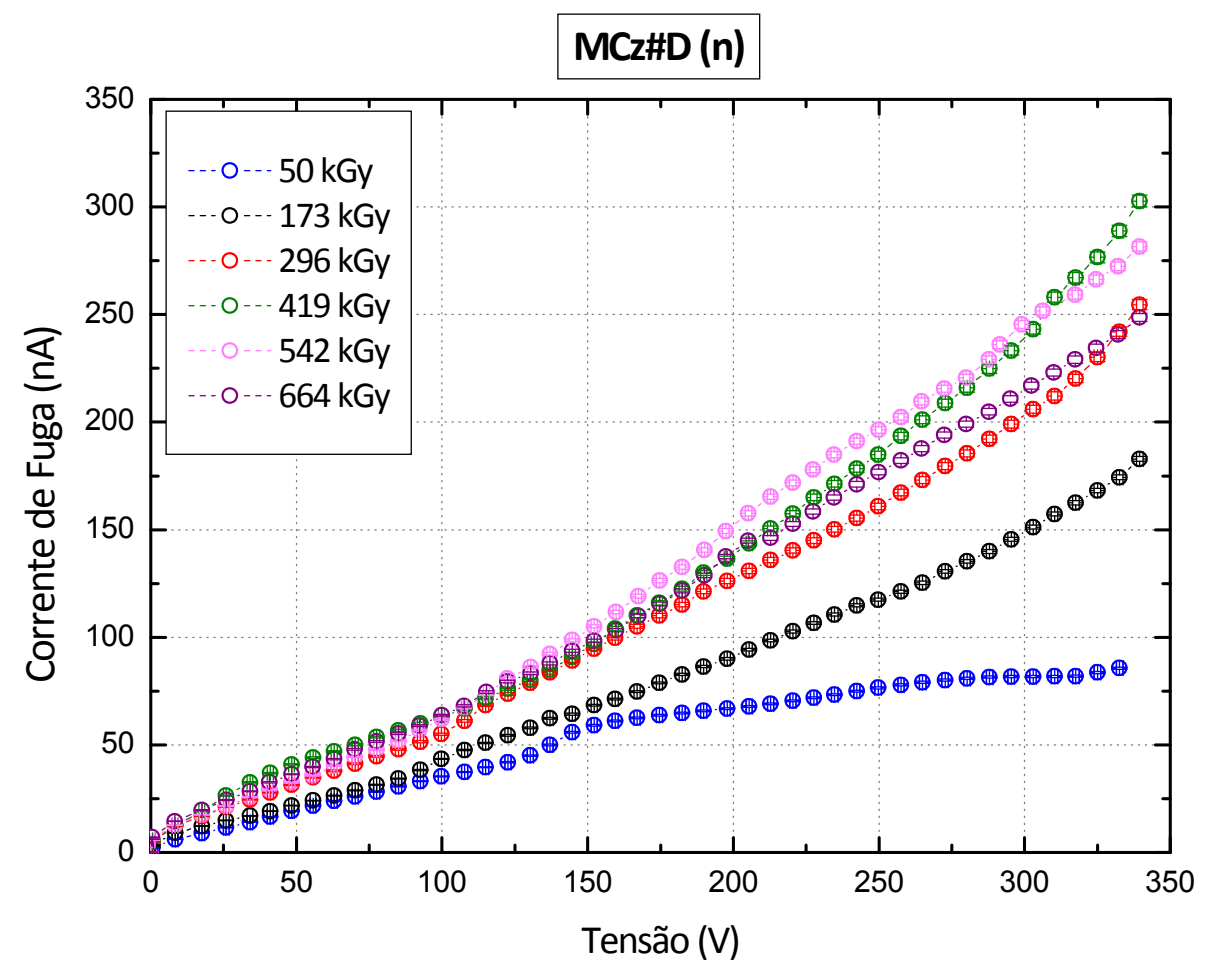

FIGURA 56 - Curvas IV do diodo MCz\#D do tipo n obtidas após cada intervalo de irradiação gama. As barras de incerteza dos valores de corrente de fuga são menores do que os pontos e representam menos do que $0,5 \%$ das medições.

Como os espectros foram registrados para uma tensão de polarização reversa de 180 V, na FIG. 57 são apresentados os valores de corrente de fuga para este mesmo valor de tensão em função da dose acumulada. 


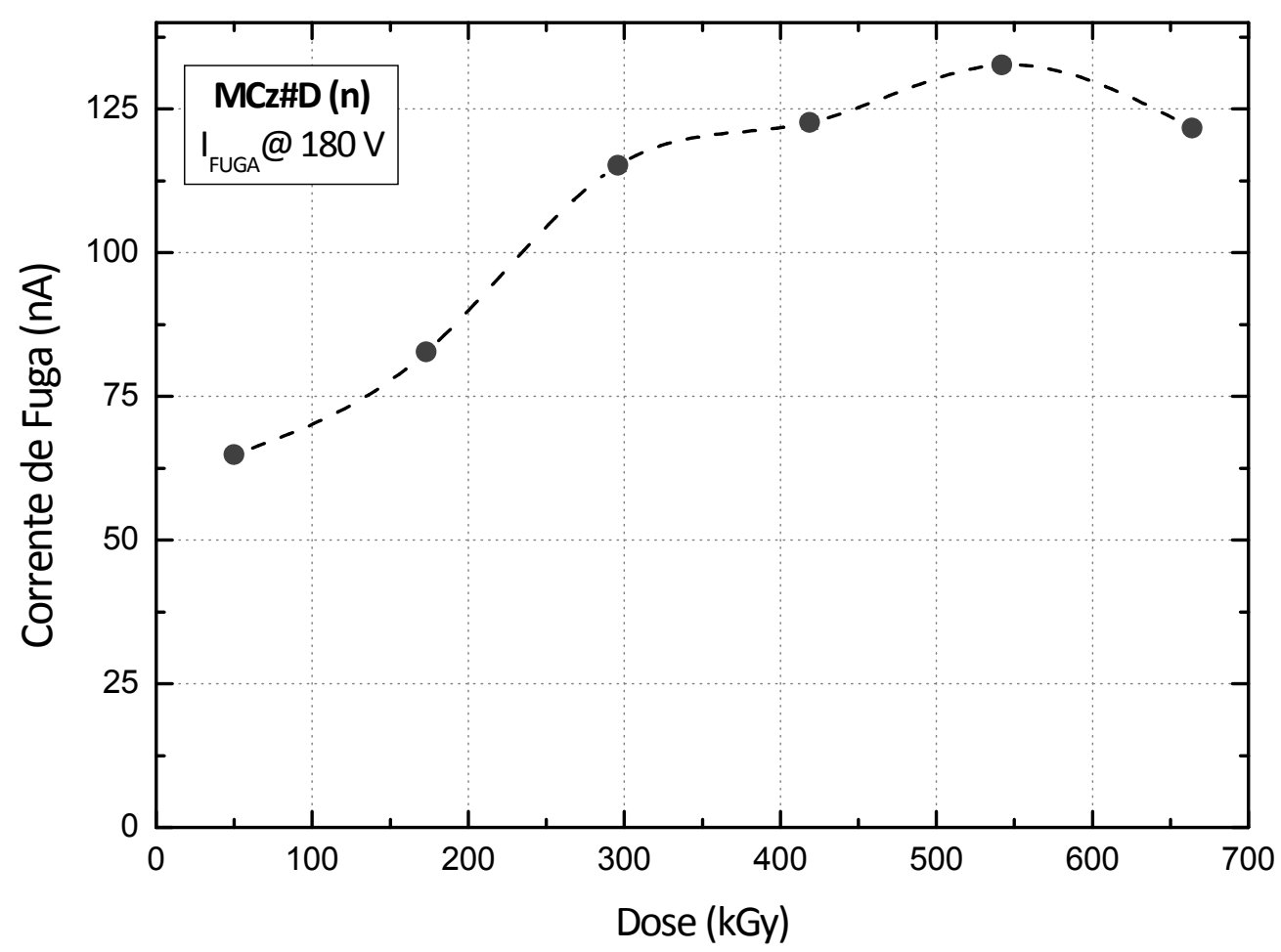

FIGURA 57 - Corrente de fuga do diodo MCz\#D do tipo $\mathrm{n}$ irradiado com raios gama, para a tensão de polarização reversa de $180 \mathrm{~V}$, em função da dose acumulada. As barras de incerteza dos valores de corrente de fuga são menores do que os pontos e representam menos do que $0,5 \%$ das medições.

De fato, observa-se um aumento da corrente de fuga, a $180 \mathrm{~V}$, com o aumento da dose acumulada. Contudo, como o comportamento da corrente de fuga para este valor de tensão não é similar ao comportamento da resolução, não é possível atribuir à corrente toda a contribuição para as diferenças relatadas.

As instabilidades nos resultados obtidos indicam que para que a técnica proposta possa ser utilizada para avaliar a influência dos danos induzidos pela radiação nos diodos, um estudo mais sistemático do aparato e eletrônica deve ser realizado. Além disso, a reprodutibilidade deve ser avaliada com diversos diodos irradiados sob as mesmas condições, descartando assim qualquer problema nos dispositivos. Como o método de espectrometria não pôde ser validado não será utilizado para a avaliação dos danos induzidos por elétrons nos diodos de $\mathrm{Si}$, de acordo com o objetivo inicial da técnica.

\subsection{Elétrons}

Aqui são apresentados os resultados obtidos para diodos irradiados com elétrons, seguido de suas discussões. 


\subsubsection{Resposta em função da taxa de dose}

A resposta em corrente dos diodos FZ\#E e MCz\#E foi estudada em função da taxa de dose em um intervalo de 2,0 kGy/s (corrente de feixe de 0,5 mA) a $20 \mathrm{kGy} / \mathrm{s}(5,0 \mathrm{~mA})$. O estudo foi repetido três vezes para diferentes valores de dose (550 kGy; 850 kGy; 1060 kGy). Os valores de corrente apresentados nas FIG. 58 e 59 correspondem aos de pico (valor máximo) registrados durante a passagem do diodo sob o feixe de elétrons.

É possível notar que, embora bastante instável, para taxas de dose inferiores a $4 \mathrm{kGy} / \mathrm{s}$ a resposta em corrente dos diodos é proporcional à taxa de dose. A saturação dos valores de corrente para taxas de dose elevadas já era esperada como consequência da contribuição dos efeitos de empilhamento de pulsos e de recombinação ou perda de portadores de carga em armadilhas [24,66]. De fato, a comparação entre as curvas de corrente em função da taxa de dose evidencia a contribuição da dose acumulada na geração de defeitos com a consequente queda de sensibilidade em corrente nos dispositivos. No entanto, estes resultados indicam a possibilidade de investigação da resposta dosimétrica destes diodos nas condições usuais de operação (corrente e velocidade da esteira) do acelerador de elétrons.

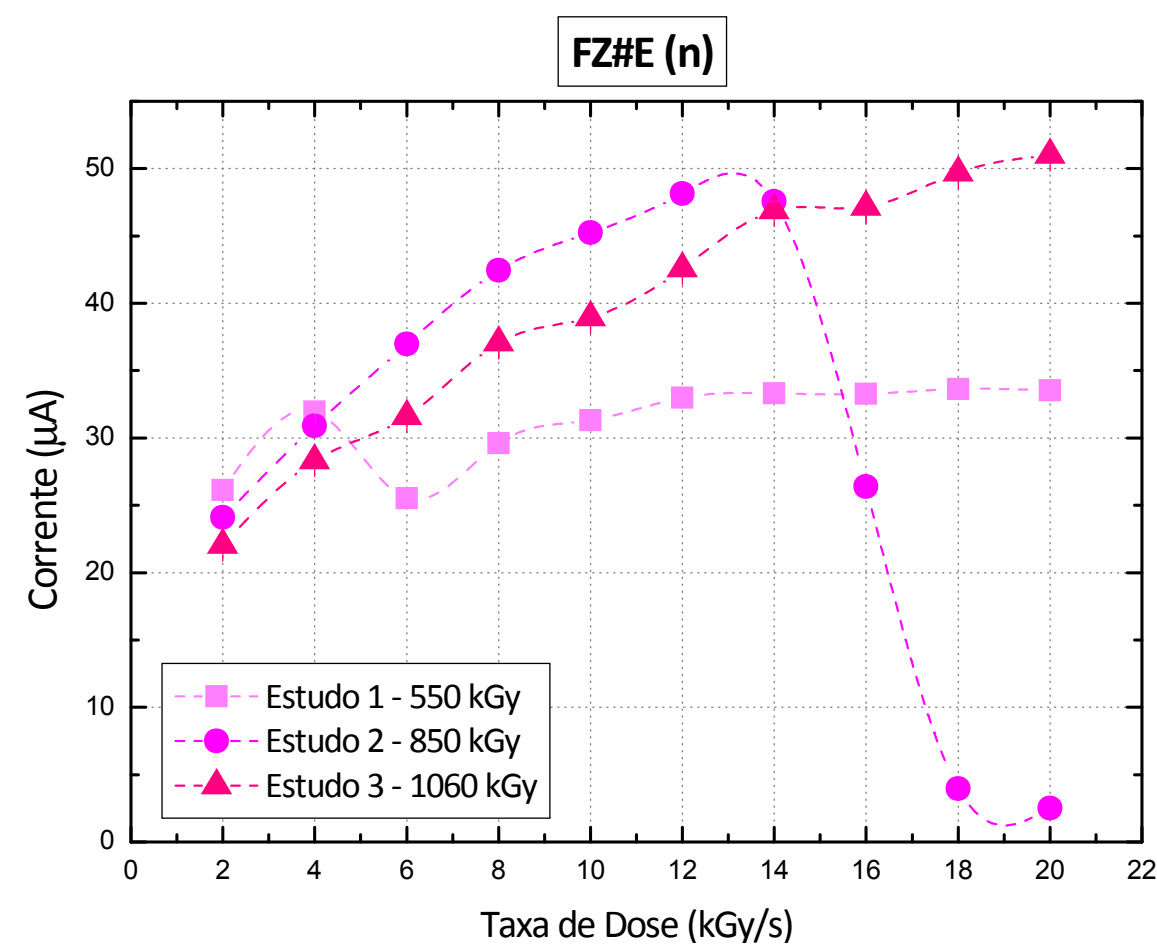

FIGURA 58 - Corrente do diodo FZ\#E do tipo $n$ em função da taxa de dose do acelerador de elétrons. As barras de incerteza dos valores de corrente são menores do que os pontos e representam menos do que $1 \%$ das medições. 


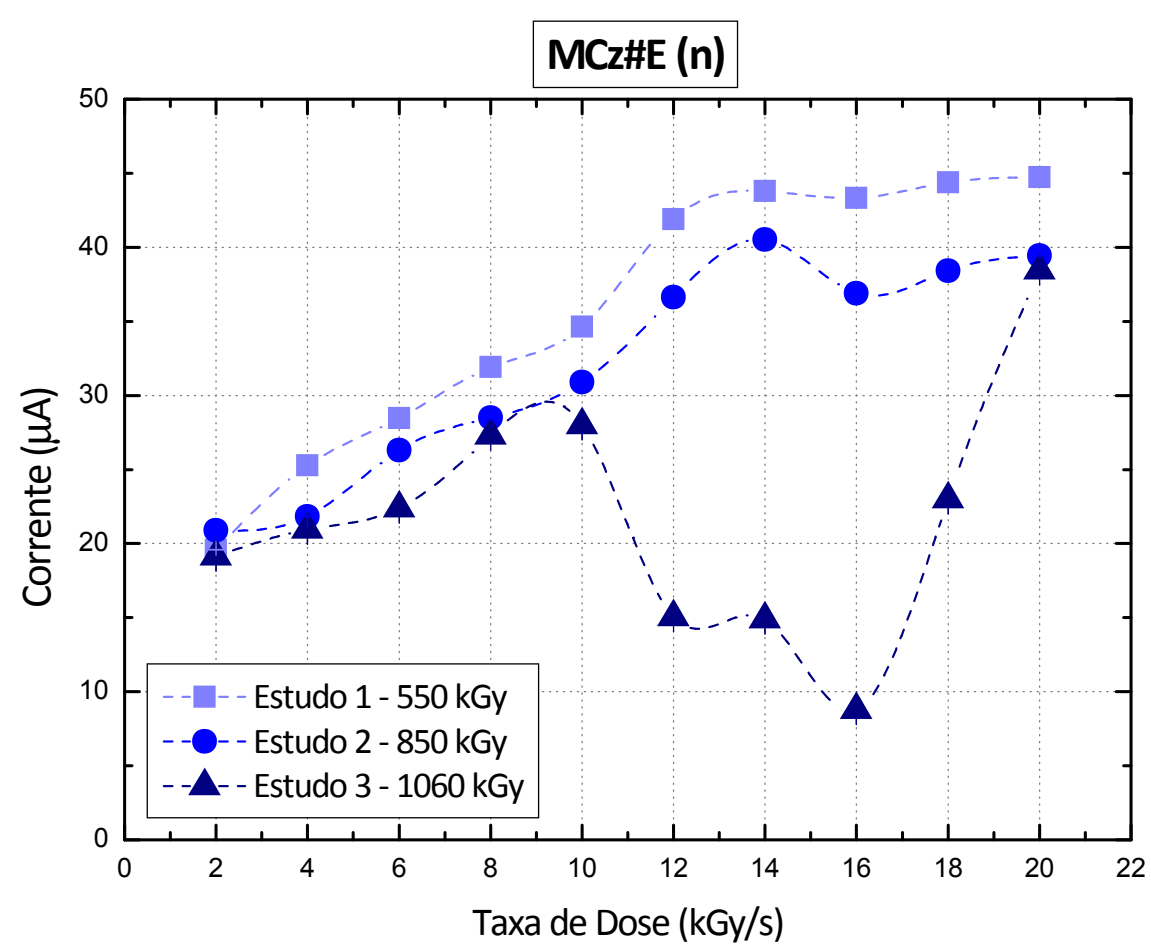

FIGURA 59 - Corrente do diodo MCz\#E do tipo $\mathrm{n}$ em função da taxa de dose do acelerador de elétrons. As barras de incerteza dos valores de corrente são menores do que os pontos e representam menos do que $1 \%$ das medições.

\subsubsection{Sinais de corrente}

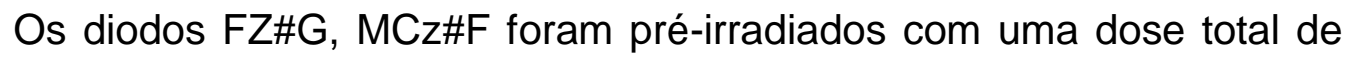
500 kGy e em seguida irradiados com uma dose total de 349 kGy e 178 kGy, respectivamente. Os sinais de corrente registrados são apresentados nas FIG. 60 e 61 para diferentes valores de dose. O primeiro pico observado corresponde ao movimento de "ida" do diodo com relação ao feixe de elétrons assim como o segundo pico representa o movimento de "volta". O valor da pré-dose foi definido com base em estudos anteriores e contempla a não deterioração da resposta dos diodos devido à influência dos danos de radiação, como será apresentado adiante.

Na FIG. 61 é possível observar uma diminuição abrupta do valor de corrente de pico obtida durante o percurso de "volta" quando comparado ao percurso de "ida", para o diodo MCz\#F. Instabilidades como essa, que foram observadas inúmeras vezes durante os procedimentos de irradiação dos diodos $F Z \# G$ e MCZ\#F, estão diretamente relacionadas com a deterioração significativa dos contatos elétricos e metalização da face $\mathrm{p}^{+}$dos dispositivos. Por este motivo os contatos elétricos foram refeitos diversas vezes, interrompendo o processo de irradiação. Para avaliar o quanto a deterioração relatada afeta a capacidade de resposta destes dispositivos, os diodos FZ\#G e MCz\#F foram irradiados 
simultaneamente com raios gama, segundo o procedimento descrito no item 4.3.1, em um estudo de repetibilidade. O procedimento foi escolhido uma vez que a forma do sinal de corrente dos diodos devido à incidência de radiação gama é conhecida e amplamente estudada em nosso grupo. As amostras foram irradiadas com uma taxa de dose de 1,272 kGy/h em 14 etapas de $1 \mathrm{kGy}$ de dose cada, sendo 7 etapas realizadas em um dia e as demais realizadas no dia seguinte. Durante todo o tempo, aproximadamente dois meses, decorrido entre o término dos procedimentos de irradiação com elétrons e o estudo de repetibilidade gama os diodos foram armazenados no laboratório em temperatura ambiente. Os sinais de corrente registrados são apresentados na FIG. 62.

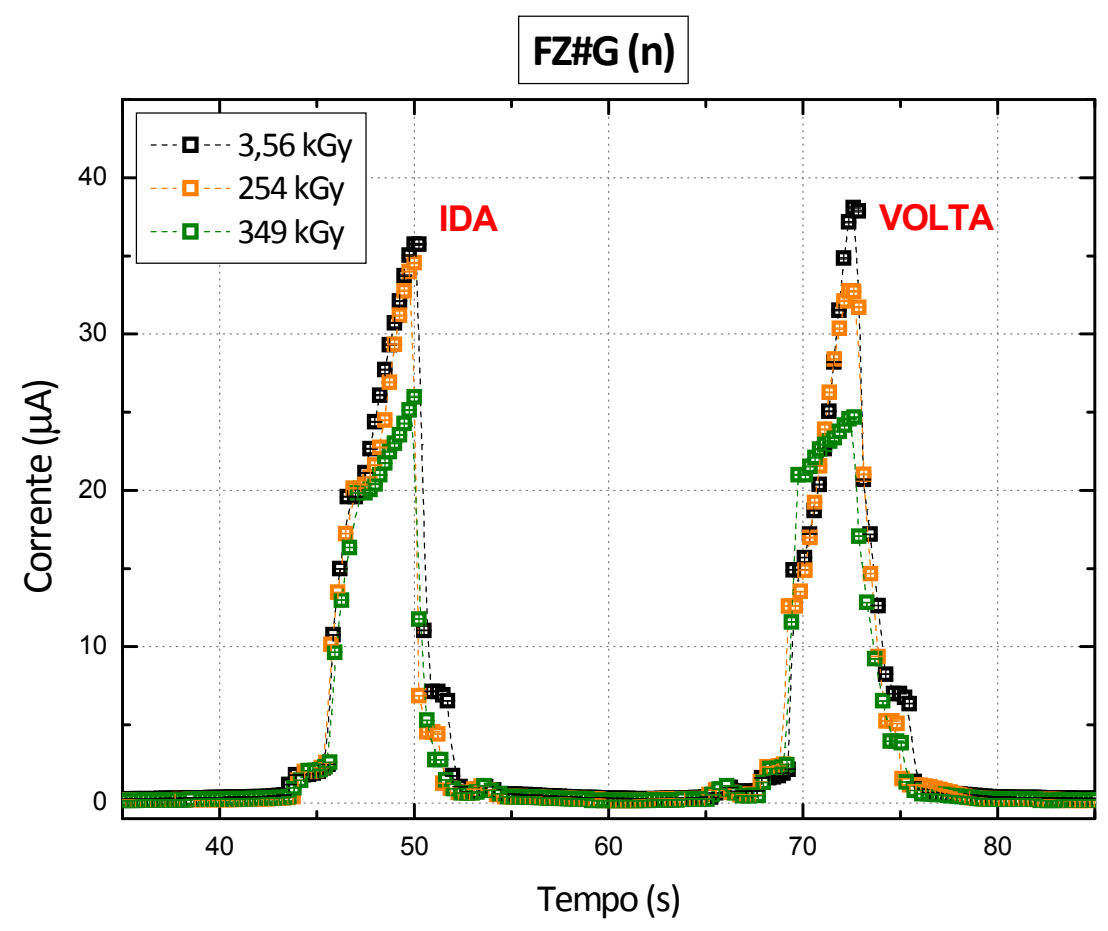

FIGURA 60 - Sinais de corrente em função do tempo obtidos com o diodo FZ\#G do tipo $\mathrm{n}$ para diferentes valores de dose. As barras de incerteza dos valores de corrente são menores do que os pontos e representam menos do que $1 \%$ das medições. 


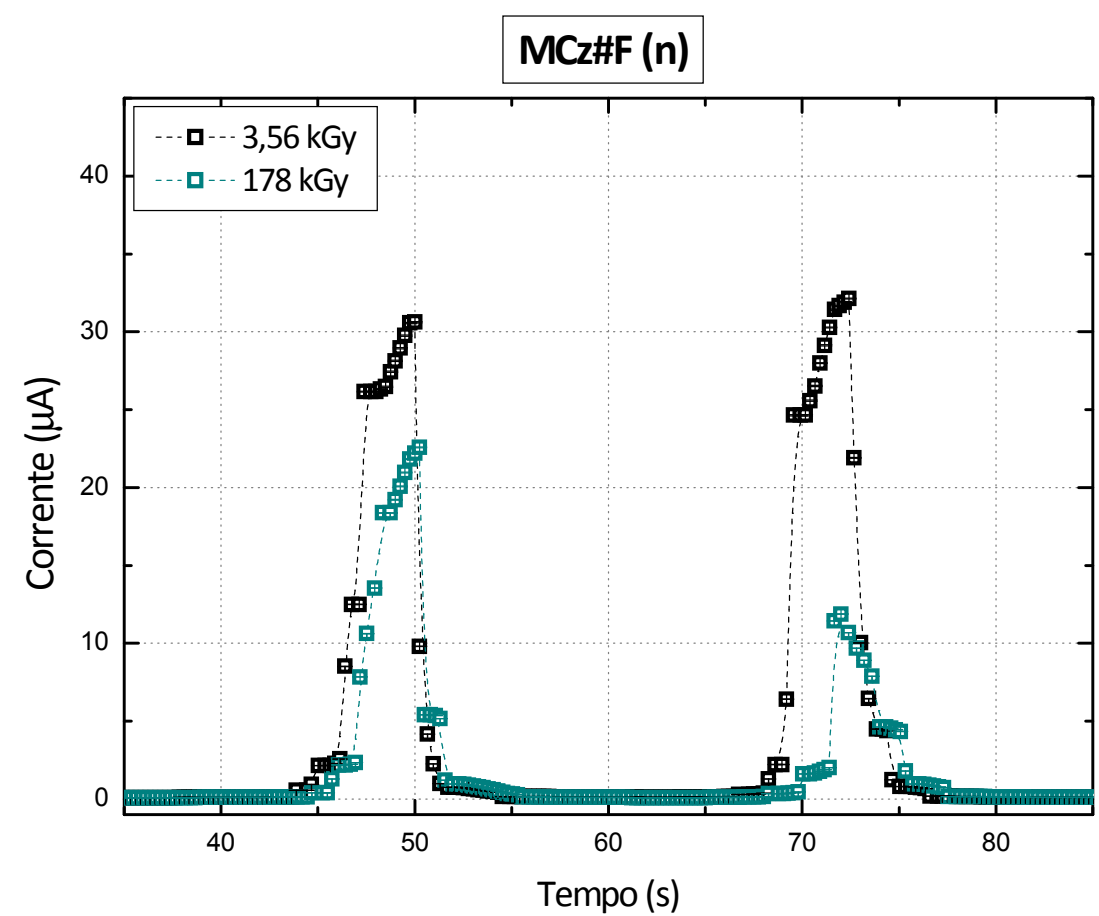

FIGURA 61 - Sinais de corrente em função do tempo obtidos com o diodo MCz\#F do tipo $\mathrm{n}$ para diferentes valores de dose. As barras de incerteza dos valores de corrente são menores do que os pontos e representam menos do que $1 \%$ das medições.

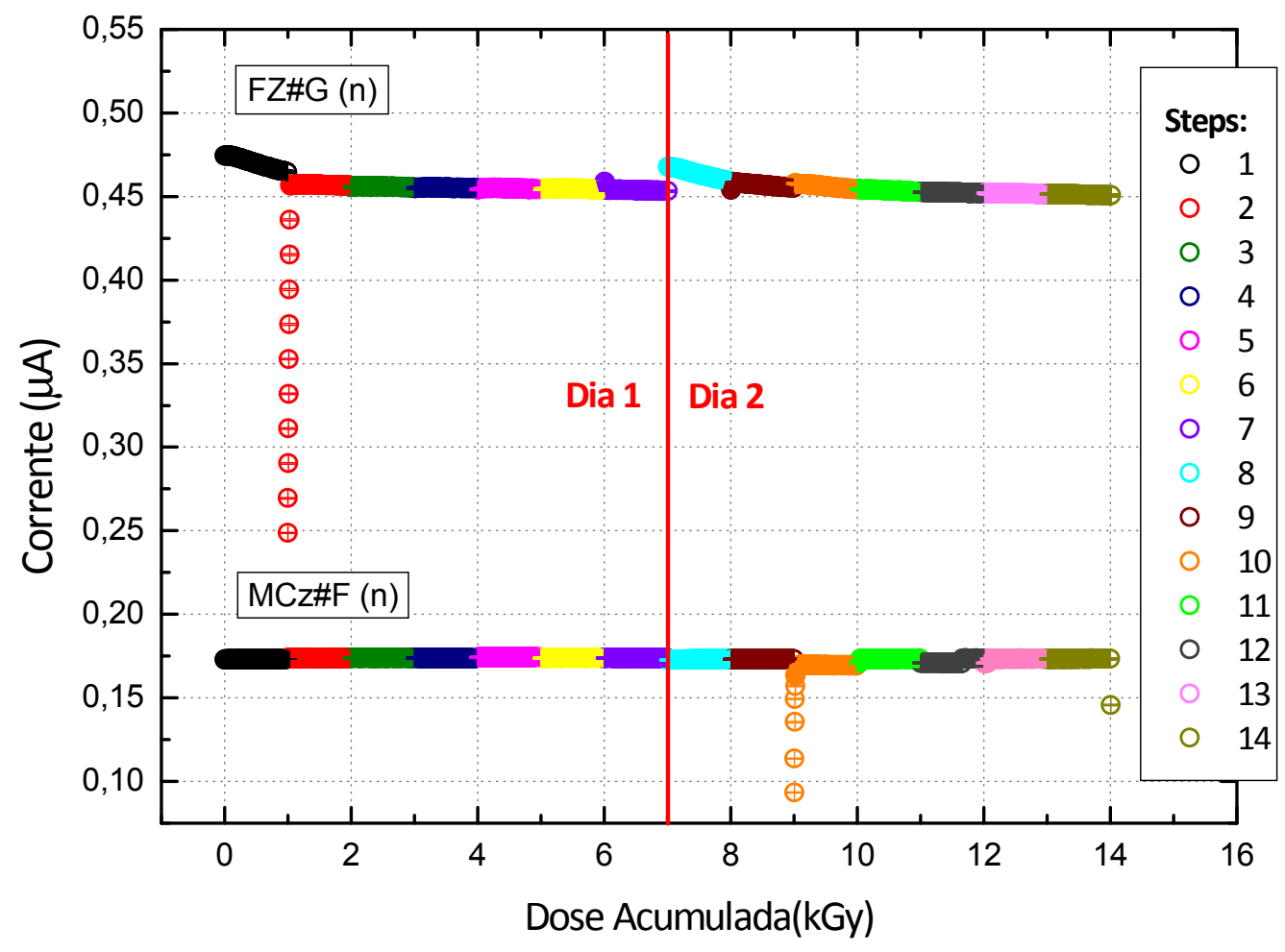

FIGURA 62 - Sinais de corrente registrados durante o estudo de repetibilidade gama dos diodos $F Z \# G$ e MCz\#F do tipo $n$. As barras de incerteza dos valores de corrente são menores do que os pontos e representam menos do que $1 \%$ das medições. 
Os coeficientes de variação, 1,1\% para o diodo FZ\#G e 0,8\% para o diodo MCz\#F, foram calculados para os valores médios de corrente obtidos em cada uma das 14 etapas de irradiação. Embora o diodo FZ\#G tenha acumulado uma dose maior (349 kGy) do que o diodo MCz\#F (178 kGy), nos procedimentos de irradiação com elétrons, este dispositivo apresentou uma instabilidade maior evidenciada nas variações dos valores de corrente registrados durante as etapas 1 e 8. Essas instabilidades indicam que o tempo de armazenamento, bem como o intervalo entre os dois dias de estudo, o diodo $F Z \# G$ recupera parcialmente sua resposta. Esta recuperação pode estar relacionada com o desarmadilhamento de portadores em níveis rasos por efeito de temperatura. De fato, existe uma recuperação benéfica das propriedades do detector observada por um período de tempo curto (da ordem de dias) após a irradiação [50,70-71]. No início da etapa 2, o diodo FZ\#G apresentou uma elevação lenta nos valores de corrente, mesmo quando já exposto à fonte radioativa. O mesmo comportamento foi observado para o diodo MCz\#F na etapa 10 de irradiação, evidenciando que o efeito da dose acumulada durante os procedimentos de irradiação com elétrons comprometeu a resolução temporal dos dispositivos. Os valores de corrente registrados com o diodo FZ\#G são superiores aos valores registrados com o diodo MCz\#F, embora o primeiro tenha acumulado uma dose mais elevada. Não é possível fazer qualquer afirmação sobre essas diferenças pois, alguns fatores, tais como irradiação individual e deterioração dos contatos elétricos, podem contribuir simultaneamente para uma deterioração mais ou menos elevada em cada um dos dispositivos estudados.

A deterioração dos contatos elétricos dos diodos, que está diretamente relacionada com todos os problemas detalhados até o momento, torna impossível a aplicação destes dispositivos, da maneira como vinham sendo utilizados, em dosimetria de processos rotineiros. Por este motivo, um novo procedimento de confecção das sondas dosimétricas foi adotado, como descrito no item 4.2 deste trabalho, onde o diodo é revestido com uma resina termorrígida. Alguns resultados preliminares já haviam sido obtidos em nosso grupo de pesquisas utilizando esse novo procedimento [24]. Nas FIG. 63 e 64 são apresentados os resultados das simulações feitas com o programa $\mathrm{CASINO}$, baseado em códigos de Monte Carlo que determinam o alcance e perda de energia de elétrons na matéria, para os dois protótipos de sondas dosimétricas utilizadas. É possível observar que, em ambos 
os casos, os elétrons com energia inicial de 1,5 MeV alcançam e atravessam a camada semicondutora, viabilizando a alteração proposta para a sonda dosimétrica.

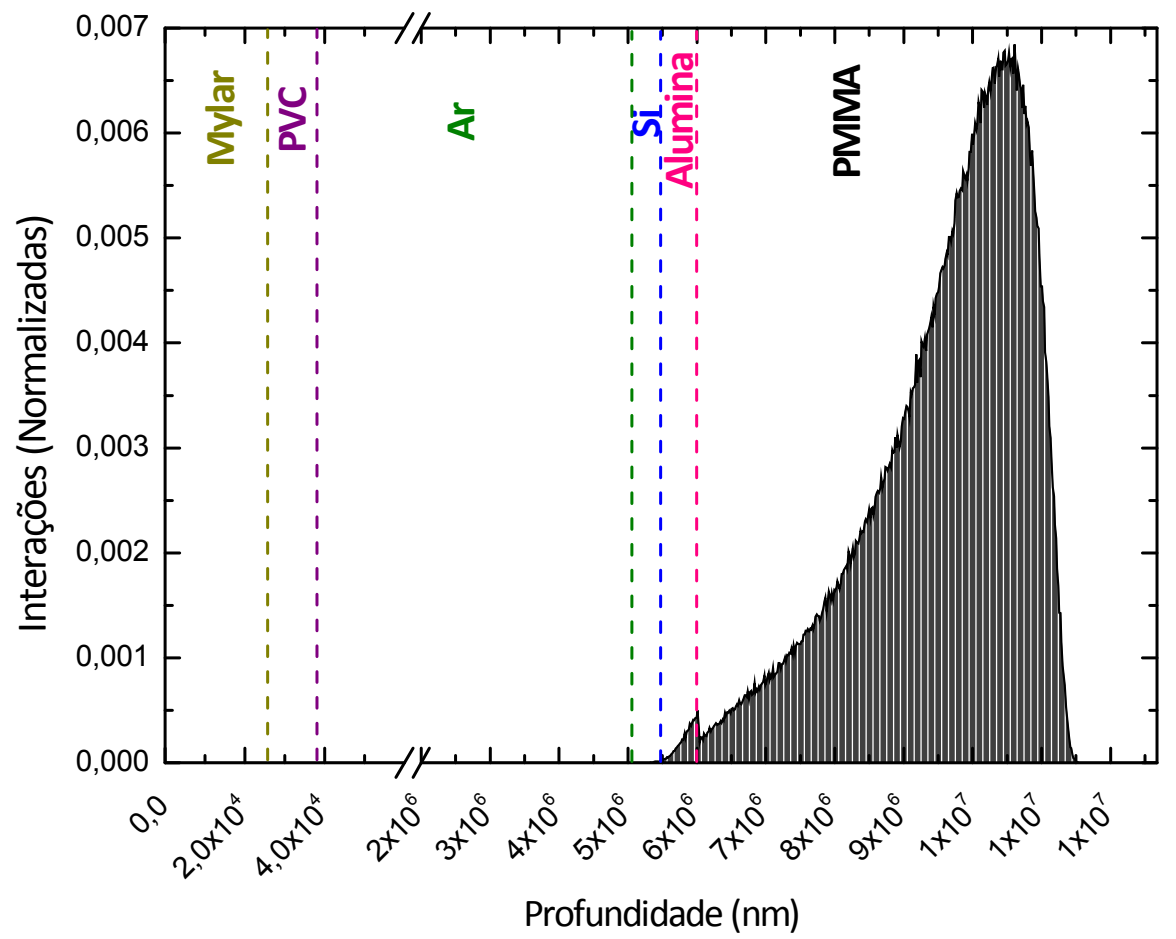

FIGURA 63 - Número de interações dos elétrons com 1,5 MeV de energia em função da profundidade, para o protótipo antigo da sonda dosimétrica (sem resina).

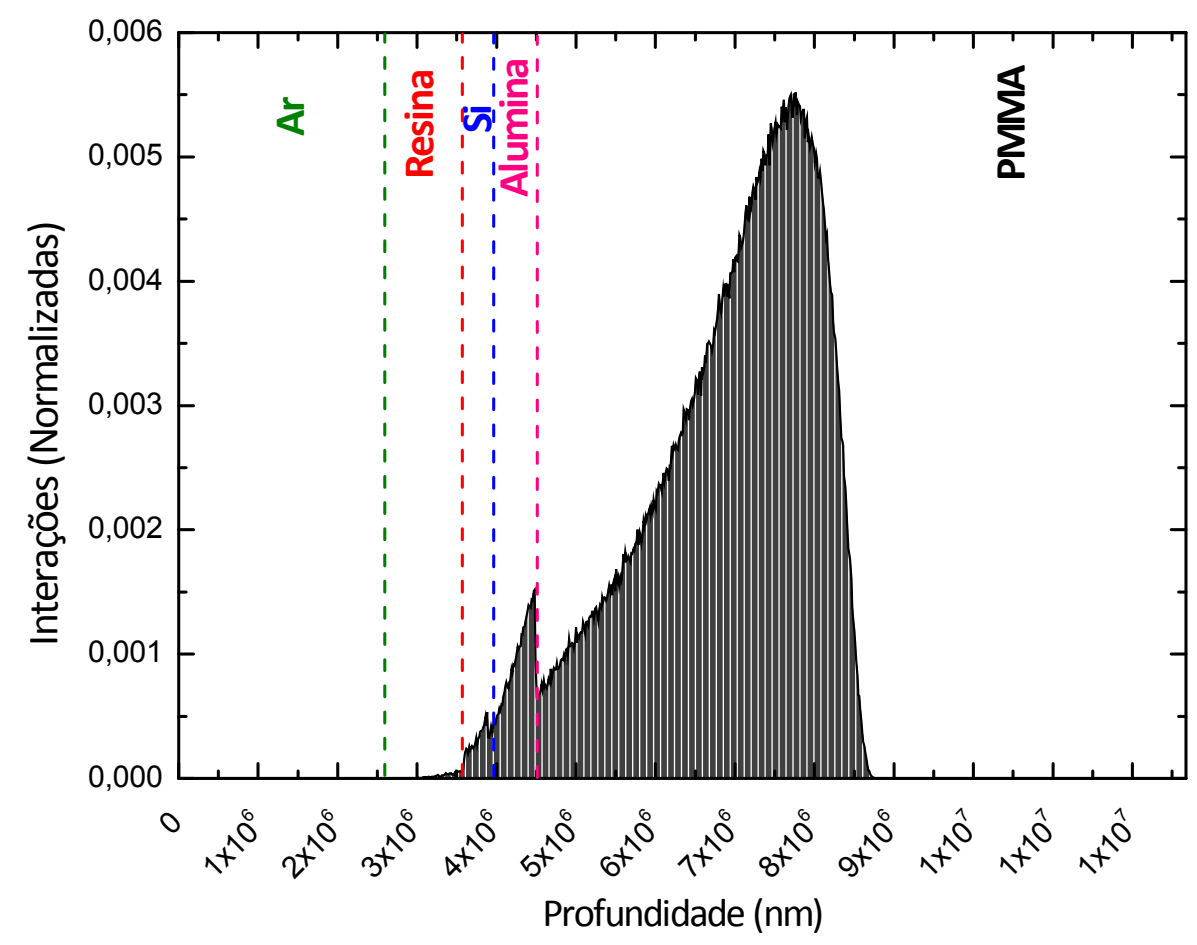

FIGURA 64 - Número de interações dos elétrons com 1,5 MeV de energia em função da profundidade, para o novo protótipo da sonda dosimétrica (resina). 
Uma alteração adicional proposta foi a irradiação simultânea dos diodos FZ\#O e MCz\#G, ambos encapsulados com resina, permitindo a comparação efetiva sem interferência de possíveis alterações nos parâmetros de irradiação, como velocidade da esteira e corrente elétrica do feixe de elétrons. Nas FIG. 65 e 66 são apresentados os sinais de corrente registrados com estes diodos após a pré-dose de 500 kGy.

A partir das informações dos parâmetros do acelerador e velocidade da esteira determina-se que o diodo permanece na região de campo de radiação uniforme (exatamente sob a saída do feixe de elétrons) por um intervalo de tempo de aproximadamente 0,45 s. Este intervalo, delimitado na FIG. 67 para o sinal de corrente obtido com o diodo FZ\#O para uma dose de 3,56 kGy, é muito menor do que o intervalo onde os picos são registrados. Isso mostra que os diodos são sensíveis tanto à radiação espalhada como possíveis alterações dos parâmetros do acelerador e velocidade da esteira. É importante ressaltar que essas variações não podem ser detectadas com dosímetros CTA e fazem dos diodos candidatos promissores à dosimetria em tempo real dos processos de irradiação no acelerador de elétrons.

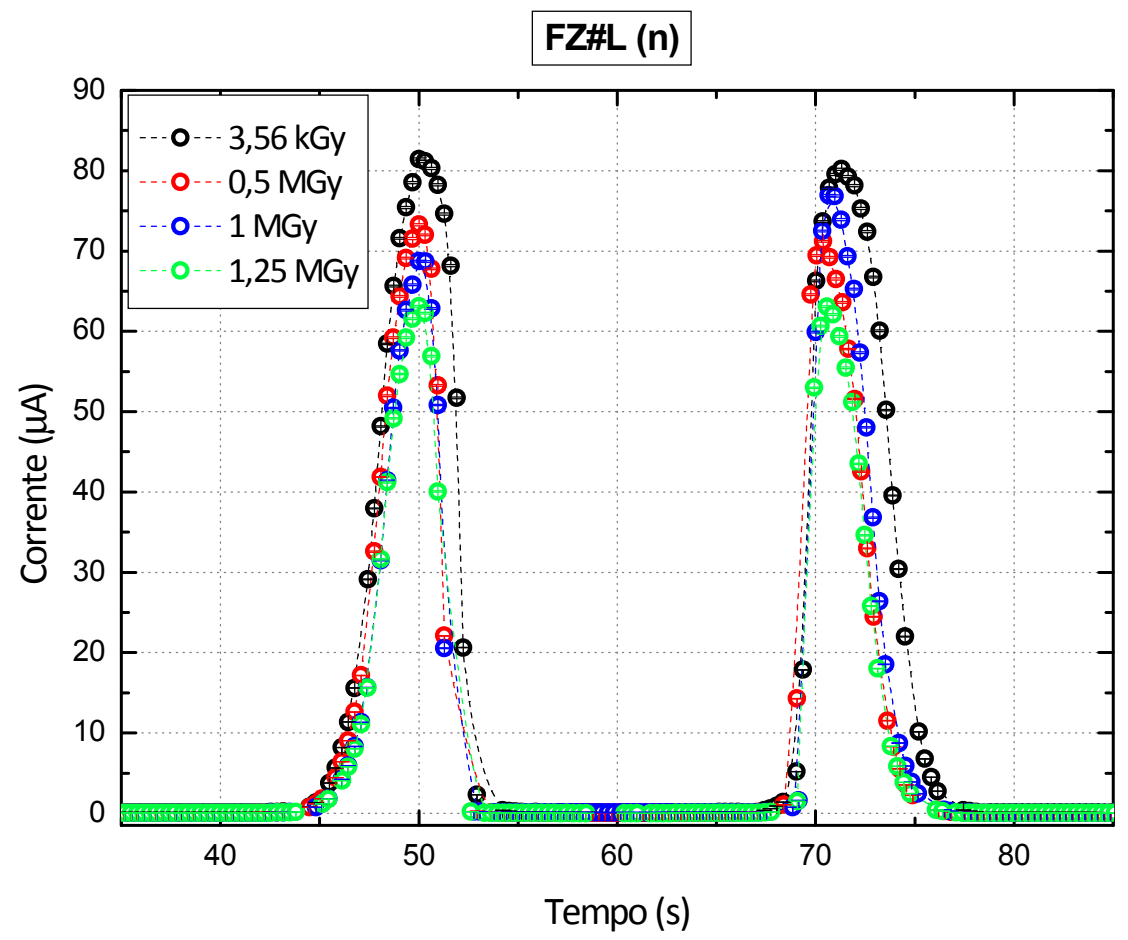

FIGURA 65 - Sinais de corrente em função do tempo obtidos com o diodo FZ\#O do tipo $\mathrm{n}$ para diferentes valores de dose. As barras de incerteza dos valores de corrente são menores do que os pontos e representam menos do que $1 \%$ das medições. 


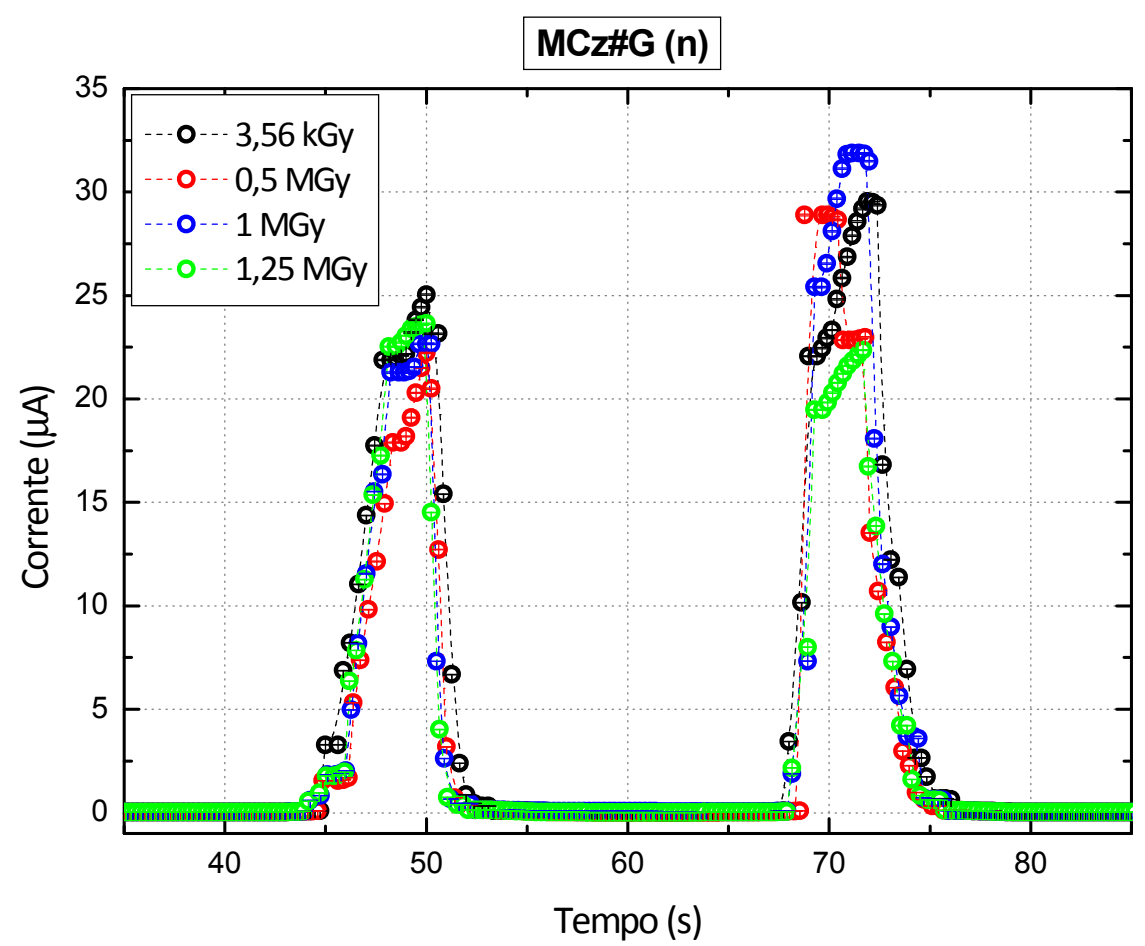

FIGURA 66 - Sinais de corrente em função do tempo obtidos com o diodo MCz\#G do tipo $\mathrm{n}$ para diferentes valores de dose. As barras de incerteza dos valores de corrente são menores do que os pontos e representam menos do que $1 \%$ das medições.

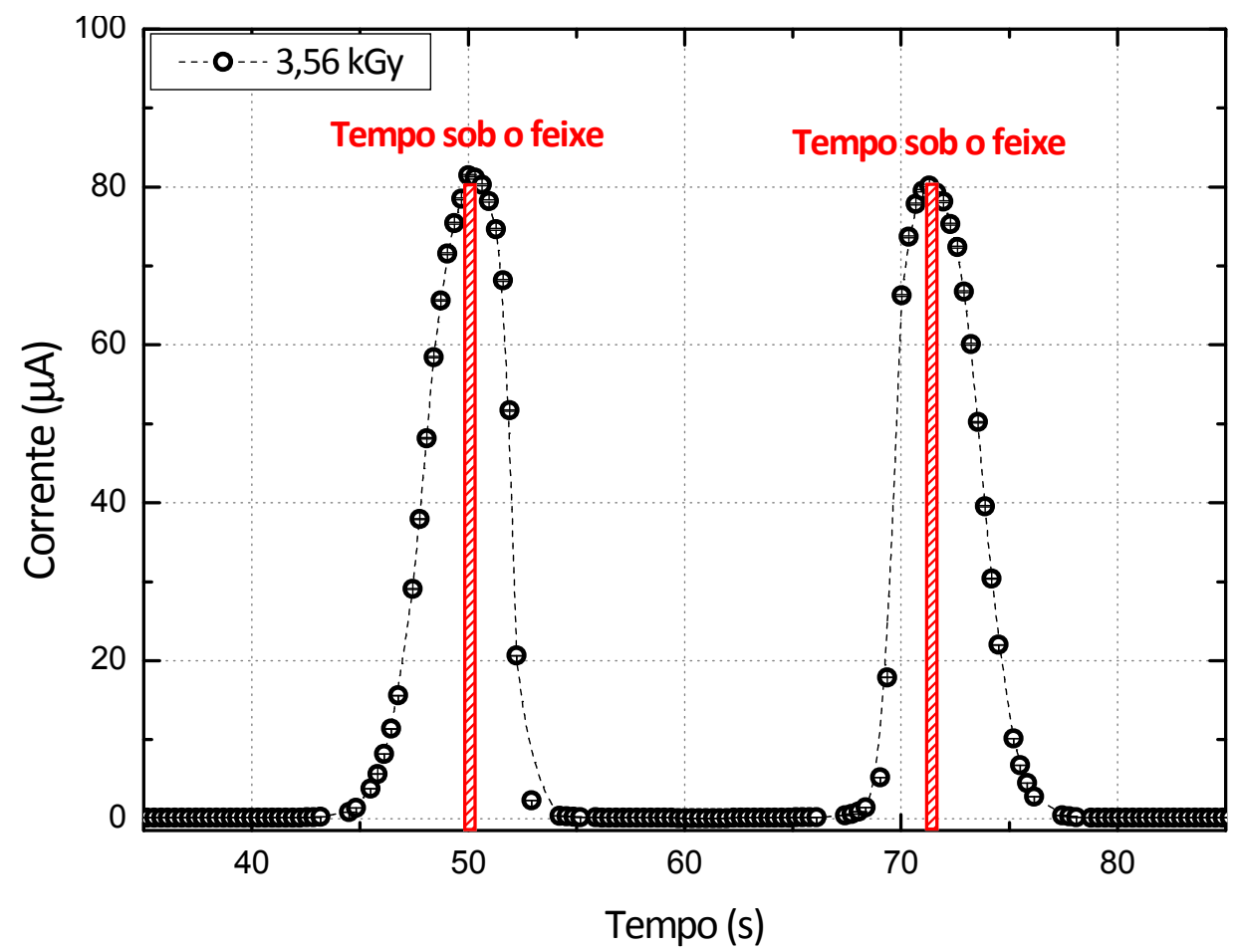

FIGURA 67 - Sinal de corrente em função do tempo obtido com o diodo FZ\#O do tipo n para uma dose de 3,56 kGy com delimitação do tempo de exposição sob o feixe de elétrons. As barras de incerteza dos valores de corrente são menores do que os pontos e representam menos do que $1 \%$ das medições. 
Para exemplificar melhor a vantagem da monitoração em tempo real, com diodos de Si, é apresentado na FIG. 68 um sinal de corrente observado durante o procedimento de irradiação do diodo $\mathrm{FZ \# O}$, onde um problema com um dos roletes da esteira fez com que o diodo permanecesse um tempo maior do que o usual sob o feixe. Não existe, atualmente, qualquer mecanismo do acelerador que permita a percepção de um problema como este durante os processos de irradiação.

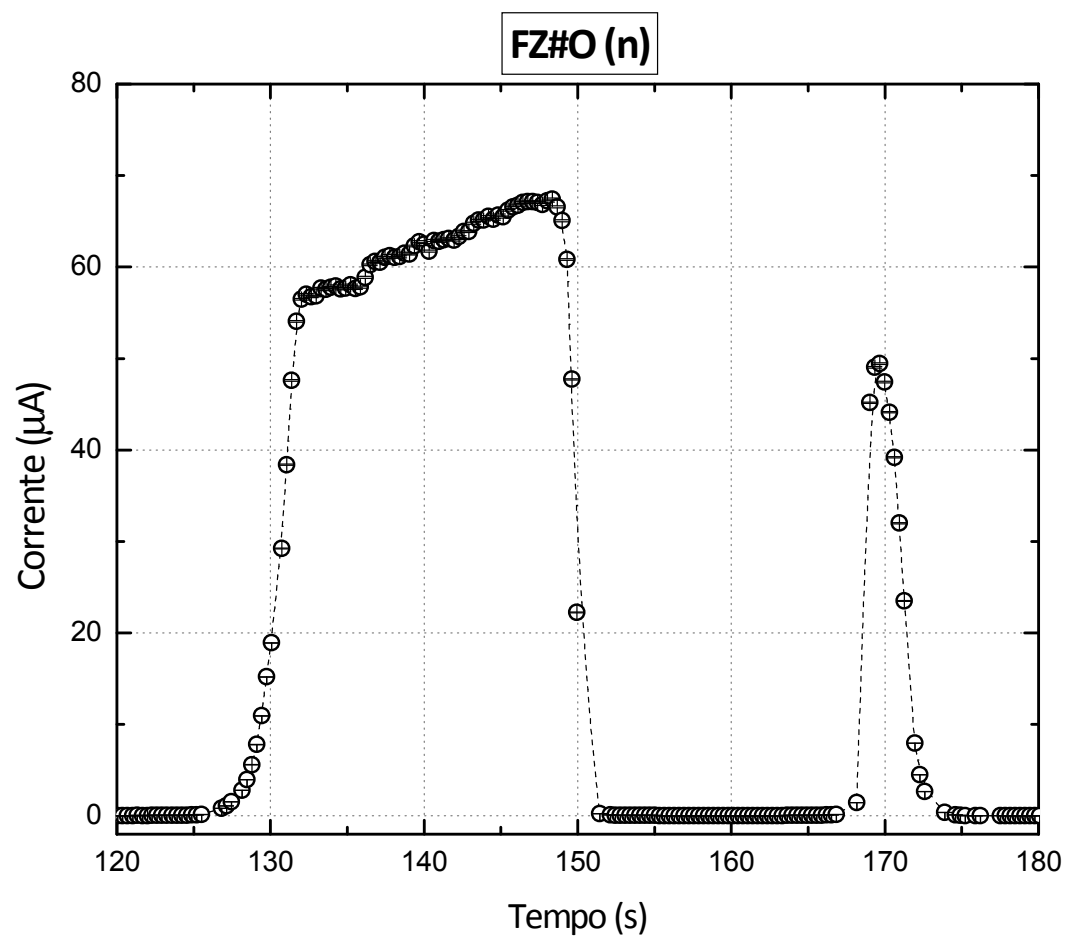

FIGURA 68 - Sinal de corrente em função do tempo obtido com o diodo FZ\#O do tipo $n$ durante um problema no rolete da esteira levando à parada do diodo sob o feixe de elétrons. As barras de incerteza dos valores de corrente são menores do que os pontos e representam menos do que $1 \%$ das medições.

\subsubsection{Queda da sensibilidade em corrente em função da dose}

O estudo comparativo da queda de sensibilidade dos diodos FZ e MCz, ambos do tipo n, é apresentado na FIG. 69. Neste gráfico, os valores de corrente normalizada dos diodos FZ\#O e MCz\#G são obtidos pela divisão dos valores médios de corrente de pico em um ciclo arbitrário e o primeiro registrado após a pré-dose.

Enquanto que a amplitude total da variação percentual dos valores de corrente de pico é de aproximadamente $20 \%$ para o diodo $\mathrm{FZ \# O}$, essa mesma medida pode chegar até $40 \%$ para o diodo MCz\#G. Pode-se afirmar que o diodo MCz\#G apresenta uma dispersão mais elevada dos valores de corrente de pico. 
Para valores de dose entre 854 kGy e 1000 kGy, aproximadamente, observa-se uma elevação dos valores de corrente de pico para ambos os diodos. Esse efeito indica uma possível alteração dos parâmetros do acelerador com relação aos demais intervalos de dose, visto que os diodos foram irradiados simultaneamente.

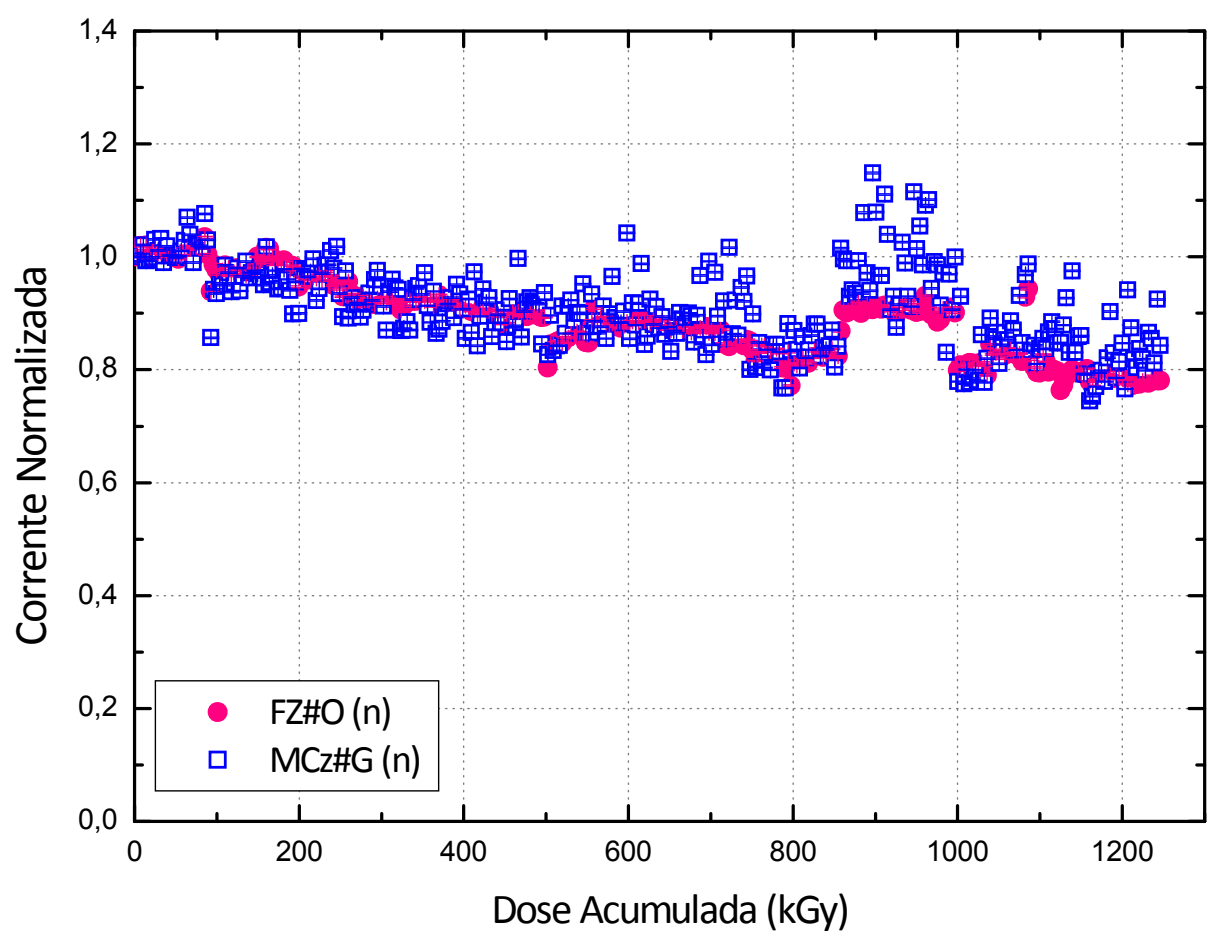

FIGURA 69 - Corrente de pico média normalizada em função da dose acumulada para os diodos $\mathrm{FZ \# O}$ e $\mathrm{MCz} \# \mathrm{G}$ do tipo $\mathrm{n}$. As barras de incerteza dos valores de corrente normalizada são menores do que os pontos e representam menos do que $0,5 \%$ da grandeza.

Assim como para a irradiação gama, a resposta de diodos do tipo $p$ e $n$ foi avaliada também para a irradiação com elétrons. Para isso, os diodos FZ\#J (n) e FZ\#N ( $p$ ) foram recobertos com a resina termorrígida e pré-irradiados com uma dose total de $250 \mathrm{kGy}$. Em seguida as duas amostras foram irradiadas simultaneamente de maneira que os valores médios de corrente de pico normalizados são apresentados na FIG. 70 em função da dose acumulada. É importante ressaltar que ambos os diodos foram irradiados com uma pré-dose de $500 \mathrm{kGy}$, entretanto, ao término do processo de pré-irradiação o diodo FZ\#J perdeu completamente sua capacidade de resposta. Isso pode ter ocorrido devido a algum problema durante a confecção dos contatos elétricos do diodo que, como ficam recobertos pela resina, não podem ser refeitos. Por este motivo e para que a sensibilidade de ambos os diodos possa ser comparada, assume-se o valor de 250 kGy como pré-dose. 
A amplitude total da variação percentual dos valores de corrente de pico é menor que $10 \%$ para o diodo FZ\#J (n) e de aproximadamente $40 \%$ para o diodo FZ\#N (p). Os resultados indicam que para a irradiação com elétrons os diodos do tipo $p$ apresentam maior variação da sensibilidade do que os diodos do tipo $\mathrm{n}$. Estes resultados devem ser reproduzidos pois, estão em oposição à teoria sobre os danos induzidos pela radiação, de acordo com a qual, diodos do tipo $p$ apresentam uma maior estabilidade de resposta quando comparados a diodos do tipo n. A possibilidade de haver um problema pontual com a amostra estudada não pode ser descartada.

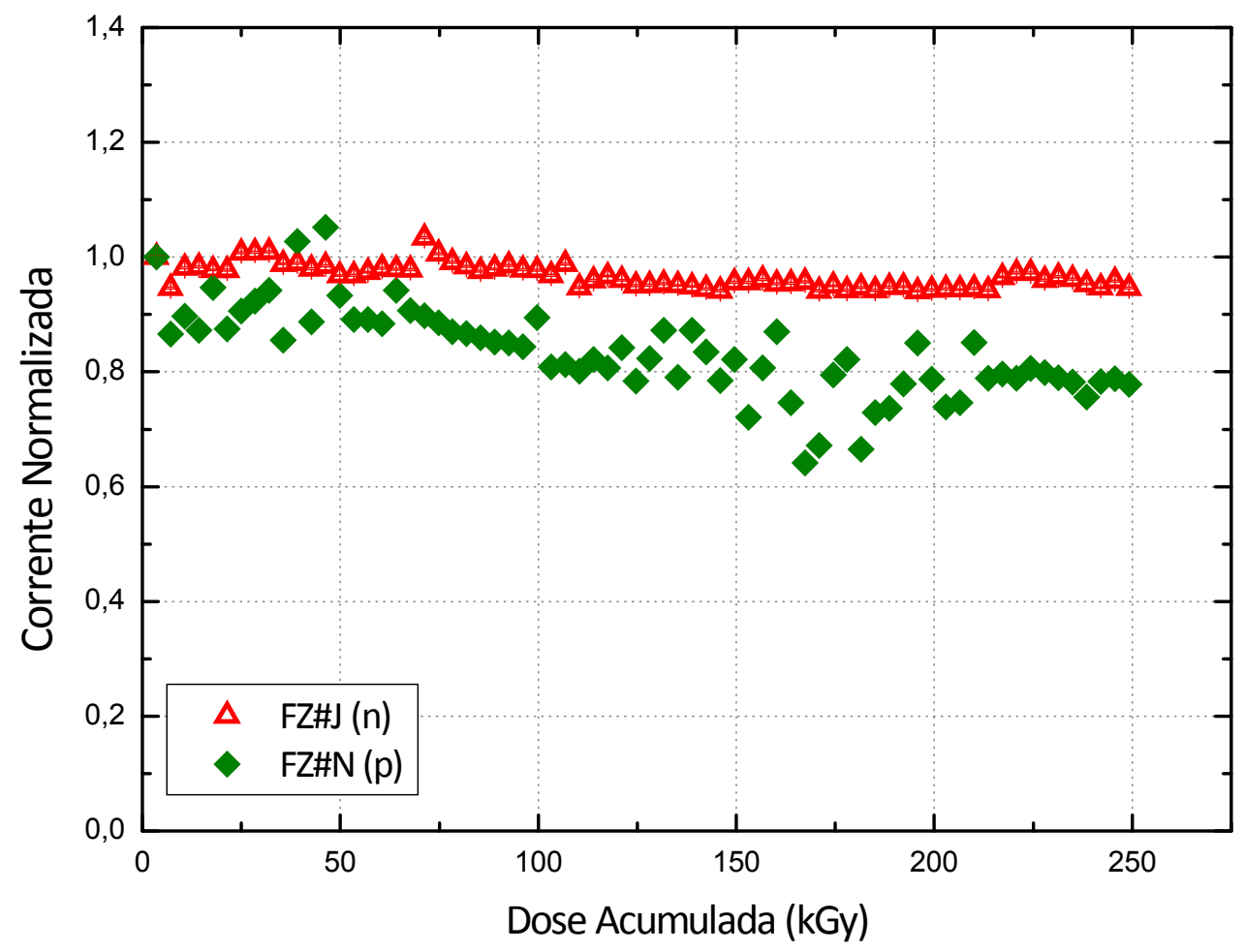

FIGURA 70 - Corrente de pico média normalizada em função da dose acumulada para os diodos FZ\#J do tipo $n$ e FZ\#N do tipo p. As barras de incerteza dos valores de corrente normalizada são menores do que os pontos e representam menos do que $0,5 \%$ da grandeza.

\subsubsection{Curva dose resposta}

As curvas dose respostas dos diodos $\mathrm{FZ \# O} \mathrm{e} \mathrm{MCz} \# \mathrm{G}$ são apresentadas na FIG. 71. O diodo FZ\#O possui uma sensibilidade em carga superior à do diodo MCz\#G como consequência da amplitude maior dos sinais de corrente registrados com este diodo. É importante lembrar que os valores de resistividade das amostras diferem por um fator 10. Ambos os resultados foram ajustados para funções polinomiais de segunda ordem. 


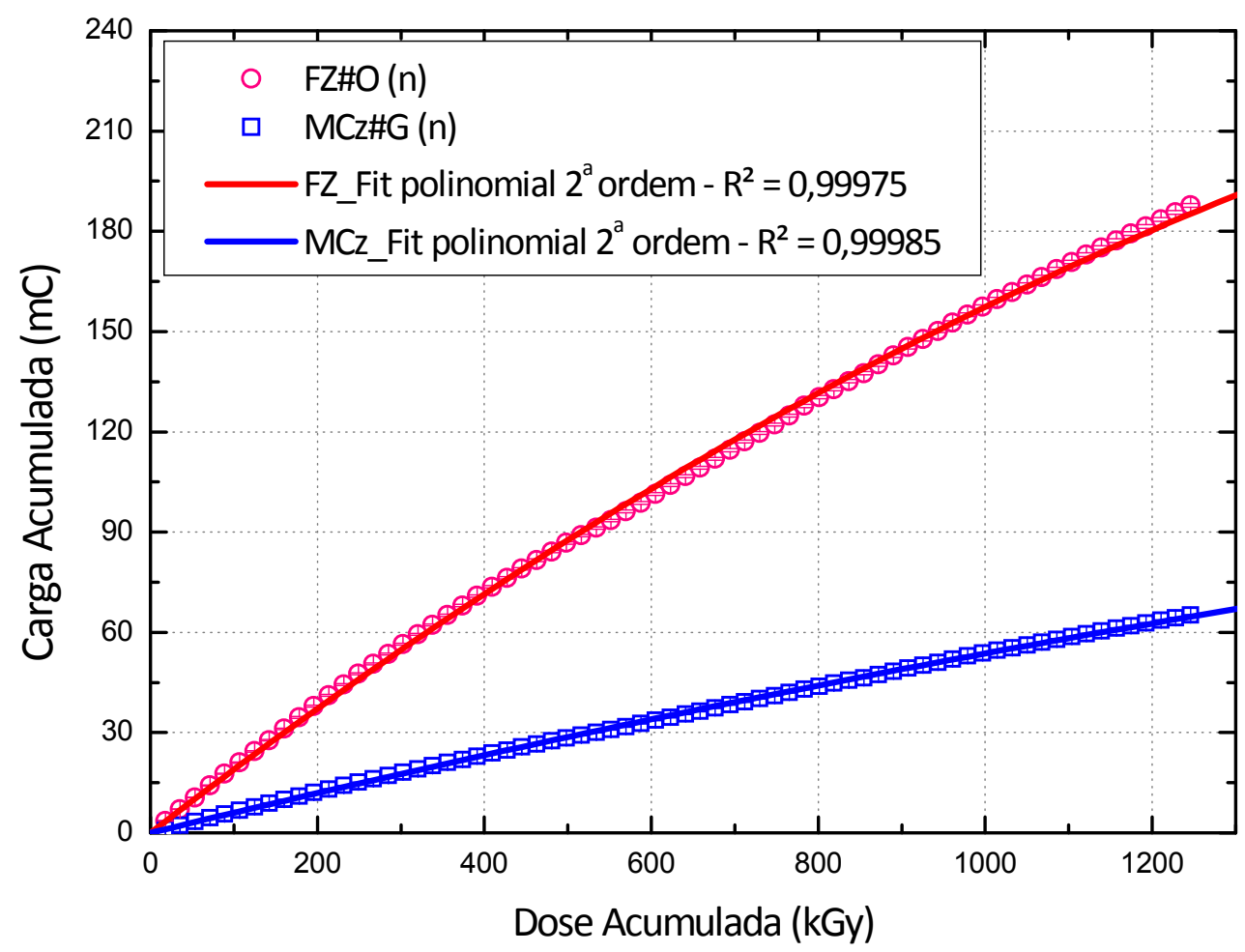

FIGURA 71 - Curvas dose respostas dos diodos FZ\#O e MCz\#G do tipo $n$ irradiados com elétrons. As barras de incerteza dos valores de carga acumulada são menores do que os pontos e representam menos do que $0,5 \%$ da grandeza.

Na FIG. 72 são apresentadas as curvas dose respostas dos diodos FZ\#J (n) e FZ\#N (p). A sensibilidade em carga do diodo $F Z \# J$ é superior à do diodo $F Z \# N$ devido à diferença dos valores de corrente de pico registrados com cada um dos diodos. Além disso, o diodo FZ\#N do tipo $p$ apresentou uma variação significativa dos valores de corrente de pico obtidos durante os percursos de "ida" e "volta" do dispositivo, contribuindo para uma diminuição dos valores de carga acumulada. Para ambos os diodos, tipo $n$ e $p$, foram ajustadas funções polinomiais de segunda ordem com coeficientes de correlação maiores que 0,9997. 


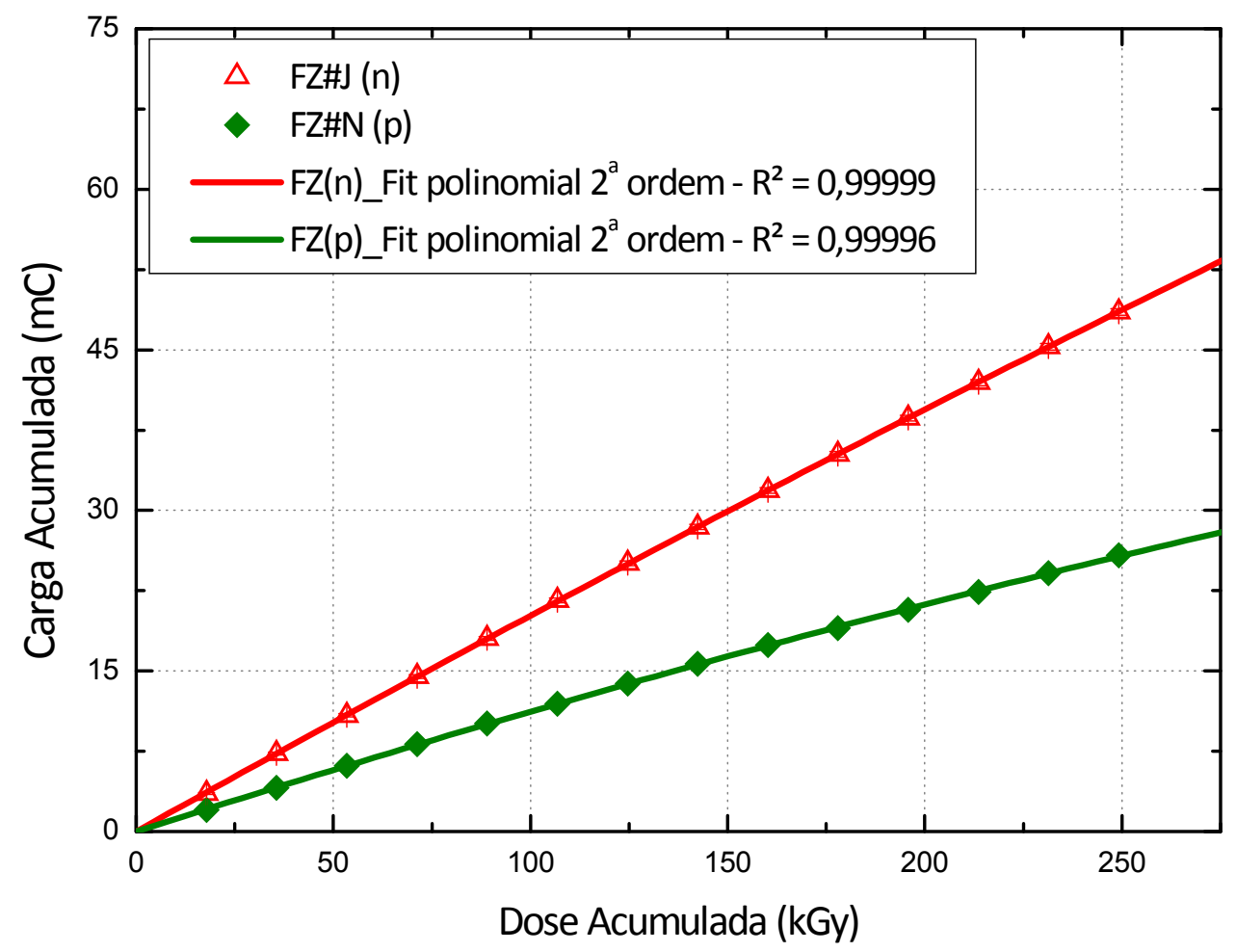

FIGURA 72 - Curvas dose respostas dos diodos FZ\#J do tipo $n$ e FZ\#N do tipo $p$ irradiados com elétrons. As barras de incerteza dos valores de carga acumulada são menores do que os pontos e representam menos do que $0,5 \%$ da grandeza.

\subsubsection{Danos induzidos pela radiação}

A influência dos danos induzidos pela radiação nas propriedades macroscópicas dos diodos irradiados com elétrons, foi avaliada a partir das curvas de corrente de fuga (IV) e capacitância (CV) em função da tensão de polarização reversa, para diferentes valores de dose acumulada.

\subsubsection{Curvas de corrente de fuga em função da tensão de polarização reversa (IV)}

Nas FIG. 73, 74, 75 e 76 são apresentadas as curvas IV obtidas com os diodos FZ\#O, MCZ\#G, FZ\#J e FZ\#N. Todos os valores foram corrigidos para a temperatura de referência de $20^{\circ} \mathrm{C}$, segundo as equações apresentadas no item 4.3.3 deste trabalho. As medidas de corrente de fuga foram efetuadas para as amostras sem dose absorvida (amostra em branco), após a pré-irradiação e após cada etapa de $250 \mathrm{kGy}$ de dose. Cabe lembrar que o valor da pré-dose das amostras $\mathrm{FZ \# O} \mathrm{e} \mathrm{MCz \# G} \mathrm{é} \mathrm{de} 500$ kGy enquanto que para as amostras FZ\#J e FZ\#N este valor é de $250 \mathrm{kGy}$, sendo esta diferença já relatada anteriormente. Para doses acumuladas acima de $500 \mathrm{kGy}$, as medidas de corrente de fuga do diodo FZ\#O foram efetuadas para tensões de até $60 \mathrm{~V}$. Para doses inferiores a $500 \mathrm{kGy}$ 
as medidas foram efetuadas para tensões de até $40 \mathrm{~V}$. Para a amostra MCz\#G, em contrapartida, as medidas de corrente de fuga foram efetuadas para tensões de até $400 \mathrm{~V}$, para valores de dose acumulada inferiores a 1 MGy, e $450 \mathrm{~V}$, para valores de dose acumulada acima de $1 \mathrm{MGy}$. $\mathrm{O}$ aumento da tensão de polarização dos diodos deve-se ao fato de que para valores de dose inferiores aos limites indicados, a depleção total não pôde mais ser observada durante a aquisição das medidas de capacitância (CV), exigindo o aumento da tensão de polarização máxima. Para padronização, o mesmo foi mantido para as medidas de corrente de fuga.

Como esperado, há um aumento da corrente de fuga com o aumento da tensão de polarização, bem como com a dose absorvida, esse último resultante da criação de centros R-G na região de carga espacial como resultado dos danos induzidos pela radiação. Como a criação de centros $R-G$ aumenta com a dose de radiação, um aumento da corrente de fuga com a dose também é esperado [16, 40, 42].

FZ\#O (n)

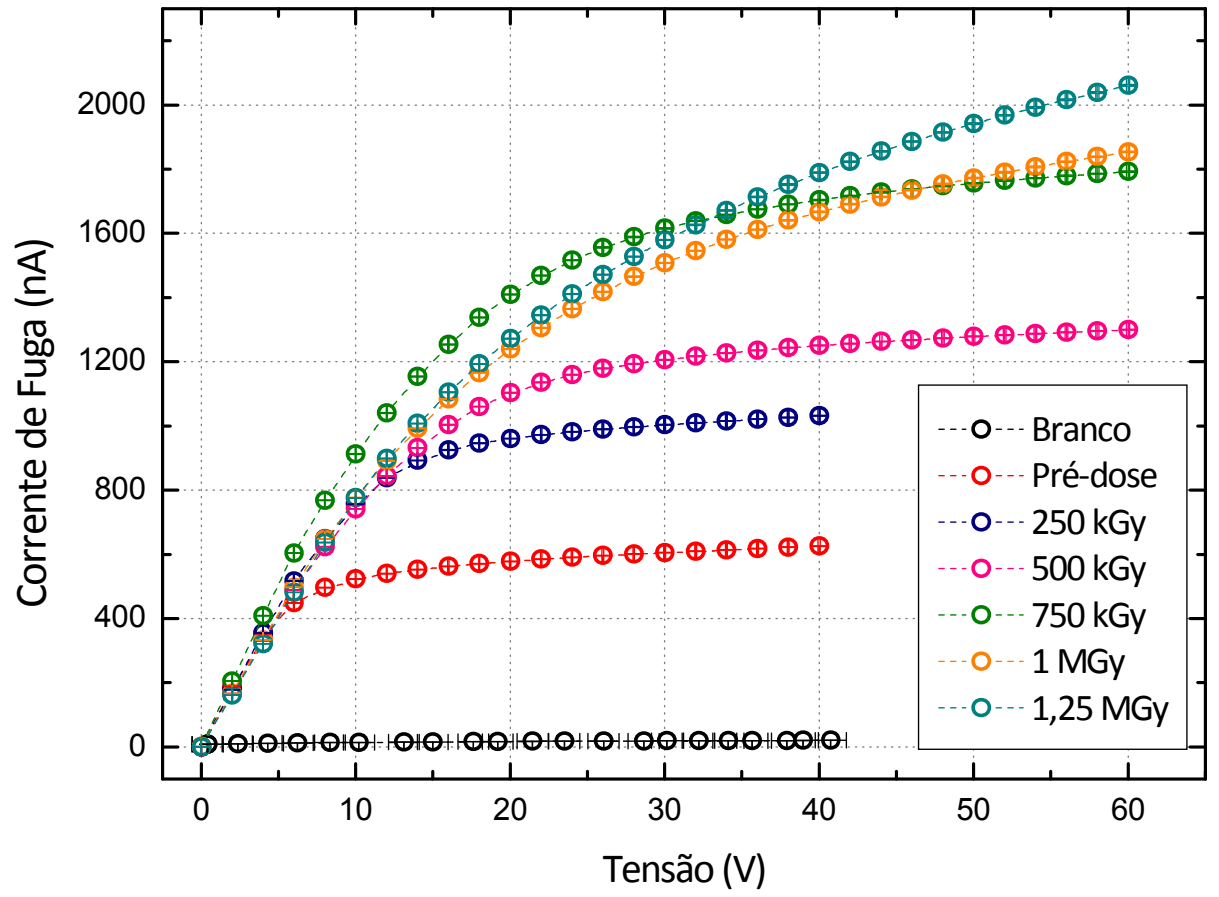

FIGURA 73 - Curvas IV do diodo FZ\#O do tipo n para diferentes valores de dose acumulada. As barras de incerteza dos valores de corrente de fuga são menores do que os pontos e representam menos do que $0,5 \%$ das medições. 


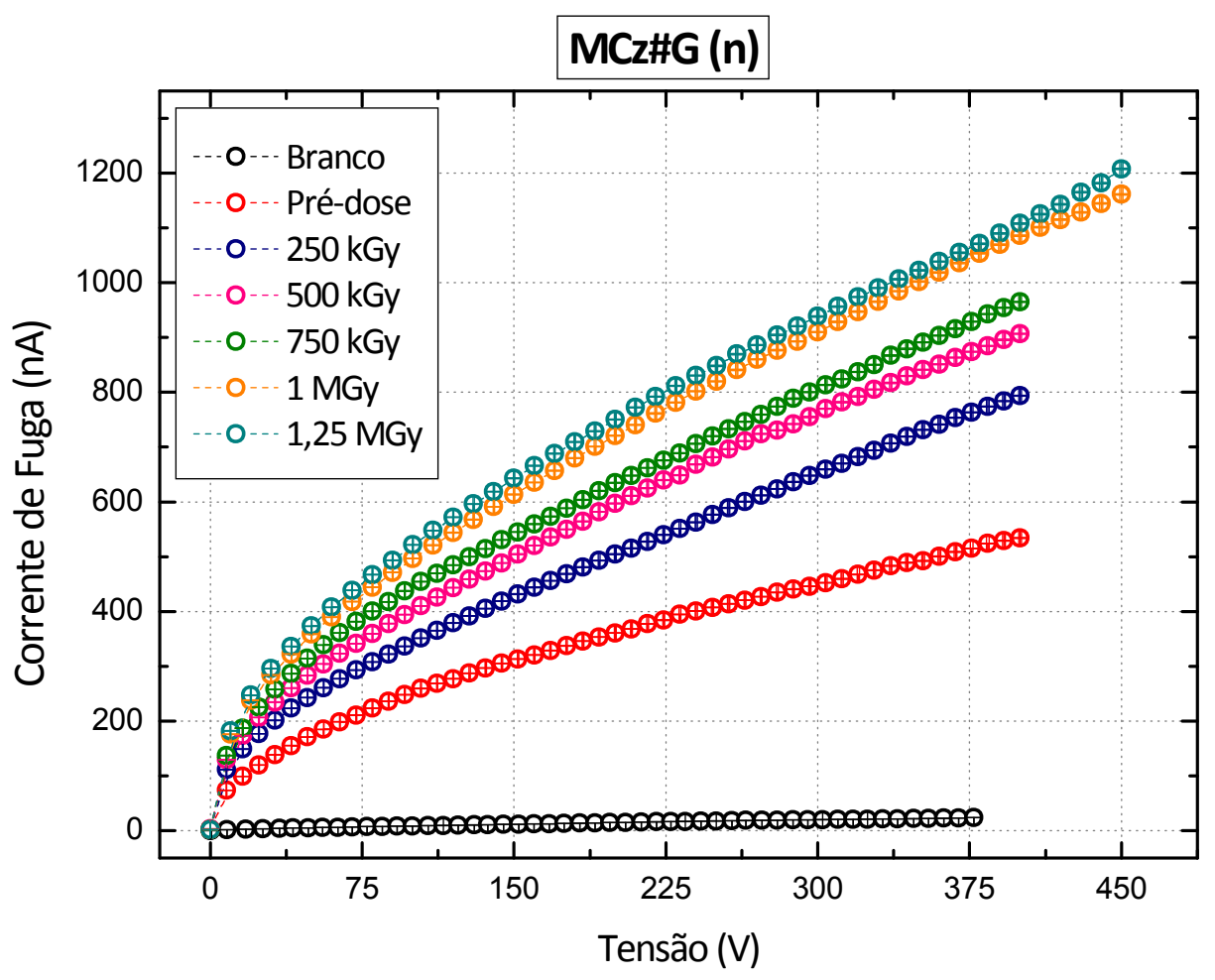

FIGURA 74 - Curvas IV do diodo MCz\#G do tipo $\mathrm{n}$ para diferentes valores de dose acumulada. As barras de incerteza dos valores de corrente de fuga são menores do que os pontos e representam menos do que $0,5 \%$ das medições.

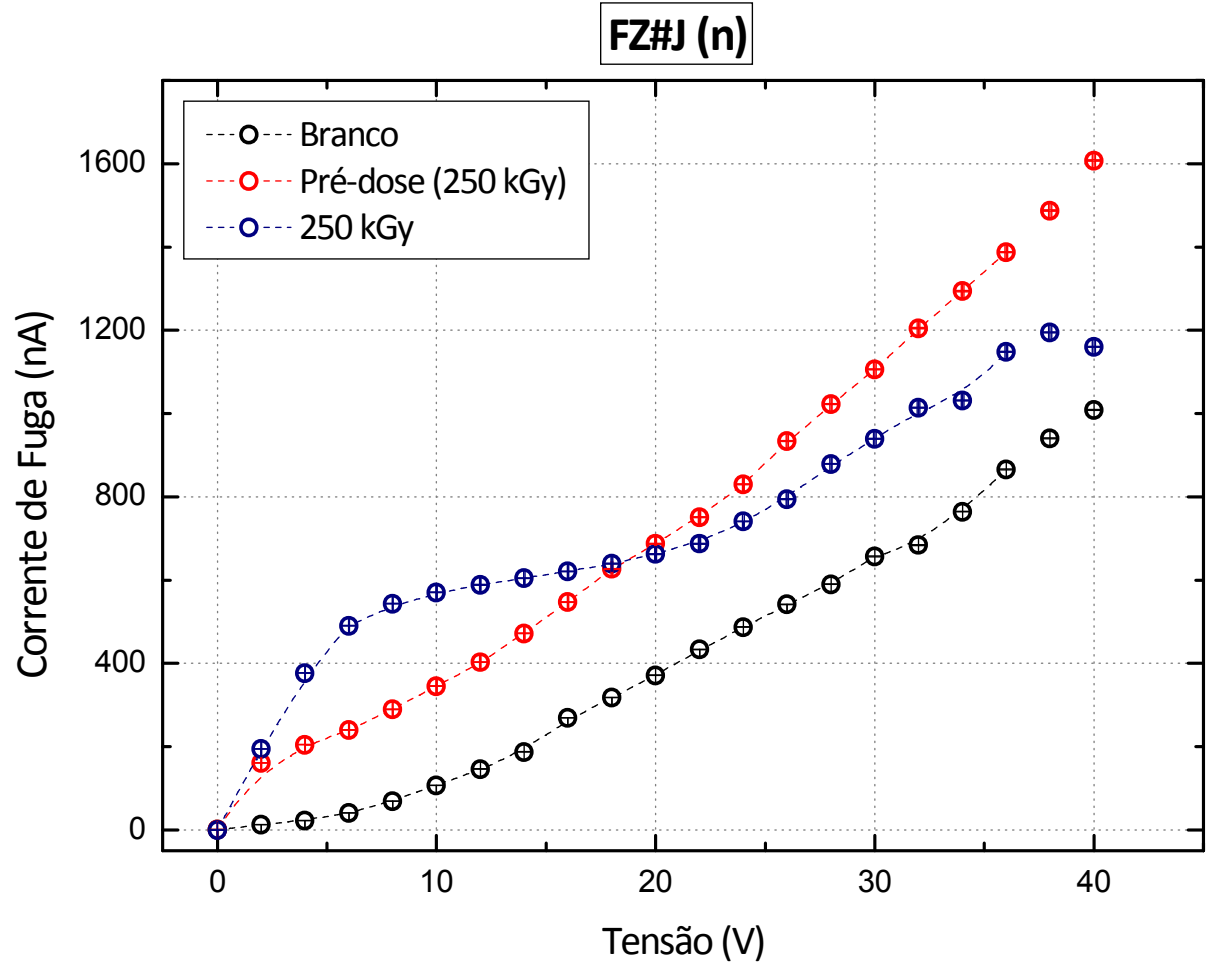

FIGURA 75 - Curvas IV do diodo FZ\#J do tipo n para diferentes valores de dose acumulada. As barras de incerteza dos valores de corrente de fuga são menores do que os pontos e representam menos do que $0,5 \%$ das medições. 


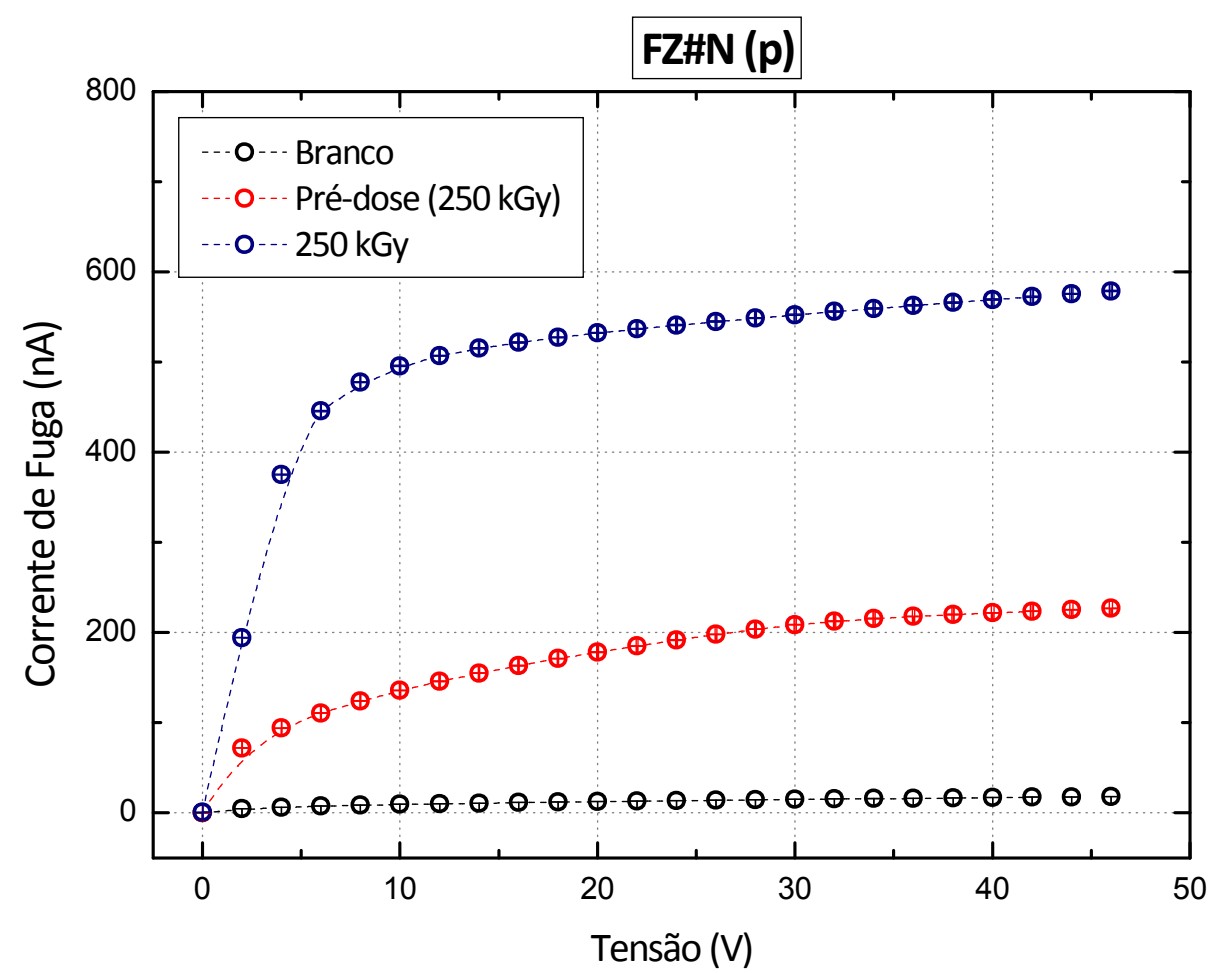

FIGURA 76 - Curvas IV do diodo FZ\#N do tipo $p$ para diferentes valores de dose acumulada. As barras de incerteza dos valores de corrente de fuga são menores do que os pontos e representam menos do que $0,5 \%$ das medições.

Durante os processos de irradiação os diodos são operados no modo fotovoltaico e, portanto, sem tensão de polarização. Assim, mesmo com o aumento em função da dose absorvida, a corrente de fuga é aproximadamente quatro ordens de grandeza menor do que a corrente gerada pela radiação. Os valores da corrente de fuga para a tensão de $0 \mathrm{~V}$ são apresentado na TAB. 3 para os diodos $F Z \# O$, MCz\#G, FZ\#J e FZ\#N em diferentes valores de dose acumulada.

O comportamento das curvas IV do diodo FZ\#J difere significativamente do comportamento observado com os demais diodos. Isso indica que os contatos elétricos dessa amostra já apresentavam instabilidades desde o início da sua utilização. Essas instabilidades, como mencionado anteriormente, não poderiam ser identificadas visualmente uma vez que, o diodo foi encapsulado com a resina termorrígida preta. A variação abrupta dos valores de corrente de fuga do diodo FZ\#J são mais significativas para valores de tensão maiores, ressaltando assim, uma vantagem da utilização dos diodos no modo fotovoltaico. Isso ocorre porque, mesmo com as instabilidades relatadas e enquanto respondia à incidência da radiação, nenhuma alteração relevante foi observada em sua resposta dosimétrica. 
TABELA 3 - Valores da corrente de fuga à $0 \mathrm{~V}$ para os diodos FZ\#O, MCz\#G, FZ\#J e FZ\#N em diferentes valores de dose.

Corrente de Fuga (nA)@ $0 \mathrm{~V}\left(20^{\circ} \mathrm{C}\right)$

\begin{tabular}{ccccc}
\hline & FZ\#O & MCz\#G & FZ\#J & FZ\#N (p) \\
$\mathbf{2 5 0}$ kGy & $0,347(1)$ & $1,403(3)$ & $0,278(1)$ & $0,485(1)$ \\
$\mathbf{5 0 0}$ kGy & $0,374(1)$ & $3,212(7)$ & $* * *$ & $* * *$ \\
$\mathbf{7 5 0}$ kGy & $0,454(1)$ & $1,339(3)$ & $* * *$ & $* * *$ \\
$\mathbf{1}$ MGy & $0,498(1)$ & $1,736(4)$ & $* * *$ & $* * *$ \\
$\mathbf{1 , 2 5}$ MGy & $0,315(1)$ & $1,605(4)$ & $* * *$ & $* * *$ \\
\hline
\end{tabular}

\subsubsection{Curvas de capacitância em função da tensão de polarização reversa} (CV)

As curvas $\mathrm{CV}$ dos diodos $\mathrm{FZ \# O,} \mathrm{MCz \# G,} \mathrm{FZ \# J} \mathrm{e} \mathrm{FZ \# N,} \mathrm{obtidas} \mathrm{por} \mathrm{meio}$ do procedimento experimental descrito anteriormente, são apresentadas nas FIG. $77,78,79$ e 80.

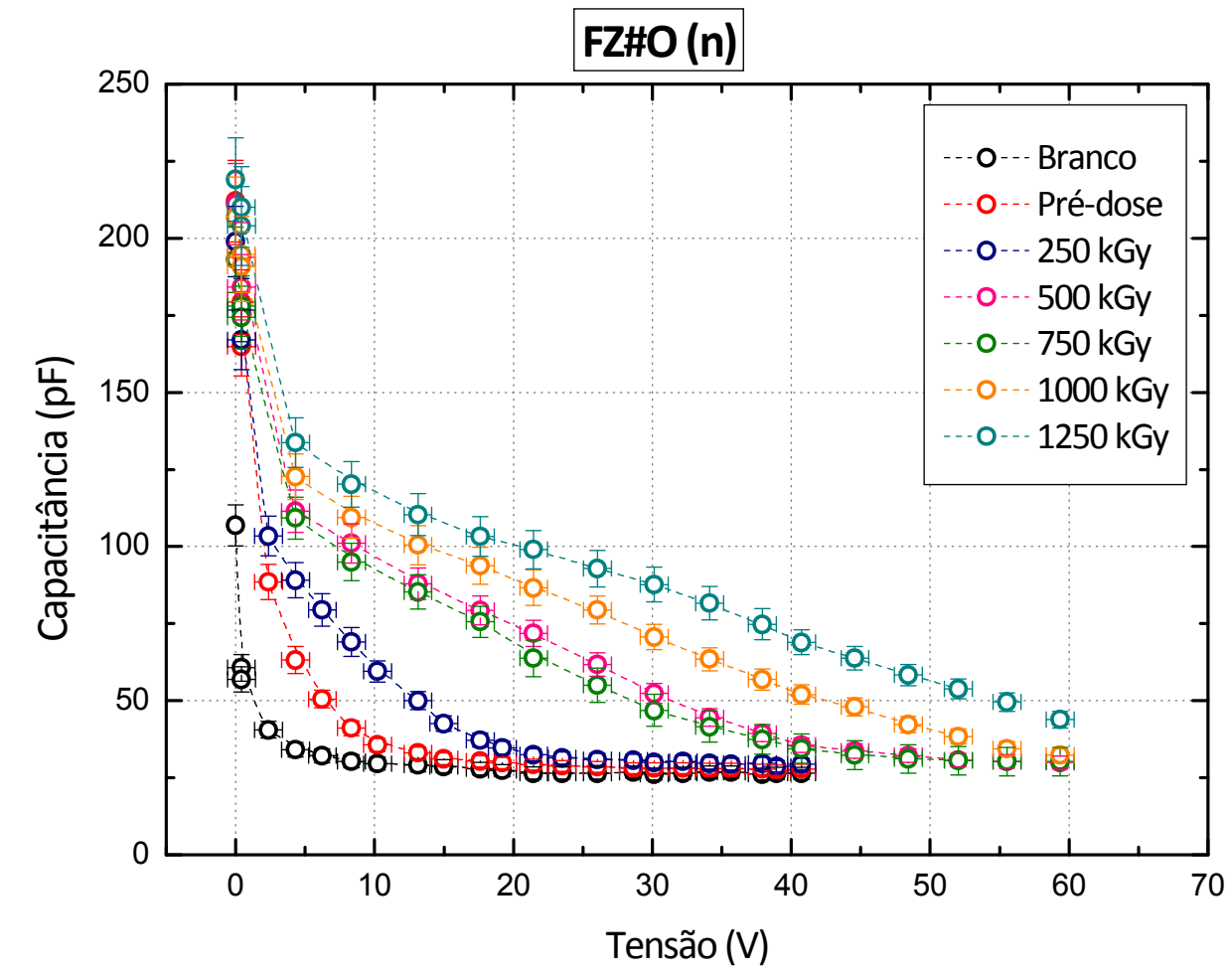

FIGURA 77 - Curvas CV do diodo FZ\#O do tipo n para diferentes valores de dose acumulada. As incertezas dos valores de capacitância representam menos do que $8 \%$ das medições. 


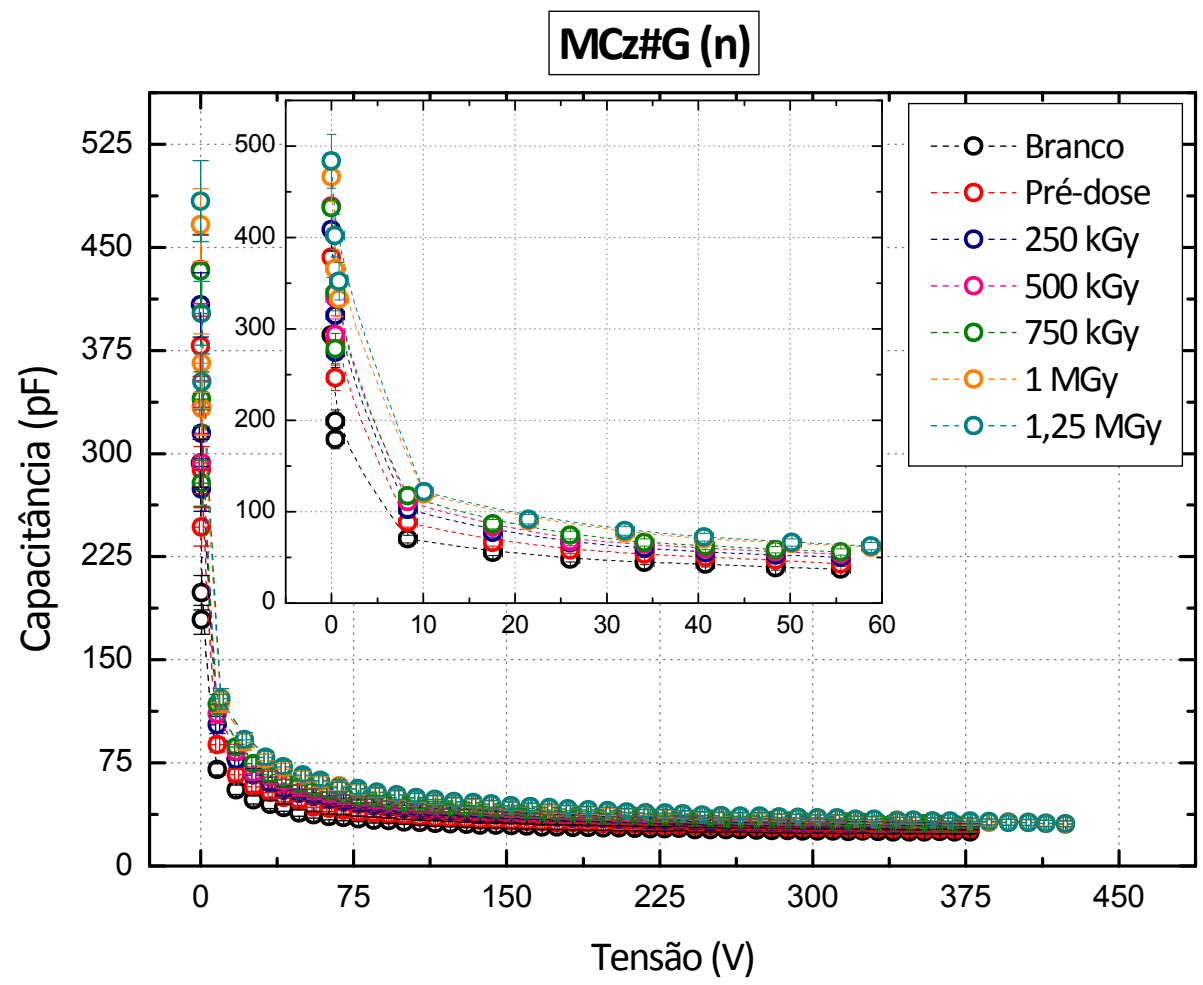

FIGURA 78 - Curvas CV do diodo MCz\#G do tipo n para diferentes valores de dose acumulada. As incertezas dos valores de capacitância representam menos do que $8 \%$ das medições.

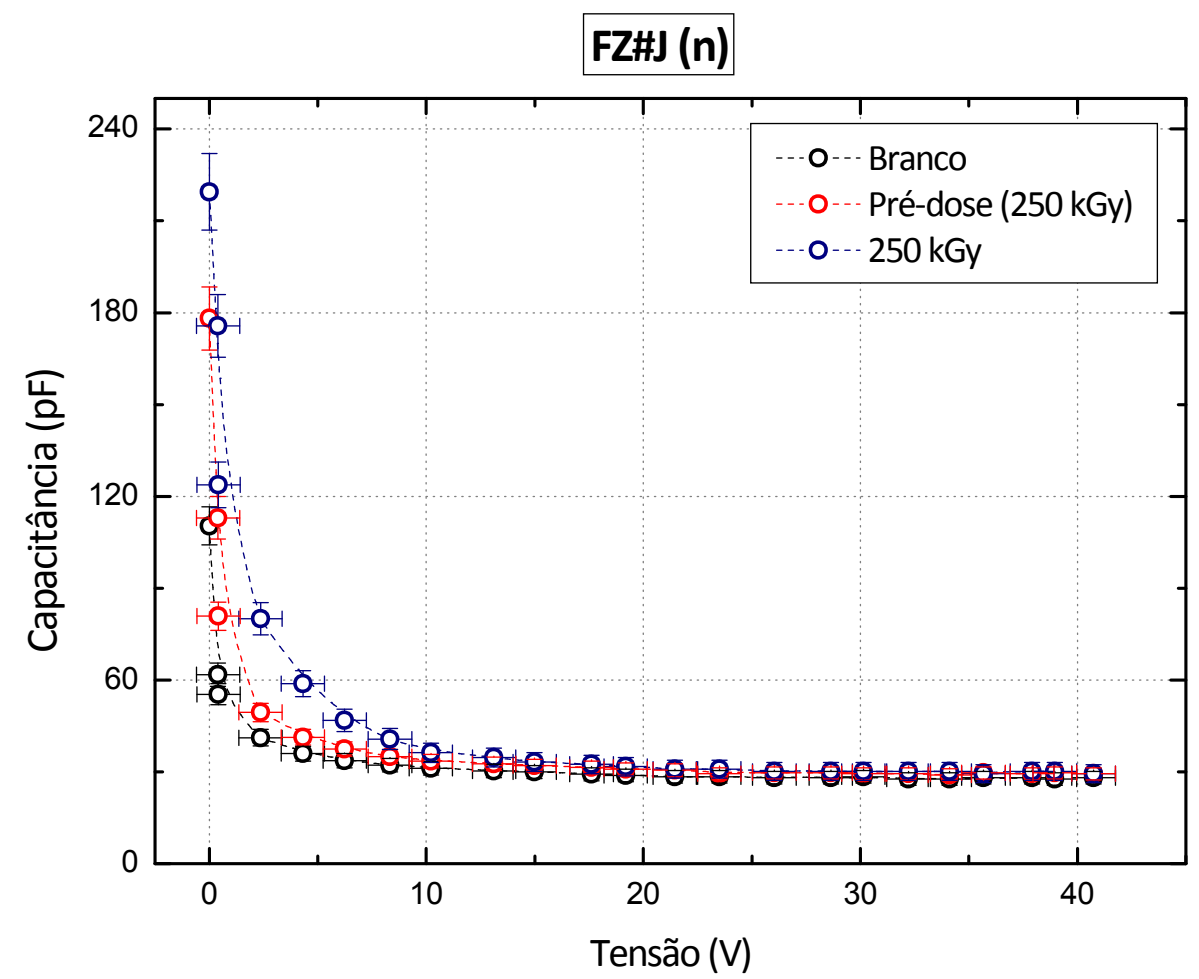

FIGURA 79 - Curvas CV do diodo FZ\#J do tipo n para diferentes valores de dose acumulada. As incertezas dos valores de capacitância representam menos do que $8 \%$ das medições. 


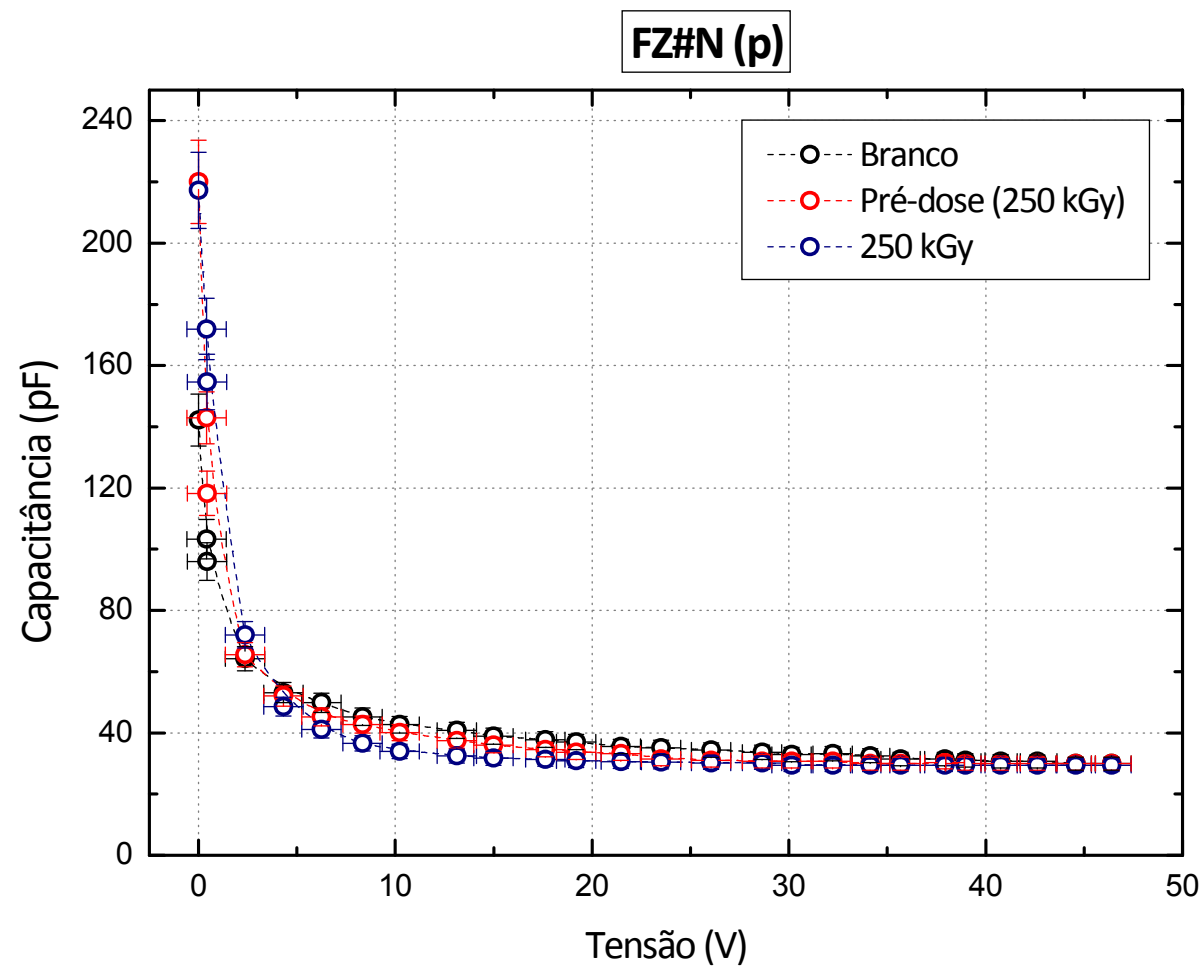

FIGURA 80 - Curvas CV do diodo FZ\#N do tipo p para diferentes valores de dose acumulada. As incertezas dos valores de capacitância representam menos do que $8 \%$ das medições.

A partir das curvas CV dos diodos pode-se extrair o valor da tensão de depleção total dos dispositivos [25-26]. Este valor é definido como o limiar a partir do qual os valores de capacitância tornam-se constantes, indicando que a espessura da região de depleção atingiu seu valor máximo. Tomando essa definição como parâmetro de análise pode-se concluir, a partir das curvas $\mathrm{CV}$, que os diodos $\mathrm{FZ}$ do tipo p (FZ\#N) e $\mathrm{MCz}$ do tipo $\mathrm{n}$ (MCz\#G) apresentam maior resistência aos danos induzidos pela radiação no tocante à alteração da tensão de depleção.

Como discutido anteriormente, a criação de defeitos induzidos pela radiação pode levar à alteração do estado de carga inicial dos dopantes contidos na estrutura do semicondutor. Com isso, o valor da densidade de carga espacial, e, portanto, da tensão de depleção total, varia com a dose de radiação. Os resultados obtidos estão de acordo com o esperado, uma vez que os dispositivos com maior concentração de oxigênio em sua estrutura, $\mathrm{MCz}$, devem apresentar maior resistência às alterações nos valores da tensão de depleção total. 
Os valores da espessura da região de depleção, $d$, podem ser calculados a partir dos valores de capacitância, C, obtidos experimentalmente, Eq. 104, e são apresentados na TAB. 4 para os diodos FZ\#O, MCz\#G, FZ\#J e FZ\#N em diferentes valores de dose acumulada.

$$
\mathrm{d}=\frac{\varepsilon_{0} \cdot \varepsilon_{\mathrm{r}} \cdot \mathrm{A}}{\mathrm{C}}
$$

sendo $\varepsilon_{0}, \varepsilon_{\mathrm{r}}$ e $A$ os valores da constante dielétrica do vácuo, constante dielétrica relativa para o Si e área efetiva dos dispositivos, respectivamente.

TABELA 4 - Valores da espessura da região de dpleção dos diodos FZ\#O,

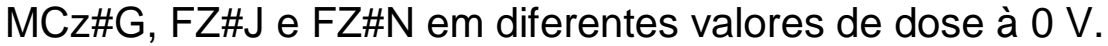

$$
\text { d }(\mu \mathrm{m}) @ 0 \text { v }
$$

\begin{tabular}{ccccc}
\hline & FZ\#O & MCZ\#G & FZ\#J & FZ\#N (p) \\
$\mathbf{2 5 0}$ kGy & $13,2(8)$ & $6,4(4)$ & $12,1(7)$ & $12,1(7)$ \\
$\mathbf{5 0 0}$ kGy & $12,7(7)$ & $6,1(3)$ & $* * *$ & $* * *$ \\
$\mathbf{7 5 0}$ kGy & $13,6(8)$ & $6,1(4)$ & $* * *$ & $* * *$ \\
$\mathbf{1}$ MGy & $12,7(8)$ & $5,7(3)$ & $* * *$ & $* * *$ \\
$\mathbf{1 , 2 5}$ MGy & $12,1(7)$ & $5,5(3)$ & $* * *$ & $* * *$ \\
\hline
\end{tabular}

Os valores apresentados na TAB. 4 não apresentam variação significativa com o acúmulo de dose, indicando que, quando utilizados no modo fotovoltaico, ambos os diodos FZ e MCz do tipo n (FZ\#O, FZ\#J e MCZ\#G) e FZ do tipo $\mathrm{p}$ (FZ\#N) podem ser utilizados em dosimetria sem que suas propriedades sejam alteradas, até os limites de dose avaliados.

\subsubsection{Influência da temperatura nas medidas de corrente}

A temperatura é um dos fatores que mais afeta a geração de portadores minoritários, que contribuem para a formação do sinal de corrente em dispositivos semicondutores. Esta contribuição leva a um aumento do ruído imposto ao sinal de corrente registrado durante os processos de irradiação [59]. Para avaliar essa influência, os valores de corrente de fuga, obtidos experimentalmente, foram extrapolados para um intervalo de temperatura de $15^{\circ} \mathrm{C}$ a $40^{\circ} \mathrm{C}$, utilizando-se as EQ. 100 e 101. Os valores são apresentados para diferentes valores de dose e 
tensão de polarização nas FIG. 81, 82, 83 e 84 para o diodo FZ\#O e nas FIG. 85, 86, 87 e 88 para o diodo MCz\#G.

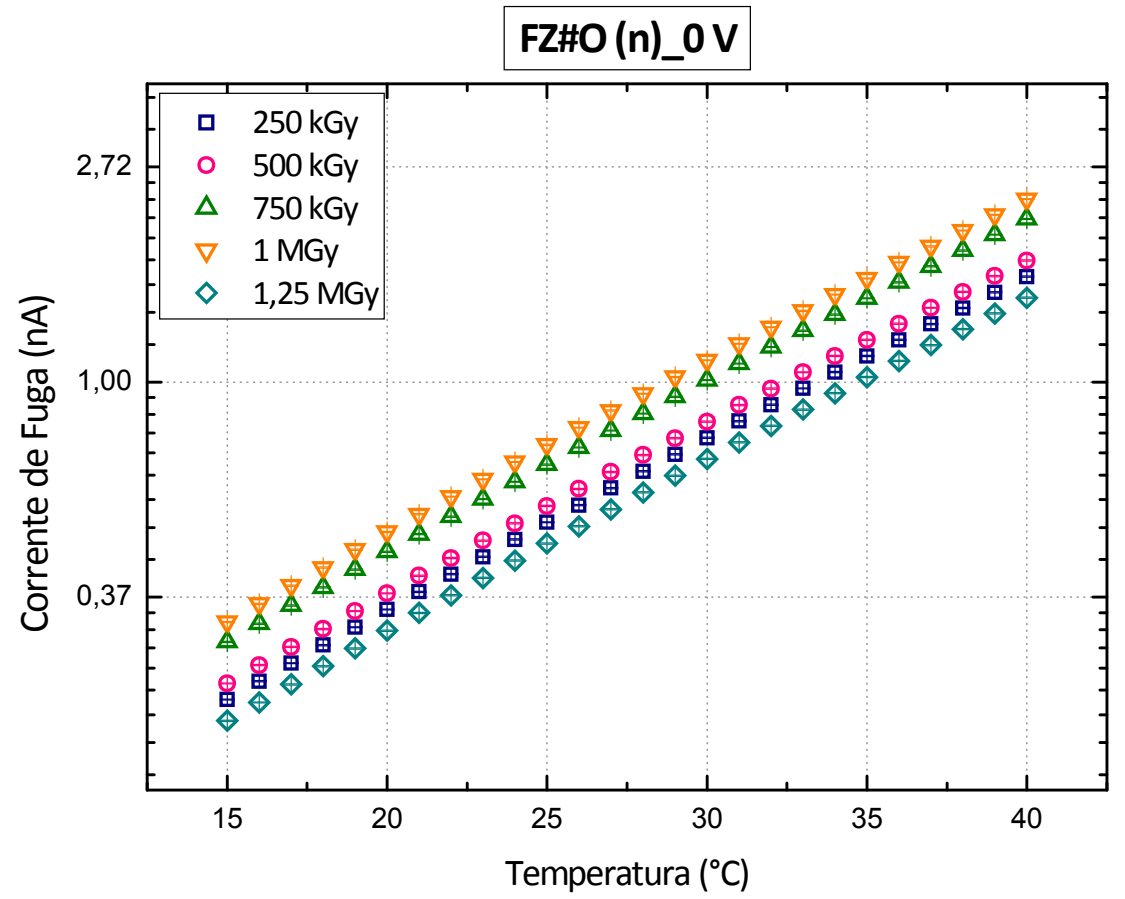

FIGURA 81 - Corrente de fuga em função da temperatura, calculada para o diodo $\mathrm{FZ \# O}$ do tipo $\mathrm{n}$ à $0 \mathrm{~V}$, para diferentes valores de dose acumulada. As barras de incerteza dos valores de corrente de fuga são menores do que os pontos e representam menos do que $0,5 \%$ da gradeza.

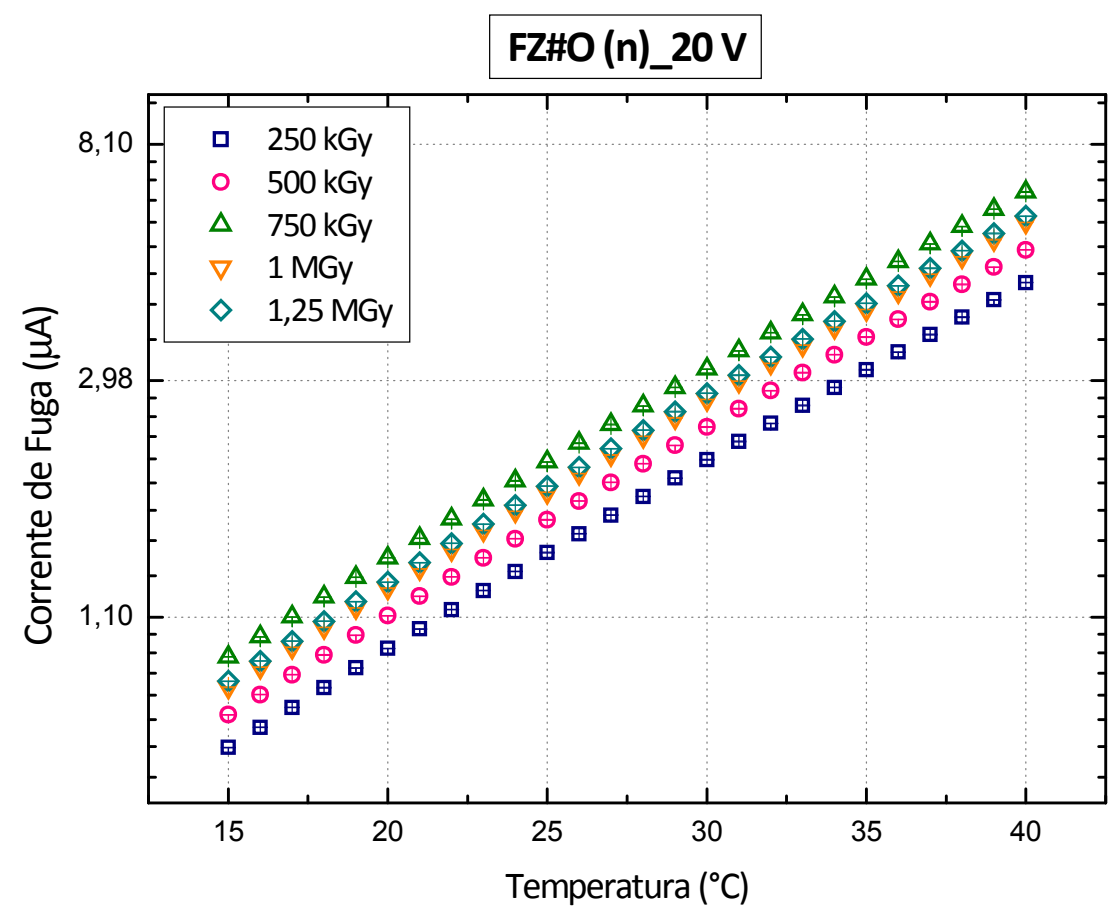

FIGURA 82 - Corrente de fuga em função da temperatura, calculada para o diodo FZ\#O do tipo $n$ à $20 \mathrm{~V}$, para diferentes valores de dose acumulada. As barras de 
incerteza dos valores de corrente de fuga são menores do que os pontos e representam menos do que $0,5 \%$ da grandeza.

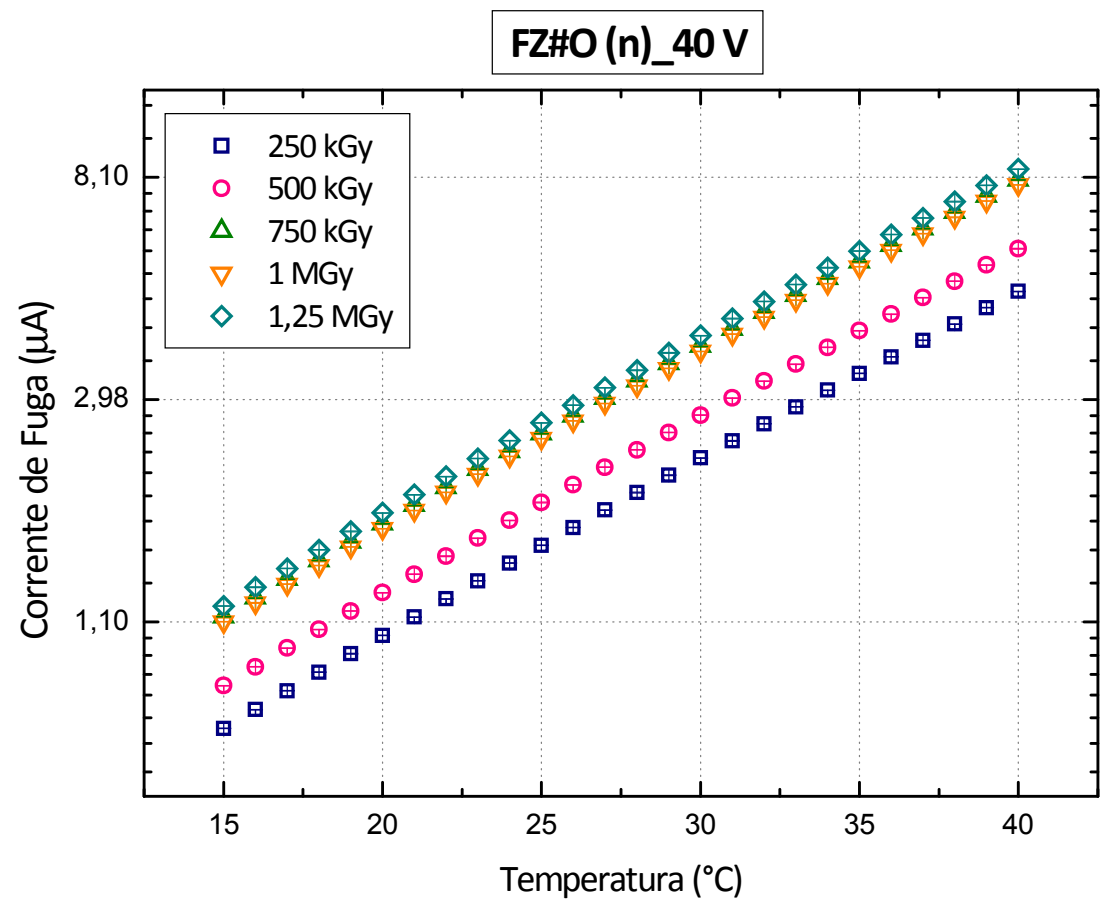

FIGURA 83 - Corrente de fuga em função da temperatura, calculada para o diodo FZ\#O do tipo $n$ à $40 \mathrm{~V}$, para diferentes valores de dose acumulada. As barras de incerteza dos valores de corrente de fuga são menores do que os pontos e representam menos do que $0,5 \%$ da grandeza.

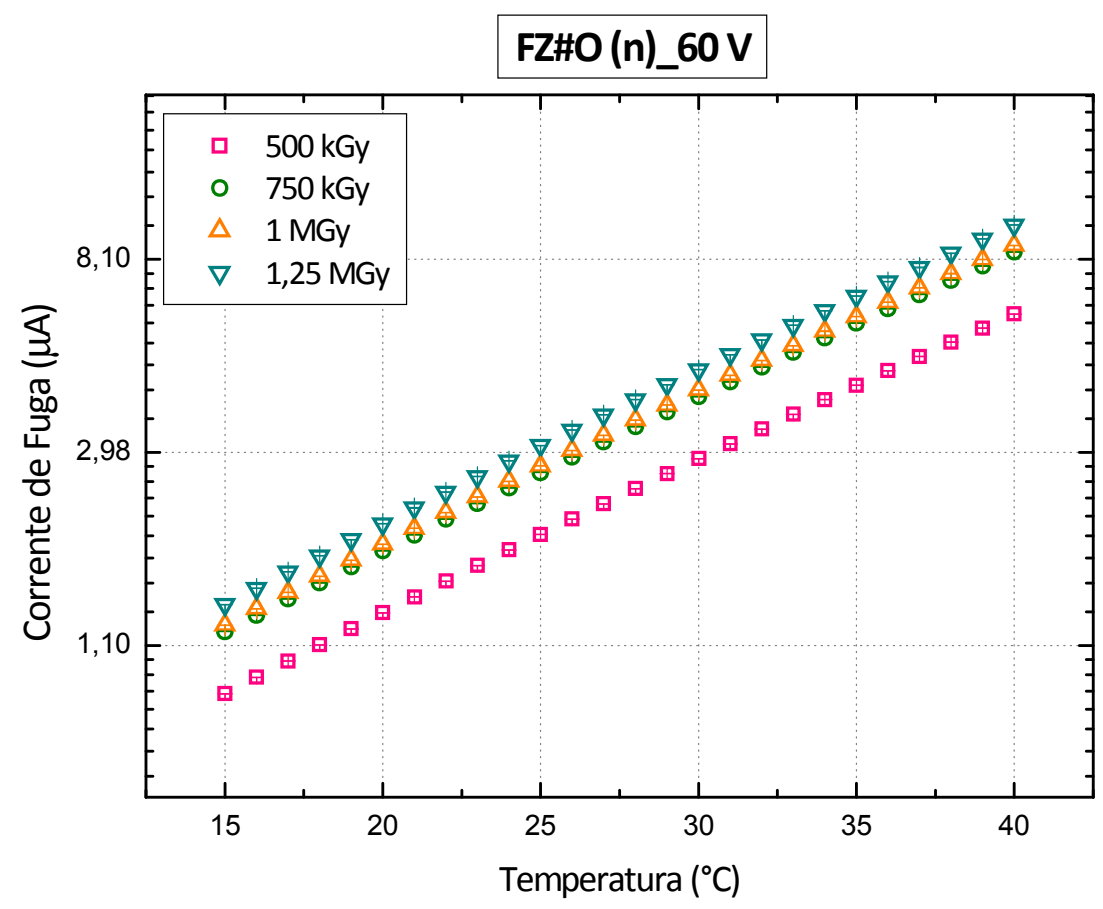

FIGURA 84 - Corrente de fuga em função da temperatura, calculada para o diodo $\mathrm{FZ \# O}$ do tipo $\mathrm{n}$ à $60 \mathrm{~V}$, para diferentes valores de dose acumulada. As barras de incerteza dos valores de corrente de fuga são menores do que os pontos e representam menos do que $0,5 \%$ da grandeza. 


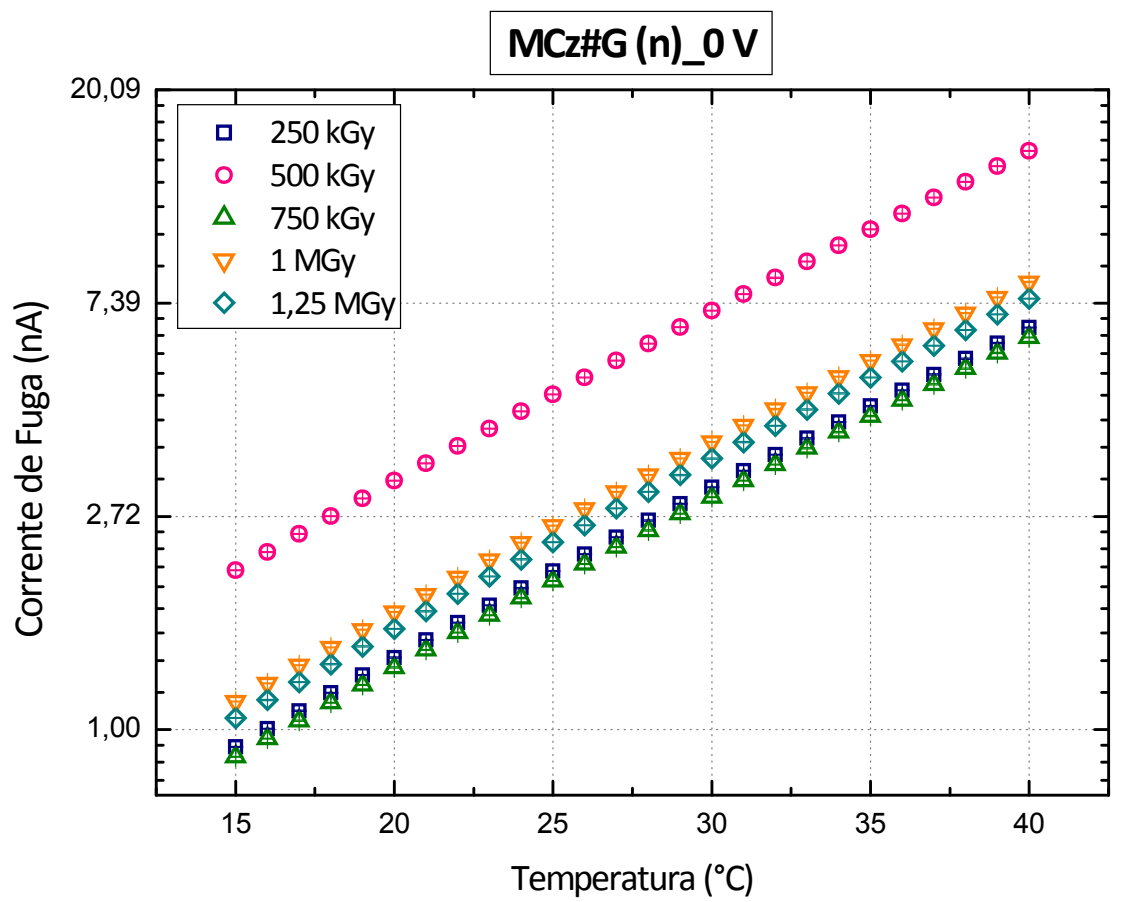

FIGURA 85 - Corrente de fuga em função da temperatura, calculada para o diodo $\mathrm{MCz \# G}$ do tipo $\mathrm{n}$ à $0 \mathrm{~V}$, para diferentes valores de dose acumulada. As barras de incerteza dos valores de corrente de fuga são menores do que os pontos e representam menos do que $0,5 \%$ da grandeza.

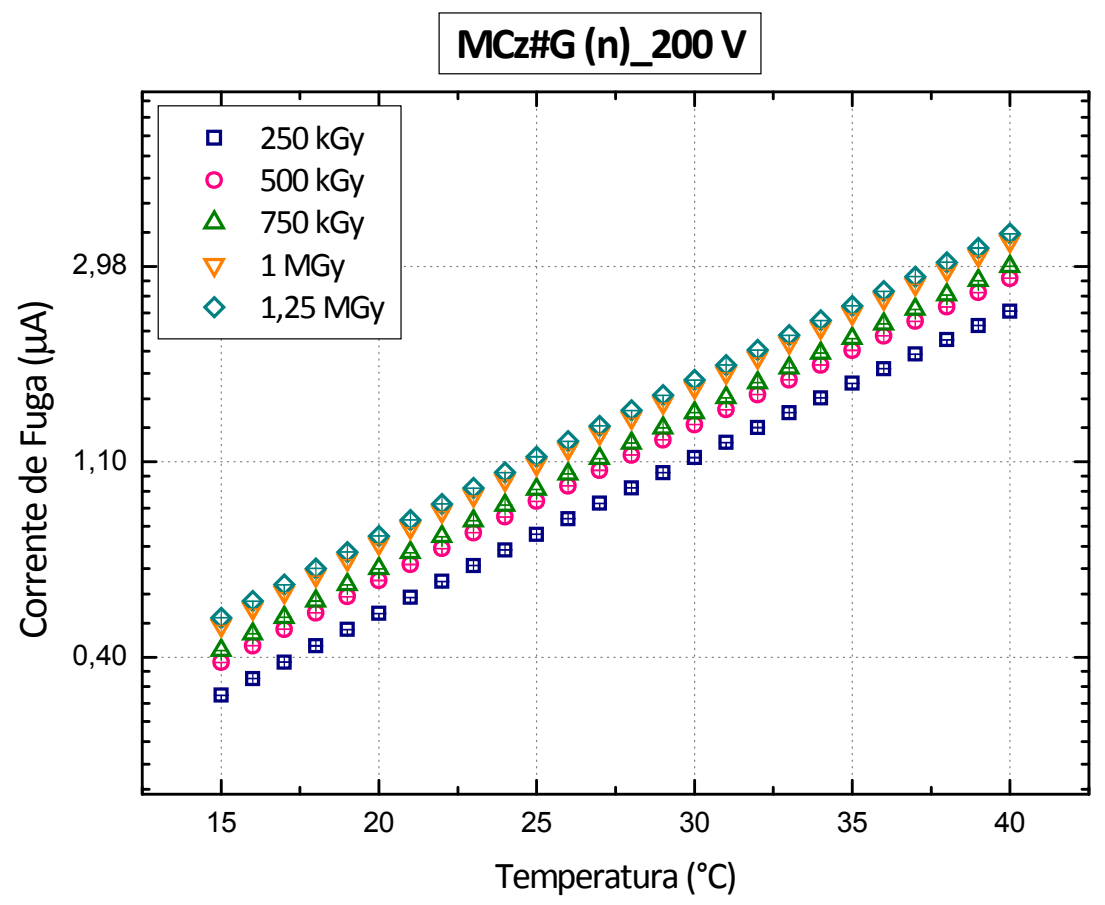

FIGURA 86 - Corrente de fuga em função da temperatura, calculada para o diodo $\mathrm{MCz}$ G do tipo $\mathrm{n}$ à $200 \mathrm{~V}$, para diferentes valores de dose acumulada. As barras de incerteza dos valores de corrente de fuga são menores do que os pontos e representam menos do que $0,5 \%$ da grandeza. 


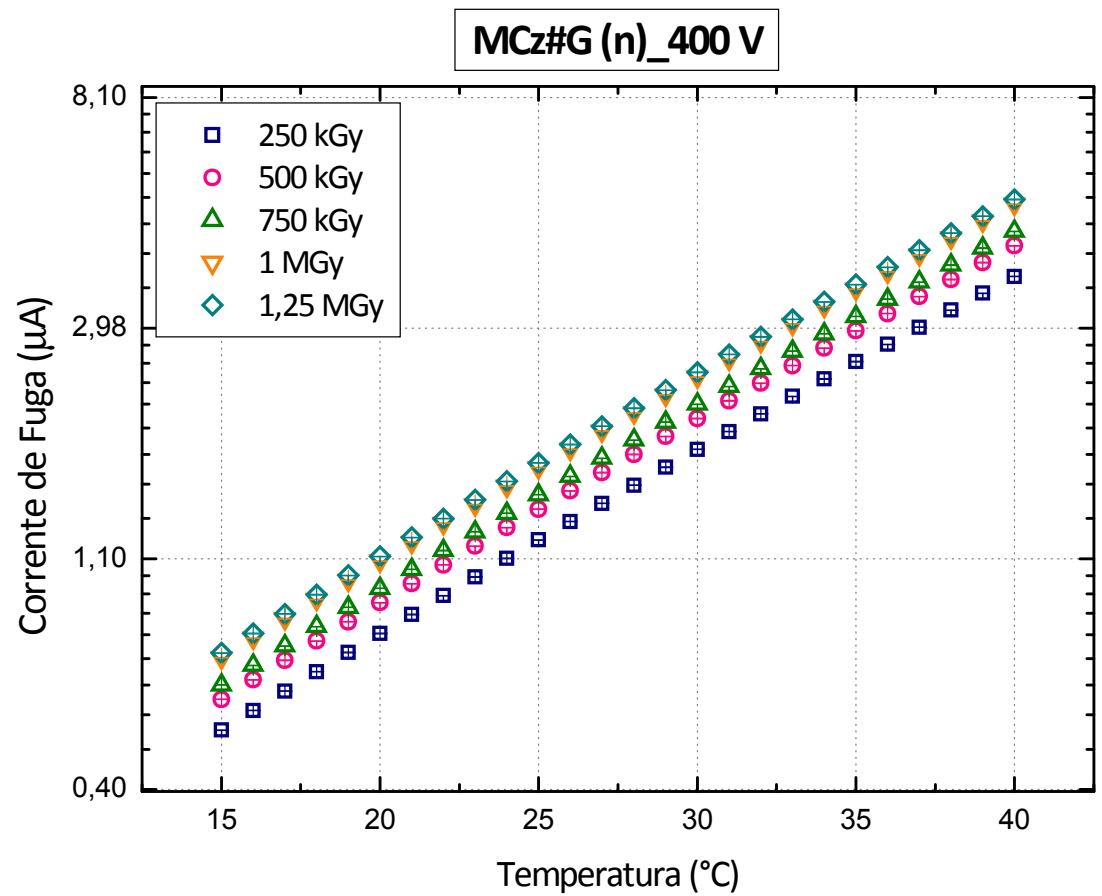

FIGURA 87 - Corrente de fuga em função da temperatura, calculada para o diodo $\mathrm{MCz} \# \mathrm{G}$ do tipo $\mathrm{n}$ à $400 \mathrm{~V}$, para diferentes valores de dose acumulada. As barras de incerteza dos valores de corrente de fuga são menores do que os pontos e representam menos do que $0,5 \%$ da grandeza.

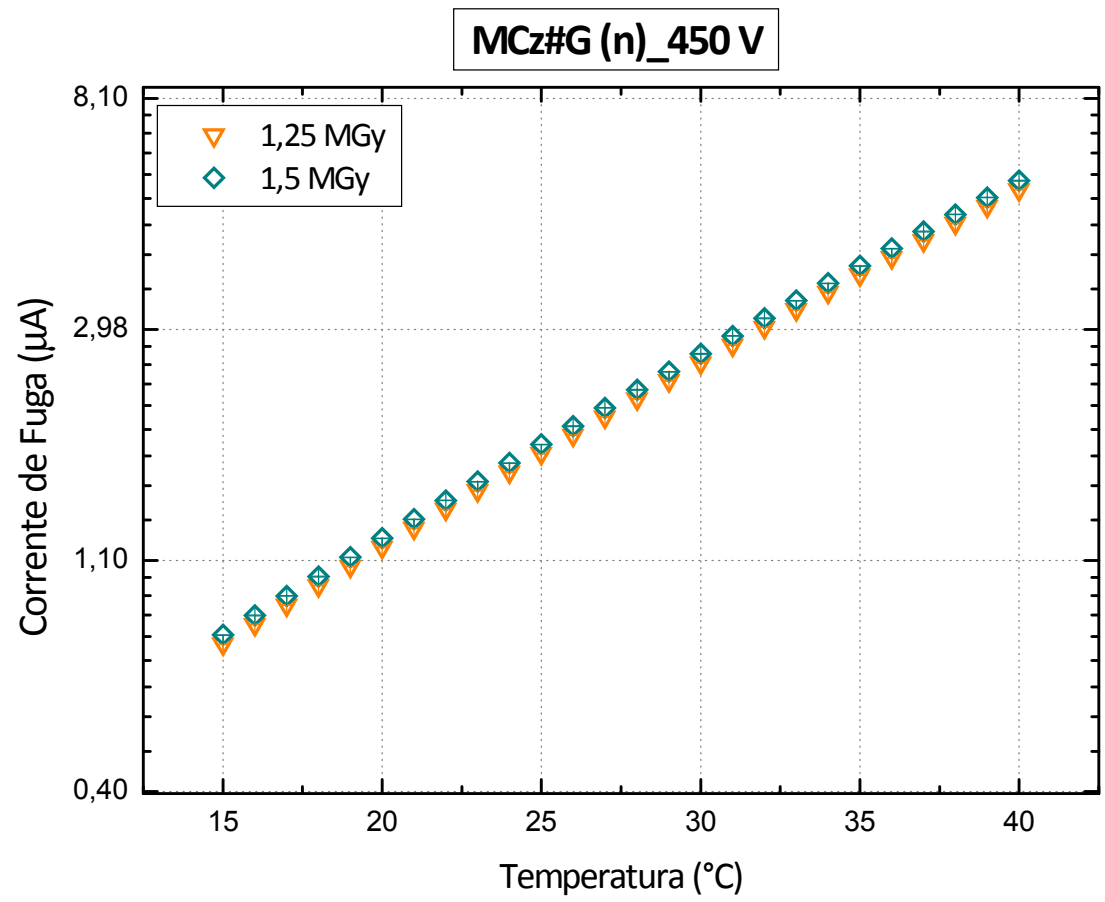

FIGURA 88 - Corrente de fuga em função da temperatura, calculada para o diodo $\mathrm{MCz}$ G do tipo $\mathrm{n}$ à $450 \mathrm{~V}$, para diferentes valores de dose acumulada. As barras de incerteza dos valores de corrente de fuga são menores do que os pontos e representam menos do que $0,5 \%$ da grandeza. 
Nas FIG. 89 e 90 os valores extrapolados de corrente de fuga são apresentados em função da temperatura para os diodos FZ\#J e FZ\#N em diferentes valores de tensão de polarização a 250 kGy de dose. Como esperado (EQ. 100 e 101) há um aumento da corrente de fuga com a temperatura e com a dose de radiação acumulada.

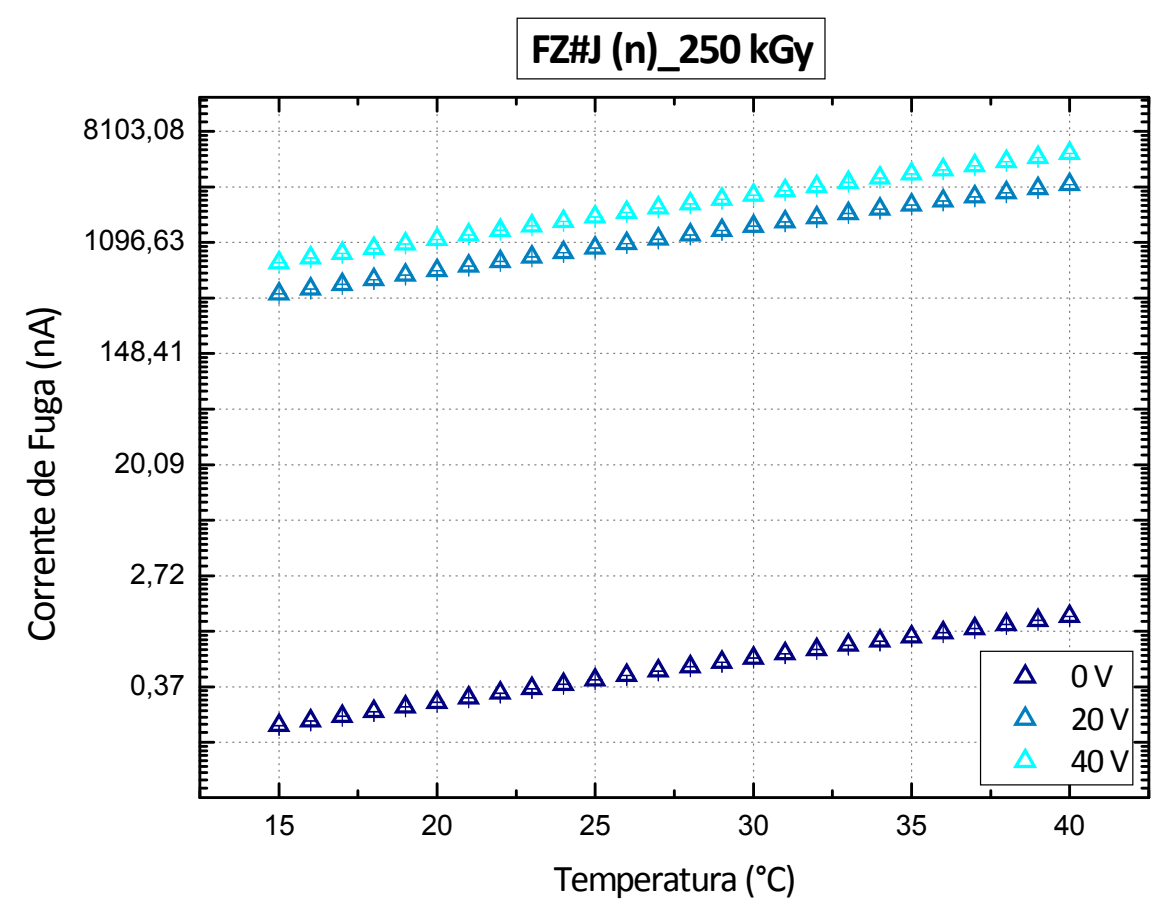

FIGURA 89 - Corrente de fuga em função da temperatura, calculada para o diodo FZ\#J do tipo $n$ à $250 \mathrm{kGy}$, para diferentes valores tensão de polarização. As barras de incerteza dos valores de corrente de fuga são menores do que os pontos e representam menos do que $0,5 \%$ da grandeza. 


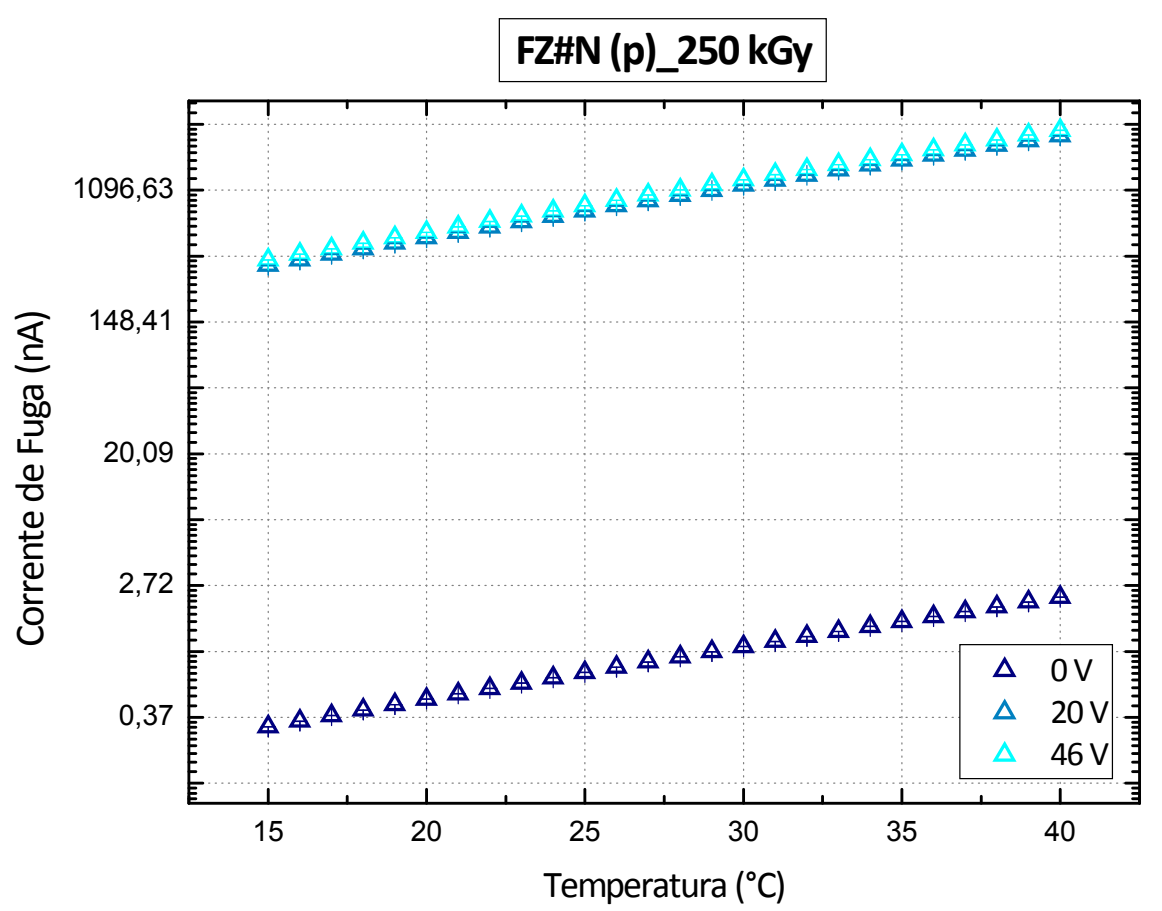

FIGURA 90 - Corrente de fuga em função da temperatura, calculada para o diodo FZ\#N do tipo p à 250 kGy, para diferentes valores tensão de polarização. As barras de incerteza dos valores de corrente de fuga são menores do que os pontos e representam menos do que $0,5 \%$ da grandeza.

As correntes de fundo obtidas durante a irradiação atingem seu valor máximo para a região de transição entre os dois picos de corrente que constituem um ciclo. Considerando o pior caso, ou seja, para a maior dose acumulada, a corrente de fundo dos diodos FZ\#O, MCZ\#G, FZ\#J e FZ\#N não ultrapassa o valor de $1 \mu \mathrm{A}$. Para avaliar a influência da corrente de fuga na corrente de fundo dos diodos, calculou-se a razão entre os valores de corrente de fuga obtidos à $0 \mathrm{~V}$ e o valor extrapolado da corrente de fundo $(1 \mu \mathrm{A})$. Essa razão é apresentada em função da temperatura na FIG. 91 para os diodos FZ\#O e MCz\#G e na FIG. 92 para os diodos FZ\#J e FZ\#N.

A contribuição da corrente de fuga na corrente de fundo dos diodos não ultrapassa $0,5 \%$ para o diodo $\mathrm{FZ \# O} \mathrm{e} 0,1 \%$ para o diodo $\mathrm{MCz} \# \mathrm{G}$, considerando as condições de irradiação utilizadas $\left(35^{\circ} \mathrm{C}\right)$. Para os diodos $\mathrm{FZ \# J} \mathrm{e} \mathrm{FZ \# N} \mathrm{a}$ contribuição da corrente de fuga na corrente de fundo é menor que $0,1 \%$ e $0,2 \%$, respectivamente, para a temperatura máxima de $35{ }^{\circ} \mathrm{C}$. A baixa contribuição da corrente de fuga na menor corrente registrada pelos diodos devido à radiação espalhada está de acordo com o esperado devido essencialmente ao valor elevado da taxa de dose utilizado. 


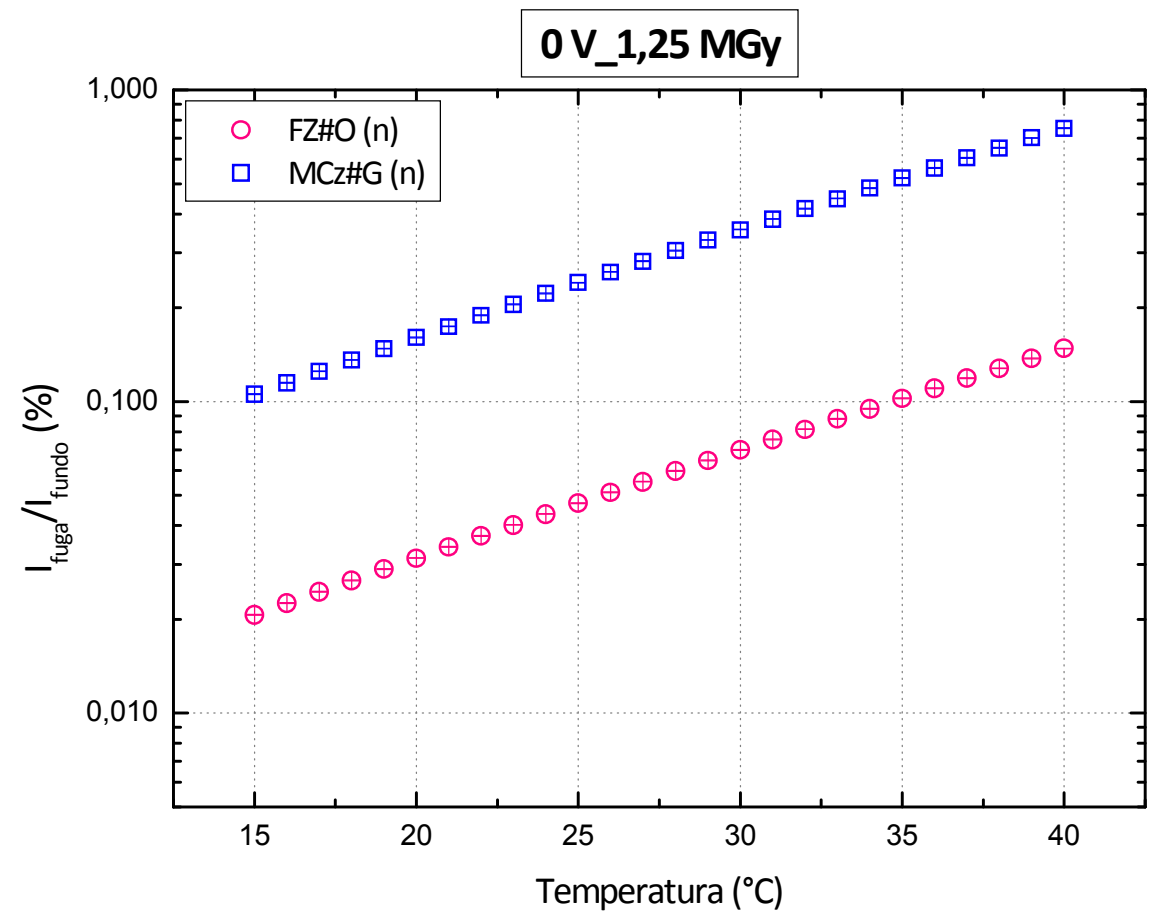

FIGURA 91 - Contribuição percentual da corrente de fuga na corrente de fundo, gerada durante a irradiação, para os diodos $F Z \# O$ e $M C z \# G$, do tipo $n$, à $0 \mathrm{~V}$ e dose acumulada de 1,25 MGy. As barras de incerteza dos valores de $\mathrm{I}_{\text {fuga }} / \mathrm{l}_{\text {fundo }}$ são menores do que os pontos e representam menos do que $0,5 \%$ da grandeza.

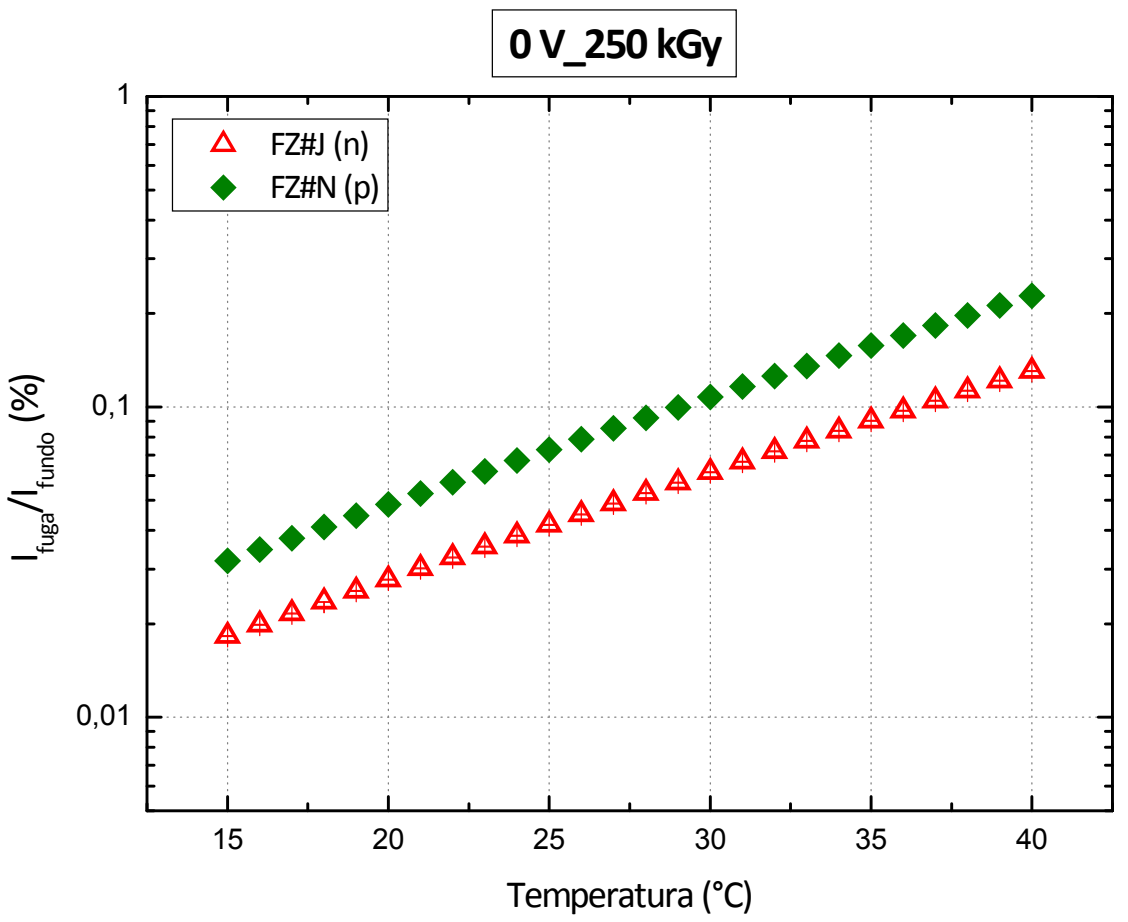

FIGURA 92 - Contribuição percentual da corrente de fuga na corrente de fundo, gerada durante a irradiação, para os diodos FZ\#J do tipo $n$ e $F Z \# N$ do tipo $p$ à $0 \mathrm{~V}$ e dose acumulada de $250 \mathrm{kGy}$. As barras de incerteza dos valores de $\mathrm{I}_{\text {fuga }} \mathrm{l}_{\text {fundo }}$ são menores do que os pontos e representam menos do que $0,5 \%$ da grandeza. 


\subsubsection{Deterioração da sonda dosimétrica e periféricos}

Diferente dos processos de irradiação gama, onde nenhuma deterioração da sonda dosimétrica ou periféricos é observada para doses acumuladas inferiores a $1 \mathrm{MGy}$, para os processos de irradiação com elétrons a deterioração é evidente e têm sido ponto de preocupação durante os procedimentos.

Em um trabalho de doutorado, desenvolvido anteriormente em nosso grupo de pesquisas [24], observou-se que após serem irradiados com elétrons e armazenados, em temperatura ambiente no interior do laboratório, a superfície metálica dos diodos era deteriorada por uma espécie de reação envolvendo a janela de Mylar® aluminizado, responsável pela deposição de uma substância líquida viscosa e esverdeada sobre a superfície dos dispositivos. Este problema foi contornado revestindo-se a sonda dosimétrica com filme plástico de PVC por baixo do Mylar® [24]. Além disso, observou-se durante o desenvolvimento inicial deste trabalho que, mesmo com o filme de PVC, a microsolda responsável pelo contato elétrico entre a face dos diodos e a base de alumina era desprendida de sua posição por efeito da radiação. Com isso, os contatos elétricos eram refeitos inúmeras vezes interrompendo os processos de irradiação, como mencionado anteriormente. Para contornar este problema a solução encontrada foi revestir os diodos com a resina termorrígida preta que, como avaliado em um trabalho anterior [24], não altera a resposta dosimétrica dos diodos.

Ainda assim, será necessário, em trabalhos futuros, solucionar os problemas com a deterioração das sondas dosimétricas (PMMA) e cabos. Quando o diodo é encapsulado com a resina termorrígida, os contatos elétricos feitos inicialmente são permanentes. Estes contatos incluem a conexão direta entre os dispositivos e o conector $L E M O \circledast$ na sonda dosimétrica. Portanto, quando a sonda tem que ser descartada por degradação, o diodo também não pode ser recuperado. A degradação das sondas dosimétricas irradiadas com elétrons de 1,5 MeV de energia pode ser observada nas FIG. 93 e 94. No segundo exemplo a degradação encontra-se ainda em estágio inicial e somente as faces laterais ou extremidades são degradadas. É importante ressaltar que em muitos casos, com o intuito de preservar o aparato, os pedaços desmembrados das sondas dosimétricas foram fixados novamente com cola adesiva específica. 


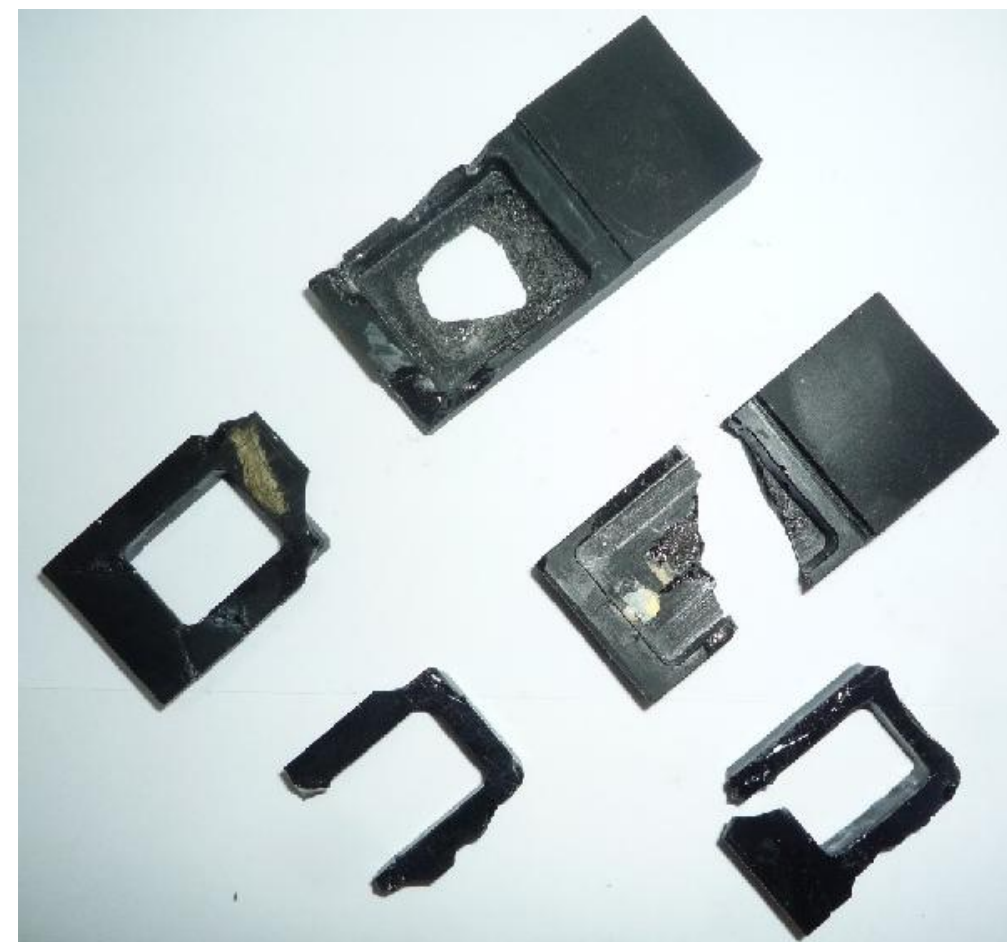

FIGURA 93 - Degradação das sondas dosimétricas após irradiação com elétrons de $1,5 \mathrm{MeV}$.
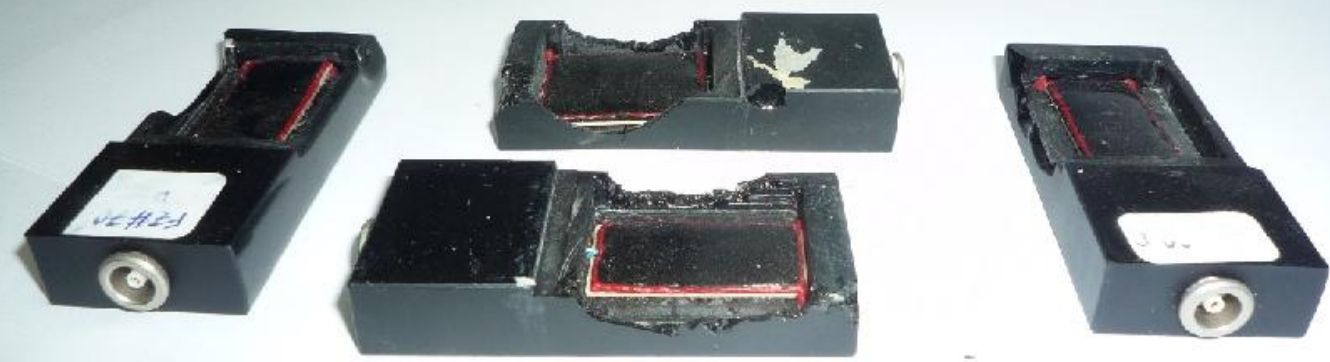

FIGURA 94 - Degradação inicial das sondas dosimétricas após irradiação com elétrons de 1,5 MeV.

Nas FIG. 95, 96 e 97 são apresentadas as imagens da deterioração da caixa de PMMA, recoberta com fita preta opaca, utilizada para a proteção dos conectores na saída da sonda dosimétrica. As imagens são apresentadas em sequência de deterioração mas, são de caixas diferentes, uma vez que este item foi refeito três vezes ao longo dos procedimentos de irradiação. $O$ terceiro estágio de deterioração, FIG. 97, é resultado de um problema em um dos roletes da esteira do acelerador, mencionado anteriormente, de maneira que o aparato permaneceu sob o feixe de elétrons por um tempo maior do que o usual. 


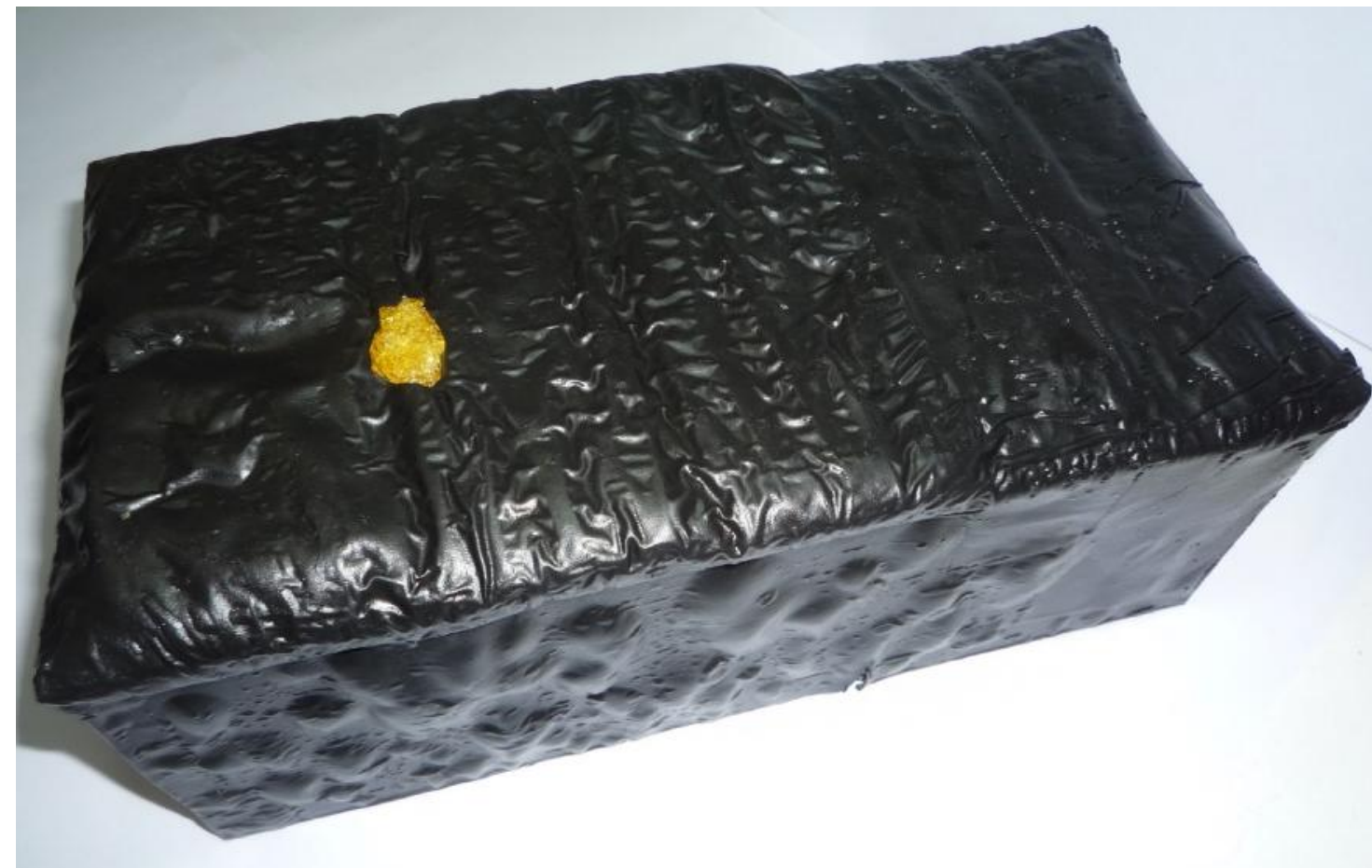

FIGURA 95 - Degradação inicial da caixa acrílica utilizada para a proteção dos conectores elétricos durante os processos de irradiação com elétrons.

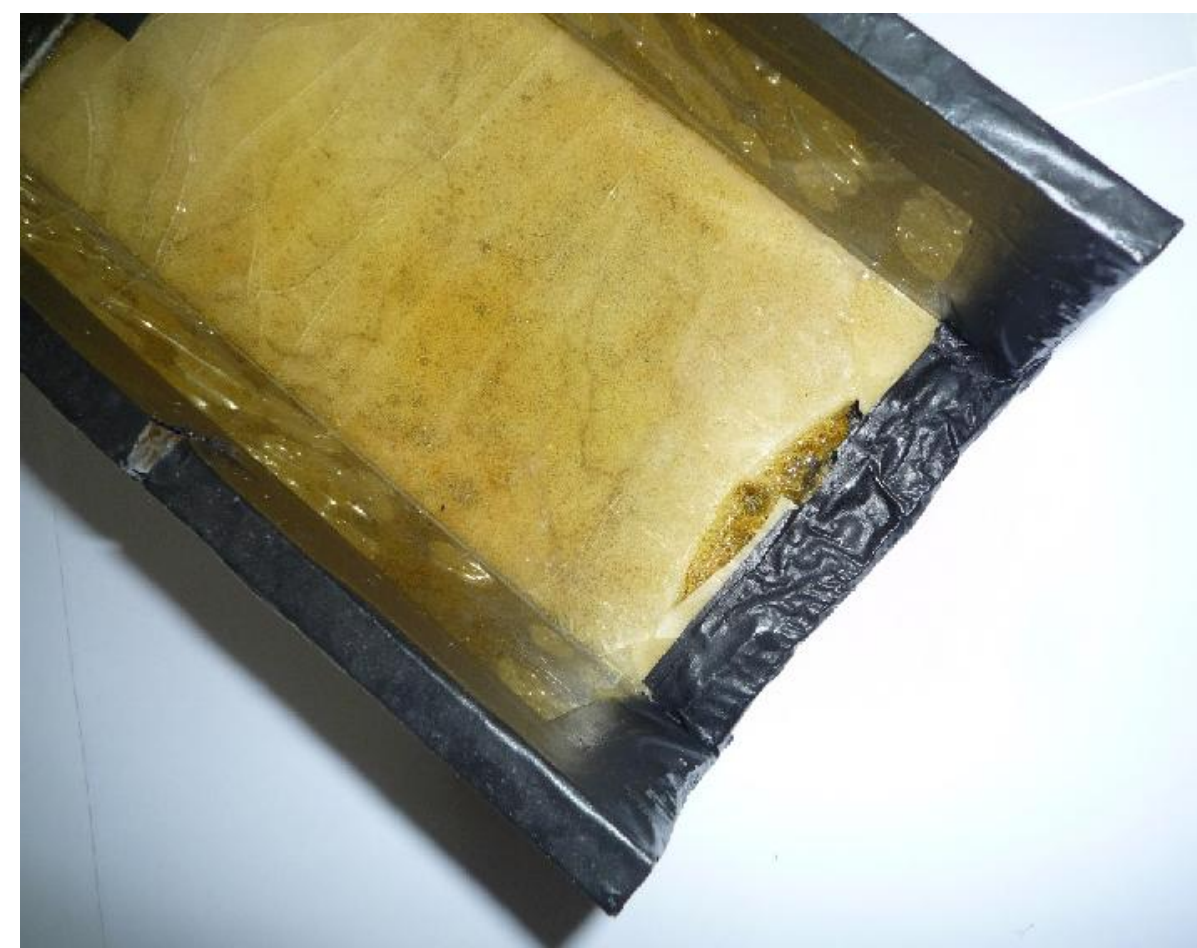

FIGURA 96 - Segundo estágio de degradação da caixa acrílica utilizada para a proteção dos conectores elétricos durante os processos de irradiação com elétrons. 


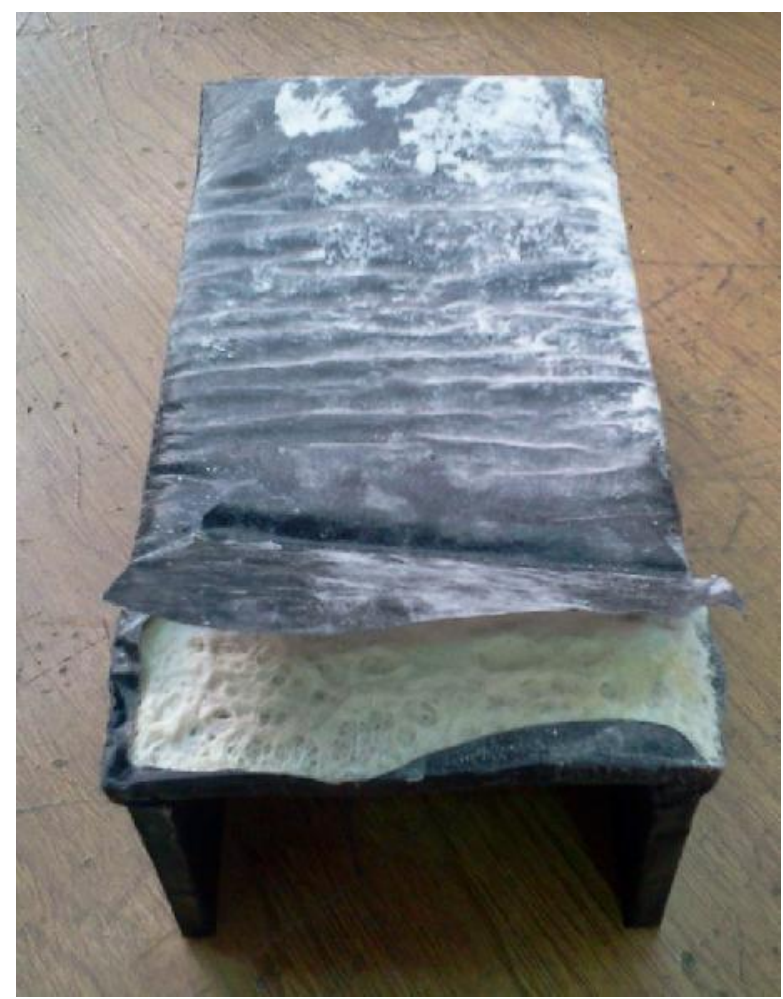

FIGURA 97 - Terceiro estágio de degradação da caixa acrílica utilizada para a proteção dos conectores elétricos durante os processos de irradiação com elétrons.

A deterioração dos cabos, por sua vez, é identificada somente quando instabilidades não previstas são observadas na resposta em corrente dos diodos quando irradiados. Neste caso todas as conexões e cabos são avaliados individualmente e trocados quando necessário.

\subsection{Influência do procedimento de pré-irradiação na estabilidade de resposta dos diodos}

O procedimento de pré-irradiação de diodos $F Z$ e $M C z$ do tipo $n$ e $p$, como solução para o problema da queda da sensibilidade dos dispositivos com o acúmulo de dose, já foi discutido nos itens anteriores deste trabalho. Entretanto, até o momento os diodos foram pré-irradiados com o mesmo tipo de radiação com a qual sua resposta dosimétrica foi avaliada. Espera-se, no entanto, que a estabilização de resposta dos diodos pré-irradiados com elétrons seja superior à de diodos pré-irradiados com raios gama, devido principalmente à taxa de dose elevada obtida durante os processos com elétrons. Este tipo de procedimento já vem sendo adotado para diodos utilizados em dosimetria médica [29, 38]. Os diodos FZ\#P e FZ\#C, ambos do tipo $n$ e com características estruturais 
semelhantes, foram pré-irradiados com raios gama, a uma dose total de $300 \mathrm{kGy}$, e elétrons de 1,5 MeV de energia com uma dose total de100 kGy. Em seguida ambos os diodos foram irradiados com raios gama com uma dose total de aproximadamente $27 \mathrm{kGy}$ fracionada em 5 etapas. Os valores de pré-dose foram escolhidos com base em estudos anteriores aliando o mínimo valor de dose necessário para a redução da queda da sensibilidade. Os sinais de corrente registrados durante este procedimento são apresentados na FIG. 98 para os diodos FZ\#C e FZ\#P.

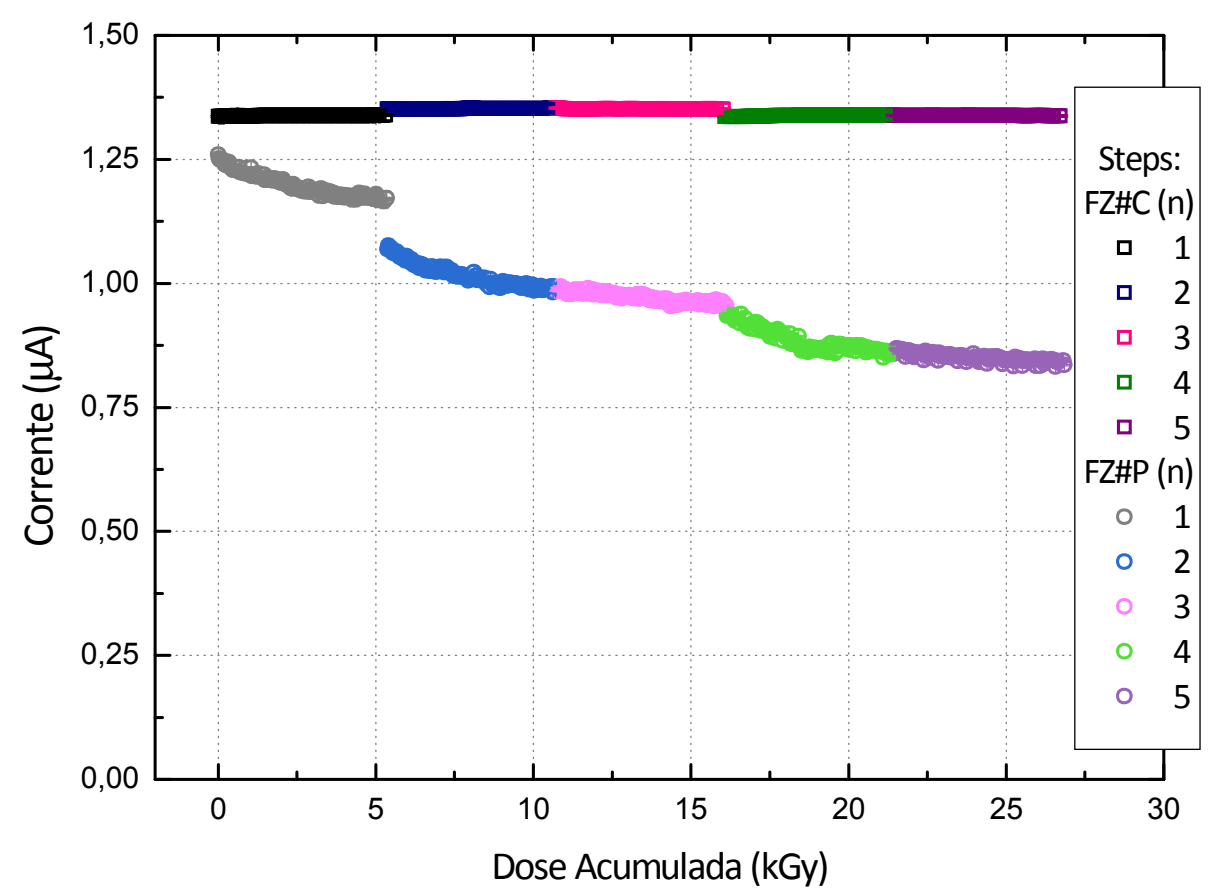

FIGURA 98 - Sinais de corrente registrados com os diodos FZ\#C (pré-irradiado com elétrons) e FZ\#P (pré-irradiado com raios gama) do tipo $n$ durante o procedimento de irradiação gama. As barras de incerteza dos valores de corrente são menores do que os pontos e representam menos do que $1 \%$ das medições.

Para avaliar a estabilidade de resposta dos diodos FZ\#C e FZ\#P durante o estudo de repetibilidade apresentado na FIG. 98, calculou-se o coeficiente de variação (CV) dos valores de carga obtidos em cada uma das cinco etapas de irradiação. Os resultados, $0,68 \%$ e 14,17\%, evidenciam a melhor estabilidade de

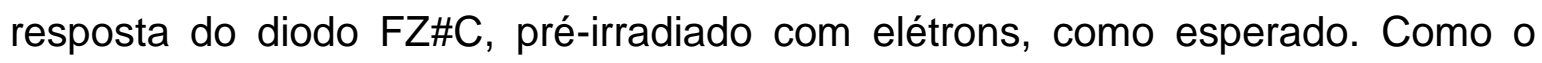
parâmetro dosimétrico dos diodos é a corrente gerada a partir da interação da radiação com sua estrutura, calculou-se também o coeficiente de variação deste parâmetro ao longo das cinco etapas de irradiação. Os resultados, 0,5\% para o 
diodo $\mathrm{FZ \# C}$ e $13 \%$ para o diodo FZ\#P, atestam novamente a maior estabilidade de resposta do diodo pré-irradiado com elétrons.

A reprodutibilidade de resposta dos diodos FZ\#C e FZ\#P também foi avaliada. Para isso, ambos os dispositivos foram irradiados com raios gama em uma única etapa com aproximadamente $27 \mathrm{kGy}$ de dose. Os sinais de corrente registrados durante esta etapa de irradiação são apresentados na FIG. 99 para ambos os diodos FZ\#C e FZ\#P.

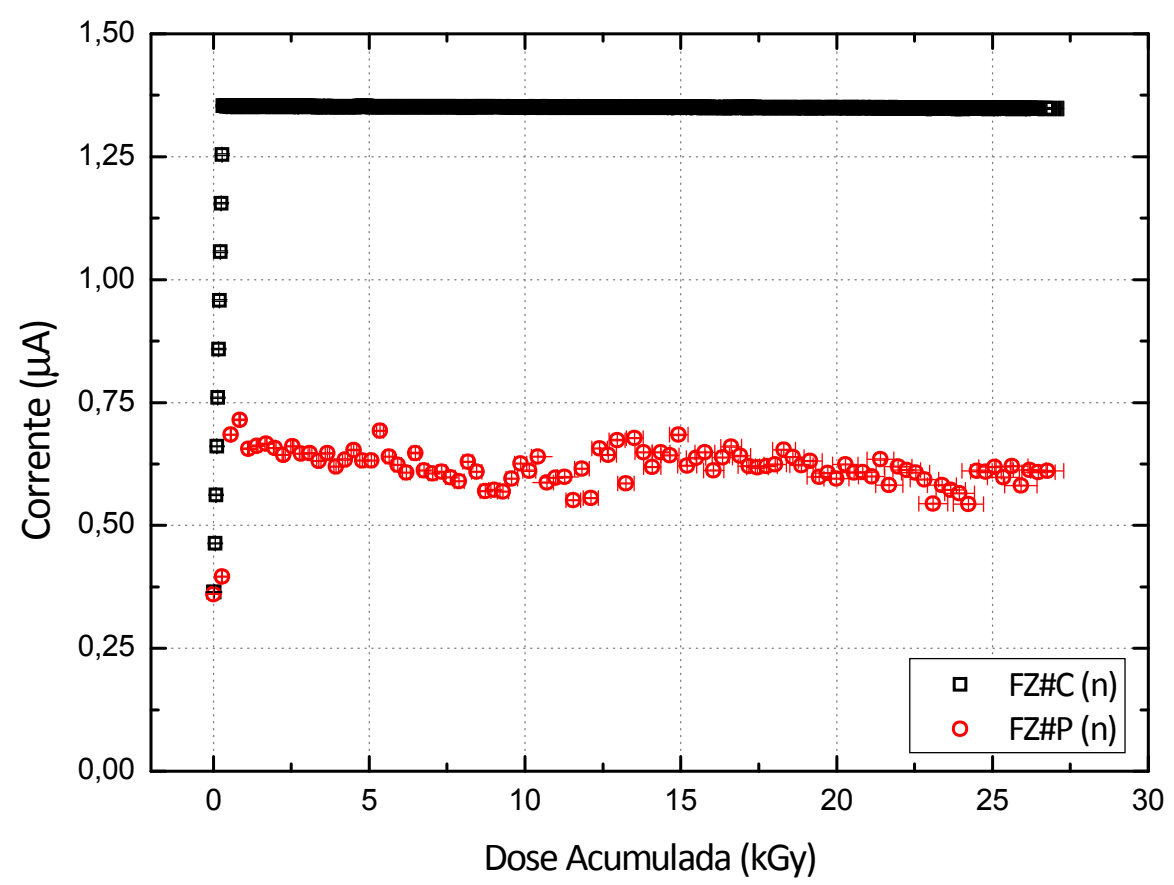

FIGURA 99 - Sinais de corrente registrados com os diodos FZ\#C (pré-irradiado com elétrons) e FZ\#P (pré-irradiado com raios gama) do tipo $\mathrm{n}$ durante 0 procedimento de reprodutibilidade gama. As barras de incerteza dos valores de corrente são menores do que os pontos e representam menos do que $1 \%$ das medições.

A variação entre os valores de carga obtidos durante as etapas de irradiação do estudo de repetibilidade e aqueles obtidos durante o estudo de reprodutibilidade são de $0,1 \%$ e $37,4 \%$ para os diodos FZ\#C e FZ\#P respectivamente. Esta variação indica que os valores de corrente registrados com o diodo FZ\#P ainda não são estáveis, fato comprovado pelo coeficiente de variação em corrente calculado para os valores apresentados na FIG. 99, 0,1\% para o diodo FZ\#C e 5\% para o diodo FZ\#P. Ainda de acordo com os resultados apresentados na FIG. 99, é possível observar que, mesmo após expostos à fonte radioativa, ambos os diodos apresentaram uma elevação lenta dos valores de corrente até que o valor máximo fosse atingido. Isso indica que, ambos os diodos, 
independentemente do tipo de pré-irradiação, estão sujeitos aos efeitos do armadilhamento de portadores em níveis rasos, como detalhado no item 5.2.2 deste trabalho, sugerindo a necessidade de uma rápida irradiação dos diodos antes da sua utilização em dosimetria.

Os valores de corrente normalizada obtidos durante todo o procedimento de irradiação, repetibilidade e reprodutibilidade, dos diodos FZ\#C e FZ\#P são apresentados na FIG. 100 em função da dose acumulada.

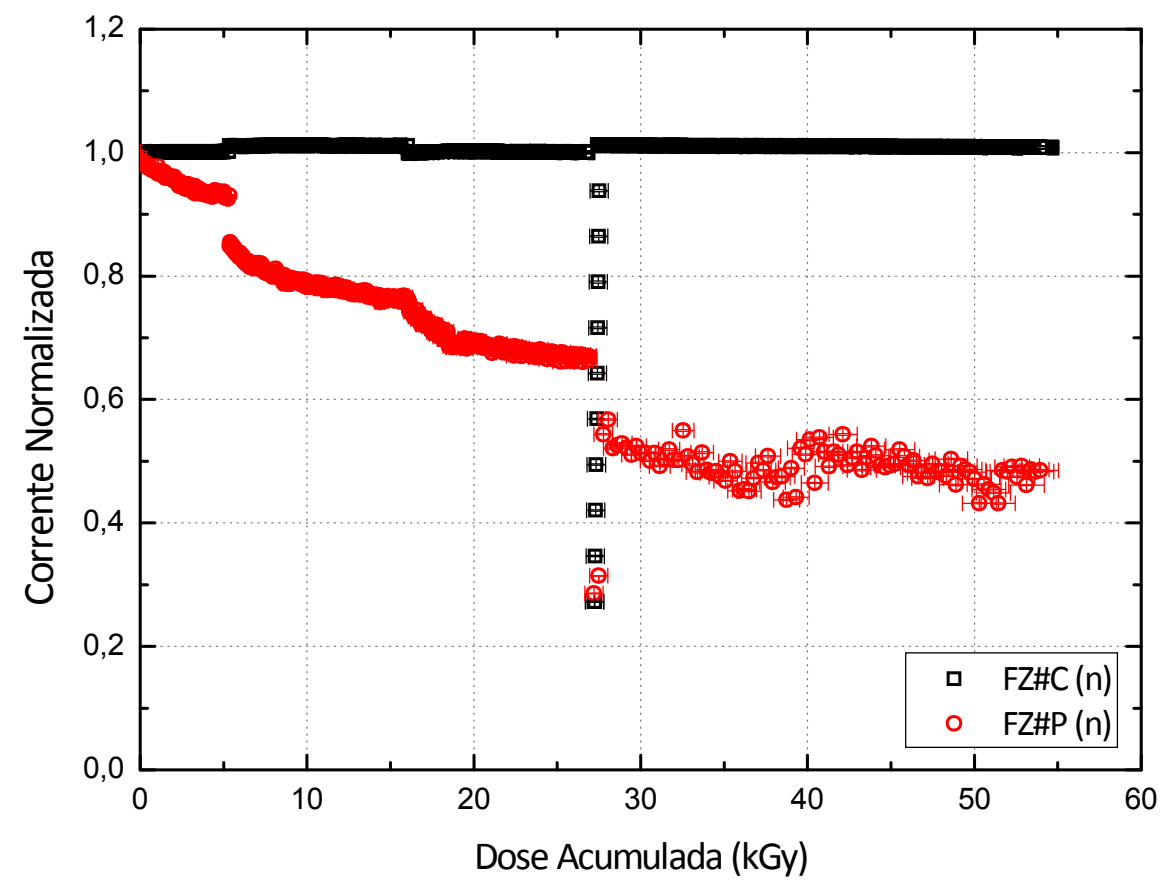

FIGURA 100 - Sinais de corrente registrados com os diodos FZ\#C (pré-irradiado com elétrons) e FZ\#P do tipo $n$ (pré-irradiado com raios gama) durante todo 0 procedimento de irradiação gama. As barras de incerteza dos valores de corrente normalizada são menores do que os pontos e representam menos do que $0,5 \%$ da grandeza. 


\section{CONCLUSÕES}

Neste trabalho estudou-se as principais características dosimétricas de diodos $\mathrm{FZ}$ e MCz, resistentes a danos de radiação, quando aplicados em dosimetria de processos de irradiação industrial com elétrons $(1,5 \mathrm{MeV})$ e raios gama $\left({ }^{60} \mathrm{Co}\right)$. Em ambos os casos observou-se uma queda da sensibilidade com o acúmulo de dose, como esperado.

A uniformidade da resposta de diodos $F Z$, pertencentes ao mesmo lote, foi avaliada para doses de até $5 \mathrm{kGy}$. Os resultados indicaram uma excelente uniformidade de resposta com coeficiente de variação máximo em corrente igual a $1,25 \%$. A influência da resistividade e tipo de dopagem na queda da sensibilidade de resposta dos diodos também foi avaliada. Diodos FZ com resistividade nominal da ordem de $1 \mathrm{k} \Omega . \mathrm{cm}$ apresentam uma queda maior de sensibilidade quando comparados com dispositivos com resistividade nominal da ordem de $10 \mathrm{k} \Omega . \mathrm{cm}$. Por outro lado, a queda da sensibilidade de diodos $\mathrm{MCz}$ do tipo $\mathrm{n}$ com características semelhantes mostrou-se reprodutível para valores de dose de até 275 kGy. Com relação ao tipo de dopagem observou-se que a queda da sensibilidade de diodos do tipo $\mathrm{p}$ é menos acentuada do que a queda registrada para diodos do tipo $\mathrm{n}$. Esse comportamento foi relatado para os dois tipos de diodos avaliados, entretanto, para diodos MCz a diferença entre a queda da sensibilidade dos dispositivo tipo $\mathrm{n}$ e p pode chegar até $37 \%$ enquanto para os diodos $\mathrm{FZ}$ essa diferença é de apenas $10 \%$, para uma dose acumulada de $45 \mathrm{kGy}$. A diferença da queda da sensibilidade com o tipo de dopagem é esperada, pois a seção de choque de captura dos portadores minoritários por centros RG é diferente. O problema da queda da sensibilidade dos diodos pode ser contornado quando os dispositivos são pré-irradiados.

A técnica de espectrometria alfa foi utilizada a fim de avaliar a diferença da resolução dos espectros obtidos com um diodo $\mathrm{MCz}$ do tipo $\mathrm{n}$ após etapas de irradiação com raios gama. Um aumento da resolução foi observado para a dose acumulada de 419 kGy. Para avaliar a origem dessa diferença foram apresentadas as curvas IV desse diodo registradas para os mesmos intervalos de dose 
acumulada. Ainda assim as instabilidades obtidas na resolução dos espectros não pôde ser atribuída ao aumento da corrente de fuga que, por sua vez, não apresentou nenhuma variação significativa para a dose acumulada de 419 kGy. Portanto, a técnica não foi aplicada para diodos irradiados com elétrons e deve ser explorada em detalhes para futura aplicação.

Diferente dos processos com raios gama, é esperado que para a irradiação com elétrons utilizando o sistema apresentado neste trabalho, ocorra uma saturação da resposta em corrente dos diodos com o aumento da taxa de dose. Isso ocorre porque nos processos com elétrons obtém-se taxas de dose elevadas que podem levar ao empilhamento de pulsos no sistema de aquisição de dados. Este efeito é observado tanto para diodos FZ quanto para diodos $\mathrm{MCz}$ ambos do tipo $n$.

As deteriorações dos contatos elétricos e metalização dos diodos foram destacadas como principais desvantagens na utilização destes dispositivos como dosímetros de processos de rotina em irradiações com elétrons. Entretanto, duas alterações no sistema dosimétrico foram propostas. A primeira consiste no encapsulamento dos diodos com uma resina termorrígida preta que, como comprovado por simulação, não altera significativamente a energia dos elétrons incidentes. Na segunda alteração os diodos cujas respostas foram comparadas passaram a ser irradiados simultaneamente, desprezando-se assim a contribuição das alterações nos parâmetros do acelerador como fonte de instabilidades na resposta individual dos diodos. Quatro diodos FZ\#O, MCz\#G, FZ\#J, ambos do tipo

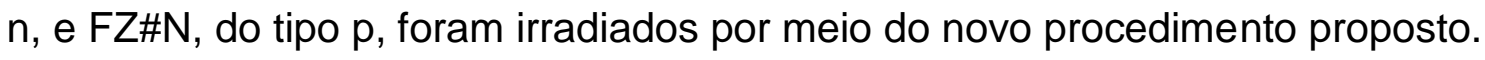

A amplitude máxima da variação da sensibilidade dos diodos $\mathrm{FZ \# O} \mathrm{e}$ MCz\#G, pré-irradiados com $500 \mathrm{kGy}$ de dose e irradiados simultaneamente, foi de aproximadamente $10 \%$ e $40 \%$, respectivamente, indicando uma elevada instabilidade na resposta dosimétrica do diodo $\mathrm{MCz}$ até o limite de dose avaliado (1,25 MGy). Com relação ao tipo de dogem, observou-se uma variação mais elevada na sensibilidade do diodo FZ do tipo $\mathrm{p}(\# \mathrm{~N})$ quando comparado ao diodo FZ do tipo n (\#J), ambos pré-irradiados com 250 kGy de dose. Este comportamento está em oposição ao observado para irradiação gama, bem como para a teoria de danos. É necessário então reproduzir os resultados com outras amostras para descartar qualquer problema pontual com os diodos utilizados. 
A influência dos danos induzidos pela radiação nas propriedades

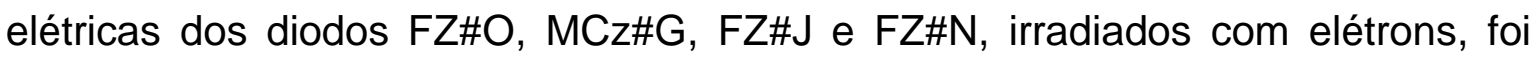
avaliada por meio do registro das curvas IV e CV em diferentes valores de dose acumulada. A corrente de fuga que aumenta com o acúmulo de dose, é no mínimo quatro ordens de grandeza menor do que a corrente de fundo dos diodos, obtida durante os procedimentos de irradiação, mesmo para a dose acumulada de 1,25 MGy. A baixa contribuição da corrente de fuga é esperada uma vez que, os diodos são operados no modo fotovoltaico, ou seja, sem tensão de polarização. As medidas de capacitância, no entanto, evidenciaram a maior tolerância aos danos induzidos pela radiação, no tocante à alteração dos valores de tensão de depleção total, do diodo MCz quando comparado ao diodo FZ, ambos do tipo n. O diodo FZ do tipo $p$ mostrou-se mais resistente do que o diodo do tipo n, pois, até 250 kGy de dose acumulada não foram observadas alterações significativas no comportamento das curvas CV.

Como durante os procedimentos de irradiação com elétrons, os diodos ficam sujeitos a variações de temperatura mais elevadas do que durante os procedimentos gama, a influência deste parâmetro também foi avaliada. $O$ aumento da temperatura altera significativamente o número de portadores minoritários e, portanto, a corrente de fuga dos diodos. Entretanto, para a maior dose acumulada (1,25 MGy), a contribuição da corrente de fuga sobre a corrente de fundo não ultrapassa $0,5 \%$ e $0,1 \%$ para os diodos $\mathrm{FZ} \mathrm{e} \mathrm{MCz}$, ambos do tipo n à $0 \mathrm{~V}$, para valores de temperatura de no máximo $35^{\circ} \mathrm{C}$.

Por último avaliou-se, neste trabalho, a influência do tipo de radiação na pré-dose do diodo FZ do tipo n. Para isso duas amostras, Fz\#C e FZ\#P, foram préirradiadas com elétrons e raios gama, respectivamente, com diferentes valores de dose escolhidos com base na variação percentual dos valores de corrente registrados em trabalhos anteriores. Após a pré-irradiação, ambos os diodos foram irradiados com raios gama em dois estudos diferentes: repetibilidade e reprodutibilidade. $O$ coeficiente de variação em corrente obtido durante o estudo de repetibilidade, $0,68 \%$ e $14,17 \%$ para os diodos pré-irradiados com elétrons e raios gama, respectivamente, indica que a pré-irradiação com elétrons é mais eficiente para a redução da queda da sensibilidade de diodo FZ. O resultado representa um avanço para a área, uma vez que os procedimentos de pré-irradiação com elétrons são mais rápidos do que os procedimentos com raios gama. 
Todos os resultados apresentados neste trabalho ressaltam a potencialidade da aplicação de diodos resistentes aos danos induzidos pela radiação como dosímetros em processos de irradiação de rotina com raios gama e elétrons. É importante ressaltar ainda que a maior vantagem da utilização do sistema proposto é a possibilidade de monitoração em tempo real dos processos, sobretudo para elétrons, permitindo a monitoração dos parâmetros do acelerador, tais como velocidade da esteira e corrente de feixe. 


\section{REFERÊNCIAS BIBLIOGRÁFICAS}

[1] INTERNATIONAL COMMISSION ON RADIATION UNITS ANS MEASUREMENTS REPORT 80. Dosimetry system for use in radiation processing. Bethesda, MD, ICRU, 2009.

[2] CALVO, W.A.P.; DUARTE, C.L.; MACHADO, L.D.B; MANZOLI, J.E.; GERALDO, A.B.C.; KODAMA, Y.; SILVA, L.G.A.; PINO, E.S.; SOMESSARI, E.S.R.; SILVEIRA, C.G.; RELA, P.R. Electron beam accelerators - trends in radiation processing technology for industrial and environmental applications in Latin America and the Caribbean. Radiat Phys Chem., v.81, p.1276-1281, 2012.

[3] BEREJKA, A.J.; CLELAND, M.R.; WALO, M. The evolution and challenges for industrial radiation processing - 2012. Radiat Phys Chem., v.94, p.141-146, 2014.

[4] KNEELAND, D.R.; NABLO, S.V.; WEISS, D.E.; SINZ, T.E. Industrial use of the real time monitor for quality assurance in electron processing. Radiat Phys Chem., v.55, p.429-436, 1999.

[5] KNEELAND, D.R.; TRUDEAU, R.G.; KESSEL, E.D.; NABLO, S.V. Control of an electron processor with a real time dose rate monitor. Radiat Phys Chem., v.57, p.675-678, 2000.

[6] KORENEV, S.; KORENEV, I. The real-time electron beam dose measurements for industrial accelerators. Proceedings of the 2003 Particle Accelerator

Conference., 2003.

[7] WONG, J.H.D.; CUTAJAR, D.; LERCH, M.L.F.; PETASECCA, M.; KNITTEL, T.; CAROLAN, M.; PEREVAERTAYLO, V.L.; METCALFE, P.; ROSENFELD, A.B. From HEP to medical radiation dosimetry - The silicon strip detector dose magnifying glass. Radiat Meas., v.46, p.1615-1618, 2011.

[8] OLIVEIRA, F.F.; AMARAL, L.L.; COSTA, A.M.; NETTO, T.G. In vivo dosimetry with silicon diodes in total body irradiation. Radiat Phys Chem., v.95, p.230-232, 2014.

[9] KHOURY, H.J.; SCHELIN, H.; SOBOLL, D.; LUNELLI, N.; BAPTISTA C. Evaluation of commercial silicon diode for electron dosimetry. Nucl Instrum Meth A., v.580, p.537-539, 2007.

[10] HARTMANN, F. Semiconductor sensors. Nucl Instrum Meth A., v.628, p.4049, 2011.

[11] BATES, A.; MOLL, M. A comparison between irradiated magnetic Czochralski and float zone silicon detectors using the transient current technique. Nucl Instrum Meth A., v.555, p.113-124, 2005. 
[12] MOLL, M. Radiation tolerant semiconductor sensors for tracking detectors. Nucl Instrum Meth A., v.565, p.202-211, 2006.

[13] LANGE, J.; BECKER, J.; FRETWURST, E.; KLANNER, R.; LINDSTRÖM, G. Propertires of a radiation-induced charge multiplication region in epitaxial silicon diodes. Nucl Instrum Meth A., v.662, p.49-58, 2010.

[14] LANGE, J.; BECKER, J.; ECKSTEIN, D.; FRETWURST, E.; KLANNER, R.; LINDSTRÖN, G. Charge collection studies of proton-irradiated $n$ - and p-type epitaxial silicon detectors. Nucl Instrum Meth A., v.622, p.49-58, 2010.

[15] CASSE, G. Overview of the recent activities of the RD50 collaboration on radiation hardening of semiconductor detectors for the sLHC. Nucl Instrum Meth A., v.598, p.54-60, 2009.

[16] MOLL, M. Development of radiation hard sensors for very high luminosity colliders - CERN-RD50 project. Nucl Instrum Meth A., v.511, p.97-105, 2003.

[17] LINDSTRÖM, G.; AHMED, M.; ALBERGO, S.; ALLPORT, P.; ANDERSON, D.; ANDRICEK, L.; ANGARANO, M.M.; AUGELLI, V.; BACCHETTA, N.; BARTALINI, P.; BATES, R.; BIGGERI, U.; BILEI, G.M.; BISELLO, D.; BOEMI, D.; BORCHI, E.; BOTILA, T.; BRODBECK, T.J.; BRUZZI, M.; BUDZYNSKI, T.; BURGER, P.; CAMPABADAL, F.; CASSE, G.; CATACCHINI, E.; CHILINGAROV, A.; CIAMPOLINI, P.; CINDRO, V.; COSTA, M.J.; CREANZA, D.; CLAUWS, P.; DA VIA, C.; DAVIES, G.; DE BOER, W.; DELL'ORSO, R.; DE PALMA, M.; DEZILLIE, B.; EREMIN, V.; EVRARD, O.; FALLICA, G.; FANOURAKIS, G.; FEICK, H.; FOCARDI, E.; FONSECA, L.; FRETWURST, E.; FUSTER, J.; GABATHULER, K.; GLASER, M.; GRABIEC, P.; GRIGORIEV, E,; HALL, G.; HANLON, M.; HAULER, F.; HEISING, S.; HOLMES-SIEDLE, A.; HORISBERGER, R.; HUGHES, G.; HUHTINEN, M.; ILYASHENKO, I.; IVANOV, A.; JONES, B.K.; JUNGERMANN, L.; KAMINSKY, A.; KOHOUT, Z.; KRAMBERGER, G.; KUHNKE, M.; KWAN, S.; LEIMELLEUR, F.; LEROY, C.; LETHEREN, M.; LI, Z.; LIGONZO, T.; LINHART, V.; LITOVCHENKO, P.; LOUKAS, D.; LOZANO, M.; LUCZYNSKI, Z.; LUTZ, G.; MACEVOY, B.; MANOLOPOULOS, S.; MARKOU, A.; MARTINEZ, C.; MESSINEO, A.; MIKU, M.; MOLL, M.; NOSSARZEWSKA, E.; OTTAVIANI, G.; OSHEA, V.; PARRINI, G.; PASSERI, D.; PETRE, D.; PICKFORD, A.; PINTILIE, I.; PINTILIE, L.; POSPISIL, S.; POTENZA, R.; RADICCI, V.; RAINE, C.; RAFI, J.M.; RATOFF, P.N.; RICHTER, R.H.; RIEDLER, P.; ROE, S.; ROY, P.; RUZIN, A.; RYAZANOV, A.I.; SANTOCCHIA, A.; SCHIAVULLI, L.; SICHO, P.; SIOTIS, I.; SLOAN, T.; SLYSZ, W.; SMITH, K.; SOLANKY, M.; SOPKO, B.; STOLZE, K.; SUNDBY AVSET, B.; SVENSSON, B.; TIVARUS, C.; TONELLI, G.; TRICOMI, A.; TZAMARIAS, S.; VALVO, G.; VASILESCU, A.; VAYAKI, A.; VERBITSKAYA, E.; VERDINI, P.; VRBA, V.; WATTS, S.; WEBER, E.R.; WEGRZECKI, M.; WEGRZECKA, I.; WEILHAMMER, P.; WHEADON, P.; WILBURN, C.; WILHELM, I.; WUNSTORF, R.; WÜSTENFELD, J.; WYSS, J.; ZANKEL, K.; ZABIEROWSKI, P.; ZONTAR, D. Developments for radiation hard silicon detectors by defect engineering - results by the CERN RD48 (ROSE) collaboration. Nucl Instrum Meth A., v.465, p.60-69, 2001.

[18] MOLL, M.; FRETWURST, E.; LINDSTRÖM, G. Investigation on the improved radiation hardness of silicon detectors with high oxygen concentration - CERN 
Project RD48 (The ROSE Collaboration). Nucl Instrum Meth A., v.439, p.282292, 2000.

[19] FRETWURST, E.; LINDSTRÖM, G.; STAHL, J.; PINTILIE, I.; LI, Z.; KIERSTEAD, J.; VERBITSKAYA, E.; RÖDER, R. Bulk damage effects in standard and oxygen-enriched silicon detectors induced by 60Co-gamma radiation. Nucl Instrum Meth A., v.514, p.1-8, 2003.

[20] CANDELORI, A. Radiation-hard detectors for very high luminosity colliders. Nucl Instrum Meth A., v.560, p.103-107, 2006.

[21] PELLEGRINI, G.; ULLÁN, M.; RAFÍ, J. M.; FLETA, C.; CAMPABADAL, F.; LOZANO, M. Annealing studies of magnetic Czochralski silicon radiation detectors. Nucl Instrum Meth A., v.552, p.27-33, 2005.

[22] CAMARGO, F.; GONÇALVES, J.A.C.; KHOURY, H.J.; NAPOLITANO, C.M.; HÄRJÖNEN, J.; BUENO, C.C. MCz diode response as a high-dose gamma radiation dosimeter. Radiat Meas., v.43, n.2-6, p.1160-1162, 2008.

[23] LI, Z.; HARKONEN, J.; CHEN, W.; KIERSTEAD, J.; LUUKKA, P.; TUOMINEN, E.; TUOVINEN, E.; VERBITSKAYA, E.; EREMIN, V. Radiation hardness of high resistivity magnetic czochralski silicon detectors after gamma, neutron and proton radiations. IEE E T Nucl Sci., v.51, n.4, p.1901-1908, 2004.

[24] SANTOS, T.C. Dosimetria de Elétrons em Processos de Irradiação com Diodos Resistentes a Danos de Radiação. 2012. Tese (Doutorado) Universidade de São Paulo, São Paulo.

[25] CAMARGO, F. Desenvolvimento de Dosímetros com Diodos de Si Resistentes à Radiação para Dosimetria de Altas Doses. 2009. Tese (Doutorado) - Universidade de São Paulo, São Paulo.

[26] PASCOALINO, K.C.S. Estudo Comparativo das Respostas de Diodos de Si para Dosimetria de Radiação Gama. 2010. Dissertação (Mestrado) Universidade de São Paulo, São Paulo.

[27] BRUZZI, M.; BUCCIONLINI, M.; CASATI, M.; MENICHELLI, D.; TALAMONTI, C.; PIEMONTE, C.; SVENSSON, B.G. Epitaxial silicon devices for dosimetry applications. Appl Phys Lett., v.90, 2007.

[28] DIXON, R.; EXTRAND, K. Silicon diode dosimetry. Int J Appl Radiat Isot., V.33, p. 1171-1176, 1982.

[29] THUNGSTRÖM, G.; MATTSON, C.G.; RÖNQVIST, C. Fabrication and characterization of silicon detectors for use in radiotherapy dosimetry, preirradiated by high energy electrons. Nucl Instrum Meth A., v.576, p.209-214, 2007.

[30] KNOLL, G. F. Radiation Detection and Measurement. 3. ed. New York: John Willey \& Sons, 1999.

[31] LEO, W. R. Techniques for Nuclear and Particle Physics Experiments. 2. ed. Heidelberg: Springer-Verlag, 1994. 
[32] MARMIER, P.; SHELDON, E. Physics of Nuclei and Particles. 2. ed. New York: Academic, 1971, v.1.

[33] NATIONAL INSTITUTE OF STANDARDS AND TECHNOLOGY. Disponível em: < http://physics.nist.gov/PhysRefData/Star/Text/ESTAR.html>. Acesso em: 3 de fevereiro de 2014.

[34] ROSENFELD, A. B. Electronic dosimetry in radiation therapy. Radiat Meas., v. 41, p. 134-153, 2006.

[35] MAHESH, K.; VIJ, D. R. Techniques of Radiation Dosimetry. 1. ed. Michigan: Willey, 1985.

[36] RIKNER, G.; GRUSELL, E. General Specifications for Silicon Semiconductors for Use in Radiation Dosimetry. Phys Med Biol., v. 32, n. 9, p. 1109-1117, 1987.

[37] SANTOS, T. C.; NEVES-JUNIOR, W. F. P.; GONÇALVES, J. A. C.; HADDAD, C. M. K.; BUENO, C. C. Evaluation of rad-hard epitaxial silicon diode in radiotherapy electron beam dosimetry. Radiat Meas., v. 46, n. 12, p. 1662-1665, 2011.

[38] SHI, J.; SIMON, W. E.; ZHU, T. C. Modeling the instantaneous dose rate dependence of radiation diode detectors. Med Phys., v. 30, n. 9, p. 2509-2519, 2003.

[39] PIERRET, R.F. Advanced Semiconductor Fundamentals. 2. ed. New Jersey: Pearson Education, 1985.

[40] LUTZ, G. Semiconductor Radiation Detectors. Springer, 1999.

[41] SZE, S.M. Semiconductor Devices Physics and Tecnology. New York: John Willey \& Sons, 1985.

[42] MOLL, M. Radiation Damage in Silicon Particle Detectors. 1999. Tese (Doutorado) - Universität Hamburg, Hamburg.

[43] REZENDE, S. M. Materiais e Dispositivos Eletrônicos. 2. ed. São Paulo: Editora Livraria da Física, 2004.

[44] AMERICAN SOCIETY FOR TESTING AND MATERIALS. Recombination Lifetime Measurements in Silicon. Julho, 1998. (STP 1340).

[45] SCHRODER, D. K. Semiconductor Material and Device Characterization. 3. ed. New Jersey: John Wiley \& Sons, 2006.

[46] LUUKKA, P-R. Characterization of Czochralski Silicon Detectors. 2006. Tese (Doutorado) - Universit of Helsinki, Helsinki.

[47] TUOVINEN, E. Processing of Radiation Hard Particle Detectors on Czochralski Silicon. 2008. Tese (Doutorado) - Universit of Helsinki, Espoo.

[48] JOHNSON, R. A.; ORLOV, A. N. Physics of Radiation Effects in Crystals. Amsterdam: North-Holland Physics Publishing, 1986. 
[49] HÖNNIGER, F. Radiation Damage in Silicon - Defect Analysis and Detec tor Properties. 2007. Tese (Doutorado) - Universität Hamburg, Hamburg.

[50] CASSE, G. The Effect of Hadron Irradiation on the Electrical Properties of Particle Detectors Made from Various Silicon Materials. 1998. Tese (Doutorado) - Universite Joseph Fourier - GRENOBLE 1, Grenoble.

[51] AMERICAN SOCIETY FOR TESTING AND MATERIALS. Standard Practice for: Characterizing Neutron Fluence Spectra in Terms of an Equivalent Monoenergetic Neutron Fluence for Radiation-Hardness Testing of Electronics. Outubro, 2009. (ASTM E722-09).

[52] Displacement Damage in Silicon. Disponível em: $<$ http://rd50.web.cern.ch/rd50/NIEL/default.html>. Acesso em: 7 de fevereiro de 2014.

[53] HÄRKÖNEN, J.; TUOVINEN, E.; LUUKKA, P.; TUOMINEN, E.; LASSILAPERINI, K.; MEHTÄLÄ, P.; NUMMELA, S.; NYSTEN, J.; ZIBELLINI, A.; LI, Z.; FRETWURST, E.; LINDSTROEM, G.; STAHL, J.; HÖNNIGER, F.; EREMIN, V.; IVANOV, A.; VERBITSKAYA, E.; HEIKKILÄ, P.; OVCHINNIKOV, V.; YLIKOSKI, M.; LAITINEN, P.; PIROJRNKO, A.; RIIHIMÄKI, I.; VIRTANEN, A. Radiation hardness of czochralski silicon, float zone silicon and oxygenated float zone silicon studied by low energy protons. Nucl Instrum Meth A., v.518, p. 346348, 2004.

[54] FRETWURST, E. Recent Advancement in the Development of Radiation Hard Semiconductor Detectors for Very High Luminosity Colliders - the RD50 Collaboration. In: International Conference on Radiation Effects on Semiconductor Materials Detectors and Devices, 5., 2004, Florence. Disponível em: $<$ http://rd50.web.cern.ch/rd50/doc/talks/2004-RESMDD04-Eckhart-Fretwurst.pdf>. Acesso em: 7 de fevereiro de 2014.

[55] HÄRKÖNEN, J. Development of radiation hard particle detectors made of czochralski grown silicon. Acta Phys Pol A., v. 124, n. 2, p. 372-376, 2013.

[56] HÄRKÖNEN, J.; TUOMINEN, E.; TUOVINEN, E.; MEHTÄLÄ, P.; LASSILAPERINI, K.; OVCHINNIKOV, V.; HEIKKILÄ, P.; YLI-KOSKI, M.; PALMU, L.; KALLIJÄRVI, S.; NIKKILÄ, H.; ANTTILA, O.; NIINIKOSKI, O.; EREMIN, V.; IVANOV, A.; VERBITSKAYA, E. Processing of microstrip detectors on Czochralski grown high resistivity silicon substrates. Nucl Instrum Meth A., v.514, n. 1, p. 173-179, 2003.

[57] DA VIA, C.; WATTS, S. J. New results for a novel oxygenated silicon material. Nucl Instrum Meth B., v.186, n. 1, p. 111-115, 2002.

[58] WATTS, S. J.; DA VIA, C.; KARPENKO, A. Macroscopic results for a novel oxygenated silicon material. Nucl Instrum Meth A., v.485, n. 1, p. 153-158, 2002.

[59] ATTIX, F.H. Introduction to Radiological Physics and Radiation Chemistry. 1. ed. John Wiley \& Sons Inc., Hoboken, New Jersey, 1986.

[60] RD50 Technical Note 2003/03 - Version 5/15.10.04. 
[61] FERREIRA, D. C. Dosimetria de Processos de Irradiação Gama com Diodos Comerciais de Silício. 2009. Dissertação (Mestrado) - Universidade de São Paulo, São Paulo.

[62] NASCIMENTO, J. S. Development of a semiconductor parameter analyzer. Private Communication.

[63] GONÇALVES, J. A. C.; SANTOS, T. C.; BARBOSA, R. F.; PASCOALINO, K. C. S.; BUENO, C. C. Dose-rate Dependence of Epitaxial Diodes Response for Gamma Dosimetry. In: XXXIV EDITION OF THE BRAZILIAN WORKSHOP ON NUCLEAR PHYSICS, June 5-10, 2011. POS - Proceedings of Science. p. 1-5, 2011.

[64] JOINT COMMITTEE FOR GUIDES IN METROLOGY. Avaliação de dados de medição - Guia para a expressão de incerteza de medição. 2008. (JCGM 100:2008).

[65] FERREIRA, D. C. Desenvolvimento e Calibração de um Sistema Dosimétrico de Rotina em Processamento por Irradiação. 2013. Tese (Doutorado) - Universidade de São Paulo, São Paulo.

[66] PASCOALINO, K. C. S.; SANTOS, T. C.; BARBOSA, R. F.; CAMARGO, F.; GONÇALVES, J. A. C.; BUENO, C. C. Studies of the Sensitivity Dependence of Float Zone Silicon Diodes on Gamma Absorbed Dose. In: XXXIV EDITION OF THE BRAZILIAN WORKSHOP ON NUCLEAR PHYSICS, June 5-10, 2011. POS Proceedings of Science. p. 78-83, 2011.

[67] BARTHE, J. Electronic dosimeters based on solid state detectors. Nucl Instrum Meth B., v.184, p.158-189, 2001.

[68] RIKNER, G.; GRUSELL, E. Effects of radiation damage on p-type silicon detectors. Phys Med Biol., v. 28, n. 11, p. 1261-1267, 1983.

[69] CAMARGO, F. Fatores que Influenciam a Resolução em Energia na Espectrometria de Partículas Alfa com Diodos de Si. 2005. Dissertação (Mestrado) - Universidade de São Paulo, São Paulo.

[70] CHATTERJI, S.; BHARDWAJ, A.; RANJAN, K.; SHIVPURI, R.K.; SRIVASTAVA, A. K.; JHA, M.; KUMAR, A.; CHOUDHARY, B. C.; NAIMUDDIN, M.; CHAUHAN, S. S.; GUPTA, P. Projection of the Annealing Behavior of Irradiated Si Sensors in the LHC Environment. In: 2004 IEEE Nuclear Science Symposium and Medical Imaging Conference, October 16-22, 2004. Nuclear Science Symposium Conference Record, 2004 IEE E. v. 2, p. 739-743, 2004.

[71] INSTITUTE OF HIGH ENERGY PHYSICS (HEPHY). Disponível em: $<$ http://www.hephy.at/user/friedl/diss/html/node14.html >. Acesso em: 3 de março de 2014. 